UNIVERSIDADE DE BRASÍLIA

FACULDADE DE CIÊNCIAS DA SAÚDE

O FARMACÊUTICO NA COMPOSIÇÃO DA FORÇA DE TRABALHO EM SAÚDE NA ATENÇÃO PRIMÁRIA DO SUS

Marselle Nobre de Carvalho

Brasília - DF

2016 


\section{O FARMACÊUTICO NA COMPOSIÇÃO DA FORÇA DE TRABALHO EM SAÚDE NA ATENÇÃO PRIMÁRIA DO SUS}

Tese apresentada ao Programa de Pós-Graduação em Ciências Farmacêuticas, Faculdade de Ciências da Saúde, Universidade de Brasília, como requisito à obtenção do título de Doutora em Ciências Farmacêuticas, sob orientação da $\operatorname{Prof}^{\mathrm{a} .} \operatorname{Dr}^{\mathrm{a}}$. Silvana Nair Leite.

Brasília - DF 
Autorizo a reprodução e divulgação total ou parcial deste trabalho, por qualquer meio convencional ou eletrônico, para fins de ensino, estudo ou pesquisa, desde que citada a fonte.

\section{Catalogação da Publicação}

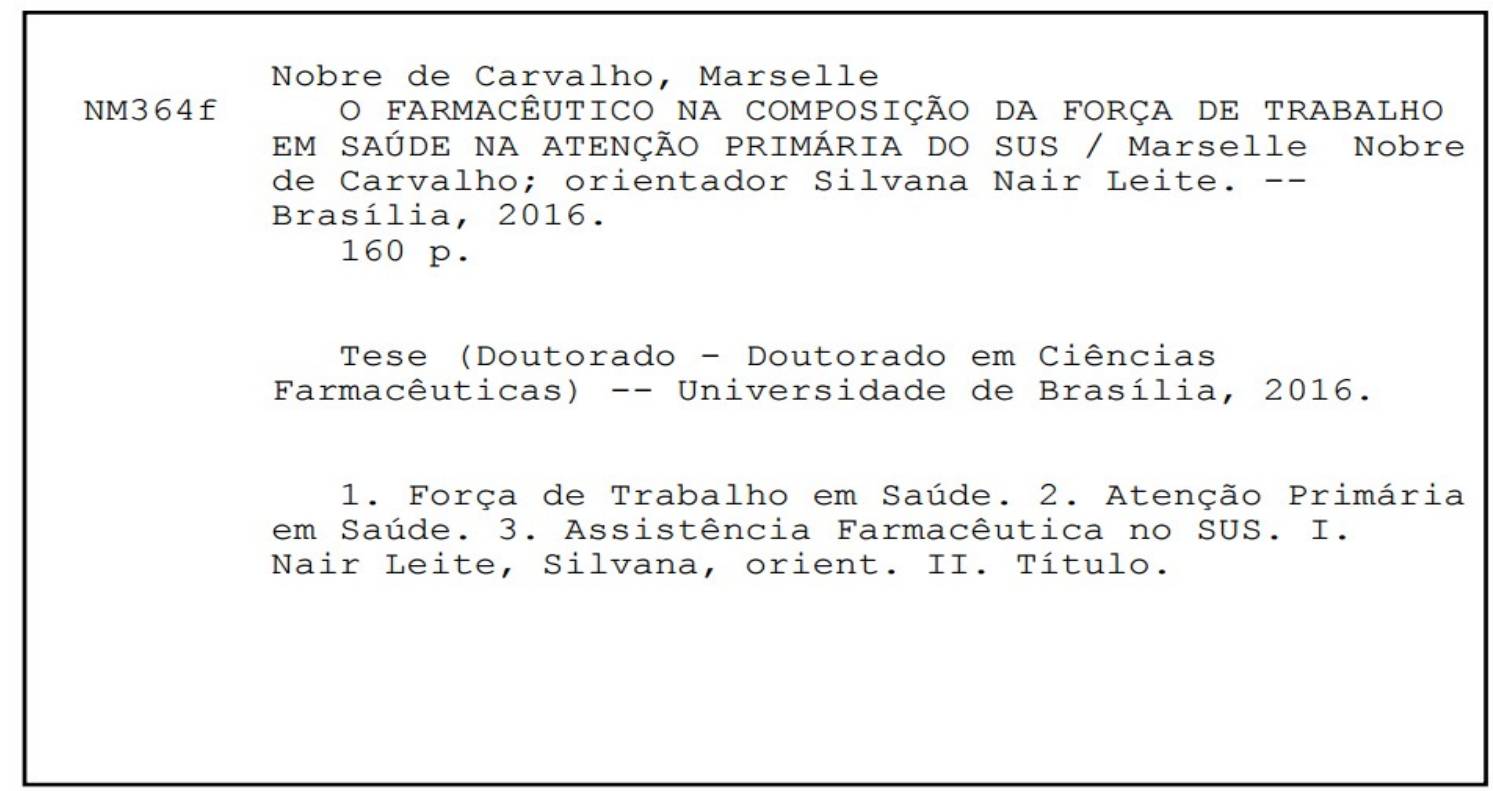




\section{O FARMACÊUTICO NA COMPOSIÇÃO DA FORÇA DE TRABALHO EM SAÚdE NA ATENÇÃO PRIMÁRIA DO SUS}

Tese apresentada ao Programa de Pós-Graduação em Ciências Farmacêuticas, Faculdade de Ciências da Saúde, Universidade de Brasília, como requisito parcial à obtenção do título de Doutora em Ciências Farmacêuticas.

Aprovada por:

Prof $^{\mathrm{a}}$. Dr ${ }^{\mathrm{a}}$. Silvana Nair Leite, Doutora (PPGCF/FS/UNB)

(Orientadora)

Prof $^{\mathrm{a}}$. Dr ${ }^{\mathrm{a}}$. Marcia Hiromi Sakai (UEL)

(Examinadora Externa)

Prof $^{\mathrm{a}} \mathrm{Dr}^{\mathrm{a}}$. Janeth Naves (PPGCF/FS/UNB)

(Examinadora Interna)

Prof $^{\mathrm{a}}$. Dr ${ }^{\mathrm{a}}$. Maria de Fátima Sousa (FS/UNB)

(Examinadora Interna)

Prof $^{\mathrm{a}}$. Dr ${ }^{\mathrm{a}}$. Noêmia Urruth Leão (FS/UNB)

(Examinadora Interna) 


\section{Aos meus amores infinitos!}

Dedico esta tese à memória dos meus avós, José Maria de Moraes Nobre ("o avô-amor"), Leida Irene dos Santos Carvalho e Pio Nortino dos Santos Carvalho ("as origens da vida"), à minha avó, Dionéa Cardoso Nobre ("linda e amada aos 86 anos"), ao meu pai, Antonio Carlos dos Santos Carvalho ("o pensador"), às minhas irmãs, Milene e Mirrelle ("os aconchegos") e, em especial à minha mãe, Tereza Cristina Nobre Carvalho ("a luz"), por sempre me colocar no colo nos meus piores momentos, e aos meus sobrinhos lindos, Paulo Vytto ("o príncipe") e Giulia Petra ("a princesa da tia")....

.... E também Peluxa, Enya, Cindy, Xinha, ("estão na eternidade”) e Quita, Ayka e Maricota ("as perigosas"). 


\section{Agradecimentos}

Em primeiríssimo lugar, a Oxalá e Iemanjá, meus orixás, meus guias na vida terrena, e a Nossa Senhora de Nazaré, minha santa de devoção.

A todos aqueles que me ofereceram o ombro amigo nas horas difíceis.

À minha orientadora (e amiga) $\operatorname{Prof}^{\mathrm{a}} \operatorname{Dr}^{\mathrm{a}}$ Silvana Nair Leite, que surgiu na minha casa com um tema totalmente estranho a mim e topei imediatamente, mesmo sem saber exatamente onde estava me metendo. Muito obrigada por sua orientação excepcional!

Às colegas e amigas de percurso acadêmico, Bruna Alencar e Débora Santos Lula, pelo maravilhoso convívio.

Às professoras Janeth Naves, Maria Inês Toledo e Rafael Mota Pinheiro, pelas aulas e debates extremamente pertinentes sobre assistência farmacêutica.

Aos professores Cristiano Guedes e Débora Diniz, pelo aprendizado durante a disciplina tópicos avançados em políticas sociais e pelas leituras recomendadas (Terry Eagleton, Judith Butler e Slavoj Zizek) que mudaram minha percepção sobre o mundo.

Meus aplausos eternos ao Professor Emérito Dr. Elioenai Dornelles (in memoriam), por toda inspiração!

Aos funcionários da Faculdade de Ciências da Saúde da Universidade de Brasília, em especial da secretaria acadêmica, por todo o carinho.

Às minhas queridas colegas de grupo de pesquisa Célia Regina Rodrigues Gil e Márcia Hiromi Sakai pelas sempre pertinentes contribuições ao texto da tese.

Aos pesquisadores, entrevistadores e todos os envolvidos na execução da Pesquisa Nacional sobre Acesso e Uso Racional de Medicamentos (PNAUM).

Aos farmacêuticos e às farmacêuticas de Norte ao Sul do Brasil, pela dedicação e amor com que exercem o seu trabalho.

Aos trabalhadores do Sistema Único de Saúde, que cotidianamente se dedicam ao cuidado das pessoas, das famílias e da comunidade.

Enfim, a todos aqueles que contribuíram direta ou indiretamente à realização desta tese. 
"Nunca escalas em vão as montanhas da verdade: ou já hoje chegas a tomar altura ou exercitas tuas forças para poder subir mais alto amanhã"

(F. Nietzsche) 


\section{RESUMO}

CARVALHO, M.N. O farmacêutico na composição da força de trabalho da atenção primária do SUS. Tese (Doutorado em Ciências Farmacêuticas) - Faculdade de Ciências da Saúde, Universidade de Brasília, Brasília, 2016.

Esta tese é uma análise acerca participação do farmacêutico na composição da força de trabalho da atenção primária do Sistema Único de Saúde (SUS), a partir da caracterização do trabalhador e do trabalho na assistência farmacêutica, visando a compreensão do trabalho farmacêutico como trabalho em saúde e, portanto, a contribuição para a sua inserção nas equipes de saúde. Trata-se de estudo baseado na hermenêutica-dialética, cujos procedimentos metodológicos foram divididos em dois tipos de pesquisa: estudo ecológico realizado a partir de bases de dados online (p. ex.: DATASUS, RAIS e SIGRAS) e estudo transversal, de abordagem quantitativa, sobre os trabalhadores na gestão da assistência farmacêutica municipal e nas unidades de dispensação de medicamentos, a partir de dados primários obtidos durante a Pesquisa Nacional de Acesso, Utilização e Uso Racional de Medicamentos (PNAUM). A força de trabalho na assistência farmacêutica básica é predominantemente composta por mulheres, na faixa etária de 18 a 39 anos, com formação superior, concursados, há mais de um ano no cargo ou atividade e jornada de trabalho semanal superior a 30 horas. A participação do farmacêutico na composição da força de trabalho na atenção primária do SUS cresceu e se consolidou nas funções de gestão, especialmente na coordenação da assistência farmacêutica $(90,7 \%)$, mas ainda é pequena nas unidades de dispensação, cujos postos de trabalho são majoritariamente ocupados por técnicos e ou auxiliares de enfermagem (43,0\%), seguidos dos farmacêuticos (33,3\%). Regionalmente, o CentroOeste e o Sudeste se destacam pela maior participação dos farmacêuticos na dispensação de medicamentos nas unidades de saúde (57,1\% e 64,1\%, respectivamente). Em conclusão, a participação do farmacêutico na composição da força de trabalho em saúde da atenção primária do sistema de saúde brasileiro se expandiu em função, de um lado, do evidente investimento em atividades relacionadas abastecimento e acesso da população aos medicamentos e, de outro, das políticas de fomento à implementação de equipes multiprofissionais nos serviços de saúde (p. ex.: NASF). Embora se apresentem como estratégia de inclusão nas equipes de saúde, essas políticas não se mostraram suficientes à ampliação do número de farmacêutico nas unidades de dispensação, cuja função é prestar cuidados diretos aos usuários e, por meio destes, realizar trabalho em equipe, o que difere enormemente do exercício de funções técnico-gerenciais do medicamento. Além disso, o farmacêutico deve compreender o seu trabalho no contexto da gestão do cuidado em saúde, seja na coordenação da assistência farmacêutica ou na execução de funções e atividades nas unidades de saúde, e, portanto, precisa ressignificar o seu trabalho, deslocando a centralidade do produto para o usuário, a família e a comunidade.

Descritores: Farmacêutico; Força de Trabalho em Saúde; Assistência Farmacêutica; Atenção Primária à Saúde. 


\begin{abstract}
CARVALHO, M.N. The pharmacist in the composition of the primary care workforce in brazilian health system. Thesis (Doctorate in Pharmaceutical Sciences) - Faculdade de Ciências da Saúde, Universidade de Brasília, Brasília, 2016.
\end{abstract}

This thesis is an analysis of participation of the pharmacist in the composition of the primary care workforce of the brazilian health system (acronym in portuguese is SUS), from the worker characteristics and work in pharmaceutical care, aimed at understanding the pharmaceutical work as health work and thus contributing to their inclusion in health teams. This is study based on hermeneutics-dialectics, whose methodological procedures were divided into two types of research: ecological study from online databases (e.g. DATASUS, RAIS and SIGRAS) and cross-sectional study approach quantitative, on the workers in the management of pharmaceutical assistance in municipalities and the drug-dispensing units from primary data obtained during a national research about access and rational use of drugs. The workforce in pharmaceutical care is predominantly made up of women, aged 18-39 years with higher education, gazetted, for over a year on the job or activity and journey higher working week to 30 hours. The pharmacist participation in the workforce composition in the primary health care has grown and consolidated in management functions, especially in the coordination of pharmaceutical care $(90.7 \%)$, but is still small in dispensing units, whose jobs they are mostly occupied by technical and or nursing assistants $(43.0 \%)$, followed by pharmaceuticals $(33.3 \%)$. Midwest and southeast regions are characterized by greater participation of pharmacists in dispensing drugs in health units $(57.1 \%$ and $64.1 \%$, respectively). In conclusion, the participation of the pharmacist in the composition of the health workforce of primary care in the brazilian health system has expanded due on the one hand, the clear investment in related supply activities and people's access to medicines and on the other, of policies encouraging the implementation of multidisciplinary support teams in health service. Although they are presented as inclusion strategy in health teams, these policies were not sufficient to increase the number of pharmacist in dispensing units, whose function is to provide direct care to users and, through them, perform teamwork, which differs from the exercise of technical and managerial functions of the drug. Furthermore, the pharmacist must understand their work in the context of health care management, is the coordination of pharmaceutical care or performing functions and activities in health facilities, and therefore need to reframe their work, shifting the centrality of the product to user, family and community.

Keywords: Pharmacist; Health Workforce; Pharmaceutical Services; Primary Health Care. 


\section{RESUMEN}

\section{CARVALHO, M.N. El farmacéutico en la composición del personal de asistencia primaria en sistema de salud brasileño. Tesis (Doctorado en Ciencias Farmacéuticas). - Faculdade de Ciências da Saúde, Universidade de Brasília, Brasília, 2016.}

Esta tesis es un análisis de la participación del farmacéutico en la composición de la fuerza laboral de atención primaria del sistema de salud brasileño (sigla en portugués es SUS), a partir de las características del trabajador y el trabajo en la atención farmacéutica, dirigidas a la comprensión de la obra farmacéutica como el trabajo de salud y contribuyendo así a su inclusión en los equipos de salud. Se trata de estudio basado en la hermenéutica-dialéctica, cuyos procedimientos metodológicos fueron divididos en dos tipos de investigación: estudio ecológico de las bases de datos en línea (por ejemplo, DATASUS, RAIS y SIGRAS) y la sección transversal enfoque de estudio cuantitativo, sobre los trabajadores en la gestión de la asistencia farmacéutica en los municipios y las unidades de dispensación de medicamentos a partir de datos primarios obtenidos durante una investigación nacional sobre el acceso y el uso racional de los medicamentos. La fuerza de trabajo en la atención farmacéutica está compuesto principalmente por las mujeres, a la edad de 18-39 años con educación superior, boletín oficial, durante más de un año en el trabajo o actividad y el viaje más alta semana laboral a 30 horas. La participación farmacéutico en la composición de la fuerza de trabajo en la atención primaria de salud ha crecido y se ha consolidado en las funciones de gestión, especialmente en la coordinación de la atención farmacéutica $(90,7 \%)$, pero sigue siendo pequeña en unidades de distribución, cuyos puestos de trabajo están ocupados en su mayoría por técnicos y o auxiliares de enfermería (43,0\%), seguidos por los productos farmacéuticos $(33,3 \%)$. Medio Oeste y sureste se caracterizan por una mayor participación de los farmacéuticos en la dispensación de medicamentos en las unidades de salud (57,1\% y 64,1\%, respectivamente). En conclusión, la participación del farmacéutico en la composición de la fuerza laboral de salud de atención primaria en el sistema de salud brasileño se ha expandido debido, por un lado, la clara inversión en las actividades de suministro relacionadas y acceso de la población a los medicamentos $\mathrm{y}$, por otro, de las políticas fomentando la implantación de los equipos multidisciplinarios de apoyo en los servicios de salud. A pesar de que se presentan como estrategia de inclusión en los equipos de salud, estas políticas no fueron suficientes para aumentar el número de farmacéuticos en unidades de distribución, cuya función es la de proporcionar una atención directa a los usuarios $\mathrm{y}$, a través de ellos, lleve a cabo el trabajo en equipo, la cual difiere enormemente del ejercicio de las funciones técnicas y de gestión de la droga. Por otra parte, el farmacéutico debe entender su trabajo en el contexto de la gestión de la asistencia sanitaria, es la coordinación de la atención farmacéutica o la realización de las funciones y actividades en los centros de salud, y por lo tanto tiene que replantear su trabajo, desplazando la centralidad del producto al usuario, familia y la comunidad.

Palabras clave: Farmacéutico; Fuerza de Trabajo de la Salud; Servicios Farmacéuticos; Atención Primaria de Salud. 


\section{Lista de Figuras}

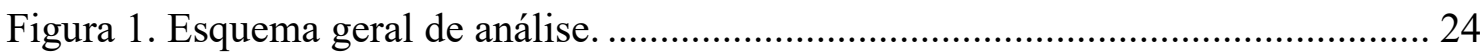

Figura 2. Fluxo de acesso e extração de dados do portal do DATASUS....................... 30

Figura 3. Fatores que influenciam a composição da força de trabalho em saúde. .......... 54

Figura 4. Distribuição da força de trabalho em saúde nas regiões do mundo................. 55

Figura 5. Relação entre educação, mercado de trabalho e serviços de saúde na oferta e

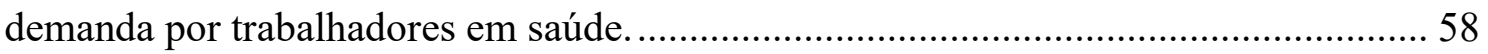

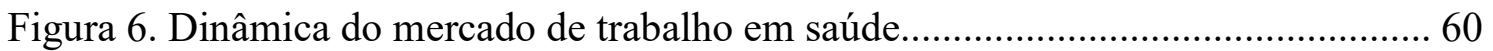

Figura 7. Evolução da graduação em saúde no Brasil (1991 - 2013)............................ 62

Figura 8. Número de cursos de saúde no Brasil, por natureza jurídica (1991 - 2013). . 62

Figura 9. Evolução da graduação em saúde no Brasil, por cursos (1991, 2008, 2013).. 63

Figura 10. Evolução do número de cursos de Farmácia no Brasil (1991 - 2013).......... 74

Figura 11. Evolução do número de vagas, ingressos e concluintes dos cursos de

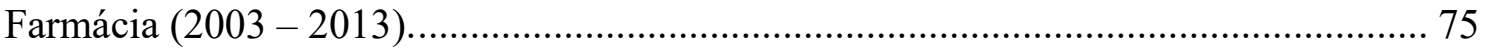

Figura 12. Evolução do emprego formal do farmacêutico no Brasil (2003 - 2013)...... 79

Figura 13. Distribuição de farmacêuticos com vínculo formal ativo, segundo o sexo. Brasil (2003 - 2013).

Figura 14. Distribuição dos farmacêuticos com vínculo formal ativo, segundo a natureza jurídica do estabelecimento. Brasil (2003 - 2013). 85

Figura 15. Distribuição dos farmacêuticos com vínculo formal ativo, segundo a remuneração média em Salários Mínimos (SM). Brasil (2003 - 2013).

Figura 16. Taxa de crescimento da população brasileira, das unidades básicas de saúde e de ocupações de nível superior por região. Brasil (dez/2008 e dez/2013). .................. 106

Figura 17. Ciclo Gerencial da Assistência Farmacêutica............................................ 125

Figura 18. Ciclo da Assistência Farmacêutica no SUS. ............................................. 126

Figura 19. Serviço de dispensação de medicamentos. ............................................... 133

Figura 20. Distribuição dos trabalhadores da coordenação e das unidades de dispensação, por sexo (Brasil e regiões, 2015).......................................................... 136

Figura 21. Distribuição dos trabalhadores da coordenação e das unidades de dispensação, por faixa etária (Brasil e Regiões, 2015).

Figura 22. Distribuição do trabalhador da coordenação da assistência farmacêutica municipal, por escolaridade e formação (Brasil e regiões, 2015). 138 
Figura 23. Distribuição dos trabalhadores das unidades de dispensação, por escolaridade

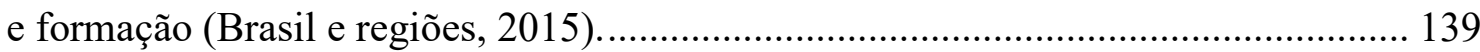

Figura 24. Distribuição dos trabalhadores da coordenação e das unidades de dispensação, por tipo de vínculo de trabalho (Brasil e Regiões, 2015)....................... 140 Figura 25. Distribuição dos trabalhadores da coordenação e das unidades de dispensação, por carga horária semanal (Brasil e Regiões, 2015)............................... 141 Figura 26. Distribuição dos trabalhadores da coordenação e das unidades de dispensação, por tempo como gestor (Brasil e Regiões, 2015).................................. 142 


\section{Lista de Mapas}

Mapa 1. Distribuição geográfica dos cursos da área de saúde no Brasil (2013). 64

Mapa 2. Distribuição dos farmacêuticos no mercado formal nas regiões brasileiras em dezembro de 2013. 88

Mapa 3. Municípios com farmacêuticos na coordenação da assistência farmacêutica municipal nas diferentes regiões do país. 143

Mapa 4. Municípios com farmacêuticos nas unidades de dispensação de medicamentos nas diferentes regiões do país. 


\section{Lista de Tabelas}

Tabela 1. Distribuição das instituições formadoras de profissionais de saúde por região da OMS

Tabela 2. Distribuição das categorias profissionais nas áreas urbana e rural, segundo sexo. Brasil (2000).

Tabela 3. Taxa de incremento dos empregos de profissionais de saúde por esfera administrativa do setor público segundo ocupações de saúde. Brasil (1995/2000).

Tabela 4. Distribuição regional e taxa de crescimento dos cursos de Farmácia no Brasil (2003 - 2013).

Tabela 5. Distribuição regional do número de vagas, ingressos e concluintes dos cursos de Farmácia (2003 - 2013). 76

Tabela 6. Distribuição regional e taxa de crescimento dos cursos de Farmácia no Brasil, segundo a natureza jurídica (2003 - 2013). 77

Tabela 7. Distribuição regional e taxa de crescimento do emprego formal do farmacêutico no Brasil (2003, 2008, 2013). 80

Tabela 8. Distribuição regional e taxa de crescimento do emprego formal farmacêuticos no Brasil por natureza jurídica (2003, 2008, 2013). 81

Tabela 9. Evolução da rede assistencial e equipes da atenção básica do SUS. 97

Tabela 10. Número absoluto, percentual e taxa de crescimento bruto dos trabalhadores cadastrados nas UBS (Brasil, 2008/2013) 101

Tabela 11. Ocupações de nível superior cadastradas nas UBS. Brasil (2008/2013)... 104 Tabela 12. Equipes de Saúde da Família (eqSF) e do Núcleo de Apoio à Saúde da Família (eqNASF) implantadas, por região do Brasil (Dez/2013).

Tabela 13. Número de trabalhadores de nível superior cadastrados nas UBS, segundo região do Brasil (dez/2008 e dez/2013). 108

Tabela 14. Taxa de crescimento das ocupações de nível superior cadastradas em UBS no CNES, segundo região do Brasil (dez/2008 e dez/2013).

Tabela 15. Razão populacional das ocupações de nível superior cadastradas em UBS por 1.000 habitantes (Dez/2013).

Tabela 16. Funções do farmacêutico nas unidades de dispensação (Brasil e Regiões, 2015).

Tabela 17. Atividades dos farmacêuticos nas unidades de dispensação (Brasil e Regiões, 2015). 146 


\section{Lista de Quadros}

Quadro 1. Variáveis e indicadores da pesquisa empírica. ........................................... 28

Quadro 2. Modalidades do Núcleo de Apoio à Saúde da Família (NASF).................. 103 


\section{LISTA DE SIGLAS E ABREVIATURAS}

ANVISA - Agência Nacional de Vigilância Sanitária

CEME - Central de Medicamentos

CIB - Comissão Intergestores Bipartite

CIT - Comissão Intergestores Tripartite

CNES - Cadastro Nacional de Estabelecimentos de Saúde

CONASS - Conselho Nacional de Secretários de Saúde

DATASUS - Departamento de Informática do SUS

ESF - Estratégia Saúde da Família

EUA - Estados Unidos da América

FIOCRUZ - Fundação Instituto Osvaldo Cruz

HORUS - Sistema Nacional de Gestão da Assistência Farmacêutica

MTE - Ministério do Trabalho e Emprego

MTPS - Ministério do Trabalho e Previdência Social

MS - Ministério da Saúde

NASF - Núcleo de Apoio à Saúde da Família

NOAS - Norma Operacional de Assistência à Saúde

NOB - Norma Operacional Básica

OMS - Organização Mundial de Saúde

OPS - Organização Pan-Americana de Saúde

PSF - Programa Saúde da Família

PNAB - Política Nacional de Atenção Básica

PNAF - Política Nacional de Assistência Farmacêutica

PNAUM - Pesquisa Nacional sobre Acesso, Utilização e Uso Racional de Medicamentos

PNM - Política Nacional de Medicamentos

RAIS - Relação Anual de Informações Sociais

RENAME - Relação Nacional de Medicamentos Essenciais

SMS - Secretaria Municipal de Saúde

SUS - Sistema Único de Saúde

UBS - Unidade Básica de Saúde

UFMG - Universidade Federal de Minas Gerais

WHO - World Health Organization 


\section{SUMÁRIO}

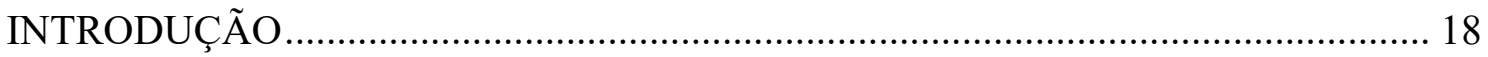

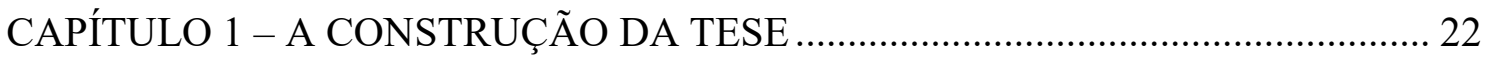

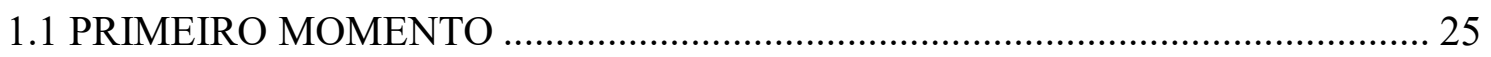

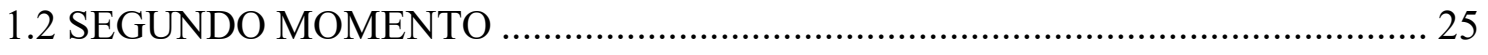

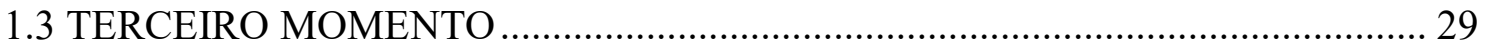

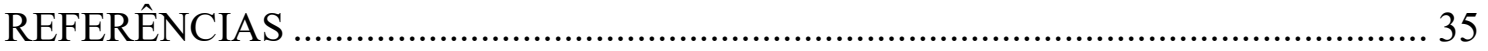

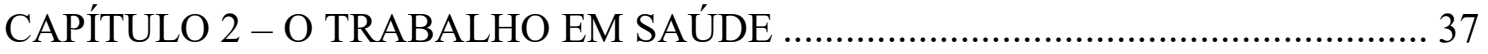

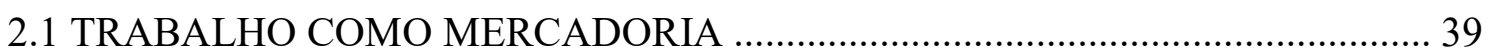

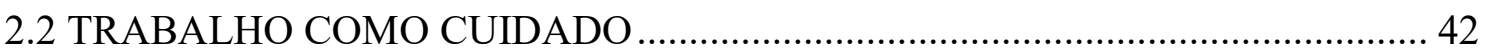

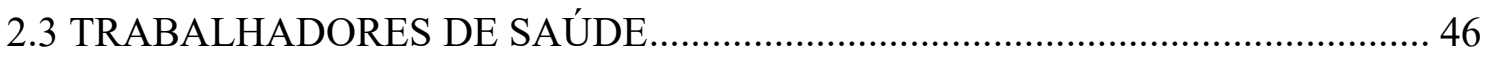

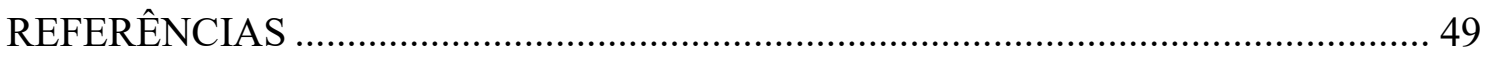

CAPÍTULO 3 - A FORÇA DE TRABALHO EM SAÚDE......................................... 52

3.1. COMPOSIÇÃO E DISTRIBUIÇÃO DA FORÇA DE TRABALHO ..................... 53

3.2 MERCADO DE TRABALHO E FORMAÇÃO EM SAÚDE NO BRASIL............ 59

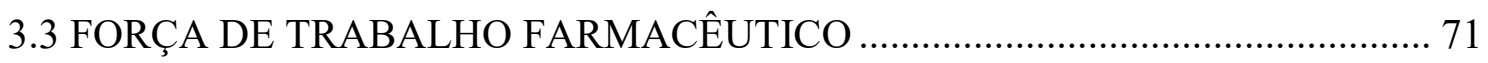

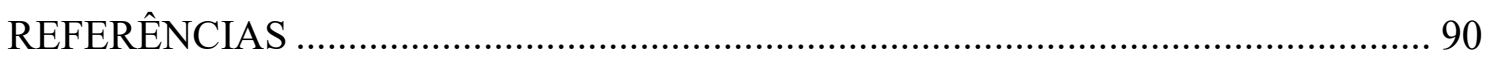

CAPÍTULO 4 - A FORÇA DE TRABALHO NA ATENÇÃO PRIMÁRIA DE

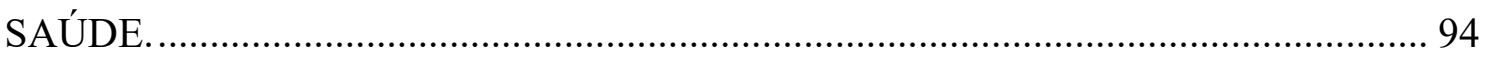

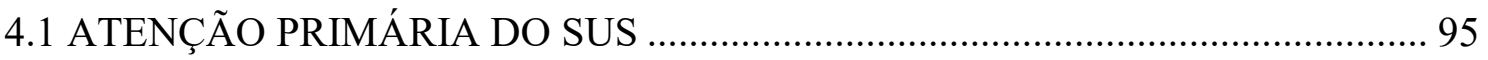

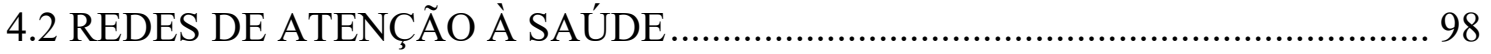

4.3 EXPANSÃO E DIVERSIFICAÇÃO DA FORÇA DE TRABALHO..................... 100

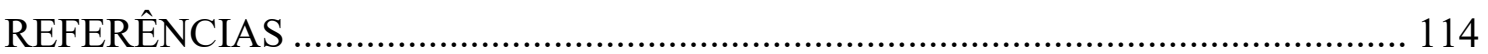

CAPÍTULO 5 - A FORÇA DE TRABALHO NA ASSISTÊNCIA FARMACÊUTICA

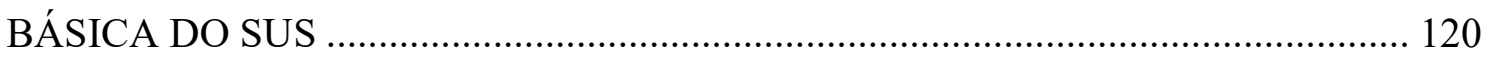

5.1 ASSISTÊNCIA FARMACÊUTICA NO SISTEMA DE SAÚDE ….................... 121

5.2 GERENCIAMENTO DO MEDICAMENTO NO SUS ....................................... 124

5.3 SERVIÇOS FARMACÊUTICOS NA ATENÇÃO PRIMÁRIA............................. 127

5.4 TRABALHADORES E TRABALHO NA ASSISTÊNCIA FARMACÊUTICA

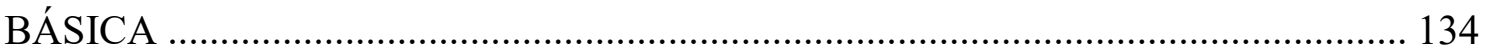

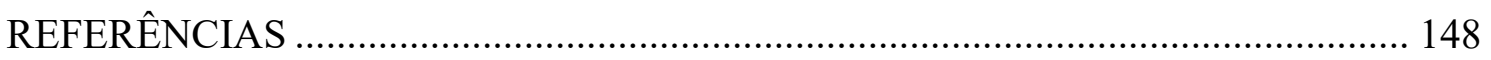

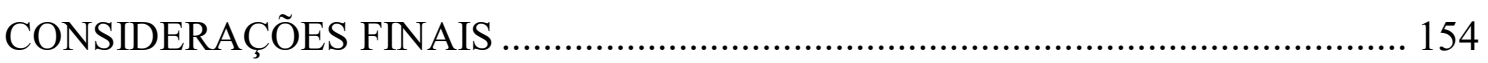

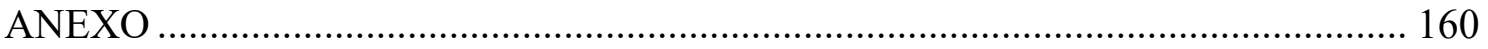




\section{INTRODUÇÃO}

As primeiras questões referentes ao objeto desta tese surgiram ainda durante o desenvolvimento da minha dissertação, intitulada "A (des) centralização da política de medicamentos no município de Barcarena - PA: discursos e práticas" ${ }^{\text {, }}$, realizada alguns anos após a publicação da portaria 3.916, em julho de 1998, que definiu a assistência farmacêutica como componente estratégico para a consolidação do Sistema Único de Saúde (SUS), e da criação do incentivo à Assistência Farmacêutica Básica, em 1999, cujo objetivo central consista no financiamento tripartite - União, Estados e Municípios - da aquisição do elenco mínimo de medicamentos básicos municipais (CARVALHO; CASTRO; COUTO, 2007).

Em 2001, ano da pesquisa de campo da dissertação, Barcarena ${ }^{2}$ representava uma das cinco maiores receitas per capita do Pará, estava na Gestão de Plena do Sistema, contava com uma rede de serviços de saúde composta por aproximadamente treze unidades de saúde - a maioria do tipo posto de saúde ${ }^{3}$, um almoxarifado de medicamentos e uma farmácia central ${ }^{4}$. Havia apenas três farmacêuticos no município, sendo um contratado, que exercia basicamente atividades no almoxarifado de medicamentos e visitava as unidades de saúde, um concursado do nível estadual, que atuava na Vigilância Sanitária, e um proprietário de laboratório de análises clínicas, que muitos anos mais tarde se tornou secretário de saúde.

No mesmo período, a situação na assistência farmacêutica na capital do estado se encontrava diferente da década anterior. Além dos avanços na estrutura e execução do ciclo logístico da assistência farmacêutica em Belém, a prefeitura realizou concurso público e contratou farmacêuticos para diversas funções e setores, o que resultou na ampliação do número de profissionais nas unidades básicas de saúde. Aqui eu começava

\footnotetext{
${ }^{1}$ A dissertação foi desenvolvida no Programa de Mestrado em Planejamento do Desenvolvimento, do Núcleo de Altos Estudos Amazônicos (NAEA), da Universidade Federal do Pará (UFPA), defendida em 2002, e publicada como "A (des) centralização da política de medicamentos no contexto da reforma do setor saúde no município de Barcarena - PA", no capítulo 1 do livro "Poder Local e Mudanças Socioambientais", em 2007.

${ }^{2} \mathrm{O}$ município localizado na região Nordeste do estado do Pará. Na época da pesquisa, o transporte de lancha era a forma mais rápida de deslocamento entre a capital (Belém) e Barcarena, com duração média de 45 minutos.

${ }^{3}$ As maiores unidades de saúde do município eram os Centros de Saúde Vila do Conde e Bairro Novo e a Unidade Mista. Entre estas, apenas o Centro de Saúde Bairro Novo estava descentralizado para o município. Os demais continuavam sob a administração estadual.

${ }^{4}$ Esta farmácia estava localizada no segundo andar do prédio da Secretaria Municipal de Saúde (SMS).
} 
a perceber que poderia haver concentração de farmacêuticos na região metropolitana e escassez no interior do estado do Pará e que este poderia ser um fenômeno de toda a região Norte e, quiçá, de todas as regiões do país.

Além da vivência no campo da pesquisa da dissertação, as inquietações tratadas nesta tese se acumularam ao longo da minha experiência profissional, porque geralmente as inquietações se comportam assim: se avolumam diante da observação repetida dos fenômenos. De 1999 a 2004, trabalhei na Secretaria Municipal de Saúde de Belém como farmacêutica de um Centro de Atenção Psicossocial (CAPS), assessora de planejamento do Departamento de Ações de Saúde e coordenadora dos Serviços Especializados. Em 2007 fui nomeada farmacêutica da Secretaria de Estado de Saúde Pública do Pará (SESPA) e exerci atividades em uma unidade de referência especializada materno-infantil e, posteriormente, na Fundação Santa Casa de Misericórdia do Pará (FSCMPA), como gerente de ensino, e na Coordenação Estadual de Assistência Farmacêutica (CEAF), como assessora de planejamento. Ademais das possíveis diferenças no número de farmacêuticos nos estabelecimentos de saúde, outra questão sempre se mostrou relevante: a dificuldade de reconhecimento do farmacêutico como membro de equipe de saúde. Em todos os lugares que trabalhei ou coordenei, o farmacêutico exercia fundamentalmente funções no abastecimento de medicamentos e interagia muito pouco com os outros membros da equipe, especialmente no cuidado direto ao paciente ${ }^{5}$.

Em 2009 coordenei um diagnóstico realizado pela CEAF sobre assistência farmacêutica. Foram enviados questionários estruturados, junto com Termo de Adesão à pactuação do Componente Básico da Assistência Farmacêutica, às secretarias de saúde dos 143 municípios do Pará. Quanto aos recursos humanos, a pesquisa revelou que a distribuição de farmacêuticos é extremamente desigual entre as macrorregiões do estado, com alta concentração de profissionais na região Norte, mais especificamente na capital, Belém ${ }^{6}$. Eis que o fenômeno que eu havia observado em 2001 realmente ocorria

\footnotetext{
5 Embora o Consenso sobre Atenção Farmacêutica tenha sido publicado em 2002, a participação do farmacêutico no cuidado ao paciente passou muito tempo a ser função secundária. $O$ trabalho farmacêutico nos estabelecimentos de saúde sempre esteve diretamente relacionado ao abastecimento de produtos farmacêuticos e garantia da qualidade desses produtos.

6 O banco de dados produzido pela pesquisa foi utilizado na elaboração da monografia "Perfil da assistência farmacêutica básica no estado do Pará", defendida por Ana Carla Godinho Pinto em 2010 como Trabalho de Conclusão de Curso de bacharelado em Farmácia do Centro Universitário do Pará (CESUPA).
} 
em todo o estado. Nesse instante apareciam as primeiras pistas de este poderia ser um fenômeno de ocorrência nacional.

Em 2012 ingressei no Curso de Doutorado do Programa de Pós-Graduação em Ciências Farmacêuticas da Universidade de Brasília (UNB) com um projeto de pesquisa de avaliação da gestão estadual da assistência farmacêutica na Amazônia Brasileira, que se manteve até a conclusão da metade dos créditos obrigatórios, quando a minha orientadora, Prof ${ }^{\mathrm{a}}$. Dr ${ }^{\mathrm{a}}$. Silvana Nair Leite, diante do convite para participar como membro da equipe da Pesquisa Nacional sobre Acesso, Utilização e Uso Racional de Medicamentos (PNAUM), do Ministério da Saúde, das recentes transformações na profissão, especialmente o debate sobre serviços farmacêuticos, da minha experiência acadêmica e a vivência profissional em diferentes esferas de governo, da nossa participação em entidades sindicais (por exemplo, Federação Nacional dos Farmacêuticos) e da ausência de publicações sobre o tema, pensadas e escritas por farmacêuticos, sugeriu a mudança do projeto original de tese para uma reflexão aprofundada sobre o trabalho farmacêutico - e que mais tarde se transformaria em uma tese sobre a participação deste profissional na composição da força de trabalho - no Sistema Único de Saúde (SUS).

Ao final de quatro anos de doutorado, escrevi esta tese que objetivou analisar a participação do farmacêutico na composição da força de trabalho da atenção primária do SUS, a partir da hermenêutica-dialética, buscando a compreensão do trabalho farmacêutico como trabalho em saúde e a contribuição à sua inserção nas equipes de saúde.

Nesse contexto, a tese central é que a participação efetiva do farmacêutico na composição da força de trabalho em saúde da atenção primária do SUS depende da ressignificação do seu trabalho, deslocando a centralidade da mercadoria (produto) para o cuidado (usuário), e a compreensão que o medicamento e outras tecnologias são, portanto, meios ou ferramentas para a produção do cuidado em saúde e não a finalidade do cuidado.

Os argumentos da tese estão apoiados em cinco afirmações: 1) o farmacêutico é um trabalhador de saúde, 2) o trabalho farmacêutico está centrado no produto, 3) o trabalho farmacêutico deve ser centrado no usuário, 4) o trabalho farmacêutico deve ser orientado pelo cuidado e 5) a participação efetiva do farmacêutico na força de trabalho da atenção primária depende de mudanças na oferta e demanda profissional. 
O conteúdo está distribuído em cinco capítulos. Logo após a introdução, em que explico as motivações, os pressupostos teóricos, o objeto e os limites da pesquisa, segue o capítulo 1 sobre o percurso metodológico adotado na construção da tese, descrito em três momentos, que vão desde a definição do objeto e das questões norteadoras, a seleção dos referenciais teóricos, a escolha das fontes de informação sobre a força de trabalho em saúde no Brasil até o desenho da pesquisa empírica.

O capítulo 2 aborda o trabalho, o trabalho em saúde e o mercado de trabalho no setor saúde, a partir de autores como Karl Marx, Ricardo Antunes, Ricardo Bruno Mendes Gonçalves, Sábado Nicolau Girardi entre outros, com a finalidade de apresentar as categorias basilares que sustentam a tese sobre o reconhecimento do farmacêutico como trabalhador de saúde e, especialmente, profissional do cuidado.

No capítulo 3, intitulado a força de trabalho em saúde, são abordados os aspectos conceituais, a composição, a distribuição, a migração e as características mundiais e regionais da força de trabalho em saúde no contexto da reestruturação produtiva e da escassez global de trabalhadores em saúde.

O capítulo 4, a força de trabalho na atenção primária de saúde, trata da composição, expansão, diversificação e desigualdade na distribuição da força de trabalho em saúde no âmbito da atenção primária do SUS.

O último capítulo aborda a força de trabalho na assistência farmacêutica básica do SUS e tem como objeto discutir o papel do farmacêutico no cuidado em saúde no contexto da assistência farmacêutica e, especialmente, na atenção primária do sistema de saúde brasileiro. A gestão em saúde e a gestão da assistência farmacêutica. Inicialmente, apresenta-se uma revisão histórica conceitual da gestão em saúde e da gestão da assistência farmacêutica. Essa revisão subsidia a discussão a respeito dos aspectos a serem considerados para a gestão da assistência farmacêutica no presente estudo. 


\section{CAPÍTULO 1 - A CONSTRUÇÃO DA TESE}

"Transportai um punhado de terra todos os dias e fareis uma montanha" (Confúcio)

Este capítulo apresenta o percurso metodológico adotado na construção da tese, que foi dividido em três momentos, que se construíram, desconstruíram e reconstruíram a partir das minhas impressões e interpretações sobre o mundo real.

Para Bourdieu (2001), construir um objeto científico é, antes de tudo, romper com o senso comum, ou seja, com representações partilhadas por todos. Assim, o préconstruído está em toda parte e o sociólogo, ou o pesquisador, tem um objeto a conhecer, o mundo social, de que ele próprio é produto. Como romper com o senso comum se o pesquisador faz parte do mundo pesquisado? Nas Ciências Sociais, as rupturas epistemológicas são muitas vezes rupturas sociais, rupturas com as crenças fundamentais de um grupo e, por vezes, com as crenças fundamentais de corpos profissionais.

Do ponto de vista epistemológico, a realidade pode ser abordada, lida, pensada e relida de várias maneiras. Entre as diversas correntes do pensamento, o objeto desta tese foi inicialmente elaborado teórica e metodologicamente a partir do materialismo dialético de Karl Marx, especialmente por se tratar de um estudo sobre o trabalho humano e a força de trabalho, e depois analisado por meio da hermenêutica-dialética de Habermas, que me ofereceu a possibilidade de compreender o trabalho farmacêutico a partir da associação da perspectiva subjetiva à análise objetiva da realidade.

O materialismo dialético pode ser resumido em dois conceitos fundamentais: modo de produção e formação social. O primeiro consiste na estrutura global formada por estruturas regionais em que sempre existe uma estrutura regional que domina as demais e que esta dominação se dá historicamente. Além disso, na estrutura global o nível econômico determina as outras estruturas. Já a formação social é a unidade complexa que articula as várias instâncias de organização social que podem conter vários modos de produção, em que um é dominante e determina os outros, na mesma realidade histórica. Portanto, se refere às forças produtivas e as relações sociais de produção, as classes sociais, as formas de produção, consumo e circulação, a população e movimentos populacionais, o desenvolvimento da sociedade, o Estado etc (MINAYO, 2010). 
Nesse sentido, o objeto da tese foi primeiramente pensado sobre o como se dá e está estruturado o trabalho farmacêutico como trabalho em saúde dentro do modo de produção contemporâneo e no contexto de formação social do Brasil, ou seja, das forças produtivas, das relações sociais, das formas de produção de bens e serviços e da própria estrutura social brasileira, o que poderia ser explorado e analisado por meio do materialismo dialético, que consiste em linhas gerais numa tentativa de pensar o mundo integrando as diferentes partes constituintes e contraditórias do mundo real, ou seja, busca as relações concretas e efetivas por trás dos fenômenos (MINAYO, 2010; ZAGO, 2013).

Embora a realidade concreta do trabalho possa ser compreendida pelo materialismo histórico dialético, a vida é repleta de subjetividade. Considerando as limitações da dialética marxista e a minha inserção no mundo social, a interpretação do texto e do contexto do trabalho farmacêutico se mostrou fundamental para os objetivos da tese. Assim surgiu a hermenêutica como possibilidade no caminho metodológico por entender que o pesquisador tem opiniões e preconceitos sobre objeto, e que estas dependem do grau inserção no contexto da sua pesquisa.

Para Gadamer (2005), aquele que quer compreender, fazer uma interpretação correta, adotar uma postura reflexiva diante do fenômeno, tem que se afastar ao máximo da arbitrariedade e da estreiteza do pensamento, embora seja fundamental, antes de tudo, antes de tudo, se apropriar de opiniões prévias e preconceitos pessoais, pois é fundamental se dar conta próprios pressupostos, a fim de confrontar a verdade do texto com as opiniões prévias pessoais do interprete.

A principal tarefa do intérprete é descobrir a pergunta a que o texto vem dar resposta; compreender um texto é compreender a pergunta. Simultaneamente, um texto só se torna um objeto da interpretação se confrontar o intérprete com uma pergunta. Nesta lógica de pergunta e resposta, um texto acaba por ser um acontecimento ao ser atualizado na compreensão, que representa uma possibilidade histórica. (BLEICHER, 2002, p.4).

Diante das limitações metodológicas e interpretativas do materialismo dialético e da própria hermenêutica, e julgando que essas limitações podiam ser superadas, optei pela hermenêutica-dialética como metodologia.

A associação entre a hermenêutica e a dialética não se reduzem ao simples tratamento de dados e, ao contrário, possibilita uma reflexão profunda sobre a práxis, 
permitindo a compreensão e a análise crítica da realidade social. Enquanto que a hermenêutica compreende a realidade como entender o outro, e entender-se no outro, a dialética baseia-se no estranhamento e na crítica da realidade, de si e do outro (MINAYO, 2010).

As categorias centrais da tese foram definidas como "força de trabalho em saúde" e "trabalho farmacêutico". As categorias foram, por sua vez, analisadas por meio de um conjunto de variáveis previamente definidas e interpretadas a partir dos dados primários e secundários obtidos durante a execução da pesquisa empírica, que teve com objetivo revelar os fenômenos manifestados pela realidade analisada (figura 1).

Figura 1. Esquema geral de análise.

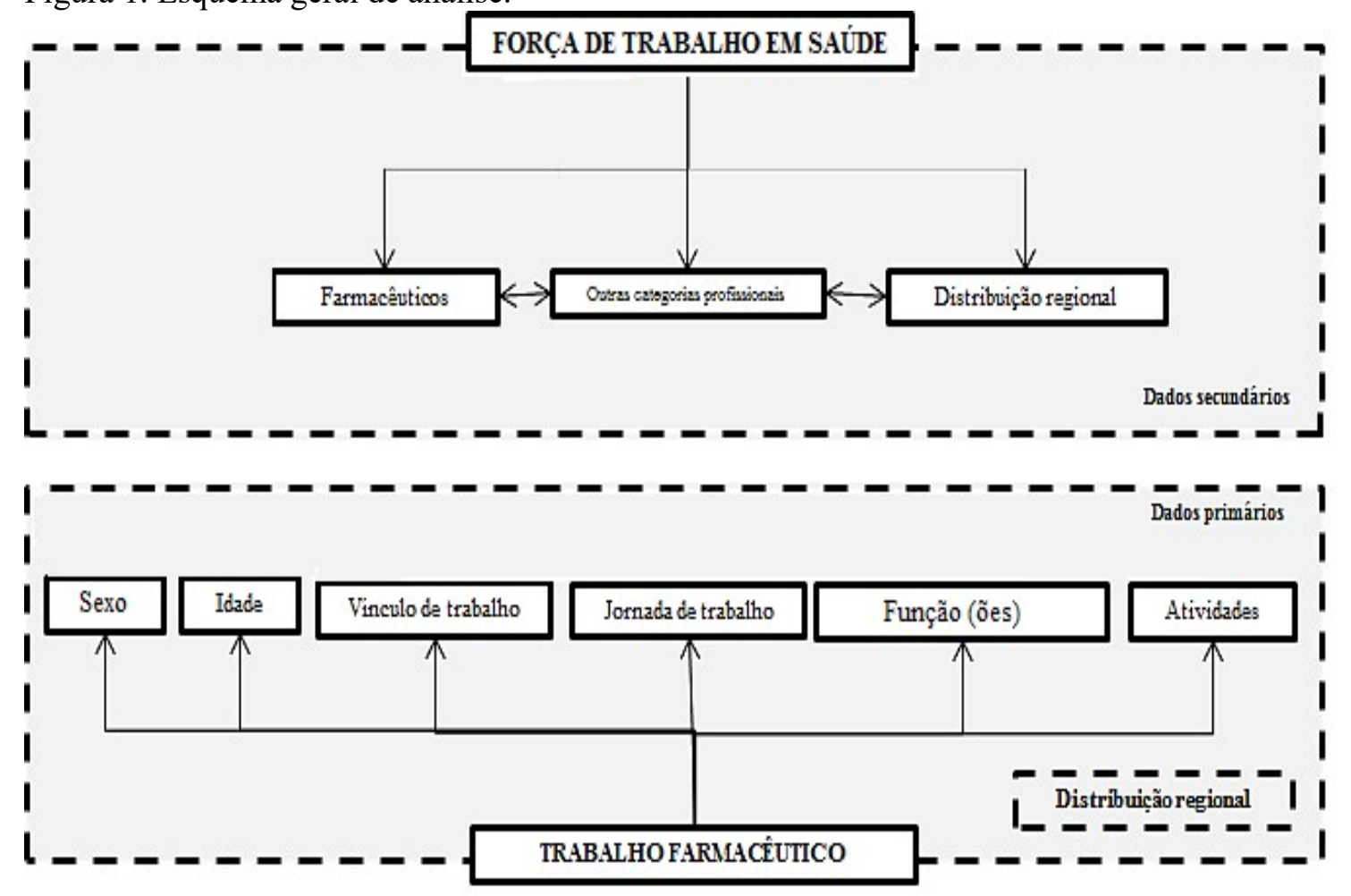

Fonte: Carvalho (2016).

Adotando a hermenêutica-dialética como estratégia metodológica e analítica, o primeiro momento consistiu na redefinição do objeto da tese e revisão do estado da arte, a partir da busca de referências bibliográficas (artigos, dissertações, teses e livros) sobre trabalho humano e força de trabalho, em bases de dados online, no acervo de bibliotecas públicas e em livrarias. O segundo na leitura dos principais referenciais teóricos, da formulação das hipóteses, na escolha das categorias de análise e seleção das variáveis do estudo e o terceiro na definição da pesquisa empírica e do plano de análise, a partir 
das categorias e variáveis previamente escolhidas, e continuamente revisitadas, e na elaboração dos argumentos e capítulos da tese.

\subsection{PRIMEIRO MOMENTO}

O objeto de estudo começou a ser pensado após a redefinição do assunto de interesse, por sugestão da minha orientadora, a professora Silvana Nair Leite, que percebeu a importância de uma tese sobre trabalho farmacêutico e suas as inúmeras contribuições para o debate atual sobre qualificação de serviços farmacêuticos.

Diante da mudança do objeto, uma questão se colocou imediatamente: existe alguma tese sobre o trabalho farmacêutico? Assim, o primeiro passou foi realizar busca de publicações em bases de dados online com as palavras "trabalho" e "farmacêutico".

Como não há estudos que tratem especificamente sobre o trabalho farmacêutico, decidi ampliar a busca para a frase "trabalho em saúde", com o objetivo conhecer o universo de publicações sobre tema no Brasil e, assim, delimitar melhor o objeto da tese. Até aqui, eu sabia que não havia nenhuma tese sobre o meu objeto de estudo e que há um grande número de publicações sobre o trabalho de outras categorias profissionais da área da saúde.

\subsection{SEGUNDO MOMENTO}

A leitura de textos sobre composição da força de trabalho em saúde, publicados nos anos 80 - com destaque para os do economista André Cezar Médici e dos médicos sanitaristas Sábado Nicolau Girardi e Roberto Passos Nogueira, do Relatório Mundial da Saúde 2006 "Trabalhando juntos pela Saúde", dos artigos "Distribuição da força de trabalho: eqüidade e negociação", de Vera Miguelote e colaboradores e "Tendências no mercado de trabalho em saúde no Brasil”, da socióloga Maria Helena Machado ${ }^{7}$ e colaboradores, "Saúde: a Cartografia do Trabalho Vivo", do médico sanitarista Emerson Elias Merhy, entre outros, me fizeram compreender que há grande lacuna no conhecimento acerca da participação do farmacêutico na composição da força de trabalho em saúde no Brasil.

\footnotetext{
7 Maria Helena Machado é organizadora do livro "Os Médicos do Brasil: um retrato da realidade", publicado em 1997.
} 


\subsubsection{Pressupostos teóricos}

a) Sem trabalhador, não há trabalho (ANTUNES, 2014).

b) Todo trabalho em saúde é trabalho vivo em ato (MERHY, 2014);

c) Sem trabalhador não há serviços de saúde. Portanto, os trabalhadores em saúde são vitais para os sistemas de saúde (ORGANIZAÇÃO MUNDIAL DA SAÚDE, 2007; MERHY, 2014);

d) Há uma escassez global de todas as categorias profissionais, o que compromete a manutenção dos sistemas de saúde e, consequentemente, as chances de sobrevivência e bem-estar das pessoas (ORGANIZAÇÃO MUNDIAL DA SAÚDE, 2007).

e) Há profundas iniquidades e distorções na distribuição da força de trabalho em saúde entre as diversas regiões do mundo. Por exemplo, os sistemas de saúde dos países africanos, que "concentram 25\% da carga de doenças do mundo, contam apenas com 1,3\% dos recursos humanos existentes" (MIGUELOTE et al, 2008, p. 319-320).

f) Os desequilíbrios da força de trabalho variam com "as diferenças geográficas entre áreas rurais e urbanas e entre regiões pobres e ricas, a escassez de médicos e enfermeiras ou de especialistas em determinadas áreas, as diferenças existentes nas instituições ou entre serviços e as disparidades entre na proporção de homens e mulheres na composição da força de trabalho" (ZURN et al, 2004 apud MIGUELOTE et al, 2008, p. 320).

g) Nas últimas décadas houve crescimento da participação das mulheres na força de trabalho em saúde, inclusive em profissões historicamente masculinas, como medicina, odontologia e farmácia (MACHADO; OLIVEIRA; MOYSES, 2011).

h) “A baixa participação das mulheres em posições de gestão e de liderança pode levar a uma menor atenção e compreensão tanto dos aspectos das condições de trabalho que caracterizam a maioria dos empregos das mulheres quanto dos cuidados de saúde especificos para as mulheres" (ORGANIZAÇÃO MUNDIAL DA SAÚDE, 2008, p. 1).

i) Desde a Conferência de Cuidados Primários em Saúde, em Alma-Ata (antiga União Soviética), a atenção primária em saúde se tornou o termo usual para as práticas que envolvem um conjunto de ações no âmbito individual e coletivo, realizadas por equipes multiprofissionais, que visam à promoção e proteção da 
saúde, à prevenção de agravos, ao diagnóstico, ao tratamento, à reabilitação e à manutenção da saúde, é considerada porta preferencial de acesso da população usuária do sistema (SOUSA e HAMANN, 2009). Apoiada em GIL (2006) e tomando como base as políticas de saúde do Brasil, entre as quais está a Política Nacional de Atenção Básica (PNAB), esta tese adota atenção básica como sinônimo de atenção primária em saúde.

\subsubsection{As questões norteadoras}

Considerando os pressupostos teóricos sobre força de trabalho em saúde e atenção primária em saúde, a implantação e consolidação do SUS, a publicação das políticas Nacional de Medicamentos (PNM), em 1998, e de Assistência Farmacêutica (PNAF), em 2004, a criação de bloco de financiamento da assistência farmacêutica, a crescente descentralização de recursos e responsabilidades dos gestores municipais, a importância do farmacêutico na Unidade Básica de Saúde (UBS) e a implantação da Estratégia de Saúde da Família (ESF), e a garantia do uso seguro de medicamentos, e entendendo que o farmacêutico é necessário e indispensável para o cuidado integral em saúde, esta tese foi elaborada partindo das seguintes questões norteadoras:

- Como está composta a força de trabalho em saúde na atenção primária do SUS?

- Qual é a participação do farmacêutico na composição da força de trabalho na atenção primária do SUS?

- Qual é a composição da força de trabalho na assistência farmacêutica da atenção primária do SUS?

- O cenário atual apresenta as condições para a mudança paradigmática do trabalho farmacêutico na atenção primária do SUS?

\subsubsection{As categorias e suas variáveis}

Para Minayo (2010), os conceitos são unidades de significação que definem a forma e o conteúdo de uma teoria e as categorias são conceitos classificatórios carregados de significação, que auxiliam o pesquisador a pensar a realidade de forma hierarquizada. 
As categorias foram operacionalizadas empiricamente por meio de variáveis, tais como ocupação, sexo, idade etc, cujos dados foram obtidos por meio de fontes primárias e secundárias, conforme demonstrado no quadro a seguir.

Quadro 1. Variáveis e indicadores da pesquisa empírica.

\begin{tabular}{|c|c|c|}
\hline VARIÁVEIS & INDICADORES & FONTES \\
\hline Ocupação & $\begin{array}{c}\text { Número de farmacêuticos cadastrados nas UBS } \\
\text { Número de outras categorias profissionais cadastradas } \\
\text { nas UBS }\end{array}$ & CNES \\
\hline Sexo & $\begin{array}{l}\text { Razão entre homens e mulheres na coordenação de } \\
\text { assistência farmacêutica } \\
\text { Razão de homens e mulheres do quadro nas unidades } \\
\text { de dispensação }\end{array}$ & PNAUM \\
\hline Idade & $\begin{array}{l}\text { Faixa etária dos trabalhadores da coordenação } \\
\text { municipal da assistência farmacêutica } \\
\text { Faixa etária dos trabalhadores das unidades de } \\
\text { dispensação }\end{array}$ & PNAUM \\
\hline $\begin{array}{l}\text { Vínculo de } \\
\text { trabalho }\end{array}$ & $\begin{array}{l}\text { Taxa de trabalhadores concursados } \\
\text { Taxa de trabalhadores contratados } \\
\text { Taxa de trabalhadores "terceirizados" }\end{array}$ & PNAUM \\
\hline $\begin{array}{c}\text { Jornada de } \\
\text { trabalho }\end{array}$ & $\begin{array}{l}\text { Taxa de trabalhadores com jornada superior } 30 \mathrm{~h} \\
\text { semanais } \\
\text { Taxa de trabalhadores com jornada inferior } 30 \mathrm{~h} \\
\text { semanais }\end{array}$ & PNAUM \\
\hline \multirow{2}{*}{$\begin{array}{l}\text { Distribuição } \\
\text { regional }\end{array}$} & \multirow{2}{*}{$\begin{array}{c}\text { Taxa de farmacêuticos nas regiões } \\
\text { Taxa das outros profissionais nas regiões }\end{array}$} & $\begin{array}{l}\text { CNES } \\
\text { RAIS }\end{array}$ \\
\hline & & PNAUM \\
\hline Funções & $\begin{array}{l}\text { Número de farmacêuticos na gestão da assistência } \\
\text { farmacêutica } \\
\text { Número de farmacêuticos nas unidades de dispensação }\end{array}$ & PNAUM \\
\hline Atividades & $\begin{array}{l}\text { Atividades exercidas pelos farmacêuticos nas unidades } \\
\text { de dispensação }\end{array}$ & PNAUM \\
\hline
\end{tabular}

Fonte: Carvalho (2016) 


\subsection{TERCEIRO MOMENTO}

Este momento se refere à descrição da pesquisa empírica, que permitiu obter os dados necessários à interpretação e análise das categorias fundamentais da tese.

\subsection{A pesquisa empírica}

A coleta de dados empíricos foi realizada em duas etapas:

\subsubsection{Etapa 1: Pesquisa em bases de dados secundários}

Esta etapa consistiu em pesquisa exploratória e descritiva, de abordagem quantitativa, destinada à obtenção dos dados secundários referentes às variáveis da categoria "força de trabalho", que são estabelecimento de saúde, ocupação e distribuição de trabalhadores.

\section{a) População e critérios de escolha}

A população definida foi composta pelas ocupações em saúde de nível superior, cadastradas nos estabelecimentos de saúde da atenção primária (Centros de Apoio à Saúde da Família - CASF, postos de saúde, Unidades Básicas de Saúde - UBS e unidades mistas), nas cinco regiões brasileiras (Norte, Nordeste, Centro-Oeste, Sudeste e Sul).

\section{b) Coleta de dados}

De dezembro de 2013 a fevereiro de 2014 foram coletados dados disponíveis no Cadastro Nacional de Estabelecimentos de Saúde (CNES), via site do Departamento de Informática do SUS (DATASUS), referentes ao período de 2008 a 2013, para conhecimento preliminar da participação do farmacêutico na composição da força de trabalho na atenção primária do SUS.

A coleta de dados foi realizada no mês de outubro de 2014 no banco de dados online disponível no portal do DATASUS, acessado pelo endereço eletrônico www.datasus.gov.br, conforme a figura abaixo. 
Figura 2. Fluxo de acesso e extração de dados do portal do DATASUS

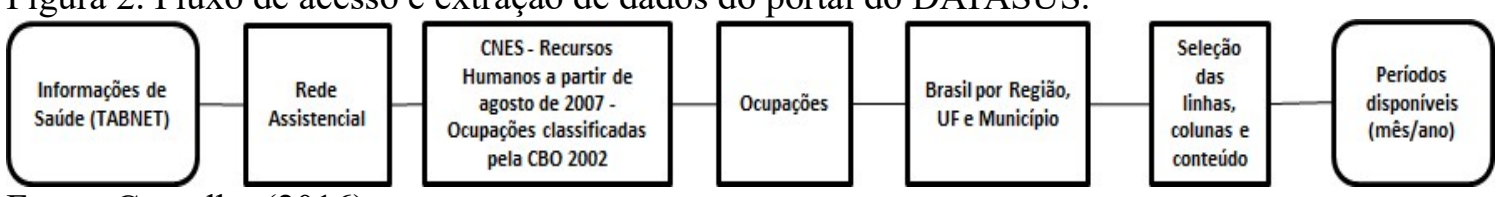

Fonte: Carvalho (2016).

As limitações do uso da base de dados do CNES dizem respeito: a) à sua abrangência, ou seja, não estão inclusos no seu universo os serviços de apoio à gestão, isto significa a não inclusão de todos os profissionais de nível administrativo, vinculados ou não ao SUS; e, b) aos estabelecimentos estritamente privados ainda não estão totalmente cadastrados na base CNES, em especial os ambulatórios de média complexidade (BRASIL, 2007).

\section{c) Fonte de dados}

As principais fontes de dados secundários adotadas nesta tese são o Cadastro de Estabelecimentos de Saúde (CNES), acessado pelo site DATASUS, do Ministério da Saúde e a Relação Anual de Informações Sociais (RAIS), do Ministério do Trabalho e Emprego (MTE) ${ }^{8}$. Contudo, outras fontes complementares foram utilizadas, tais como do Instituto Brasileiro de Geografia e Estatística (IBGE), do Observatório de Recursos Humanos em Saúde/Estação de Pesquisa Sinais de Mercado, do Núcleo de Educação em Saúde Coletiva/Faculdade de Medicina da Universidade Federal de Minas Gerais (OBSERVATÓRIO DE RECURSOS HUMANOS EM SAÚDE), da Estação de Trabalho do IMS/UERJ e do Conselho Federal de Farmácia (CFF).

A partir do início de 2008, as informações do CNES, tanto no que se refere à estrutura física como ao quadro de profissionais, estão sendo utilizadas para validar o faturamento SUS de cada estabelecimento. Para análise dos dados acerca da força de trabalho, Sala, Carro e Seixas (2010) recomendam a utilização dos meses a partir do início de 2008, períodos em que a confiabilidade das informações prestadas tem sido progressivamente maior.

\footnotetext{
${ }^{8}$ Em 02 de outubro de 2015, o Ministério do Trabalho e Emprego (MTE) passou a ser denominado como Ministério do Trabalho e Previdência Social (MTPS).
} 
O CNES disponibiliza informações dos postos de trabalho ${ }^{9}$ (classificados a partir da $\mathrm{CBO}$ ), bem como dos trabalhadores, sendo possível determinar a quantidade de vínculos de trabalho de cada trabalhador. Estão incluídos todos os trabalhadores dos estabelecimentos de saúde, ou seja, os de nível superior, médio e elementar relacionados diretamente à assistência, bem como os de áreas administrativas e de gerenciamento do estabelecimento. Estas informações podem ser analisadas segundo diferentes características dos estabelecimentos de saúde cadastrados (SALA; CARRO; SEIXAS, 2010).

O CNES é a única fonte em nível nacional que identifica os profissionais vinculados a cooperativas e os profissionais estrangeiros que atuam nos serviços de saúde no Brasil. Uma das limitações do uso da base CNES diz respeito à sua abrangência, ou seja, não estão inclusos no seu universo, por não ser obrigatório e sim facultativo, os serviços de apoio à gestão, isto significa a não inclusão de todos os profissionais de nível administrativo vinculados ou não ao SUS. A outra limitação se refere aos estabelecimentos estritamente privados que ainda não estão totalmente cadastrados na base CNES, em especial os ambulatórios de média complexidade, a despeito de todo o esforço da Secretaria de Atenção à Saúde (SAS) e dos gestores para captação dessas informações (BRASIL, 2007).

Dimensionar o tamanho do mercado de trabalho na atenção primária de saúde não é tarefa fácil, porque as bases de dados não permitem identificar se o individuo ocupado exerce ou não atividades desse nível de atenção. No setor público, essa tarefa é menos árdua porque é possível identificar, por meio do CNES, os trabalhadores ocupados em estabelecimentos públicos destinados exclusivamente à realização de atendimentos na atenção primária (VAN DER MASS et al, 2014).

A coleta de dados foi realizada no mês de novembro de 2014 no banco de dados online da Relação Anual de Informações Sociais (RAIS), disponível no Business Inteligence (BI) do Ministério do Trabalho e Emprego (MTE), referentes ao período de 2003 a 2013, para conhecimento preliminar do mercado forma de trabalho do profissional farmacêutico no setor saúde.

\footnotetext{
9 “Os postos de trabalho ocupados representam o número empregados assalariados. O número de ocupados em uma empresa (os empregados) pode ser menor que o número de postos de trabalho, pois uma empresa pode estar com postos vagos, logo após uma demissão, ou aguardando uma contratação" (CORSEUIL e SERVO, 2006, p. 17). Nesta tese, os postos de trabalho são entendidos como o número de vagas ocupadas na unidade de saúde.
} 
A RAIS é o censo anual do emprego formal no país, que abrange informações sobre os estoques do emprego no conjunto dos segmentos institucionais do mercado regulamentado (CLT, estatutário, temporário e avulso). A unidade analítica é o emprego, e não o empregado, se constituindo como a principal fonte sobre oferta e demanda de força de trabalho. É possível encontrar dados sobre natureza jurídica, tipo de atividade, faixa etária, grau de instrução, sexo, ocupação, remuneração média, tipo de vínculo, tempo de serviço, etc. Além disso, também podem ser analisados os fluxos de mercado de trabalho por tipo de admissão e causa de desligamento. Os dados da RAIS são limitados por se restringirem ao mercado formal (WAN DER MAAS et al, 2014).

\subsubsection{Etapa 2: Pesquisa Nacional sobre Acesso, utilização e Uso Racional de Medicamentos (PNAUM)}

Para conhecer o trabalho farmacêutico na gestão da assistência farmacêutica e nas farmácias dos estabelecimentos de saúde foram utilizados dados primários obtidos na execução do componente "Serviços de Saúde" da Pesquisa Nacional sobre Acesso, utilização e Uso Racional de Medicamentos (PNAUM), do Departamento de Assistência Farmacêutica do Ministério da Saúde (DAF/MS). ${ }^{10}$

A metodologia adotada na realização do componente "Serviços de Saúde" da PNAUM é do tipo exploratória e avaliativa, tendo a região como unidade de análise e a unidade de informação, o município e o distrito (ÁLVARES et al, 2016).

\section{a) Sujeitos da pesquisa}

Para os fins desta tese, foram considerados apenas os dados coletados durante as entrevistas com os secretários de saúde, os coordenadores da assistência farmacêutica e os dispensadores, acessados da seguinte maneira:

- Municípios sorteados: uma pessoa em cada município;

\footnotetext{
${ }^{10}$ Pesquisa instituída pela Portaria n. 2.077, de 17 de setembro de 2012, executada pelo Ministério da Saúde, por meio da Secretaria de Ciência, Tecnologia e Insumos Estratégicos (SCTIE/MS), em parceria com Instituições de Ensino Superior (IES) e dividida metodologicamente em dois componentes: inquérito domiciliar e serviços de saúde. A pesquisa de campo ainda não foi concluída e, portanto, ainda não há dados disponíveis.
} 
- Serviços de saúde dos municípios sorteados: uma pessoa por serviço (supõe-se a existência de somente um responsável pela dispensação);

\section{b) Processo de amostragem}

A amostragem foi estratificada por região (Norte, Nordeste, Centro-Oeste, Sudeste e Sul).

Amostra de secretários de saúde e responsáveis pela assistência farmacêutica

Foram sorteados 120 municípios em cada região, estratificados em: capitais, municípios maiores (tendo sido tomados os $0,5 \%$ maiores municípios da região) e municípios menores.

Amostra de dispensadores das unidades de saúde dos municípios

A amostra foi sorteada em dois estágios: municípios e serviços de saúde. No primeiro estágio, foram sorteados 60 municípios, a partir dos 120 municípios selecionados previamente. No segundo estágio foram sorteados, em cada município, serviços de saúde referentes aos estabelecimentos da atenção primária, registrados no CNES como sendo dos tipos 1 (posto de saúde), 2 (centro de saúde/unidade básica de saúde) e 3 (unidade mista), sendo excluídas as unidades móveis fluviais e terrestres, o que resultou em um total de serviços 360 serviços de saúde em cada região.

\section{c) Coleta de dados}

A coleta de dados foi realizada por uma equipe coordenada pela Universidade Federal de Minas Gerais (UFMG), mediante a aplicação de roteiros de observação direta e entrevistas (usuários, responsáveis pela entrega de medicamentos e prescritores), além de entrevistas telefônicas com gestores municipais por meio de questionários semiestruturados.

As entrevistas foram realizadas com a utilização de um questionário estruturado para cada população de estudo: secretário municipal de saúde, responsável pela assistência farmacêutica no município, responsável pela entrega de medicamentos, 
médico e usuário. As entrevistas duraram em média 30 minutos. Contudo, para os usuários, este tempo variou de acordo com o número de comorbidades apresentadas e de medicamentos utilizados. Foram coletadas informações pessoais de todos os entrevistados, além das questões específicas do estudo.

Os questionários aplicados aos secretários municipais de saúde e aos responsáveis pela assistência farmacêutica foram aplicados por meio de entrevista telefônica. Os questionários destinados aos médicos foram autoaplicáveis e os questionários destinados aos dispensadores de medicamentos e usuários foram aplicados presencialmente nos serviços de atenção primária.

A entrevista com o responsável pela entrega de medicamentos foi realizada na unidade de saúde, farmácia ou dispensário. E finalmente as entrevistas com os usuários foram realizadas nos serviços de atenção primária, na maioria das vezes antes da consulta médica. Todos os questionários apresentavam questões de campo aberto para avaliação do desempenho e fatores relacionados ao funcionamento dos serviços de saúde.

\section{c) Critérios éticos}

Os participantes assinaram o Termo de Consentimento Livre e Esclarecido (TCLE). A PNAUM foi aprovada pelo Comitê Nacional de Ética em Pesquisa do Conselho Nacional de Saúde, sob parecer nº 398.131/2013 (ALVARES et al, 2016).

\section{d) Análise dos dados}

Os dados foram analisados com o auxílio do software SPSS, versão 22, extraindo-se as freqüências das variáveis do estudo. Todas as análises levaram em conta os pesos amostrais e a estrutura do plano de análise para amostras complexas. Para a análise de associação estatística foi realizado teste de correlação Pearson para as variáveis categóricas. $O$ nível de significância adotado foi de $p<0,05$. Os resultados apresentaram representatividade para as regiões geográficas do Brasil. 


\section{REFERÊNCIAS}

ÁlVAreS, J. et al. Pesquisa Nacional sobre Acesso, Utilização e Promoção do Uso Racional de Medicamentos (PNAUM) - componente serviços: percurso metodológico. 2016 (Encaminhado para publicação na Revista de Saúde Pública da USP).

ANTUNES, R. (Org.). A dialética do trabalho. São Paulo: Expressão Popular, 2013.

BLEICHER, J. Hermenêutica Contemporânea. Edições 70, LDA, Lisboa, Portugal, 2002. Disponível em: http://www.ruipaz.pro.br/fenomenologia/hermeneutica.pdf. Acesso 10 junho 2016.

BOURDIEU, P. O Poder Simbólico. 4a ed. Rio de Janeiro: Bertrand Brasil, 2001.

CORSEUIL, C.H.; SERVO L.M.S. (Orgs.). Criação, destruição e realocação de empregos no Brasil. Brasília: IPEA, 2006. Disponível em: http://www.en.ipea.gov.br/agencia/images/stories/PDFs/livros/criacao destruicao realo cacao.pdf. Acesso em: 05 jun. 2015.

GADAMER, H. Verdade e método. 7a ed. Petrópolis: Vozes, Bragança Paulista: EDUSF, 2005.

GIL, C.R.R. Atenção primária, atenção básica e saúde da família: sinergias e singularidades do contexto brasileiro. Cadernos de Saúde Pública, Rio de Janeiro, v. 22, n. 6, p. 1171-81, 2006.

MACHADO, M.H.; OLIVEIRA, E.S.; MOYSES, N.M.N. Tendências do Mercado de Trabalho em Saúde no Brasil. In: PIERANTONI, C.; POZ, M.R.D.; FRANÇA, T. (Orgs.). O Trabalho em Saúde: abordagens quantitativas e qualitativas. $1^{\mathrm{a}} \mathrm{ed}$. Rio de Janeiro: CEPESC, UERJ, 2011.

MERHY, E.E. Saúde: a cartografia do trabalho vivo. $4^{\text {a }}$ edição. São Paulo: HUCITEC, 2014.

MIGUELOTE, V.R.S. et al. Distribuição da Força de Trabalho: eqüidade e negociação. Rio de Janeiro. Physis Revista de Saúde Coletiva, 2008. v.18, n. 2, p. 317-338. Disponível em http://www.scielo.br/pdf/physis/v18n2/v18n2a07.pdf. Acesso em: 25 ago. 2015.

MINAYO, M.C.S. O desafio do conhecimento. Pesquisa qualitativa em saúde. $12^{\mathrm{a}}$. ed. São Paulo: Hucitec/Rio de Janeiro: ABRASCO, 2010.

ORGANIZAÇÃO MUNDIAL DA SAÚDE. Trabalhando juntos pela saúde. Brasília: Ministério da Saúde, 2007. 210 p. - (Série B. Textos Básicos de Saúde). Disponível em http://www.who.int/whr/2006/06_overview_pr.pdf. Acesso em: 15 jan. 2014. 
ORGANIZAÇÃO MUNDIAL DA SAÚDE. Estatísticas sobre gênero e força de trabalho em saúde. In: Spotlight: estatísticas da força de trabalho em saúde. Edição n.2, fevereiro de 2008.20 Disponível em http://www.who.int/hrh/statistics/Spotlight 2 PO.pdf. Acesso em: 15 jan. 2015.

SALA, A.; CARRO, A.R.L.; SEIXAS, P.H.A. Comparação entre as bases de dados relativas à força de trabalho em saúde no Estado de São Paulo. Boletim eletrônico do grupo técnico de avaliação e informações de saúde, Janeiro, 2010. p. 1-7. Disponível em http://portal.saude.sp.gov.br/resources/ses/perfil/gestor/homepage//gaisinforma/gais_jornal_4.pdf. Acesso em: 15 dez. 2013.

SOUSA, M.F.; HAMANN, E.M. Programa Saúde da Família no Brasil: uma agenda incompleta?. Ciência \& Saúde Coletiva, Rio de Janeiro, v. 14, supl. 1, p. 1325-1335, Out. 2009. Disponível em: http://www.scielo.br/scielo.php?script=sci arttext\&pid=S141381232009000800002\&lng=en\&nrm=iso. Acesso em: 19 ago. 2016.

WAN DER MAAS, L. et al. Estudo de levantamento de aspectos demográficos, de formação e de mercado de trabalho das profissões de saúde nível superior no Brasil entre 1991 e 2010 (relatório final). Belo Horizonte: UFMG - NESCON, dezembro de 2014. Disponível em http://epsm.nescon.medicina.ufmg.br/epsm/Relate Pesquisa/Mercado $\% 20 \mathrm{de} \% 20$ trabalh o $\% 20$ das $\% 20$ profiss $\%$ C3 $\%$ B5es $\% 20 \mathrm{de} \% 20$ sa $\%$ C3 $\%$ BAde $\% 20 \mathrm{de} \% 20 \mathrm{n} \% \mathrm{C} 3 \%$ ADvel $\%$ 20superior\%20no\%20Brasil\%20(Rel.\%20Final).pdf. Acesso em: 05 out. 2015.

ZAGO, L.H. O método dialético e a análise do real. Kriterion, Belo Horizonte, n. 127, Jun./2013, p. 109-124. 


\section{CAPÍTULO 2 - O TRABALHO EM SAÚDE}

"Na manufatura e no artesanato, o trabalhador utiliza a ferramenta;

Antes de falar sobre o trabalho em saúde e suas características, é imprescindível abordar o trabalho em si, especialmente sobre o seu significado no contexto do capitalismo e do cuidado em saúde. Nesse sentido, este capítulo aborda os aspectos conceituais e históricos do trabalho, do trabalho em saúde e dos trabalhadores em saúde, a partir do pensamento de autores da sociologia e da saúde, entre os quais se destacam Karl Marx, Maria Cecília Donnangelo, Ricardo Bruno Mendes Gonçalves, Luiz Carlos de Oliveira Cecílio e Emerson Elias Merhy.

Os sentidos do trabalho não são fixos e a sua forma de organização varia de acordo com a sociedade e o período histórico. Nas sociedades de caçadores e coletores, o trabalho era propriedade de cada um e o produto pertencia a quem o realizou. Nas sociedades escravistas, o trabalho do escravo pertencia ao senhor, o dono do escravo. Já nas sociedades capitalistas, a força de trabalho é mercadoria e o produto do trabalho não pertence ao trabalhador (SOUZA; OLIVEIRA; CASTRO, 2011).

No livro O Capital, Karl Marx diz que a riqueza das sociedades capitalistas é uma "imensa coleção de mercadorias", estas satisfazem "necessidades humanas de qualquer espécie" e o trabalho "é um processo entre o homem e a natureza". Portanto, o trabalho é atividade que transforma a natureza em objeto, coisa útil, mercadoria, com o objetivo de satisfazer as necessidades, os desejos e as ambições humanas (MARX, 1996, p. 165 e 297).

As coisas úteis, as mercadorias, possuem valor de uso e valor de troca. A utilidade de uma coisa faz dela um valor de uso, que só se realiza no momento do consumo. O valor de troca aparece, antes de tudo, como a "proporção na qual os valores de uso de uma espécie se trocam por valores de uso de outra espécie uma relação que muda constantemente com o tempo e o lugar", ou seja, o valor de troca é relacional, se realiza na esfera social (MARX, 1996, p. 166).

No processo produtivo de uma mercadoria, o dispêndio de força de trabalho para um fim específico consiste em trabalho concreto útil, que, por sua vez, produz valor de uso. As mercadorias vêm ao mundo como valores de uso produzidos pela diferença qualitativa dos trabalhos úteis, executados independentemente uns dos outros, numa 
divisão social do trabalho. Nessa perspectiva, ao transformar a natureza externa, o trabalho humano também altera a sua própria natureza, num processo de transformação recíproca, que converte o trabalho em condição de existência social. Além das mercadorias produzidas pelo trabalho, o próprio trabalho tem valor de troca (MARX, 1996; DUARTE e POLA, 2009; ANTUNES, 2013).

Embora seja extremamente importante para a produção de riquezas em uma sociedade, o trabalho é, sem dúvida, um dos meios que os indivíduos possuem para o estabelecimento de relações com outros indivíduos, porque todo trabalho é realizado coletivamente e gera a necessidade de comunicação entre as pessoas. É esse caráter coletivo que faz com que o trabalho tenha também um caráter social (SOUZA; OLIVEIRA; CASTRO, 2011).

É na esfera social que as mercadorias e o próprio trabalho se transformam em algo além da sua utilidade direta. Na verdade, a mercadoria e o trabalho dependem da sociedade para existir e ter sentido, bem como também influenciam e modificam a forma como uma sociedade está organizada ao longo do tempo.

O mundo contemporâneo do trabalho se caracteriza pela flexibilização das relações de trabalho, desconstrução do espaço produtivo, expansão do trabalho precarizado, parcial, temporário, terceirizado e informal, bem como pelo aumento do trabalho feminino, que já significa $40 \%$ da força de trabalho em diversos países economicamente desenvolvidos (ANTUNES, 2003; MARQUES, 2013).

Especificamente em relação ao trabalho em saúde, os primeiros estudos no Brasil foram realizados pela médica e intelectual Maria Cecília Donnangelo, autoria de várias publicações sobre o trabalho profissional, entre as quais se destaca o livro Medicina e Sociedade, que trata em linhas gerais das modalidades do trabalho médico, a participação no mercado e a sua relação com os meios de produção de serviços de saúde (NUNES, 2008).

A pesquisadora Lilia Schraiber ressalta que:

(...) ao examinar a medicina como prática técnica e social, Donnangelo abriu oportunidades para a construção de um quadro teórico específico - a teoria do trabalho em saúde, voltado para o "processo de trabalho em medicina", constituindo uma verdadeira escola de pensamento, investigação e prática, com base nesse referencial teórico (apud NUNES, 2008, p. 914). 
Maria Cecília Donnangelo orientou a dissertação de mestrado de Emerson Elias Merhy e a tese de Ricardo Bruno Mendes Gonçalves. Enquanto o primeiro se dedicou a estudar o trabalho em saúde como trabalho vivo, em ato, e o uso das tecnologias no processo de cuidado, o segundo formulou a teoria do processo de trabalho em saúde (NUNES, 2008; MERHY, 2014; AYRES, 2015).

No estudo do processo de trabalho em saúde, Ricardo Bruno Mendes Gonçalves aplica a teoria maxista do trabalho ao campo da saúde e analisa o objeto do trabalho, os instrumentos, a finalidade e os agentes. Em 1979, publicou a dissertação intitulada "Medicina e história: raízes sociais do trabalho médico" e em 1986, sob orientação de Maria Cecília Donnangelo, publicou a tese "Tecnologia e organização social das práticas de saúde: características tecnológicas do processo de trabalho da rede estadual de Centros de Saúde de São Paulo”. Na tese, Ricardo Bruno Mendes Gonçalves identificou a polarização dos saberes nas unidades de saúde em torno de duas modalidades de racionalidade, a clínica e a epidemiológica, e demonstrou como esses pólos estão relacionados a processos de trabalho na organização da atenção à saúde, que implicam objetos, instrumentos e finalidades estruturalmente interdependentes (AYRES, 2015).

Igualmente inspirado pela teoria marxista do trabalho, as contribuições do estudo sobre o trabalho vivo em ato de Merhy, especialmente da sua tese de livre docência "Reflexões sobre as tecnologias não materiais em saúde e a reestruturação produtiva do setor", defendida em 2000, foram fundamentais para o pensamento acerca do trabalho como cuidado em saúde (MERHY, 2014).

Nas seções seguintes abordarei o trabalho como mercadoria, inspirada em Karl Marx, Ricardo Antunes, Ricardo Bruno Mendes Gonçalves e Roberto Passos Nogueira, e o trabalho como cuidado, que tem Luiz Carlos de Oliveira Cecílio e Emerson Elias Merhy como referenciais teóricos.

\subsection{TRABALHO COMO MERCADORIA}

O debate sobre o trabalho em saúde parte de duas premissas importantes: a primeira é que o capitalismo transforma tudo em mercadoria, inclusive o trabalho e a saúde, e a segunda é que o trabalho em saúde pertence à esfera dos serviços, o que confere características peculiares à exploração da força de trabalho e ao processo produtivo. 
Karl Marx escreveu que "a utilização da força de trabalho é o próprio trabalho" e "o comprador da força de trabalho a consome ao fazer trabalhar o vendedor dela" (MARX, 1996, p. 297).

Para além do valor de uso e valor de troca, as mercadorias possuem uma forma comum de valor: o dinheiro. Nesse contexto, o capitalismo transformou o trabalho em mercadoria, que semelhantemente a outras mercadorias, pode ser vendido e comprado pelo dinheiro, por meio do assalariamento, e a circulação de mercadorias, por sua vez, transformou o dinheiro em capital e a sua personificação, o capitalista, passou a explorar o trabalhador para a produção de mais-valia e lucro (MARX, 1996; ANTUNES, 2013).

Se por um lado, podemos considerar o trabalho como um momento fundante da vida humana [...], por outro lado, a sociedade capitalista o transformou em trabalho assalariado, alienado, fetichizado. O que era uma finalidade central do ser social converte-se em meio de subsistência. A força de trabalho torna-se uma mercadoria, ainda que especial, cuja finalidade é criar novas mercadorias e valorizar o capital. Converte-se em meio e não primeira necessidade de realização humana (ANTUNES, 2009, p. 48).

O trabalho é mercadoria e circula em um mercado: o mercado de trabalho. Segundo Bauman (2008), para todos os mercados valem as mesmas regras: o destino final de toda mercadoria é ser consumida por compradores. Os compradores desejarão obter mercadorias para consumo, se consumi-las for algo que prometa satisfazer seus desejos, e o preço que o potencial consumidor está preparado para pagar pelas mercadorias dependerá da credibilidade da promessa de satisfação e da intensidade dos seus desejos.

$\mathrm{Na}$ área da saúde, Ricardo Bruno Mendes Gonçalves foi um dos primeiros pesquisadores brasileiros a adotar a categoria trabalho para compreensão da produção de saúde e sistematizou o conhecimento sobre trabalho em saúde. Apoiado na concepção marxista do trabalho, para este autor o trabalho é um agente mediador que estabelece conexão entre objeto (de trabalho), os instrumentos e a atividade do trabalho - ou força de trabalho. O trabalho em saúde tem compromisso com as necessidades sociais relacionadas à estrutura produtiva da sociedade (PEDUZZI, 2003; MOTA et al, 2004; FEUERWERKER, 2014). 
O trabalho em saúde é essencial à vida humana, se situa no setor de serviços, consiste na transformação de algo para atender necessidades, pode ter como resultado um produto material ou não material, indissociável do processo que o produz, e envolve um objeto a ser transformado, instrumentos e força de trabalho (PIRES, 2011, p. 4142).

A assistência de saúde é ofertada na esfera do setor de serviços ou de prestação de serviços dentro dos grandes segmentos que compõem a divisão social do trabalho e, em geral, não produz mercadorias. É um trabalho da esfera da produção não material, que somente existe durante o processo produtivo, não sendo possível manter estoque dos produtos obtidos. Portanto, não tem como resultado um produto material, independente do processo de produção e comercializável no mercado. O produto é a própria realização no momento do trabalho (SOUZA, 2010).

O conceito de serviço se refere ao consumo de um dos tipos de valor de uso, mercadoria ou trabalho, ambos imateriais, com o objetivo de satisfazer alguma necessidade humana, ou seja, consiste na efetiva realização da utilidade das mercadorias ou do trabalho. Nos sistemas de saúde, o trabalho do médico, do dentista, do enfermeiro e de todos os outros prestadores de serviços deve ser sempre útil para os usuários. Todavia, diferentemente das empresas do setor saúde, o trabalho nos serviços da administração pública não produz mais-valia, ou seja, o resultado (o produto) não possui valor maior do que os elementos participantes de prestação do serviço, ao contrário da produção capitalista de mercadorias. Contudo, esses serviços de saúde possuem uma dimensão econômica (p. ex. assalariamento, procedimentos, consultas, insumos etc) que justificam o seu enquadramento no setor mercantil da sociedade (NOGUEIRA e GOMES, 2012).

Embora até possa parecer para alguns trabalhadores, o usuário dos serviços de saúde nunca é mera "matéria-prima" do processo de trabalho. É, na verdade, sujeito ativo no processo de trabalho de qualquer trabalhador em saúde, que presta informações, segue (ou não) prescrições médicas ou orientações, e assim por diante.

O trabalhador em saúde - e em qualquer serviço de consumo - não é explorado pelo fato de produzir diretamente mais-valia, mas porque possibilita, com seu trabalho, a participação do capitalista na maisvalia social. O médico assalariado, se trabalhasse por conta própria, com um pequeno capital de profissional liberal, receberia por seus serviços o correspondente ao valor de sua força de trabalho, acrescido de um lucro que ele mesmo embolsaria. Mas, ao trabalhador, numa empresa como assalariado, durante um mesmo período de tempo 
recebe apenas o equivalente de sua força de trabalho. É através de seu trabalho que o capital satisfaz a demanda de seus clientes e através dele é que pode, por conseguinte, auferir lucro (NOGUEIRA e GOMES, 2012, p. 55).

As forças produtivas nos serviços de saúde são coletivas e a divisão social do trabalho ocorre entre várias categorias profissionais. As atividades executadas nesses serviços usam intensivamente a mão de obra, a despeito mesmo do intenso dinamismo com que novas tecnologias são incorporadas no setor. Ao contrário de outros setores econômicos, as novas tecnologias na saúde geralmente não substituem as preexistentes e, na maioria das vezes, acrescenta-se a elas, exigindo novas qualificações para sua operação, o que, no final das contas, aumenta a demanda por força de trabalho (FUNDAÇÃO OSWALDO CRUZ, 2012).

Por outro lado, quanto mais se utiliza tecnologia nas intervenções em saúde, tais como equipamentos e exames sofisticados, com o objetivo estrito de maximizar a produtividade e a lucratividade, mais desvalorizado fica o trabalho humano, da escuta, do atendimento personalizado, da interação entre quem adoece e quem cuida. Neste sentido, podemos considerar o uso da ciência e da tecnologia, também no setor saúde, “como expressão do processo de desvalorização da força de trabalho" (SOUZA, 2010, p. 341).

\subsection{TRABALHO COMO CUIDADO}

Cuidar é ato e cuidado é um mix de processo e resultado. O cuidar está contido no cuidado. Cuidar é ato de reciprocidade, ação complexa que requer habilidades humanas específicas, tais como a empatia, a paciência, a dedicação e o esforço, tanto físico quanto psicológico. No processo de cuidado, as necessidades são múltiplas e diversas, mas também as respostas. Todo cuidado é relacional: tem "alguém que dá e alguém que recebe". O componente relacional do cuidado tem importância especial porque as práticas sociais se baseiam, em geral, na interação social por meio da reciprocidade, solidariedade ou troca. Outro componente importante é o emocional que explica a dedicação de quem cuida. Portanto, não tem como cuidar sem ter vínculo e não tem como estabelecer vínculo sem se envolver, inclusive emocionalmente (TOBIO et al, 2010; HERNÁNDEZ et al, 2011).

De acordo com Cecílio e Lacaz (2012), o conceito de trabalho em saúde pode ser sintetizado em uma única palavra: cuidar. O trabalho em saúde produz - ou deveria 
produzir - o cuidado que as pessoas necessitam em algum momento da vida e os serviços de saúde existem, ou deveriam, para atender as necessidades das pessoas, o que não se resume no consumo de produtos: consultas médicas, realização de exames, medicamentos etc.

Nitidamente influenciado por Marx, Merhy conceitua o trabalho em saúde como trabalho vivo em ato, que "não pode ser globalmente capturado pela lógica do trabalho morto, expresso pelos equipamentos e pelo saber tecnológico estruturado" (MERHY, 2014, p. 49).

$\mathrm{Na}$ verdade, o trabalho em saúde se afirma nos encontros entre subjetividades, do encontro entre trabalhador de saúde e usuários dos serviços, que utilizam tecnologias relacionais nesses encontros, o que será abordado mais detalhadamente na seção seguinte.

Todo processo de trabalho combina trabalho em ato e consumo de produtos feitos em trabalhos anteriores. Por exemplo, a produção de uma cadeira exige tábuas de madeira e parafusos, que foram produzidos por outros trabalhadores. Merhy e Franco (2013) denominam o trabalho feito em ato de "trabalho vivo em ato", e o trabalho feito antes - a tábua de madeira e os parafusos, que só chega através do seu produto - é denominado "trabalho morto".

A superação do trabalho em saúde como mercadoria talvez seja possível se a produção científica e tecnológica, especialmente de tecnologias duras (p. ex. fármacos, equipamentos, hospitais etc), romper a lógica da produção capitalista, que medicaliza a vida, e passar para a esfera da produção do cuidado em saúde, que visa atender as necessidades de saúde das pessoas, da família e da comunidade.

O trabalho em saúde acontece majoritariamente na modalidade de trabalho multiprofissional e em cooperação, mas geralmente por meio de ações fragmentadas, em que cada área técnica se responsabiliza por uma parte da atividade (SCHERER; PIRES; SCHWARTZ, 2009).

Historicamente, a formação do modelo assistencial de saúde esteve centrada nas consultas, equipamentos e exames, visto que é resultado de uma pressão do complexo médico-industrial (empresas médicas, indústria farmacêutica etc) e o mercado sobre a rede de serviços por um processo produtivo do cuidado centrado nos procedimentos (MERHY, 2014).

O modelo centrado nos procedimentos transformou os serviços de saúde em uma fábrica e o processo de trabalho em uma linha de montagem orientada pela cura ou 
reabilitação de uma doença, na qual o usuário é fatiado em inúmeras unidades de produção e o resultado é obtido pelo somatório das ações individuais e específicas de cada profissional, que geralmente se relacionam de forma rígida e hierarquizada (MALTA e MERHY, 2010; MEHRY, 2014).

Diferentemente da lógica capitalista de produção da saúde, que transforma tudo em mercadoria, o usuário deve ser o centro do cuidado nos serviços de saúde, ou seja, o processo de trabalho deve ser orientado para o atendimento das necessidades das pessoas e da comunidade, o que envolve as tecnologias leves, leve-duras e duras. As tecnologias duras são os equipamentos, as máquinas, e que encerram trabalho morto, resultado de outros momentos de produção. As tecnologias leve-duras são as normas, os protocolos, o conhecimento produzido em áreas específicas do saber, como a clínica, a epidemiologia, o saber administrativo e outros, e se caracterizam por conterem trabalho capturado, porém com possibilidade de expressarem trabalho vivo. As tecnologias leves são as produzidas em ato, no trabalho vivo, e se materializam no acolhimento, vínculo, responsabilização e autonomia dos usuários. Geralmente, as pessoas procuram produzir vínculos no sistema de saúde ${ }^{11}$ e a tecnologia leve é o primeiro tipo de tecnologia acessada no momento que o usuário busca cuidado em um serviço de saúde (FERRI et al, 2007; MALTA e MERHY, 2010; CECILIO e LACAZ, 2012).

Vimos até aqui que o cuidado em saúde se realiza fora dos serviços de saúde, no indivíduo, na família e na comunidade, e se materializa no interior destes por meio do trabalho em saúde. Os serviços de saúde atendem a necessidades complexas e variáveis e não podem ser totalmente padronizados. Os profissionais precisam de autonomia para traduzir normas gerais a casos particulares, decidir como e qual serviço prestar para atender às necessidades de saúde. As organizações de saúde dependem do trabalho de profissionais da saúde e de outros grupos de trabalhadores que não são profissionais de saúde, o que resulta numa heterogeneidade que dificulta a construção do espírito de equipe. É um contexto de recursos limitados e necessidades sempre múltiplas, ilimitadas e variáveis. $\mathrm{O}$ ambiente é propício a conflitos entre atores com diversos interesses, nem

\footnotetext{
${ }^{11}$ Segundo a Organização Mundial da Saúde (OMS), os sistemas de atenção à saúde são um conjunto de atividades cujo propósito é promover, restaurar e manter a saúde de uma população, a fim de atingir os seguintes objetivos: o alcance de um nível ótimo de saúde, distribuído de forma equitativa; a garantia de uma proteção adequada contra os riscos, para todos os cidadãos; o acolhimento humanizado dos cidadãos; a provisão de serviços seguros e efetivos e sua prestação de modo eficiente. Assim, os sistemas de atenção à saúde podem ser entendidos como respostas sociais deliberadas às necessidades de saúde da população, que se expressam em situações demográficas e epidemiológicas singulares (MENDES, 2010).
} 
sempre convergentes, o que demanda um processo de negociação permanente (SCHERER; PIRES; SCHWARTZ, 2009).

Os profissionais, as equipes e os serviços de saúde podem - ou não - contribuir para a produção de maiores graus de autonomia das pessoas, a depender do modo como atuam, organizam seu processo de trabalho, fazem a escuta das necessidades de saúde e atuam a partir de tais princípios, o que tem relação direta com as múltiplas dimensões do cuidado em saúde: individual, familiar, profissional, organizacional, sistêmica e social. A dimensão mais nuclear, a individual, significa que cada um de nós pode ter ou tem um modo singular de conduzir a própria vida, fazendo escolhas. A dimensão social é a mais ampla da gestão do cuidado e refere como cada sociedade produz cidadania, direito à vida e acesso a toda forma de consumo que contribua para uma vida melhor. Entre a dimensão nuclear e a social, se encontra a dimensão profissional do cuidado que pode ser compreendida como mediadora entre as dimensões e é aquela que ocorre entre os profissionais e usuários e é regida pela competência técnica do seu núcleo específico, ou seja, sua formação e experiência, postura ética e capacidade de construir vínculo com quem precisa de cuidados (CECILIO e LACAZ, 2012).

De certa maneira, sempre há algo desconhecido no trabalho em saúde, na prescrição do cuidado. Cada projeto vai provocar cooperação e conflitos entre os profissionais, na definição dos problemas prioritários, bem como dos recursos e meios para resolvê-los. Os saberes adquiridos ao longo do processo de formação são necessários para atuar nesse cenário, mas insuficientes. $\mathrm{O}$ contexto organizacional e profissional coloca a seguinte questão: como avançar no sentido de um projeto que exige flexibilidade, humildade e construção de campos de conhecimento? (SCHERER; PIRES; SCHWARTZ, 2009).

O trabalho em saúde envolve sempre uma combinação explícita de ações e operações entre pessoas que acumulam formação, interesses, projetos, culturas e intencionalidades distintas ou assemelhadas. As posturas e conhecimentos parcelares de cada uma das profissões, ao desenvolver o trabalho de modo isolado, sem interação - a não ser em situações ocasionais e com gradações diferentes-, comprometem a composição cooperativa e fortalece a permanência do trabalho fragmentado, oposto à proposta de atenção integral para a consolidação do SUS (SOUZA; OLIVEIRA; CASTRO, 2011; FEUERWERKER, 2014).

O trabalho como cuidado é afetado pela transição tecnológica, que altera de modo significativo à lógica de produção do cuidado, e muda o seu núcleo tecnológico 
de acordo com as necessidades do usuário dos serviços de saúde, ou seja, em vez de procedimento-centrado, tende a ser relacional-centrado, olhando sempre e se subordinando ao mundo das necessidades de saúde, individuais e coletivas.

\subsection{TRABALHADORES DE SAÚDE}

Não há trabalho sem trabalhadores ou não há trabalhadores sem trabalho? Ontologicamente, essa é uma questão relativamente simples de responder. O homem surge antes do trabalho e, portanto, não há trabalho sem trabalhadores. Por analogia imediata, nenhum sistema de saúde pode existir se não houver trabalhadores de saúde.

Conceitualmente, os trabalhadores de saúde são aqueles que se inserem, direta ou indiretamente, na prestação de serviços de saúde, no interior dos estabelecimentos de saúde ou em atividades de saúde, podendo deter ou não formação específica para o setor (PEREIRA, 2004).

Os trabalhadores de saúde compõem um conjunto grande e diverso de profissionais e técnicos influenciados por diferentes sistemas de formulação de políticas com autonomia, direcionalidade e centralizações próprias, não reguladas estritamente pelas políticas setoriais, pouco sensíveis à regulação de mercado, às leis da oferta e da procura e dos preços. O processo de trabalho em saúde depende de múltiplas e diferenciadas dimensões e fatores que cercam o financiamento, a organização e o desempenho dos sistemas de saúde. Mais ainda, profissionais com especificidades e habilidades distintas incorporadas no processo de trabalho e no desenvolvimento de um trabalho com características cada vez mais coletivas em saúde (FUNDAÇÃO OSWALDO CRUZ, 2012).

A despeito dos avanços técnicos e científicos, o trabalho humano continua sendo imprescindível para a realização das ações de saúde, um elemento central. A força de trabalho na saúde assume uma dimensão particular por ela ter a potencialidade de direcionar, de forma significativa, a condução das ações de saúde, podendo interferir no resultado da prestação dos serviços (SOUZA, 2010).

A OMS vem alertando há mais de três décadas sobre o papel estratégico dos trabalhadores do setor para o alcance das metas das políticas globais e locais de saúde. Com o objetivo de chamar atenção das autoridades sanitárias para a crise global da força de trabalho em saúde, a Organização lançou no dia 7 de abril de 2006 o Relatório Mundial de Saúde intitulado "Trabalhando juntos para a saúde", que deu início à 
Década da Força de Trabalho em Saúde 2006-2015 (ORGANIZAÇÃO MUNDIAL DA SAÚDE, 2007; MIGUELOTE et al, 2008).

Para Nogueira (1983), há duas formas distintas de tratar os trabalhadores de saúde ou, nas palavras do autor os profissionais empregados do setor saúde: como recursos humanos ou força de trabalho. Recursos humanos é uma expressão advinda da administração e é utilizada quando o propósito é administrar a capacidade de trabalho dos indivíduos, assim como se administra outros recursos (materiais, financeiros etc). Já o termo força de trabalho tem origem na economia política e remete à produção, ao binômio emprego-desemprego, renda, divisão do trabalho, assalariamento etc, além de ter relação com as dimensões demográficas e macroeconômicas do trabalho em saúde.

A Aliança Global da Força de Trabalho em Saúde, da OMS, publicou em 2013 um relatório intitulado "Uma verdade universal: não há saúde sem força de trabalho" (ORGANIZAÇÃO MUNDIAL DA SAÚDE, 2013).

Nesse relatório, os autores apresentam uma estrutura conceitual para reforçar o papel central da força de trabalho em saúde, que considera quatro dimensões críticas centrais para a efetiva cobertura universal dos sistemas de saúde: disponibilidade, acessibilidade, aceitabilidade e qualidade. No nível mais simples, sem os trabalhadores de saúde não pode haver serviços de saúde. A disponibilidade de trabalhadores de saúde é, portanto, o principal determinante para uma cobertura eficaz (ORGANIZAÇÃO MUNDIAL DA SAÚDE, 2013, p. 11).

- Disponibilidade - o abastecimento suficiente, estoque adequado de profissionais de saúde, com as competências e habilidades relevantes mix que corresponde às necessidades de saúde da população;

- Acessibilidade - a distribuição equitativa dos trabalhadores de saúde em termos de tempo de viagem e transporte (espacial), horário de funcionamento e correspondente força de trabalho de atendimento (temporal), atributos da infraestrutura (físicas - tais como edifícios não acessíveis) mecanismos, encaminhamento (organizacionais) e custos diretos e indiretos dos serviços (financeiro);

- Aceitabilidade - as características e capacidade da força de trabalho para tratar todos os pacientes com dignidade, criar confiança e permitir ou promover a procura de serviços; esta pode assumir diferentes formas, tais como um provedor de pessoas do mesmo sexo ou de um fornecedor que compreende e fala uma 
língua de e cujo comportamento é respeitoso de acordo com a idade, religião, social e valores culturais etc.

- Qualidade - as competências, habilidades, conhecimento e comportamento do profissional de saúde como (os padrões orientadores ou outros) avaliadas de acordo com as normas profissionais e como são sentidos pelos usuários.

Assim como os sistemas de saúde, os trabalhadores de saúde estão sujeitos diariamente às pressões decorrentes, de um lado, do capitalismo e do complexo industrial da saúde (ou seria complexo industrial da doença?) e, de outro, do cuidado em saúde, humanizado, centrado na pessoa e baseado no uso equilibrado das tecnologias leves, leve-duras e duras.

Nesse contexto, o trabalhador de saúde anda o tempo todo no fio da navalha no cotidiano dos serviços de saúde porque toma decisões no seu processo de trabalho influenciado por fatores macro e micropolíticos, visando possivelmente à mediação entre essas duas dimensões, mesmo inconscientemente.

O professor Henrique Amorim nos chama atenção para as transformações do capitalismo nas últimas quatro décadas e as suas implicações na subjetividade do trabalhador no trecho a seguir.

“(...) Às técnicas de produção taylor-fordista foram somadas novas formas de persuasão que, articuladas, informam a ideia de que o trabalhador é um parceiro e, como tal, deveria incorporar o 'espírito da empresa capitalista'. A 'subjetividade' do trabalhador é, assim, reclamada pelo capital e colocada a seu serviço" (AMORIM, 2011, p. 379).

Independente da oscilação entre trabalho-mercadoria e trabalho-cuidado, é fundamental que o trabalhador de saúde compreenda que, mesmo realizando trabalho humanizado, centrado na pessoa, baseado na intersubjetividade do trabalhador e do usuário do serviço de saúde, a sua subjetividade será sempre colocada a serviço do capital. 


\section{REFERÊNCIAS}

AMORIM, H. Centralidade e imaterialidade do trabalho: classes sociais e luta política. Trabalho, Educação e Saúde, Rio de Janeiro, v. 8, n. 3, p. 367-385, nov.2010/fev.2011. Disponível em http://www.scielo.br/pdf/tes/v8n3/02.pdf. Acesso 10 abril 2015.

ANTUNES, R. O caráter polissêmico e multifacetado do mundo do trabalho. Trabalho, Educação e Saúde, v. 1, n. 2, p. 229-237, 2003. Disponível http://www.scielo.br/pdf/tes/v1n2/04.pdf. Acesso 10 abril 2015.

ANTUNES, R. O trabalho, sua nova morfologia e a era da precarização estrutural. Revista Theomai. n. 19: 47-57, 2009. Disponível em: http://www.revistatheomai.unq.edu.ar/numero19/ArtAntunes.pdf. Acesso 10 abril 2015.

ANTUNES, R. (Org.). A dialética do trabalho. São Paulo: Expressão Popular, 2013.

AYRES, J.R.C.M. Ricardo Bruno: história, processos sociais e práticas de saúde. Ciênc. saúde coletiva, Rio de Janeiro, v. 20, n. 3, p. 905-912, Mar. 2015. Disponível em: http://www.scielosp.org/scielo.php?script $=$ sci arttext\&pid $=\mathrm{S} 1413-$

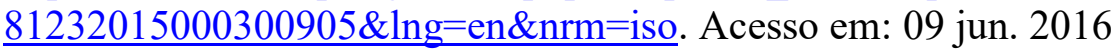

BAUMAN, Z. Vida para consumo: a transformação das pessoas em mercadoria. Rio de Janeiro: Jorge Zahar Ed., 2008. Disponível em: http://www.zahar.com.br/sites/default/files/arquivos/t1142.pdf. Acesso 10 abril 2015.

CECILIO, L.C.O.; LACAZ, F.A.C. O trabalho em saúde. Rio de Janeiro: CEBES, 2012. Disponível em http://cebes.org.br/site/wp-content/uploads/2015/02/7O-Trabalho-emSa\%C3\%BAde.pdf. Acesso 10 abril 2015.

DUARTE, E.C; POLA, K.D. Trabalho em Marx e Serviço Social. Serviço Social em Revista. $\quad$ v. $12, \quad$ n. $1, \quad 2009 . \quad$ Disponível em http://www.uel.br/revistas/uel/index.php/ssrevista/article/view/10058. Acesso 10 abril 2015.

FERRI, S.M.N et al. As tecnologias leves como geradoras de satisfação em usuários de uma unidade de saúde da família. Interface. Botucatu, v. 11, n. 23, Botucatu Set./Dez. 2007. DOI: http://dx.doi.org/10.1590/S1414-32832007000300009.

FEUERWERKER, L.C.M. (Org.). Micropolítica e saúde: produção do cuidado, gestão e formação. Porto Alegre: Rede UNIDA, 2014.

FRANCO, T.B.; MERHY, E.E. (orgs.).Trabalho, produção do cuidado e subjetividade em saúde: textos reunidos. 1a edição. São Paulo: HUCITEC, 2013.

FUNDAÇÃO OSWALDO CRUZ. A saúde no Brasil em 2030: diretrizes para a prospecção estratégica do sistema de saúde brasileiro. Rio de Janeiro: Fiocruz/IPEA/Ministério da Saúde /Secretaria de Assuntos Estratégicos da Presidência da República, 2012. Disponível em http://andromeda.ensp.fiocruz.br/teias/sites/default/files/biblioteca_home/Saude_Brasil 2030.pdf. Acesso em: 05 out. 2015. 
HERNÁNDEZ, M.L.G. et al. Construcción emergente del concepto: cuidado profesional de enfermería. Textos \& Contextos Enfermagem, Florianópolis, v. 20, p. 74-80, 2011.

MARQUES, A.P.P. Reestruturação produtiva e recomposições do trabalho e emprego: um périplo pelas "novas" formas de desigualdade social. Ciência \& Saúde Coletiva, Rio de Janeiro, v. 18, n. 6, p. 1545-1554, Junho 2013. Disponível em: http://www.scielo.br/scielo.php?script $=$ sci arttext\&pid=S141381232013000600007\&lng=en\&nrm=iso. Acesso em: 09 mar. 2016.

MALTA, D.C; MERHY, E.E. O percurso da linha do cuidado sob a perspectiva das doenças crônicas não transmissíveis. Interface. Botucatu, v. 14, n. 34, p. 593-606,

Set. 2010 Disponível em:

http://www.scielo.br/scielo.php?script=sci arttext\&pid=S1414-

32832010000300010\&lng=en\&nrm=iso. Acesso em: 09 mar. 2016

MARX, K. O Capital. Livro 1, Volume 1. São Paulo: editora Nova Cultural, 1996. Disponível em http://www.histedbr.fe.unicamp.br/acer_fontes/acer_marx/ocapital-1.pdf. Acesso em: 10 abr. 2015.

MENDES, E. V. As redes de atenção à saúde. Ciência \& Saúde Coletiva, v. 15, n. 5, p. 2297-2305, 2010.

MERHY, E.E. Saúde: a cartografia do trabalho vivo. $4^{\text {a }}$ edição. São Paulo: HUCITEC, 2014.

MIGUELOTE, V.R.S. et al. Distribuição da Força de Trabalho: eqüidade e negociação. Rio de Janeiro. Physis Revista de Saúde Coletiva, 2008. v.18, n. 2, p. 317-338. Disponível em http://www.scielo.br/pdf/physis/v18n2/v18n2a07.pdf. Acesso em: 25 ago. 2015.

MOTA et al. Contribuições pragmáticas para a organização dos recursos humanos em saúde e para a história da profissão médica no Brasil: à de obra Maria Cecília Donnangelo. Brasília: Ministério da Saúde, 2004.

NOGUEIRA, R.P. A força de trabalho em saúde no contexto da reforma sanitária. Caderno de Saúde Pública. v. 3, n. 3, p. 332-3421987. Disponível em: http://www.scielosp.org/scielo.php?script $=$ sci arttext\&pid=S0102-

311X1987000300011\&lng=pt. Acesso em: 05 out. 2015.

NOGUEIRA, R.P.; GOMES, R.M. Capitalismo e Saúde. Rio de Janeiro: CEBES, 2012. Disponível em http://cebes.org.br/site/wp-content/uploads/2015/02/2Capitalismoe-Sa\%C3\%BAde.pdf. Acesso em: 10 abr. 2015.

NUNES, E.D. Cecília Donnangelo: pioneira na construção teórica de um pensamento social em saúde. Ciência \& Saúde Coletiva, Rio de Janeiro , v. 13, n. 3, p. 909-916, Jun. 2008 Disponível em:

http://www.scielo.br/scielo.php?script=sci arttext\&pid=S1413-

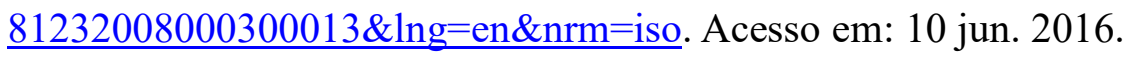


ORGANIZAÇÃO MUNDIAL DA SAÚDE. Trabalhando juntos pela saúde. Brasília: Ministério da $\quad$ Saúde, $2007 . \quad$ Disponível em http://www.who.int/whr/2006/06_overview_pr.pdf. Acesso em: 15 jan. 2014.

PEREIRA, L.D. A gestão da força de trabalho em saúde na década de 90. Physis: Revista de Saúde Coletiva, v. 14, n. 2, p. 363-382, 2004. Disponível em http://www.scielo.br/scielo.php?script=sci arttext\&pid=S0103-

73312004000200010\&lng=pt\&nrm=iso\&tlng=pt. Acesso em: 15 dez. 2013.

SCHERER, M.D.A; PIRES, D; SCHWARTZ, Y. Trabalho coletivo: um desafio para a gestão em saúde. Revista de Saúde Pública. São Paulo, v. 43, n. 4, p. 721-25, 2009. Disponível em http://www.scielo.br/pdf/rsp/v43n4/90.pdf. Acesso em: 15 dez. 2013.

SOUZA, M.A.S.L. As Novas Configurações do Trabalho em Saúde: os indicativos do processo de desregulamentação. Textos \& Contextos, Porto Alegre, n. 9, agosto/dezembro, 2010.2 Disponível em $\leq$ http://www.redalyc.org/articulo.oa? id=321527167014>. Acesso em: 15 dez. 2013.

SOUZA, A.I.S.; OLIVEIRA, L.M.L.; CASTRO, M.M.C. O trabalho coletivo e as profissões de saúde. Revista Tempus Actas de Saúde Coletiva, v. 5, n. 1, 2011. Disponível em http://www.tempusactas.unb.br/index.php/tempus/article/view/921/931. Acesso em: 15 dez. 2013.

TOBÍO, C. et al. El cuidado de las personas: um reto para el siglo XXI. Coleccion Estudios Sociales. n. 28. Barcelona: Fundación "La Caixa", 2010. 


\section{CAPÍTULO 3 - A FORÇA DE TRABALHO EM SAÚDE}

"Leve é a tarefa quando muitos dividem o trabalho"

(Homero)

Neste capítulo são abordados os aspectos conceituais, a composição, a distribuição, a migração e as características mundiais e regionais da força de trabalho em saúde no contexto da reestruturação produtiva e da escassez global de trabalhadores em saúde.

Em 1973, a Conferência Pan-Americana sobre Planejamento de Recursos Humanos em Saúde (RHS), realizada em Ottawa (Canadá), identificou uma série de problemas nos sistemas de saúde, entre os quais estão a centralidade no profissional médico e o desenvolvimento limitado das outras categorias profissionais, a concentração de pessoal em centros urbanos e a tendência à formação especializada, centrada no hospital e em tecnologias sofisticadas, porém, desvinculada dos problemas dos serviços de saúde (OPAS, 1974 apud CARVALHO; SANTOS; CAMPOS, 2013).

Segundo Nogueira (1983), os termos recursos humanos e força de trabalho não são sinônimos. O primeiro é uma expressão originada na ciência da administração e se relaciona às funções gerenciais ou de planejamento, ou seja, é utilizada quando o propósito é intervir com o objetivo de produzir, aprimorar ou administrar esse recurso específico. Esse termo coloca o trabalho humano no mesmo nível de outros recursos, tais como materiais e financeiros, que são também sujeitos à racionalização. Já o termo força de trabalho tem relação com a economia política e está intimamente ligada à produção, emprego e desemprego, renda, divisão do trabalho, ramo produtivo, assalariamento etc.

O termo RHS também vem sendo substituído em muitos países no mundo, e em especial na América Latina, por outros diversos e com amplitude variada, tais como Talento Humano em Saúde (Colômbia), Gestão de Pessoas (Chile), Capital Humano (Argentina), Capacidades Humanas (Estados Unidos), Força de Trabalho em Saúde (Brasil), o que demonstra um possível esgotamento, ou pelo menos diminuição do espaço, da lógica mercantil nos sistemas de saúde. Contudo, possivelmente à exceção da FTS, alguns desses termos não contemplam as tensões presentes no mundo do trabalho, entre as quais se destaca a dicotomia formação e atuação profissional (PEDUZZI, 2013). 
Por definição, a força de trabalho em saúde consiste na "parcela da população que, tendo alguma formação, preparo, ou um conjunto de determinadas destrezas nas profissões da saúde, encontra-se ocupada ou à procura de ocupação em atividades do setor" (GIRARDI, 1986, p. 424).

Apesar de alguns esforços anteriores, a última década significou o reconhecimento da centralidade do trabalho humano no desenvolvimento dos sistemas de saúde, especialmente à realização das prioridades nacionais e das metas internacionais. Entre os exemplos disso estão o Relatório Mundial de Saúde 2006 e a Aliança Global da Força de Trabalho em Saúde, ambos lançados em 2006, e os fóruns globais sobre recursos humanos para a saúde ${ }^{12}$. Essas ações resultaram em um movimento global para enfrentar a crise de trabalhadores em saúde, especialmente em relação à escassez crônica, os desequilíbrios distributivos e as más condições de trabalho (WORLD HEALTH ORGANIZATION, 2013).

Diferentemente de outros setores produtivos, os trabalhadores em saúde estão para além de meros recursos. Na verdade, como o setor saúde está na esfera dos serviços, não há sistema de saúde se não houver trabalhador de saúde, que não é "peça de reposição". Cada trabalhador carrega consigo um conjunto de ferramentas, habilidades e conhecimentos únicos, o que faz com que cada produto seja igualmente único. Portanto, o termo força de trabalho em saúde é o mais adequado para definir sobre o que estamos tratando nesta tese, pois se refere à parcela da população com algum preparo ou formação nas profissões de saúde e está ocupada ou à procura de ocupação no setor saúde e não são "peças de reposição" para a manutenção dos sistemas de saúde (GIRARDI, 1986; MERHY, 2014).

\subsection{COMPOSIÇÃO E DISTRIBUIÇÃO DA FORÇA DE TRABALHO}

A composição da força de trabalho em saúde se refere à quantidade de pessoas formadas (números), o nível em que elas refletem as características socioculturais e demográficas da população (diversidade) e que tarefas os trabalhadores de saúde, em diferentes níveis, formados e capazes de desempenhar (habilidades). A figura 3 evidencia que a manutenção de um equilíbrio razoável em termos de números,

\footnotetext{
${ }^{12}$ O primeiro fórum foi realizado em Uganda (2008), o segundo na Tailândia (2011) e o terceiro no Brasil
} (2013) 
diversidade e habilidades da força de trabalho em saúde depende do entendimento das necessidades de saúde, da organização e funcionamento dos sistemas de saúde e das características do contexto, tais como globalização, setor público, mercado de trabalho e educação (ORGANIZAÇÃO MUNDIAL DA SAÚDE, 2007).

Figura 3. Fatores que influenciam a composição da força de trabalho em saúde.

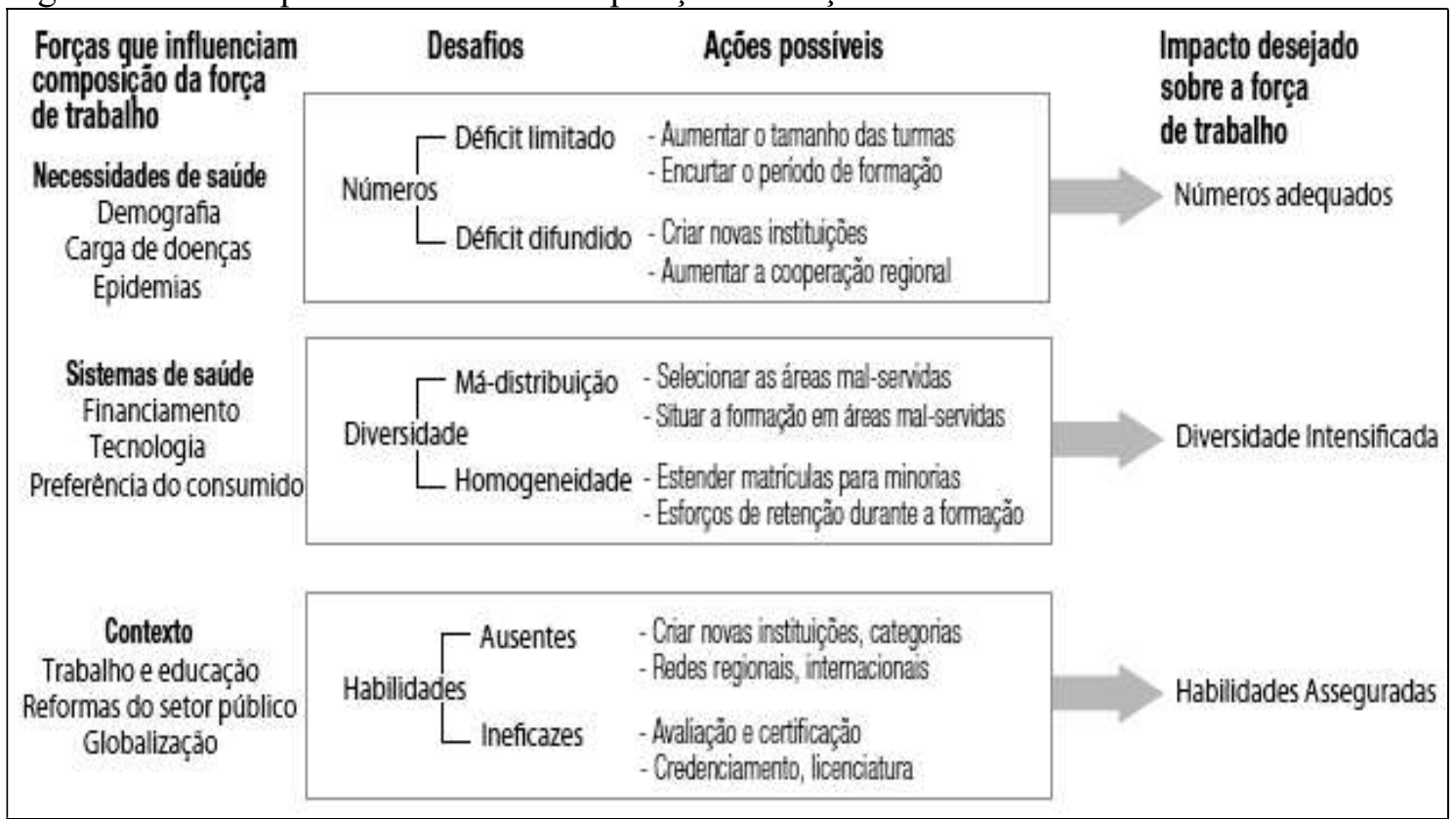

Fonte: ORGANIZAÇÃO MUNDIAL DA SAÚDE (2007, p. 42).

Há aproximadamente 59 milhões de trabalhadores no setor saúde; o déficit global oscila entre 2,4 e 4,3 milhões de profissionais de saúde ${ }^{13}$; a falta de recursos humanos ocorre em praticamente todos os países, sendo os países africanos e asiáticos os mais afetados pela escassez; o desequilíbrio entre gêneros é marcante em algumas categorias profissionais (por exemplo, predomínio de homens na medicina e de mulheres na enfermagem); os profissionais estão concentrados nas áreas urbanas e a migração de trabalhadores dos países pobres para os mais ricos é crescente e acelerada. Além disso, existem atualmente 57 países com carências críticas equivalentes a um déficit global de 2,4 milhões de médicos, profissionais de enfermagem e parteiras, sendo maior na África Subsaariana e no Sudeste Asiático (ORGANIZAÇÃO MUNDIAL DA SAÚDE, 2007; MIGUELOTE et al, 2008).

\footnotetext{
${ }^{13}$ Atualmente, são necessários 2,4 milhões de médicos, enfermeiros e parteiras adicionais, para atingir as metas de cobertura universal de intervenções na saúde, especialmente em 57 países que estão abaixo do limiar. Quando estendida para outras categorias (dentistas, farmacêuticos, assistentes de medicina, técnicos de laboratório etc), a necessidade global é estimada em 4,3 milhões a mais de trabalhadores de saúde (ORGANIZAÇÃO MUNDIAL DA SAÚDE, 2007).
} 
Em 2013, de acordo com a assistente da OMS em Genebra, Marie-Paule Kieny, o déficit global da força de trabalho em saúde chegou a 7,2 milhões de profissionais no mundo e deve continuar crescendo e chegar a 12,9 milhões até 2035 (BRASIL, 2014, p 2).

Para ter uma idéia da dimensão dos desequilíbrios regionais, as Américas, com 10\% da carga global de doenças, têm 37\% dos trabalhadores de saúde e despende mais de $50 \%$ do financiamento mundial de saúde, enquanto a África tem $24 \%$ da carga, mas apenas 3\% dos trabalhadores de saúde e menos de 1\% das despesas mundiais com saúde (figura 4) (ORGANIZAÇÃO MUNDIAL DA SAÚDE, 2007).

Figura 4. Distribuição da força de trabalho em saúde nas regiões do mundo.

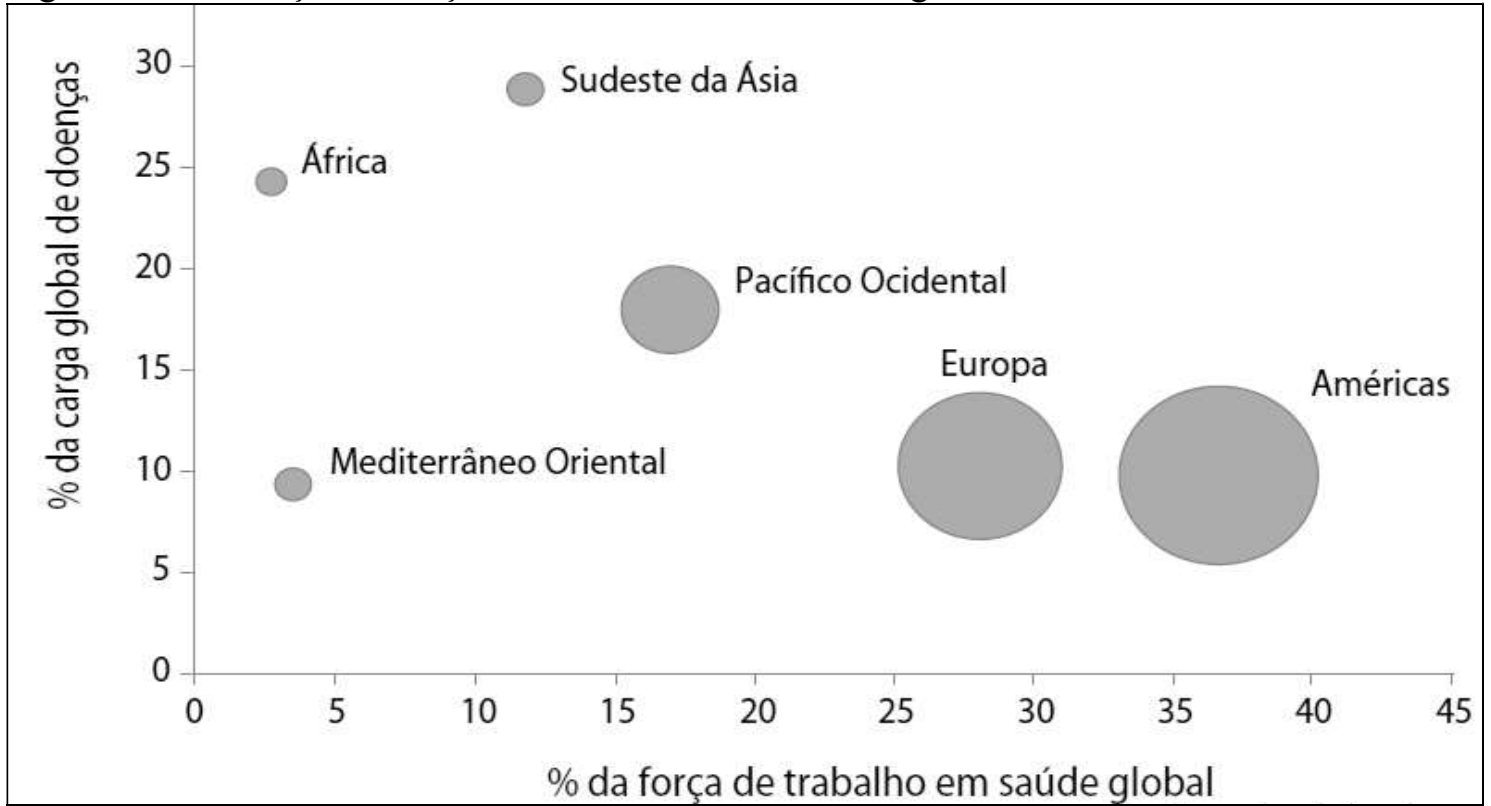

Fonte: ORGANIZAÇÃO MUNDIAL DA SAÚDE (2007, p. 56).

$\mathrm{Na}$ África do Sul, a proporção é de um trabalhador para mil pessoas, enquanto que na Europa e América do Norte, é de 10 profissionais para mil pessoas. Nos países da África existem hoje menos trabalhadores em saúde do que há 30 anos, apesar de a população atual ter aumentado e, conseqüentemente, suas necessidades (MIGUELOTE et al, 2008, p. 321).

Quer dizer que o problema está concentrado na África e na Ásia? A resposta é não. De um lado, a África se mostra no epicentro da crise global da força de trabalho em função da carga de doenças e da migração intensa de trabalhadores, enquanto que, do outro, os países ricos enfrentam um futuro de baixa fertilidade e envelhecimento crescente, o que provocará um aumento da demanda da população idosa por cuidados, 
resultando na necessidade de uma força de trabalho mais especializada e, muito provavelmente, intensificará a saída de trabalhadores dos países pobres para os ricos.

No artigo de revisão "Distribuição da força de trabalho: equidade e negociação", publicado em 2008, as autoras destacam que, apesar da reconhecida importância da força de trabalho na dinâmica dos serviços de saúde, a negligência sistemática com as políticas necessárias ao desenvolvimento de recursos humanos conduziu a uma crise internacional e a análise da distribuição da força de trabalho em saúde está centralizada na desigualdade e no desequilíbrio permanente entre os sistemas de saúde africanos e o resto do mundo (MIGUELOTE et al, 2008).

O relatório "Uma verdade universal: não há saúde sem força de trabalho" atribui o aumento do déficit a fatores como o envelhecimento ou aposentadoria dos profissionais de saúde, substituição por empregos melhor remunerados e uma quantidade insuficiente de jovens entrando nas universidades, que muitas vezes não oferecem um ensino de qualidade. Além disso, a OMS afirma que países que conseguem atrair mais profissionais de saúde são, normalmente, aqueles que oferecem maior remuneração, como os EUA. De fato, no continente americano, 70\% dos países têm quantidade suficiente de trabalhadores de saúde para a realização de atividades básicas, mas ainda enfrentam desafios significativos ligados à distribuição dos profissionais, sua migração e formação adequada (WORLD HEALTH ORGANIZATION, 2013).

Para a OMS, a principal causa de desequilíbrio na distribuição mundial da força de trabalho em saúde é o movimento migratório internacional de profissionais de seus países de origem (em desenvolvimento) para países economicamente mais estáveis (ORGANIZAÇÃO MUNDIAL DA SAÚDE, 2007; WORLD HEALTH ORGANIZATION, 2014).

(...) a partir dos anos 1990, aumentou significativamente a migração internacional de médicos e, especialmente enfermeiros, buscando oportunidades e segurança no emprego em mercados de trabalho mais dinâmicos. Além disso, a emergência ou a reemergência de doenças de grande impacto na população e a aceleração da epidemia de HIV/AIDS, no mesmo período, contribui de maneira importante para aumentar a demanda por mais pessoal de saúde. Ainda que o conjunto de problemas não seja exatamente novo, esse contexto gerou o que se convencionou chamar de crise global da FTS (POZ, 2013, p. 1924). 
A migração internacional de profissionais não é um fato recente e pode ocorrer em várias direções. Enquanto nos anos 60 muitos médicos deixavam seus países de origem (em geral, países desenvolvidos) para trabalhar em países em desenvolvimento e até países pobres, nos anos 90 houve uma inversão e os profissionais de países em desenvolvimento começaram a buscar outros mercados de trabalho. $\mathrm{O}$ envelhecimento da população, a globalização e a crise financeira de muitos países desenvolvidos, como é o caso recente de Portugal e Espanha, acabaram deslocando as demandas sobre a força de trabalho em saúde e estimularam os indivíduos a exercerem a liberdade de mobilização, inclusive entre países desenvolvidos, como, por exemplo, Austrália, Áustria, Bélgica, Dinamarca, entre outros (ORGANIZAÇÃO MUNDIAL DA SAÚDE, 2007; MIGUELOTE et al, 2008; WORLD HEALTH ORGANIZATION, 2014).

A oferta de trabalhadores para o mercado de trabalho parece influenciar, juntamente com outros fatores, a distribuição regional da força de trabalho. Enquanto o número de trabalhadores é maior na maioria na Europa e nas Américas, a África Subsaariana e o Sudeste Asiático apresentam os maiores índices de escassez de profissionais de saúde. Além disso, existe uma tendência da concentração de trabalhadores nos grandes centros urbanos. O mesmo fenômeno acontece com os centros formadores de trabalhadores. A África possui o menor número de instituições de formação das profissões de saúde. Em 2006 havia apenas 66 escolas de medicina, 57 de farmácia e 34 de odontologia, o que demonstra a relação entre o input de profissionais no mercado e a distribuição da força de trabalho (ORGANIZAÇÃO MUNDIAL DA SAÚDE, 2007).

Por exemplo, a localização, estrutura, métodos e critérios das escolas médicas têm mostrado influenciar na escolha da especialidade do local de trabalho. Recémgraduados em escolas médicas localizadas fora dos grandes centros urbanos são mais favoráveis a pratica em áreas rurais e acabam escolhendo as especialidades relacionadas à atenção primária, como medicina da família. Portanto, a descentralização da formação tem sido proposta, embora raramente implementada. Além disso, é recomendável que as reformas curriculares dos cursos de medicina enfatizem a formação em medicina da família e comunidade (DUSSAULT e FRANCESCHINI, 2006).

O Relatório Mundial de Saúde 2006 é certamente o documento mais marcante dessa década. Segundo esse relatório, a força de trabalho de cada sistema de saúde é central para promover o avanço da saúde de uma comunidade ou país. Contudo, a composição da força de trabalho não é tarefa fácil e depende da formação eficiente e 
dinâmica, que propicie um input de trabalhadores qualificados no sistema de saúde. Além disso, tem que ser capaz de responder às mudanças socioculturais, demográficas e epidemiológicas das populações e compreender para quais tarefas os trabalhadores de saúde são formados e capazes de desempenhar. Em suma, requer o entendimento das forças motrizes e dos desafios enfrentados pelos sistemas de saúde e de educação, assim como do mercado de trabalho (ORGANIZAÇÃO MUNDIAL DA SAÚDE, 2007).

No contexto da ocorrência de novos agravos, de reemergência de doenças erradicadas em vários países, da manutenção de velhos problemas, da expansão dos serviços, da migração internacional e do déficit dos trabalhadores, a formação e qualificação da força de trabalho é um dos desafios mais importantes para os sistemas de saúde em todo o mundo.

A força de trabalho está diretamente relacionada com os centros de formação em todos os níveis, da educação básica ao ensino superior, e o mercado de trabalho, especialmente da demanda dos estabelecimentos de saúde públicos e privados (ORGANIZAÇÃO MUNDIAL DA SAÚDE, 2007).

Figura 5. Relação entre educação, mercado de trabalho e serviços de saúde na oferta e demanda por trabalhadores em saúde.

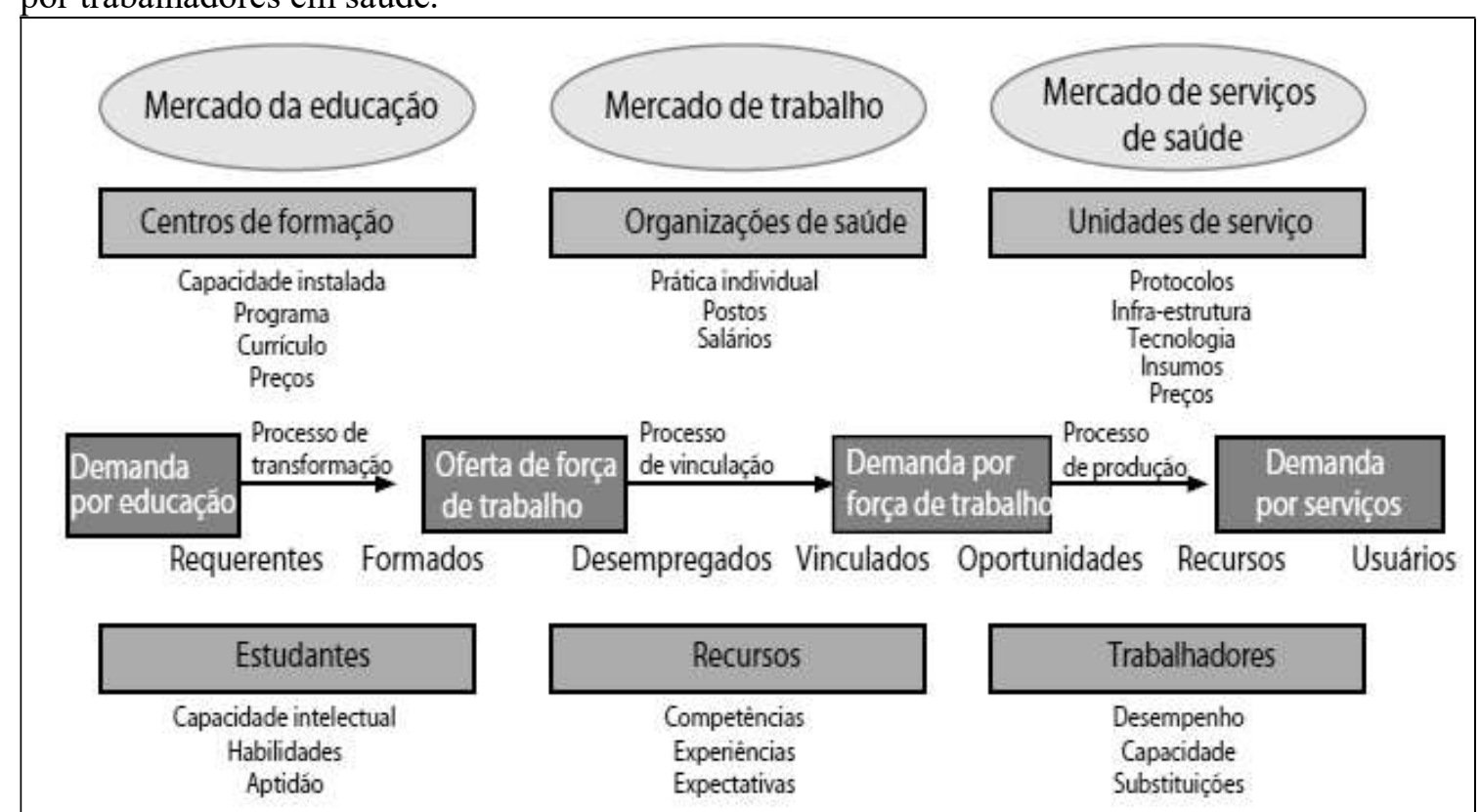

Fonte: ORGANIZAÇÃO MUNDIAL DA SAÚDE (2007, p. 56).

$\mathrm{Na}$ figura 5 se verifica exatamente isso: a oferta de força de trabalho é expressão da demanda por educação, enquanto a demanda de força de trabalho reflete o resultado da demanda por serviços de saúde, mediada pelos empregadores e por mecanismos de 
financiamento. Em teoria, o equilíbrio do mercado de trabalho pode ser alcançado quando a demanda por força de trabalho se iguala ao fornecimento de trabalhadores.

Tabela 1. Distribuição das instituições formadoras de profissionais de saúde por região da OMS.

\begin{tabular}{lcccc}
\hline Região da OMS & Medicina & Enfermagem & Farmácia & Odontologia \\
\hline África & 66 & 288 & 57 & 34 \\
Américas & 441 & 947 & 272 & 252 \\
Sudeste Asiático & 295 & 1.145 & 118 & 133 \\
Europa & 412 & 1.338 & 219 & 247 \\
Mediterrâneo oriental & 137 & 225 & 46 & 35 \\
Pacífico ocidental & 340 & 1.549 & 202 & 72 \\
\hline Total & $\mathbf{1 . 6 9 1}$ & $\mathbf{5 . 4 9 2}$ & $\mathbf{9 1 4}$ & $\mathbf{7 7 3}$
\end{tabular}

Fonte: Adaptado de ORGANIZAÇÃO MUNDIAL DA SAÚDE (2007, p. 44).

Semelhantemente à distribuição dos postos de trabalho, a distribuição de escolas de formação profissional também é desigual entre as profissões, às regiões e os países. Na tabela 1 vemos que, em 2006, de modo geral, havia 1.691 e 5.492 instituições de ensino superior, destinadas à formação de médicos e enfermeiros, respectivamente, em contraste com 914 faculdades de farmácia e 773 de odontologia. Regionalmente, a distribuição é extremamente desigual, vide, por exemplo, a diferença entre a África e a Europa.

\subsection{MERCADO DE TRABALHO E FORMAÇÃO EM SAÚDE NO BRASIL}

A composição interna da força de trabalho em saúde tem se modificado desde a década de 1970. A participação dos trabalhadores com formação universitária cresceu ao longo do tempo, enquanto que houve redução dos níveis médio e elementar, especialmente atendentes e parteiras. Dentre os profissionais de nível superior, os enfermeiros e os médicos foram os que mais cresceram, na medida em que apresentaram incrementos brutos da ordem de $142,9 \%$ e $125,6 \%$, entre 1970 e 1980 , respectivamente. Quanto aos profissionais de nível médio e elementar, destaca-se o crescimento do pessoal de enfermagem (124\%), capitaneado pelo largo incremento absoluto do número de atendentes. Outra característica marcante das décadas de 1970 e 1980 foi a diversificação da força de trabalho de nível superior, com a incorporação de 
novas categorias como os psicólogos, fonoaudiólogos e fisioterapeutas no mercado de trabalho do setor saúde (MÉDICI, 1986; NOGUEIRA, 1987).

Segundo Nogueira (1987), o principal problema que se encontra numa análise da composição interna da força de trabalho em saúde, no Brasil, é a polarização entre a categoria de maior qualificação, os médicos, e a de menor qualificação, os atendentes. Mais de $60 \%$ do emprego, entre 18 categorias, são assumidos por médicos e atendentes. Enquanto isso, os enfermeiros compõem $3,6 \%$ do total de empregos em estabelecimentos de saúde e os odontólogos permanecem num patamar de 4\%, o que bem ilustra a situação deplorável de nosso atendimento odontológico-institucional.

O processo de participação da força de trabalho no mercado de trabalho em saúde começa com a formação (sistema educacional) e pela definição da oferta das diferentes ocupações e profissões de saúde, cada uma com seus próprios mecanismos de escolhas e organização (figura 6). O outro lado desse processo se refere à demanda por serviços de saúde organizados num sistema de saúde. Portanto, a manutenção de um equilíbrio razoável entre números, diversidade e habilidades da força de trabalho em saúde depende da compreensão das forças que movem e desafiam os sistemas de saúde - e de educação - e os mercados de trabalho (ORGANIZAÇÃO MUNDIAL DA SAÚDE, 2007; FUNDAÇÃO OSWALDO CRUZ, 2012).

Figura 6. Dinâmica do mercado de trabalho em saúde.

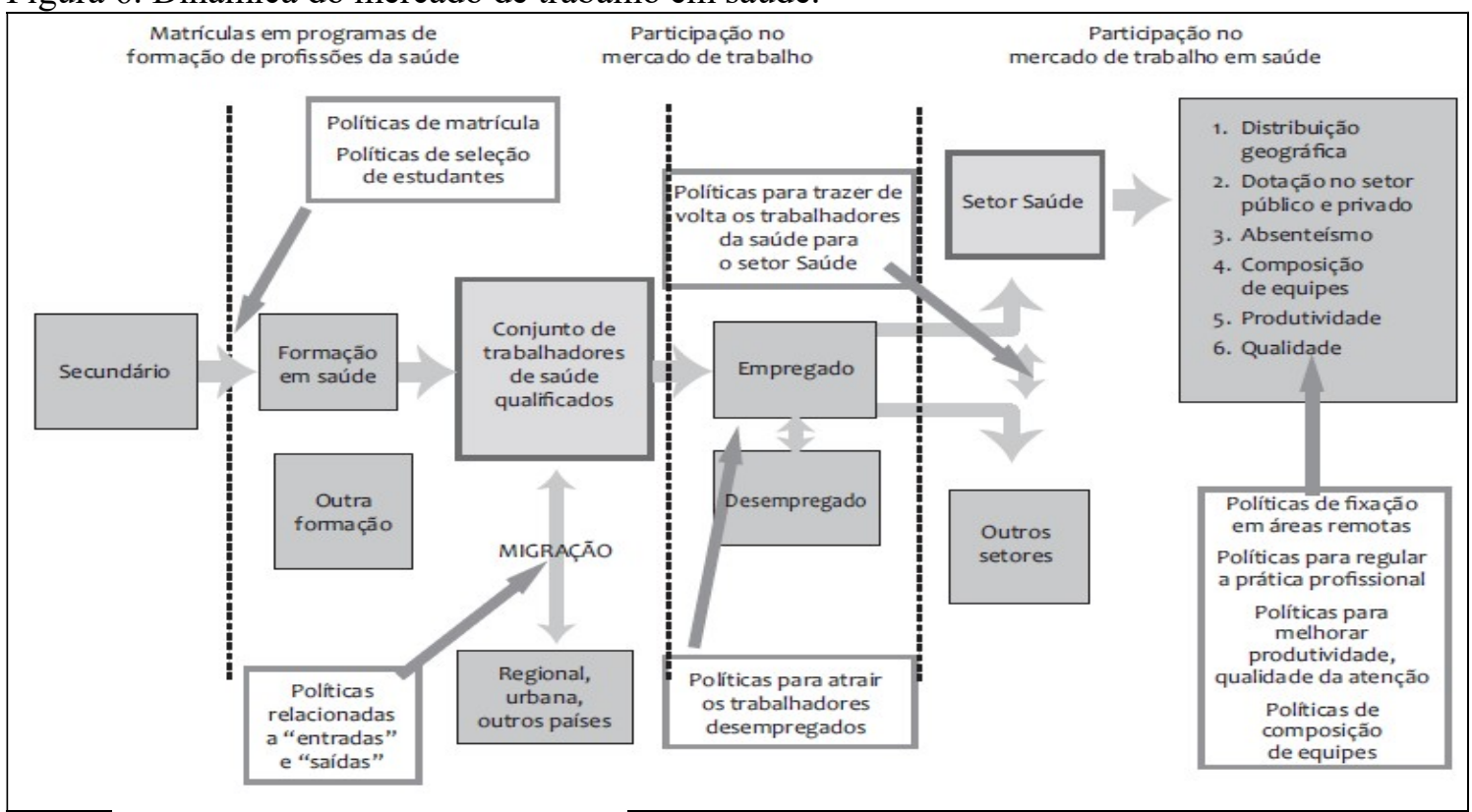

Fonte: FUNDAÇÃO OSWALDO CRUZ (2012, p 159). 
A disponibilização oportuna de análises sobre a estrutura e dinâmica dos mercados de trabalho pode subsidiar a ação de gestores governamentais, das profissões de saúde, das organizações do trabalho, dos provedores de serviços e dos usuários do sistema de saúde (ORGANIZAÇÃO MUNDIAL DA SAÚDE, 2007; GIRARDI et al, 2012).

A educação e a formação de profissionais de saúde e as práticas de saúde e o mercado de trabalho não representam momentos distintos e independentes na dinâmica da prestação de serviços de saúde. Ao contrário, a formação e o mercado de trabalho possuem relações íntimas e recíprocas, em que um influencia o outro (PEDUZZI, 2013).

Nesse contexto, a força de trabalho pode ser analisada sob dois pontos de vista, combinados ou não: a oferta e a demanda. A oferta corresponde ao número de pessoas disponíveis para o trabalho em um determinado setor de atividade ou tipo de ocupação em uma determinada região. Entre as profissões e ocupações fortemente regulamentadas, como é o caso das profissões de saúde, a dinâmica dos mercados de trabalho é fortemente dependente das potencialidades e tempos do sistema educacional e da própria regulação profissional. Já a demanda corresponde ao número de postos ou posições de trabalho disponíveis (ocupados e vacantes) no setor e o tipo de ocupação por áreas geográficas em um determinado período de tempo (GIRARDI e WAN DER MASS, 2011).

\subsubsection{Graduações em saúde}

Em 1991, a educação superior contava com 897 cursos, 78.747 vagas, 73.246 ingressos e 46.060 concluintes (egressos ou recém-graduados) das catorze profissões de saúde. Quase uma década depois, em 2000, esse número tinha aumentado para 1.942 cursos, com 207.361 vagas, 185.713 ingressos e 69.323 concluintes. Em 2013, havia 1.096 instituições, publicas e privadas, ofertando mais de seis mil cursos de graduação, com um total de 822.404 vagas, 484.392 ingressos e 187.850 egressos (figura 7).

De 1991 a 2013, o número de cursos na área de saúde aumentou 593\%. Entre 1991 e 2001, as taxas de crescimento foram as seguintes: os cursos cresceram 143\%, as vagas $202 \%$, o número de ingressos $198 \%$ e egressos $81 \%$. Na década seguinte, entre 2001 e 2013, os cursos cresceram 185\%, as vagas $246 \%$, os ingressos $122 \%$ e os egressos 125\% (SIGRAS, 2015). 
Figura 7. Evolução da graduação em saúde no Brasil (1991 - 2013).

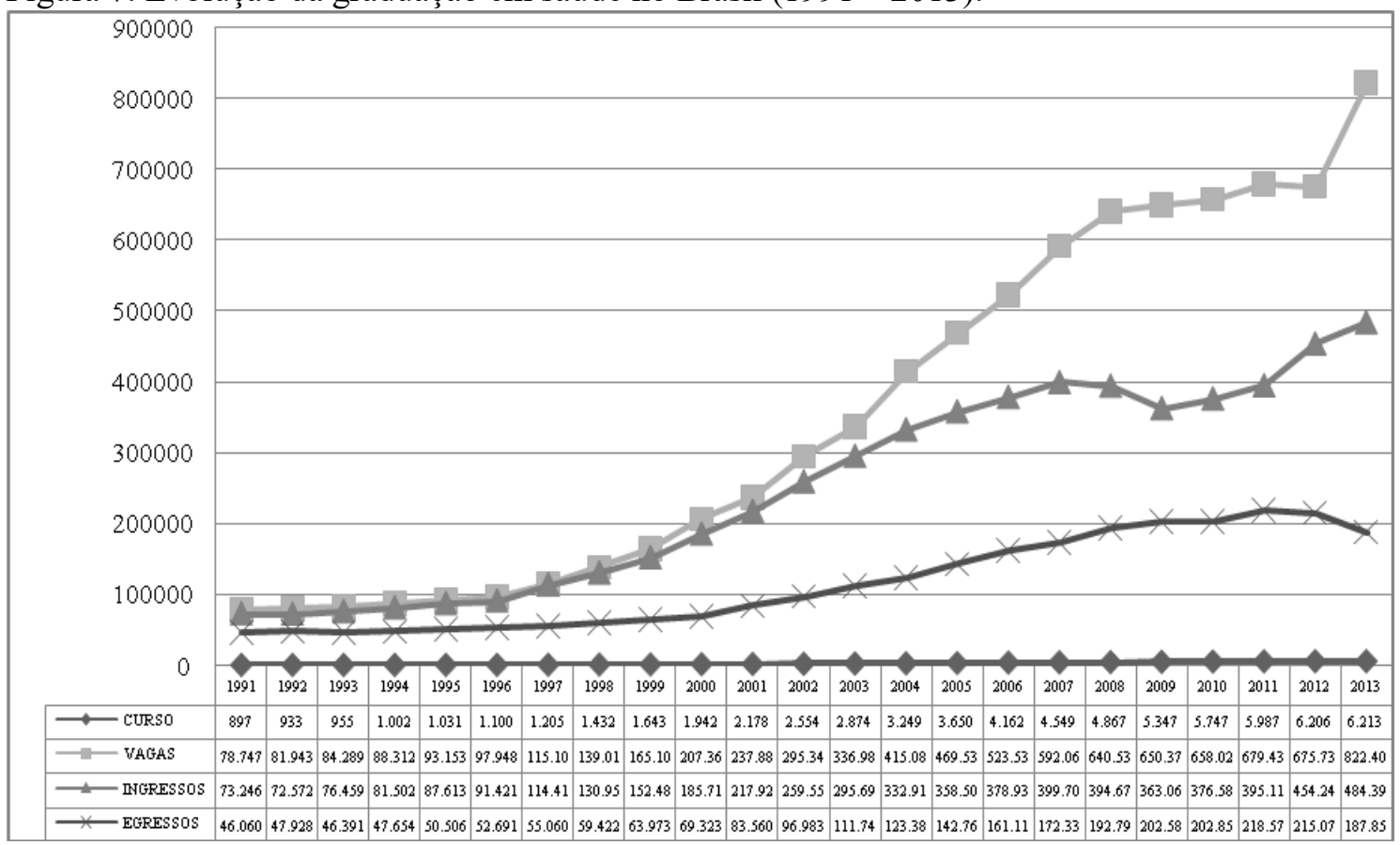

Fonte: INEP/MEC, SIGRAS/ObservaRH - IMS/UERJ (2015).

O crescimento evidente da educação superior em saúde no período analisado foi possível pela participação do setor privado nesse processo (figura 8). Em vinte anos, a participação do setor privado na composição do mercado total passou de 51\% (1991) para $72 \%(2013)$.

Figura 8. Número de cursos de saúde no Brasil, por natureza jurídica $(1991$ - 2013).

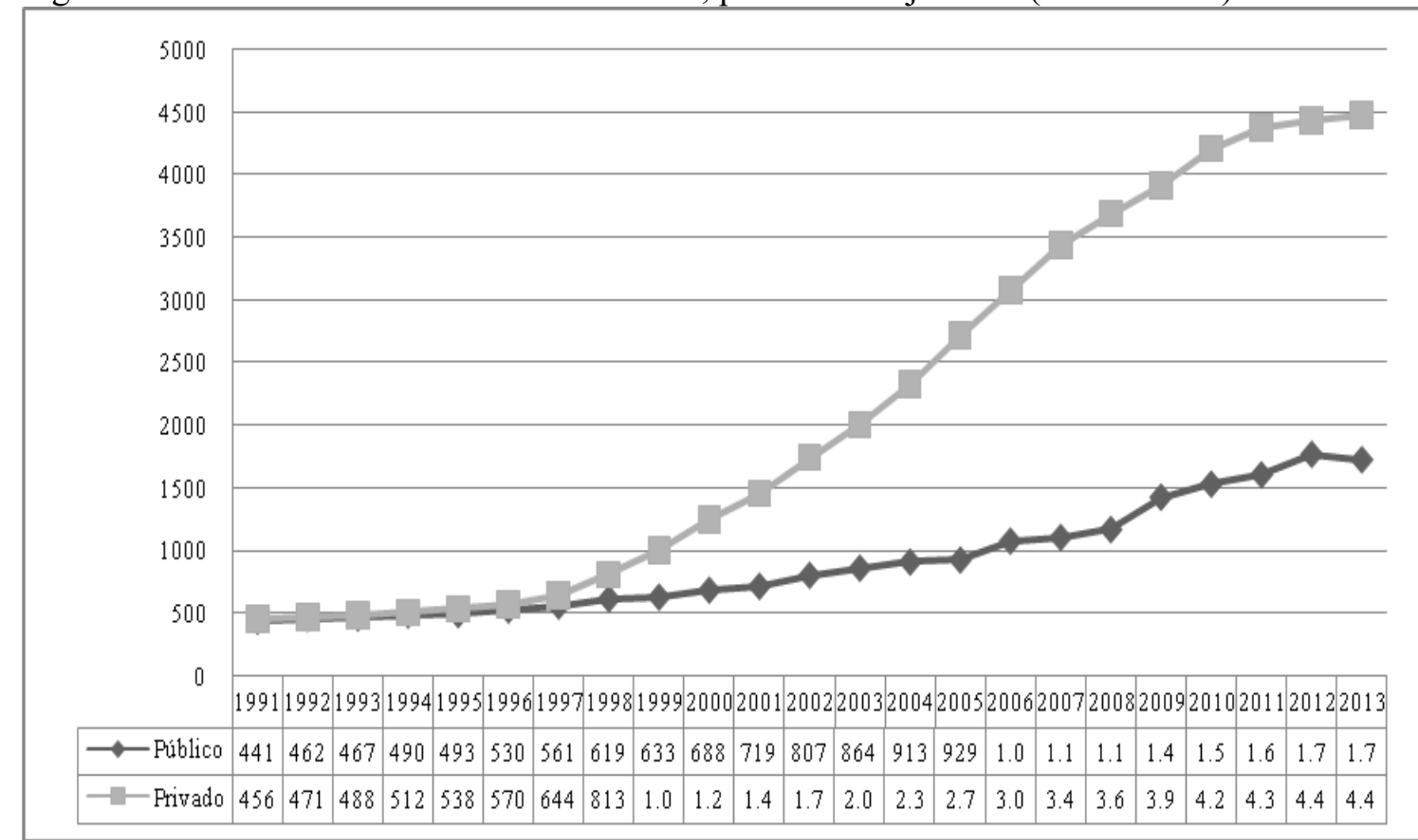

Fonte: INEP/MEC, SIGRAS/ObservaRH - IMS/UERJ (2015). 
Entre 1991 e 2008, todos os cursos cresceram taxas superiores a $100 \%$, com destaque para Fisioterapia (892\%) e Nutrição (640\%), seguidos da Farmácia (566\%), Biologia (562\%), Educação Física (553\%) e Enfermagem (536\%). Medicina e Odontologia foram os cursos com as menores taxas de crescimento no período ( $121 \% \mathrm{e}$ 137\%). No período seguinte, entre 2008 e 2013, o desempenho não foi o mesmo. Alguns cursos apresentaram taxas de crescimento negativas, como é o caso de Fonoaudiologia (-14\%) e Terapia Ocupacional (-9\%). Entre os cursos que mais cresceram no país estão Biologia (42\%), Educação Física (37\%) e Serviço Social (34\%). Os cursos de Enfermagem e Farmácia cresceram taxas iguais, 26\% cada um (SIGRAS, 2015).

Nos anos de 1991, 2008 e 2013 houve crescimento de todos os cursos superiores da área da saúde no Brasil (figura 9).

Figura 9. Evolução da graduação em saúde no Brasil, por cursos (1991, 2008, 2013).

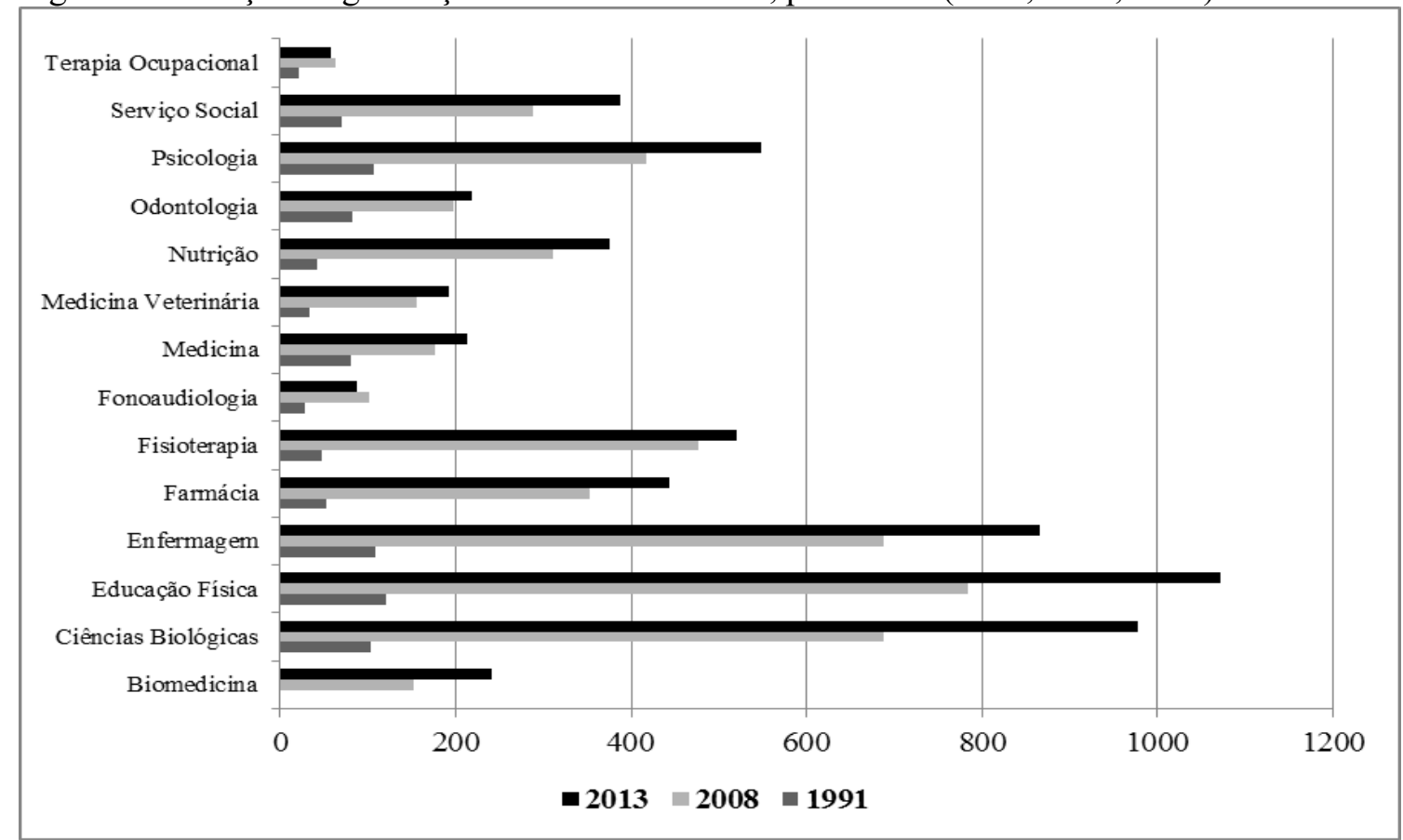

Fonte: INEP/MEC, SIGRAS/ObservaRH - IMS/UERJ (2015).

Seguindo tendência mundial, as mulheres são maioria em todos os cursos da área da Saúde, com exceção da Educação Física. Historicamente, os homens sempre foram à maioria dos estudantes de medicina. Contudo, em 2007, as mulheres também passaram a ser maioria entre os ingressantes $(56,3 \%)$ e os concluintes $(54,7 \%)$ dos cursos de Medicina. Em 2013, as mulheres já representavam 73\% dos ingressantes e 72\% dos egressos. Nos cursos de Fonoaudiologia, Serviço Social, Terapia Ocupacional e 
Nutrição, as mulheres representam mais de 90\% dos estudantes (FUNDAÇÃO OSWALDO CRUZ, 2012; SIGRAS, 2015).

Em quase nenhum dos cursos [da área da saúde] se observa diferença estatisticamente significativa entre o gênero de ingressantes e o de concluintes, o que indica uma estabilidade do aumento da participação feminina nos cursos da área (FUNDAÇÃO OSWALDO CRUZ, 2012, p.198).

Em 2013, as 1.096 instituições de ensino superior (IES) se distribuíram geograficamente da seguinte maneira: Norte (418; 8,39\%), Nordeste (1.221;22,45\%), Centro-Oeste $(546 ; 9,49 \%)$, Sudeste $(2.882 ; 44,34 \%)$ e Sul $(1.146 ; 15,33 \%)$, conforme mapa 1.

Mapa 1. Distribuição geográfica dos cursos da área de saúde no Brasil (2013).

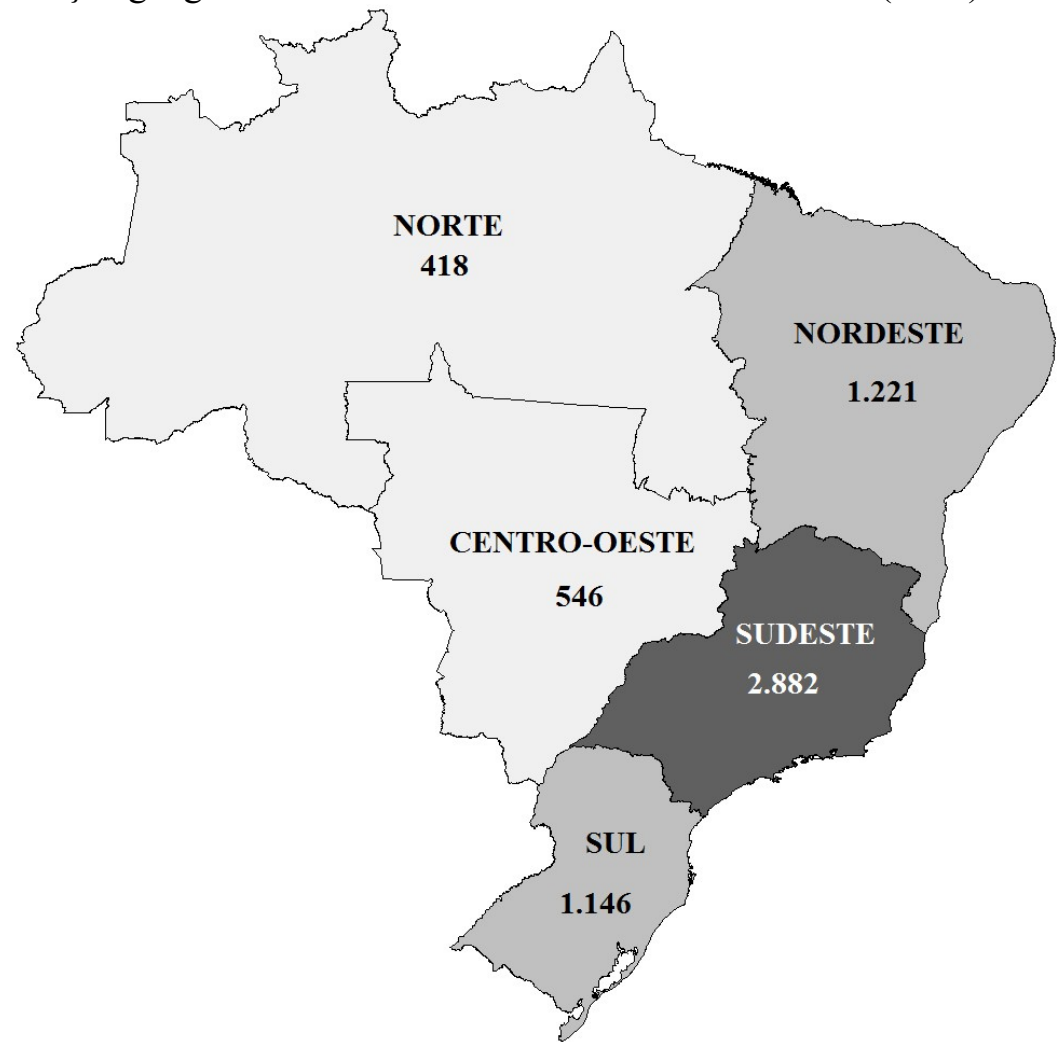

Fonte: INEP/MEC, SIGRAS/ObservaRH - IMS/UERJ (2015). Elaborado com auxilio do Tabwin®.

Além dos cursos, as vagas também se concentram na região Sudeste, especialmente dos cursos de Medicina, Enfermagem e Odontologia, embora as regiões Norte e Centro-Oeste tenham expandido o número de vagas na última década. De modo geral, o número de vagas tem se mantido acima do número de egressos, o que 
provavelmente se deve ao preenchimento incompleto e ou um alto percentual de desistência (FUNDAÇÃO OSWALDO CRUZ, 2012).

A região Sudeste se caracterizada pelo desenvolvimento econômico, por ser constituída pelas as maiores cidades, o que inclui São Paulo, Rio de Janeiro e Belo Horizonte, a maior densidade populacional, o maior mercado de trabalho e, consequentemente, a que mais oferta cursos para a formação de profissionais de saúde. Contudo, Pierantoni et al (2012) observa que a desigualdade regional na distribuição dos cursos de saúde tem diminuído na última década. Por exemplo, entre 2000 e 2010, o número de cursos de Medicina cresceu 375\% no Norte e 216\% no Nordeste. Além disso, a região Norte apresentou a maior taxa de crescimento de vagas (269\%) no mesmo período.

Contudo, a expansão acentuada do ensino superior em saúde e as políticas federais de apoio à formação na área não têm sido suficientes para superar as desigualdades de oferta do sistema educativo para a formação profissional na saúde, tanto quantitativas, exemplificadas por sua concentração regional, quanto qualitativas, que demonstram a proliferação desordenada de cursos em determinadas áreas de formação e dependências administrativas, constituindo, assim, graves problemas no âmbito do SUS (VIEIRA e AMÂNCIO FILHO, 2006; FUNDAÇÃO OSWALDO CRUZ, 2012).

\subsubsection{Mercado de trabalho no setor saúde}

A demanda por trabalhadores pode ser medida diretamente pela oferta de emprego e postos de trabalho ocupados no setor saúde, cuja principal característica é o uso intensivo da força de trabalho.

O mercado de trabalho em saúde é dependente de um contingente expressivo de trabalhadores sem formação ou habilitação específica para o trabalho a ser desenvolvido no setor, desempenhando funções auxiliares em diversos planos laborais, por exemplo, administrativas, legais, o que acentua as diferenças no plano da técnica e da responsabilidade pelo trabalho executado (FUNDAÇÃO OSWALDO CRUZ, 2012).

Durante as décadas de 70 e 80, a Pesquisa de Assistência Médico-Sanitária (AMS) do IBGE foi a base de dados mais utilizada nas avaliações sobre a evolução e a composição da força de trabalho em saúde. A partir da metade da década de 90, essas avaliações passam a utilizar outras fontes, tais como a Relação Anual de Informações 
Sociais (RAIS) e o Cadastro Geral de Empregados e Desempregados (CAGED), do Ministério do Trabalho e Emprego (GIRARDI e CARVALHO, 2002).

Uma das características marcantes da composição interna da força de trabalho em saúde, pelo menos até o final dos anos 70, é a polarização entre a categoria de maior qualificação, especialmente os médicos, e a de menor qualificação, como, por exemplo, os atendentes. Os empregos de nível superior representavam $40 \%$ e os de nível elementar 41\% do setor saúde (GIRARDI, 1986; NOGUEIRA, 1987).

Na década de 1980, a força de trabalho em saúde no Brasil significava algo em torno de um milhão e 800 mil trabalhadores e metade deste número era composto por profissionais com qualificação específica em saúde ${ }^{14}$. Entre 1977 e 1983 foram criados 75 mil empregos para médicos, sendo que foram formados apenas 57 mil no mesmo período, o que resultou em uma relação de 1,3 empregos/médico. Em 1984, os médicos ocupavam 200 mil postos de trabalho, de um total de 600 mil empregos de profissionais de saúde no Brasil, ou seja, representavam mais de $30 \%$ do total da força de trabalho em saúde (NOGUEIRA, 1987).

Ao longo dos anos 80, todas as categorias profissionais de nível superior experimentaram crescimento no número de empregos no setor, embora não tenha sido na mesma proporção. Enquanto algumas categorias cresceram acima de 100\%, como é o caso dos médicos $(125,64 \%)$ e enfermeiros (142,94\%), outras apresentaram desempenho inferior a 50\%. Os farmacêuticos cresceram apenas 34,37\% no mesmo período, possivelmente em função dos avanços tecnológicos e a industrialização, o que resultou na redução percentual da sua participação na composição da força de trabalho em saúde (GIRARDI, 1986; MÉDICI, 1986).

Outro fenômeno presente no contexto da força de trabalho em saúde é a feminização. Até a década de 1970, a participação das mulheres estava reduzida às categorias profissionais tradicionalmente femininas, tais como as parteiras, auxiliares de enfermagem e enfermeiras. Diversos fatores contribuíram para esse fenômeno, entre os quais estão o aumento da participação das mulheres na População Economicamente Ativa (PEA) no mundo e no trabalho doméstico, em função da perda substancial de poder aquisitivo dos trabalhadores com o arrocho salarial na época, e as mudanças sociais e culturais em direção da aceitação da mulher no mercado de trabalho,

\footnotetext{
14 “Entre 1970 e 1980, os profissionais com nível superior passaram de 28,6 para 36,5\% do conjunto dos ocupados no setor saúde” (MÉDICI, 1986, p. 65).
} 
especialmente nos empregos de nível superior, por causa do incremento do ingresso de mulheres nas universidades, particularmente em cursos hegemonicamente masculinos, como medicina e odontologia (MÉDICI, 1986; WERMELINGER et al, 2010).

O trecho a seguir deixa evidente o crescimento da participação das mulheres no mercado de trabalho em todo o mundo, especialmente Europa e América Latina:

Na Europa, no período de 1965 a1991, o número de mulheres na força de trabalho aumentou de 39,6 para 53,2 milhões, enquanto o de homens diminuiu de 83 para 81,8 milhões. Na América Latina, entre 1960 e 1990, o quantitativo de mulheres economicamente ativas mais que triplicou, passando de 18 milhões para 57 milhões. Em termos de participação no mercado de trabalho, o aumento foi da ordem de $18 \%$ para $27 \%$, enquanto a masculina diminuiu de $77,5 \%$ para $70,3 \%$ (WERMELINGER et al, 2010, p. 3).

Entre 1970 e 1980, a participação das mulheres nas atividades de saúde evoluiu de 41,5 para $62,9 \%$, com destaque para o crescimento entre os profissionais com formação universitária, que passou de 18,0 para 35,2\%. O número de médicas aumentou de 11,6 para 20,6\%. A reforma universitária, que possibilitou ingresso das mulheres em diversos cursos da área da saúde, especialmente aqueles com predominância masculina, como medicina e odontologia, foi fundamental para a mudança do cenário (MÉDICI, 1986).

A década de 1980 também foi marcada pela inversão na distribuição de postos de trabalho no setor saúde, passando de predominantemente privado para público. Em 1982, por exemplo, 59,41\% dos empregos em saúde estavam localizados em estabelecimentos conveniados ao INAMPS, enquanto que $30 \%$ em estabelecimentos privados com algum tipo de convênio com a Previdência Social e, portanto, algo em torno de $18 \%$ eram empregos mantidos exclusivamente pela iniciativa privada sem intermediação do estado no financiamento direto (GIRARDI, 1986).

Além do predomínio de profissionais de nível superior, com destaque para a hegemonia médica, e do fenômeno da feminização da força de trabalho, entre as décadas de 70 e 80 houve relativa melhoria na distribuição regional dos profissionais de saúde. Esta melhoria, contudo, não teve peso suficiente para inverter a tendência de concentração nos grandes centros urbanos das regiões mais desenvolvidas do país. Em 1982, a região Sudeste, com 43,61 da população brasileira, detinha $43,55 \%$ dos estabelecimentos de saúde do país e 55,3\% dos empregos de saúde. Quando observada a razão emprego em saúde por habitante, a região Sudeste possuía, em 1982, um emprego 
de profissional de saúde para cada 181 habitantes e a região Sul um emprego para cada 239 habitantes, enquanto que as regiões Norte e Nordeste um para 365 e um para cada 332 habitantes, respectivamente. A região Sul representava $15,61 \%$ da população do Brasil e a região Nordeste $29,07 \%$. A má distribuição geográfica dos profissionais de saúde é reforçada pela concentração nas grandes regiões metropolitanas do país (GIRARDI, 1986; NOGUEIRA, 1987).

A década de 1990 foi marcada por um quadro de retrocesso das conquistas sociais da década anterior e a reforma do Estado, como consequência das imposições macroeconômicas orientadas por organismos financeiros internacionais, e alcançadas por meio de processos de privatização, desregulação e terceirização, repercutiu no mundo do trabalho, resultando no aumento do desemprego e na precarização das relações trabalhistas (VARELLA e PIERANTONI, 2008; CARVALHO; SANTOS; CAMPOS, 2013).

O mercado de trabalho em saúde teve uma dinâmica muito particular na década de 90, com crescimento do emprego nos setores público e privado. Em 2000, havia cerca de dois milhões e seiscentos mil vínculos formais de emprego em estabelecimentos direta ou indiretamente vinculados à economia da saúde, dos quais um milhão e setecentos mil correspondiam a postos de trabalho assalariados em estabelecimentos do núcleo do setor (hospitais, clínicas e serviços diagnósticos e terapêuticos). Aproximadamente $70 \%$ da ocupação assalariada estavam lotados em atividades de serviços de saúde. No setor público de saúde, os estabelecimentos hospitalares eram os maiores empregadores, enquanto que as atividades assistenciais em estabelecimentos sem internação correspondiam a cerca de $10 \%$ do emprego formal (GIRARDI e CARVALHO, 2002; VARELLA e PIERANTONI, 2008).

Além da expansão do mercado de trabalho no Brasil, especialmente no setor público, as décadas de 1990 e 2000 foram marcadas pelo aumento da participação feminina na maioria das profissões de saúde, confirmando a tendência de uma maior ocupação de postos de trabalho pelas mulheres (GIRARDI e CARVALHO, 2002; WERMELINGER et al, 2010).

Segundo o Censo Demográfico de 2000, a força de trabalho em saúde no Brasil era eminentemente feminina e urbana, o que inclui os farmacêuticos. As exceções eram as categorias profissionais dos médicos, em que a força de trabalho masculina e urbana representava $63 \%$ do total, e a dos veterinários, em que $62 \%$ são homens de áreas urbanas. Quanto às áreas rurais, apenas $4 \%$ da força de trabalho estava nesses locais, e o 
maior contingente de profissionais é o de níveis médio e elementar, correspondendo a $85 \%$ do total da força de trabalho em saúde nessas áreas, conforme a tabela 2 (WERMELINGER et al, 2010).

Tabela 2. Distribuição das categorias profissionais nas áreas urbana e rural, segundo sexo. Brasil (2000).

\begin{tabular}{lcccc}
\hline \multirow{2}{*}{ Ocupação } & \multicolumn{2}{c}{ Urbana } & \multicolumn{2}{c}{ Rural } \\
\cline { 2 - 5 } & Homens & Mulheres & Homens & Mulheres \\
\hline Assistente Social & 12.883 & 67.282 & 845 & 2.020 \\
Cirurgião-Dentista & 74.654 & 77.517 & 633 & 609 \\
Enfermeiro & 5.056 & 48.114 & 141 & 759 \\
Farmacêutico & 16.204 & 28.515 & 400 & 414 \\
Médico & 125.825 & 70.794 & 1.109 & 424 \\
Nutricionista & 1.214 & 25.238 & 43 & 246 \\
Psicólogo & 6.266 & 55.303 & 34 & 474 \\
\hline
\end{tabular}

Fonte: Modificado de Wermelinger et al (2010).

Em meados da década de 1960, o Brasil vivenciou a expansão das relações de produção capitalistas no setor saúde, com o crescimento dos grupos de medicina privada, direcionados para tornar o setor rentável ao capital privado, o que se traduziu em alterações técnicas e físicas na prestação de serviços, bem como no redirecionamento do perfil e do volume da sua força de trabalho (SOUZA, 2010 p. 70).

Tabela 3. Taxa de incremento dos empregos de profissionais de saúde por esfera administrativa do setor público segundo ocupações de saúde. Brasil (1995/2000).

\begin{tabular}{lccc}
\hline \multirow{2}{*}{ Ocupação } & \multicolumn{2}{c}{ Taxa de Crescimento Bruto 1995/2000 (\%) } \\
\cline { 2 - 4 } & $\begin{array}{c}\text { Setor público } \\
\text { federal }\end{array}$ & $\begin{array}{c}\text { Setor público } \\
\text { estadual }\end{array}$ & $\begin{array}{c}\text { Setor público } \\
\text { municipal }\end{array}$ \\
\hline Assistente Social & $-83,6$ & 5,1 & 31,3 \\
Cirurgião-Dentista & $-84,1$ & $-11,0$ & 26,2 \\
Enfermeiro & $-91,1$ & 5,3 & 39,5 \\
Farmacêutico & $-80,4$ & $-5,9$ & 141,0 \\
Médico & $-88,9$ & 12,8 & 36,1 \\
Nutricionista & $-93,9$ & 11,6 & 57,5 \\
Psicólogo & $-72,9$ & 26,1 & 67,1 \\
\hline
\end{tabular}

Fonte: Modificado de Girardi e Carvalho (2002). 
No setor público, a situação foi singular em decorrência do processo de descentralização das ações de saúde. Em 1999, a esfera municipal detinha a gestão de $92 \%$ dos estabelecimentos de saúde no país, restando ao nível estadual $6 \%$ e federal apenas 2\%. Entre 1995 e 2000, todas as profissões de saúde apresentaram taxas de crescimento negativo na esfera federal e altas taxas de crescimento no setor público municipal, conforme demonstrado na tabela 3 (GIRARDI e CARVALHO, 2002; VARELLA e PIERANTONI, 2008).

Em dezembro de 2000, as profissões de saúde somavam 930.189 vínculos de emprego, representando $3,5 \%$ do mercado de trabalho assalariado formal brasileiro. Entre 1995 e 2000, houve um ganho de 113.351 vínculos de emprego, o que representou um crescimento bruto de $13,9 \%$. No mesmo período, o aumento do emprego assalariado no conjunto da economia foi menor, de 23,8 para 26,2 milhões, representando um incremento de $10,4 \%$. Além disso, observou-se que enquanto o setor privado perdeu trabalhadores, no setor público houve incremento de trabalhadores, o que demonstra a importância do SUS no mercado de trabalho em saúde (GIRARDI e CARVALHO, 2002).

A Secretaria de Gestão do Trabalho e da Educação em Saúde (SGTES) foi criada em 2003 com o objetivo de formular políticas orientadoras da gestão, formação, qualificação e regulação dos trabalhadores da saúde no Brasil. A mudança na denominação da área - de "recursos humanos em saúde" para "gestão do trabalho e da educação em saúde" -, no âmbito do MS, possivelmente foi um reflexo dos diversos debates que ocorreram em torno desses conceitos desde a década de 80, e que conseguiram visibilidade com a eleição de outro governo no país, em 2003, que assumia o poder defendendo mudanças na área social (ASSUNÇÃO et al, 2007).

Em 2005, do total de empregos do setor saúde, 56,0\% eram públicos. Sob uma análise mais qualitativa, pode-se observar que o segmento público do setor saúde concentra um grande contingente de profissionais com maior escolaridade $\mathrm{e}$ qualificação. Por exemplo, no setor privado há uma maior proporção de pessoal de enfermagem que no setor público, enquanto a proporção de médicos e enfermeiros é maior no público. Os profissionais com nível de escolaridade superior representam $44,6 \%$ no setor público enquanto que no privado somam 19,5\% (VARELLA e PIERANTONI, 2008).

O período de 2005 a 2014 tem sido marcado pela expansão do SUS, o que resultou, de um lado, no incremento na participação dos municípios e relativa queda da 
União no total de empregos públicos em saúde, na "ambulatorização" dos empregos, no aumento do grau de escolaridade e no número de mulheres no mercado de trabalho em saúde, o que possivelmente se deu em função do crescimento extraordinário no número de enfermeiros entre 2002 e 2005, e, de outro, na expansão dos vínculos precários de trabalho, especialmente no âmbito da Estratégia de Saúde da Família (ESF) (MACHADO et al, 2011).

\subsection{FORÇA DE TRABALHO FARMACÊUTICO}

Os farmacêuticos compõem a força total de trabalho em saúde e esses variam consideravelmente entre as regiões do mundo de acordo, entre outros fatores, com os indicadores de desenvolvimento econômico e social do país, por exemplo, Produto Interno Bruto (PIB) e Índice de Desenvolvimento Humano (IDH).

Diante da situação global da força de trabalho em saúde e da escassez de estudos específicos sobre o trabalho farmacêutico, especialmente no Brasil, esta seção traz contribuições para o debate sobre a oferta e a demanda no mercado de trabalho dos farmacêuticos no Brasil na última década, considerando os cursos de graduação (formação superior) como oferta e os postos de trabalho nos setores público e privado como a demanda da força de trabalho.

Globalmente, a prática, a ciência e a educação farmacêutica têm experimentado transformações sem precedentes, entre as quais estão a expansão das escolas de farmácia, o aumento das matriculas de estudantes, o crescimento da oferta de serviços, a expansão do mercado de trabalho, as mudanças na formação em graduação e pósgraduação, tudo isso possivelmente provocado pela mudança de foco do produto (medicamento) para o paciente e conseqüente ampliação do escopo de atuação do farmacêutico, especialmente como prestador de cuidados em saúde (HAWTHORNE e ANDERSON, 2009; ANDERSON et al, 2013; COVVEY e COHRON, 2015).

A Federação Internacional dos Farmacêuticos, conhecida mundialmente como FIP, tem publicado relatórios sobre a força de trabalho farmacêutico no mundo, entre os quais se destacam dos anos de 2006 e 2012. Os farmacêuticos representam o terceiro maior grupo profissional do mundo. A maioria da prática farmacêutica ocorre em farmácias comunitárias, hospitais e outros serviços de saúde. Um pequeno número de farmacêuticos está empregado na indústria farmacêutica (FIP, 2006). 
O cenário global apresenta uma grande variação no número de escolas e cursos de Farmácia nos continentes e países, o que tem impacto direto na oferta de profissionais para o mercado de trabalho e, consequentemente, no tamanho da força de trabalho farmacêutico. De um lado, está a África com déficit de escolas e trabalhadores, com menos de 0,5 farmacêuticos recém-graduados por 10.000 habitantes, e, do outro, alguns países da Europa (Itália, Portugal e Espanha), da Ásia (Japão) e da Oceania (Nova Zelândia e Austrália) com mais de um farmacêutico recém-graduado para cada 5.000 habitantes (HAWTHORNE e ANDERSON, 2009; FIP, 2013).

Segundo o 2013 FIPEd Global Education Report, o número de escolas de farmácia na Inglaterra cresceu 91\%, porque passou de 12 (1999) para 23 (2013), e o número de estudantes de farmácia aumentou de 42.001 em 1999/2000 para 109.513 em 2011/2012, o que significa crescimento de $161 \%$ no período. O número de licenciados em Portugal também aumentou significativamente na última década, devido ao crescimento do número de Faculdades de Farmácia, de 03 em 1998 para 09 em 2013 (FIP, 2013).

Os farmacêuticos compõem a força total de trabalho em saúde e, de modo geral, variam consideravelmente entre países e regiões, de acordo com o nível dos indicadores de desenvolvimento econômico do país.

Um estudo publicado por Hawthorne e Anderson, em 2009, sobre as características e distribuição da força de trabalho farmacêutico no mundo demonstrou que o continente africano tem menos farmacêuticos que farmácias por 10.000 habitantes, enquanto que a situação na Europa é praticamente o oposto: menos farmácias e mais farmacêuticos. Além disso, o emprego farmacêutico na África, Oriente Médio e Sudeste Asiático é predominantemente composto por homens (entre 68 e 61\%, respectivamente). Na Europa e Américas, as mulheres são a maioria da força de trabalho farmacêutico. No Reino Unido, Irlanda, Canadá e EUA a distribuição entre os sexos varia de acordo com a faixa etária: as mulheres predominam na faixa entre $30 \mathrm{a}$ 45 anos e os homens na situada acima de 50 anos. A distribuição também é desigual entre áreas urbana e rural ou locais remotos, principalmente em paises pouco desenvolvidos, como é o caso do continente Africano.

Nos EUA e do Reino Unido, o incremento do número de farmacêuticos no mercado de trabalho parece ter relação com a expansão das instituições de formação superior em farmácia. Além disso, como o emprego é predominantemente privado, a abertura dessas instituições deve ser fortemente influenciada pela cadeia produtiva e do 
comercio de medicamentos e pelo sistema local de saúde (HAWTHORNE e ANDERSON, 2009).

O relatório global sobre força de trabalho em Farmácia, publicado pela FIP em 2012, refere que, nos países de baixa renda per capita (República do Congo e Haiti), a escassez de farmacêuticos acabou resultando na dependência de trabalhadores de nível médio. Já nos países de alta renda per capita (Austrália, Reino Unido e Japão), os farmacêuticos são a maioria na composição da força de trabalho. A participação de trabalhadores de nível técnico, em geral profissionais regulamentados e qualificados para apoiar o farmacêutico, varia de 43,2\% na Europa a 28,4\% nas Américas, enquanto que no Sudeste Asiático representa $67,5 \%$ do total da força de trabalho na área farmacêutica. Cabe ressaltar que esses resultados se referem ao mercado de trabalho de modo geral, sem qualquer abordagem específica em relação aos serviços da atenção primária de saúde nos países analisados (FIP, 2012).

\subsubsection{Formação de farmacêuticos no Brasil}

Os cursos de Farmácia no Brasil foram criados em 1832, passando a funcionar nas Faculdades de Medicina da Bahia e do Rio de Janeiro. A primeira escola exclusiva para o ensino da profissão só surgiu em 1839, em Ouro Preto. A partir da década de 1930, o ensino passou por várias mudanças curriculares, relacionadas principalmente às transformações da prática farmacêutica (SATURNINO et al, 2012; FUNDAÇÃO OSWALDO CRUZ, 2012).

Segundo dados do Instituto Nacional de Estudos e Pesquisas Educacionais Anísio Teixeira (INEP), do Ministério da Educação (MEC), em 2013 havia 6.213 cursos de graduação em saúde distribuídos em 1.096 instituições de ensino superior, sendo a maioria localizada na região Sudeste $(46,39 \%)$ e de natureza privada $(71,19 \%)$. Por sua vez, a formação de farmacêuticos ocorre em 444 cursos, ofertados em 347 instituições, correspondendo a 7,15\% do total de cursos da área da saúde (SIGRAS, 2015).

Em 1991 havia 53 cursos de Farmácia no país, ofertando pouco mais de quatro mil vagas. No período de 1991 a 2003, taxa de crescimento dos cursos foi de $298 \%$. Na década seguinte, entre 2003 e 2013, o número de cursos de farmácia passou de 211 para 444, o que significa uma taxa de crescimento de 110\% (figura 10). Contudo, o crescimento dos cursos não foi constante. Na primeira metade do periodo analisado, entre 2003 e 2008, houve o incremento de 142 cursos, enquanto que a metade seguinte 
foi marcada por oscilação do número de cursos, com retração em alguns momentos, como é o caso de 2009/2010 (- 01 curso) e 2012/2013 (- 08 cursos).

Figura 10. Evolução do número de cursos de Farmácia no Brasil (1991 - 2013).

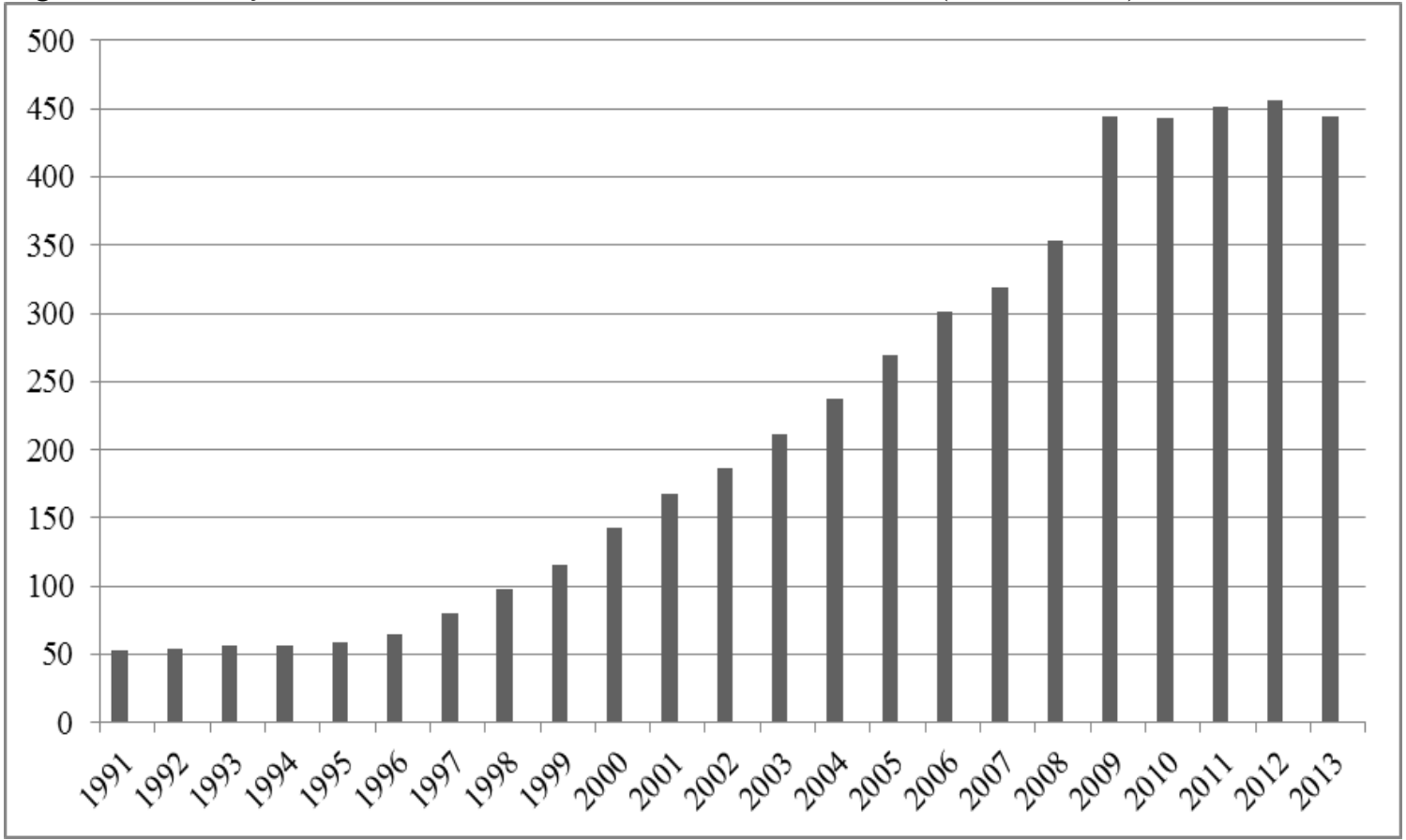

Fonte: SIGRAS/ObservaRH - IMS/UERJ (2015).

Entre 2003 e 2013, o aumento do número de cursos veio acompanhado da ampliação das vagas e, consequentemente, do crescimento do número ingressos na formação superior em Farmácia. Contudo, dois fenômenos evidenciados na figura 11 merecem destaque: a) o desequilibrio entre vagas e ingressos e b) a queda no número de concluintes no período analisado.

Em 2003 foram ofertadas 22.553 vagas e ingressaram 21.704 estudantes, uma diferença de 849 vagas. Em uma década, o número de vagas ofertadas aumentou para 146.424 e de ingressos para 31.503 estudantes (figura 11). Enquanto a taxa de crescimento de vagas foi $171 \%$, o ingresso de estudantes nos cursos superiores de Farmácia cresceu $45 \%$ no período, resultando na "sobra" de 29.654 vagas.

Os cursos de Farmácia geraram input de 9.703 concluintes ao mercado de trabalho em 2003. Em 2008, esse número aumentou para 13.394 concluintes, o representa o incremento de 3.691 concluintes e taxa de crescimento de $38 \%$ entre 2003 e 2008. O crescimento do número egressos do curso de farmácia no período foi relativamente constante. 
Figura 11. Evolução do número de vagas, ingressos e concluintes dos cursos de Farmácia (2003 $-2013)$.

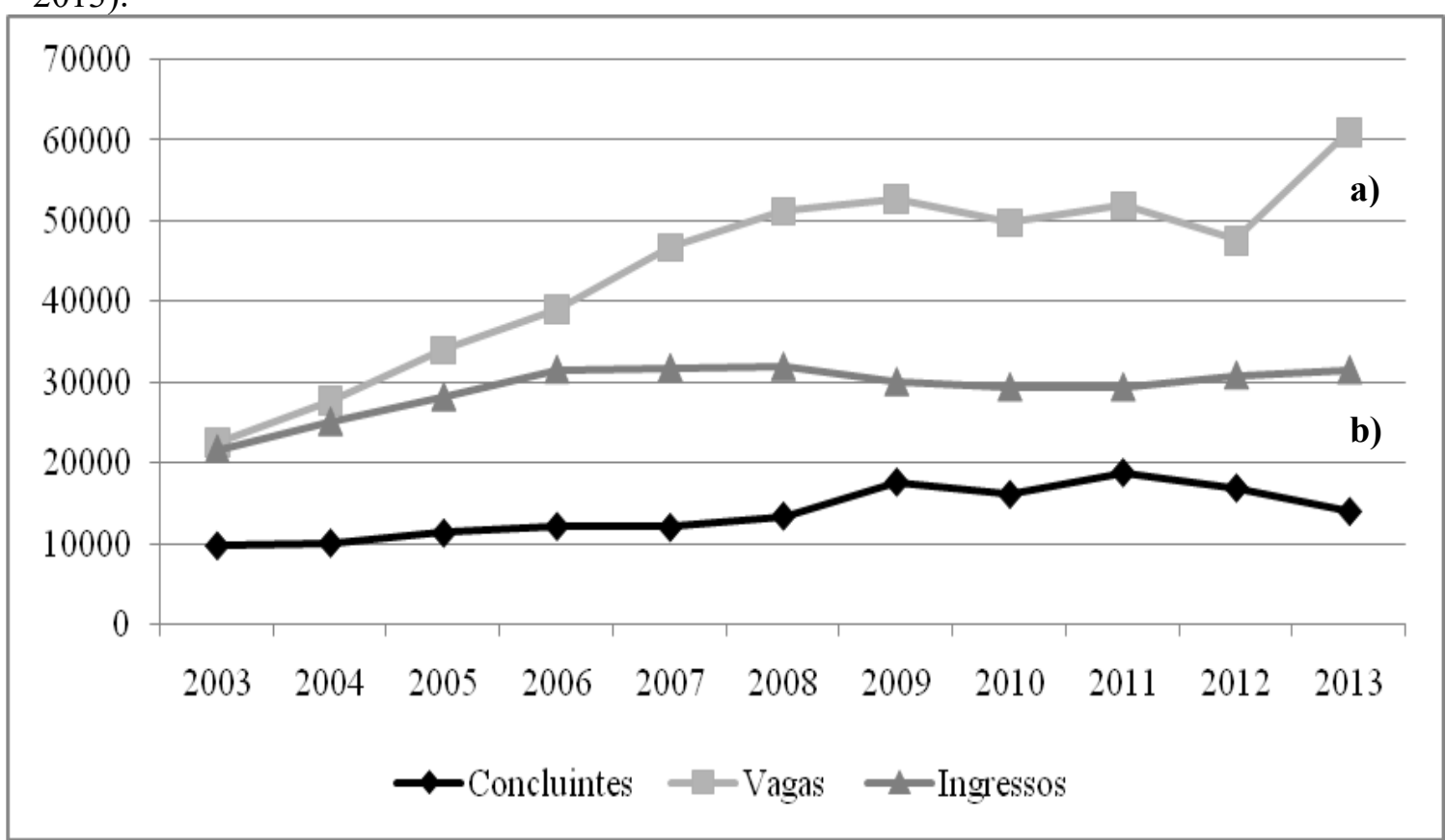

Fonte: SIGRAS/ObservaRH - IMS/UERJ (2015).

Embora a taxa de crescimento tenha sido baixa (4\%) no período de 2008 a 2013, em comparação ao período anterior, o número anual de egressos oscilou bastante. Em 2008/2009, o número de concluintes passou de 13.394 para 17.617, ou seja, o número de concluintes cresceu 32\% em apenas um ano. Em 2010/2011 e 2012/2013, o número de concluintes caiu, cresceu e caiu novamente, chegando ao valor de 13.957 concluintes.

Tabela 4. Distribuição regional e taxa de crescimento dos cursos de Farmácia no Brasil (2003 2013).

\begin{tabular}{lccccccc}
\hline \multirow{2}{*}{ Regiões } & \multicolumn{2}{c}{$\mathbf{2 0 0 3}$} & \multicolumn{2}{c}{2008} & \multicolumn{2}{c}{$\mathbf{2 0 1 3}$} & \multirow{2}{*}{ Tx. Cresc. (\%) } \\
\cline { 2 - 6 } & $\mathbf{n}$ & $\mathbf{\%}$ & $\mathbf{n}$ & $\mathbf{\%}$ & $\mathbf{n}$ & $\mathbf{\%}$ & \\
\hline Norte & 08 & 04 & 17 & 05 & 27 & 06 & 238 \\
Nordeste & 19 & 09 & 42 & 12 & 65 & 15 & 242 \\
Centro-Oeste & 17 & 08 & 43 & 12 & 55 & 12 & 224 \\
Sudeste & 117 & 55 & 185 & 52 & 216 & 50 & 85 \\
Sul & 50 & 24 & 66 & 19 & 81 & 18 & 62 \\
\hline Brasil & $\mathbf{2 1 1}$ & $\mathbf{1 0 0}$ & $\mathbf{3 5 3}$ & $\mathbf{1 0 0}$ & $\mathbf{4 4 4}$ & $\mathbf{1 0 0}$ & $\mathbf{1 1 0}$
\end{tabular}

Fonte: SIGRAS/ObservaRH - IMS/UERJ (2015). Tx. Cresc. = Taxa de Crescimento Bruto.

Regionalmente, conforme demonstrado na tabela 4, o Sudeste lidera em número de cursos, seguido pelo Sul, Nordeste, Centro-Oeste e Norte. No período analisado, o 
cálculo da taxa de crescimento demonstra que as regiões Norte (271\%), Centro-Oeste $(247 \%)$ e Nordeste (242\%) apresentaram o maior crescimento percentual no número de cursos, seguido das regiões Sudeste (83\%) e Sul (62\%).

Houve crescimento no número vagas, ingressos e egressos em todas as regiões, embora se concentrem na região Sudeste, que, em 2013, contava com 33.985 vagas, 14.475 ingressos e 7.626 concluintes, o que significa três farmacêuticos recémformados por 10.000 habitantes (tabela 5).

Tabela 5. Distribuição regional do número de vagas, ingressos e concluintes dos cursos de Farmácia (2003 - 2013).

\begin{tabular}{lccccccccc}
\hline \multirow{2}{*}{ Regiões } & \multicolumn{3}{c}{$\mathbf{2 0 0 3}$} & & & $\mathbf{2 0 1 3}$ & \multicolumn{3}{c}{ Tx. Cresc. (\%) } \\
\cline { 2 - 10 } & Vag & Ing & Conc & Vag & Ing & Conc & Vag & Ing & Conc \\
\hline Norte & 772 & 745 & 265 & 3.155 & 1.802 & 862 & 309 & 142 & 225 \\
Nordeste & 1.875 & 2.278 & 1.118 & 9.258 & 6.422 & 1.733 & 394 & 182 & 55 \\
Centro-Oeste & 1.705 & 1.903 & 704 & 7.362 & 5.043 & 1.521 & 332 & 165 & 116 \\
Sudeste & 13.631 & 11.951 & 4.689 & 33.985 & 14.475 & 7.626 & 149 & 21 & 63 \\
Sul & 4.570 & 4.827 & 2.927 & 7.397 & 3.761 & 2.215 & 62 & -22 & -24 \\
\hline Brasil & $\mathbf{2 2 . 5 5 3}$ & $\mathbf{2 1 . 7 0 4}$ & $\mathbf{9 . 7 0 3}$ & $\mathbf{6 1 . 1 5 7}$ & $\mathbf{3 1 . 5 0 3}$ & $\mathbf{1 3 9 5 7}$ & $\mathbf{1 7 1}$ & $\mathbf{4 5}$ & $\mathbf{4 4}$
\end{tabular}

Fonte: SIGRAS/ObservaRH - IMS/UERJ (2015). Vag = Vagas; Ing = Ingressos; Conc = Concluintes. Tx. Cresc. $=$ Taxa de Crescimento Bruto.

Cabe destacar a região Nordeste, que passou de 1.875 para 9.258 vagas, 2.278 para 6.422 ingressos e 1.118 para 1.733 recém-graduados no período de 2003 a 2013, com taxas de crescimento de 394\%,182\% e 55\%, respectivamente (tabela 5). Apesar do crescimento nas vagas e ingressos, o Nordeste tem uma das piores taxas de densidade populacional de recém-graduados $(0,3 / 10.000$ habitantes $)$.

A ampliação dos cursos de Farmácia ocorreu de forma desigual entre os setores público e privado, sendo a maioria ofertada em instituições privadas (78\%). Assim, o setor privado pode ser considerado o principal responsável pelo crescimento dos cursos de Farmácia no país, passando de 163, em 2003, para 345, em 2103, o que representa uma taxa de crescimento de $112 \%$. Nas regiões Nordeste e Centro-Oeste, as maiores taxas foram verificadas no setor privado, e no Sul o fenômeno foi diferente: maior nas instituições públicas (tabela 6). 
Tabela 6. Distribuição regional e taxa de crescimento dos cursos de Farmácia no Brasil, segundo a natureza jurídica (2003 - 2013).

\begin{tabular}{lcccccccc}
\hline \multirow{2}{*}{ Regiões } & \multicolumn{2}{c}{$\mathbf{2 0 0 3}$} & \multicolumn{2}{c}{$\mathbf{2 0 0 8}$} & \multicolumn{2}{c}{$\mathbf{2 0 1 3}$} & \multicolumn{2}{c}{ Tx. Cresc. (\%) } \\
\cline { 2 - 8 } & Público & Privado & Público & Privado & Público & Privado & Público & Privado \\
\hline Norte & 02 & 05 & 04 & 12 & 07 & 19 & 250 & 280 \\
Nordeste & 12 & 07 & 15 & 27 & 20 & 45 & 67 & 543 \\
Centro-Oeste & 05 & 10 & 10 & 31 & 14 & 38 & 180 & 280 \\
Sudeste & 16 & 104 & 22 & 166 & 30 & 190 & 88 & 83 \\
Sul & 13 & 37 & 13 & 53 & 28 & 53 & 115 & 43 \\
\hline Brasil & $\mathbf{4 8}$ & $\mathbf{1 6 3}$ & $\mathbf{6 4}$ & $\mathbf{2 8 9}$ & $\mathbf{9 9}$ & $\mathbf{3 4 5}$ & $\mathbf{1 0 6}$ & $\mathbf{1 1 2}$ \\
\hline
\end{tabular}

Fonte: SIGRAS/ObservaRH - IMS/UERJ (2015). Tx. Cresc. = Taxa de Crescimento Bruto.

Semelhantemente aos Estados Unidos e alguns países da Europa, entre 2003 e 2013, também se verificou expansão da oferta de cursos e vagas na graduação em Farmácia no Brasil, cujas taxas de crescimento foram $110 \%$ e $171 \%$, respectivamente (tabelas 4 e 5).

Embora a maioria $(77,7 \%)$ das escolas de Farmácia pertença ao setor privado, que cresceu $112 \%$ entre 2003 e 2013, o setor público também cresceu a uma taxa superior a $100 \%$ no mesmo período. Ambos os setores foram fortemente estimulados pelo governo federal por meio de alguns programas importantes. As instituições privadas receberam dois grandes estímulos para ampliação de cursos, vagas e ingressos: o Fundo de Financiamento Estudantil (FIES) e o Programa Universidade para Todos (ProUni). O primeiro é um programa de financiamento destinado a estudantes matriculados em instituições privadas de educação superior e o segundo, criado em 2004, consiste na concessão de bolsas de estudos integrais e parciais a estudantes de cursos de graduação e de cursos sequenciais de formação específica, em instituições privadas de educação superior (PIERANTONI et al, 2012).

Regionalmente, as instituições públicas cresceram mais que as de natureza privada nas regiões Sudeste e Sul do país, o que provavelmente se deveu a algumas ações governamentais, tais como o Programa de Apoio aos Planos de Reestruturação e Expansão das Universidades Federais (Reuni), que teve como objetivo ampliar o ensino superior, cuja meta era dobrar o número de alunos nos cursos de graduação em dez anos, a partir de 2008 (PIERANTONI et al, 2012).

Nota-se que o crescimento das escolas de Farmácia veio acompanhado (ou acompanhou) a expansão do mercado de trabalho formal, que cresceu $96 \%$, passando de 54.990 para 107.785 farmacêuticos empregados no período. 
Apesar da concentração na região Sudeste, os resultados apontam uma tendência de crescimento das instituições de formação superior em locais com possibilidade de expansão do mercado de trabalho, que, por sua vez, pode ser afetado pela presença de escolas de formação superior. Por exemplo, na década analisada, o número de cursos de Farmácia cresceu 238\%, 242\% e 224\% nas regiões Norte, Nordeste e Centro-Oeste respectivamente, assim como o emprego formal do farmacêutico cresceu 194\%, 126\% e $106 \%$ nessas mesmas regiões.

O desempenho da região Nordeste merece uma analise mais detalhada. Entre 2003 e 2013, o número de cursos de Farmácia cresceu 424\%, as vagas cresceram 394\% e o número de ingressos $182 \%$, ou seja, foi a região que apresentou as maiores taxas de crescimento de cursos, vagas e ingressos no período. Contudo, a taxa de crescimento de concluintes foi apenas 55\%, inferior ao desempenho da região Sudeste, com 63\%.

Apesar da tendência de expansão para outras regiões, assim verificado na distribuição dos cursos de graduação em Farmácia, os empregos farmacêuticos estão concentrados no Brasil. Em 2013, o emprego formal estava distribuído da seguinte maneira: o Norte com 6\%, o Nordeste $21 \%$, o Centro-Oeste $9 \%$, o Sudeste $45 \%$ e o Sul $19 \%$ do mercado de trabalho formal dos farmacêuticos do país.

Se compararmos as regiões brasileiras em relação à situação regional mundial, a região Sudeste (três recém-graduados em Farmácia por 10.000 habitantes) supera países como, por exemplo, Portugal, Itália e Austrália, que possuem 0,5 recém-graduados por 10.000 habitantes, enquanto que o Nordeste tem 0,3 recém-graduados por 10.000 habitantes, se aproximando ao nível crítico de 0,36, apontado no relatório de 2013 (FIP, 2013).

Apesar do cenário de escassez global da força de trabalho em saúde, inclusive de farmacêuticos, que ganhou centralidade no debate internacional com a publicação do Relatório Mundial de Saúde 2006, há uma preocupação crescente quanto à oferta excessiva de farmacêuticos em função do crescimento contínuo no setor de educação em Farmácia nos EUA. Há uma previsão que 21 estados dos EUA aumentarão o número de graduados em $100 \%$ ou mais, sem nenhum sinal de uma desaceleração ou diminuição da demanda no mercado. A situação dos EUA não parece ser isolada, porque outros países, como o Reino Unido e Canadá, também há proliferação de escolas de farmácia e aumento do número de farmacêuticos recém-formados (HAWTHORNE e ANDERSON, 2009; RENNIE e ANDERSON, 2013). 


\subsubsection{Mercado brasileiro de trabalho farmacêutico}

Diante da situação global e da escassez de estudos específicos sobre a força de trabalho farmacêutico no Brasil, esta seção traz uma breve análise do mercado de trabalho formal dos farmacêuticos no Brasil na última década, considerando o contexto das transformações do próprio mercado e especialmente do sistema de saúde. Embora tome como ponto de partida a demanda, especialmente os postos de trabalho ocupados pelos farmacêuticos no mercado formal de trabalho, a formação superior (a oferta) será considerada como elemento importante de análise dos fenômenos observados na estrutura e dinâmica do emprego farmacêutico no setor saúde.

No período de 1995 a 2000, caracterizado por retração do mercado de trabalho de algumas profissões de saúde, entre as quais odontologia (-1,3\%), enfermagem ($1,9 \%)$ e serviço social $(-5,4 \%)$, o número de empregos farmacêuticos passou de 30.447 e 40.040, o que significa taxa de crescimento de $31,5 \%$ no período. À exceção dos médicos, que sempre possuem estoques constantes de profissionais no mercado, o farmacêutico passou a figurar entre as profissões que mais cresceram nas últimas décadas (GIRARDI e CARVALHO, 2002; WAN DER MASS et al, 2014).

Em 2013, enquanto metade dos empregos estava distribuído entre médicos (27\%) e enfermeiros (24\%), os farmacêuticos apareceram como a terceira profissão de saúde com maior participação no mercado formal de trabalho do país, com $11 \%$ dos vínculos ativos (BRASIL, 2015a).

Figura 12. Evolução do emprego formal do farmacêutico no Brasil (2003 - 2013).

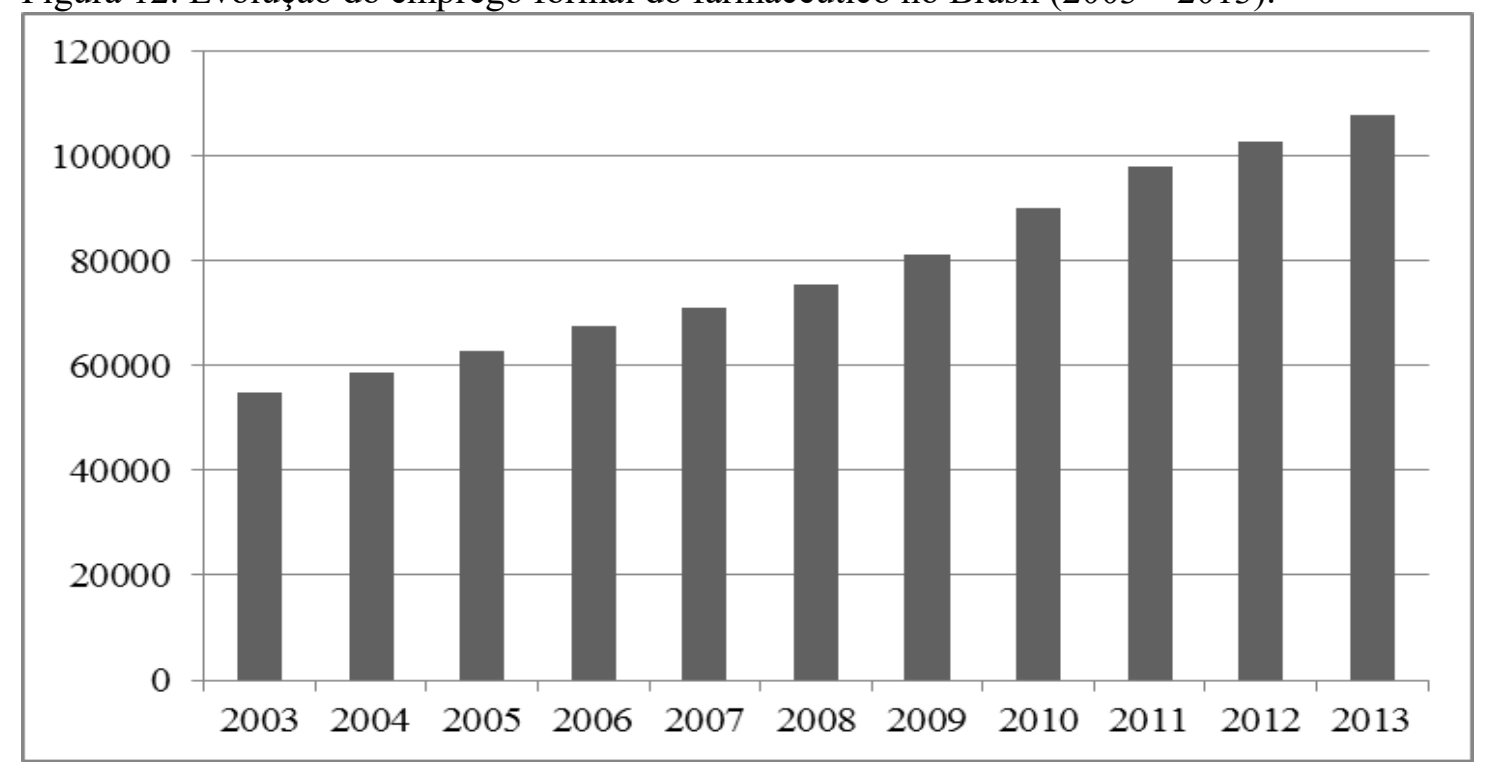

Fonte: MTE - RAIS (BRASIL, 2015a). 
Na figura 12 podemos ver que, entre 2003 e 2013, o número de farmacêuticos no mercado formal passou de 54.990 para 107.785 , o que representa uma taxa de crescimento de $96 \%$. Em consequencia, nota-se o crescimento da razão populacional do número de farmacêuticos, que saiu de 3,1: 10.000, em 2003, para 5,4: 10.000, em 2013. Além disso, se essa década for divida em duas partes, se percebe que houve incremento de aproximadamente 20 mil empregos na primeira metade, e pouco mais de 32 mil empregos e uma taxa de crescimento de $43 \%$ somente na segunda metade.

Embora as regiões Norte, Nordeste e Centro-Oeste tenham apresentado as maiores taxas de crescimento regional do emprego farmacêutico do país no período de 2003 a $2013(194 \%, 126 \%$ e 106\%, respectivamente), os postos de trabalho continuam concentrados no Sudeste, que ocupa $45 \%$ do total de empregos formais do país. Todavia, o desempenho do Nordeste merece destaque: saiu de 9.936 para 22.417 postos de trabalho ocupados no período de 2003 a 2013, ultrapassando a região Sul e assumindo a segunda posição no mercado de trabalho farmacêutico formal, com $21 \%$ do emprego formal do país em 2013 (tabela 7).

Tabela 7. Distribuição regional e taxa de crescimento do emprego formal do farmacêutico no Brasil (2003, 2008, 2013).

\begin{tabular}{lccccccc}
\hline \multirow{2}{*}{ Regiões } & \multicolumn{2}{c}{$\mathbf{2 0 0 3}$} & \multicolumn{2}{c}{$\mathbf{2 0 0 8}$} & \multicolumn{2}{c}{$\mathbf{2 0 1 3}$} & \multirow{2}{*}{ Tx. Cresc. } \\
\cline { 2 - 6 } & $\mathbf{n}$ & $\mathbf{\%}$ & $\mathbf{n}$ & $\mathbf{\%}$ & $\mathbf{n}$ & $\mathbf{\%}$ & (\%) \\
\hline Norte & 2.110 & 04 & 3.442 & 05 & 6.207 & 06 & 194 \\
Nordeste & 9.936 & 18 & 15.132 & 20 & 22.417 & 21 & 126 \\
Centro-Oeste & 4.591 & 08 & 6.238 & 08 & 9.472 & 09 & 106 \\
Sudeste & 27.275 & 50 & 34.930 & 46 & 49.000 & 45 & 80 \\
Sul & 11.078 & 20 & 15.863 & 21 & 20.689 & 19 & 87 \\
\hline Brasil & $\mathbf{5 4 . 9 9 0}$ & $\mathbf{1 0 0}$ & $\mathbf{7 5 . 6 0 5}$ & $\mathbf{1 0 0}$ & $\mathbf{1 0 7 . 7 8 5}$ & $\mathbf{1 0 0}$ & $\mathbf{9 6}$ \\
\hline
\end{tabular}

Fonte: MTE - RAIS (BRASIL, 2015a). Tx. Cresc. = Taxa de Crescimento Bruto.

O emprego no setor público cresceu $107 \%$ no período analisado, passando de 10.520 para 21.733 farmacêuticos, enquanto que o privado cresceu $94 \%$, com variação de 44.470. Regionalmente, o Centro-Oeste ampliou postos de trabalho tanto no setor público quanto no privado. No Norte, o número de empregos no setor público era maior que o privado em 2003 e 2008, e, em 2013, a situação se inverteu, com predomínio do setor privado. O emprego público teve cresceu $148 \%$ e o privado $120 \%$ no Nordeste e as 
regiões Sudeste e Sul perderam postos de trabalho ocupados no período analisado (tabela 8)

Tabela 8. Distribuição regional e taxa de crescimento do emprego formal farmacêuticos no Brasil por natureza jurídica $(2003,2008,2013)$.

\begin{tabular}{lcccccccc}
\hline \multirow{2}{*}{ Regiões } & \multicolumn{2}{c}{$\mathbf{2 0 0 3}$} & \multicolumn{2}{c}{$\mathbf{2 0 0 8}$} & \multicolumn{2}{c}{$\mathbf{2 0 1 3}$} & \multicolumn{2}{c}{ Tx. Cresc, (\%) } \\
\cline { 2 - 8 } & Público & Privado & Público & Privado & Público & Privado & Público & Privado \\
\hline Norte & 1.139 & 971 & 1.952 & 1.490 & 2.502 & 3.705 & 120 & 282 \\
Nordeste & 2.055 & 7.881 & 3.988 & 11.144 & 5.095 & 17.322 & 148 & 120 \\
Centro-Oeste & 776 & 3.815 & 1.136 & 5.102 & 8.240 & 40.760 & 962 & 968 \\
Sudeste & 4.598 & 22.677 & 5.843 & 29.087 & 4.000 & 16.689 & -13 & -26 \\
Sul & 1.952 & 9.126 & 2.608 & 13.255 & 1.896 & 7.576 & -3 & -17 \\
\hline Brasil & $\mathbf{1 0 . 5 2 0}$ & $\mathbf{4 4 . 4 7 0}$ & $\mathbf{1 5 . 5 2 7}$ & $\mathbf{6 0 . 0 7 8}$ & $\mathbf{2 1 . 7 3 3}$ & $\mathbf{8 6 . 0 5 2}$ & $\mathbf{1 0 7}$ & $\mathbf{9 4}$
\end{tabular}

Fonte: RAIS - MTE (BRASIL, 2015a). Tx. Cresc = Taxa de Crescimento Bruto.

\section{A feminização da força de trabalho}

Em um artigo publicado em 1986, o economista André Cezar Médici apontou o rejuvenescimento e a feminização do emprego em saúde como duas grandes tendências do mercado de trabalho no Brasil.

No decênio 1970-80 ocorreu discreto rejuvenescimento dos profissionais de saúde. Aqueles com idade entre 20 e 29 anos passaram de 29,8 para $35,6 \%$ da totalidade desses profissionais. Tal rejuvenescimento, no entanto, é mais nítido no tocante ao pessoal de nível superior, onde os profissionais com menos de 30 anos de idade passam de 14,4 para $26,1 \%$, ocorrendo, também, expressivo aumento na participação dos profissionais com idade entre 30 e 39 anos no conjunto desse segmento da forma de trabalho em saúde (MÉDICI, 1986, p. 64).

A tendência observada por Médici se confirmou: todas as profissões da área da saúde rejuveneceram entre 1991 e 2010 (WERMELINGER et al, 2010).

Segundo dados do Ministério do Trabalho e Emprego (MTE), os farmacêuticos apresentaram aumento da participação da faixa etária entre 18 e 29 anos, especialmente entre 2003 e 2013 , passando de $30 \%(\mathrm{n}=17.217)$ para $40 \%(\mathrm{n}=51.453)$ do total de empregos formais no país (BRASIL, 2015a).

Embora a faixa etária compreendida entre 30 e 49 anos ainda seja predominante no trabalho formal, a participação dos jovens cresceu $80 \%$ no período, se aproximando 
aos patamares atingidos pela faixa de predominante. Para ilustrar melhor esse cenário, em 2003, a diferença entre essas faixas etárias era de 18.115, em 2013, caiu para 7.043 farmacêuticos.

Além de jovem, a força de trabalho da profisssão farmacêutica passou por um processo de feminização, que se refere, normalmente, ao crescimento do número de mulheres em algumas profissões que historicamente eram desempenhadas por homens, como exemplo medicina e odontologia (WERMELINGER et al, 2010; COSTA; DURÃES; ABREU, 2010)

Segundo os Censos 1970 e 2000, a participação feminina no trabalho farmacêutico cresceu de $11,3 \%$ para $63,4 \%$ no período. Enquanto a medicina saiu do mesmo patamar que a farmácia (11,6\%), chegou ao ano 2000 com aproximadamente $35 \%$ de mulheres nos empregos médicos. Já a enfermagem, historicamente feminina, caiu de $95,8 \%$ para $90,4 \%$ no mesmo período (BRASIL, 2007).

Entre 2003 e 2013 houve input de 37.922 mulheres no mercado de trabalho farmacêutico, o que significa uma taxa de crescimento de $102 \%$. A diferença entre homens e mulheres aumentou, passando de 18.850, em 2003, para 41.927, em 2013 (figura 13).

Figura 13. Distribuição de farmacêuticos com vínculo formal ativo, segundo o sexo. Brasil (2003 - 2013).

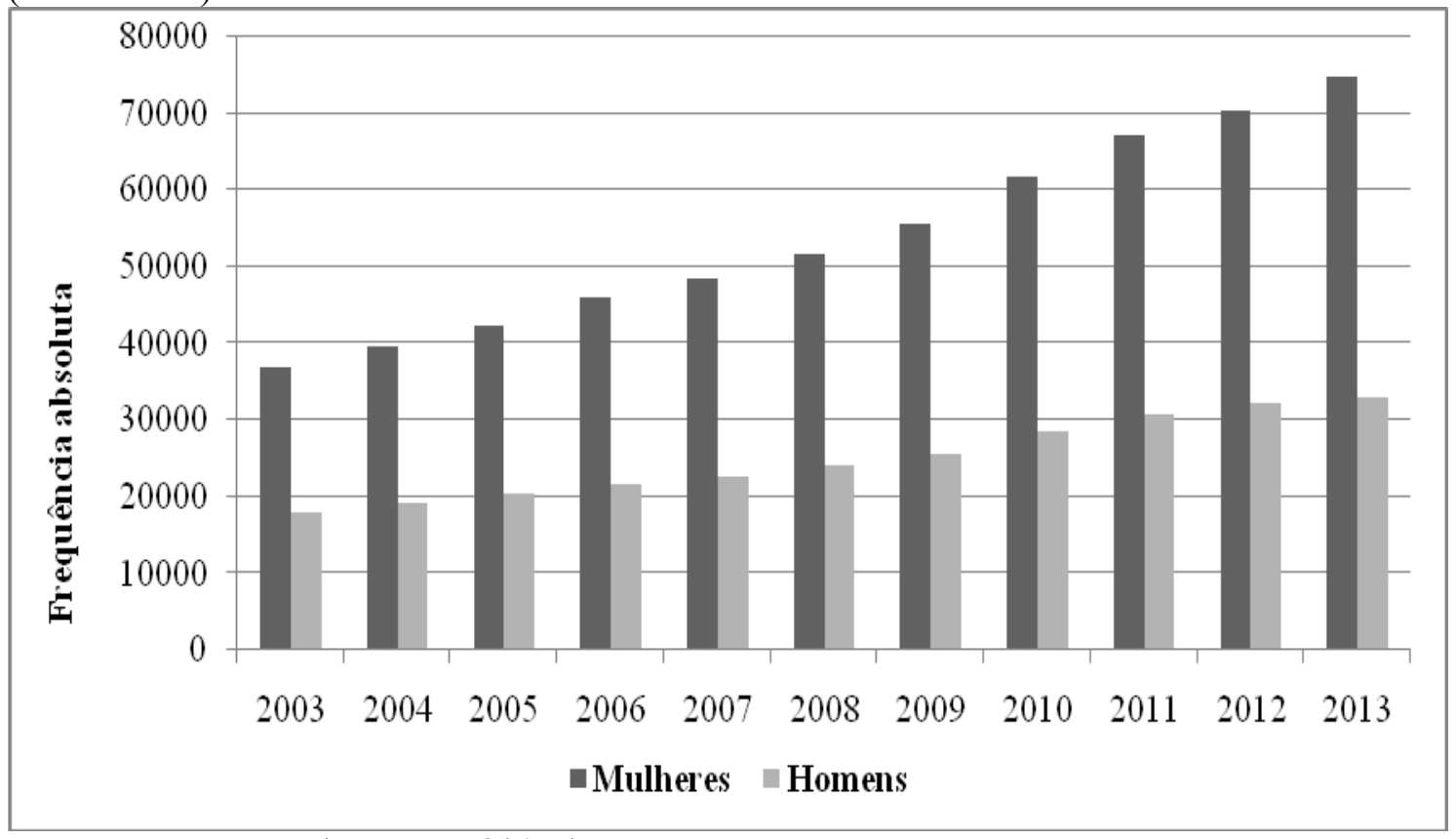

Fonte: RAIS - MTE (BRASIL, 2015a). 
A participação das mulheres na força de trabalho da profissão farmacêutica no Brasil (69\%) se aproxima do nível europeu (70\%), em especial de países como Alemanha, Franca e Itália, e está acima da média das Américas (66\%), superando países como EUA e Canadá (FIP, 2012).

Apesar da feminização do mercado de trabalho, ambos os sexos se distribuem semelhantemente nas faixas etárias. Embora a última década tenha presenciado o crescimento da participação de farmacêuticos com idade inferior aos 30 anos, a faixa situada entre 30 e 49 anos ainda é predominante. Por exemplo, em 2013, havia 38.920 mulheres (57\%) e 18.619 homens (53\%) entre 30 e 49 anos, e 28.944 mulheres (39\%) e 10.295 homens (33\%) entre 18 e 29 anos (BRASIL, 2015a).

O emprego é predominante no setor privado

Apesar da discreta superioridade do setor público em 1982, o emprego formal das profissões de saúde se concentrou historicamente no setor privado, especialmente da assistência médico-hospitalar, como podemos ver no trecho a seguir:

Embora tenha ocorrido expressivo aumento da força de trabalho em saúde, vale destacar o rápido aumento da participação do setor assistência médico-hospitalar privada na absorção do emprego. A participação desse setor aumentou de 22,9 para $34 \%$ no decênio [1970-1980], indicando um incremento bruto real de 196,8\%, contra os $71,7 \%$ encontrados para o conjunto da força de trabalho em saúde alocada aos demais setores (MÉDICI, 1986, p. 66).

A partir da metade da década de 1980, o número de empregos no setor público começa a ultrapassar o privado. Em 1980 havia 265.956 empregos no setor público e 307.679 no privado e em cinco anos esse cenário se inverteu, com o setor público empregando 496.799 trabalhadores e o privado 318.296. Em 2005, o setor público já estava empregando mais de um milhão de trabalhadores. Além do aumento da participação do setor público, se observa que o emprego aumentou na esfera municipal. Entre 1992 e 2005 ocorreu retração na oferta de empregos na esfera federal (- 7,3\%) e aumento do emprego no município (225,3\%). Em 2000, o setor público representava $51 \%$ dos empregos e destes $24,6 \%$ eram municipais e apenas $5,9 \%$ federais. A mudança na oferta de empregos entre os dois setores e o aumento do emprego na esfera municipal se deve, em grande parte, à implantação do Sistema Único de Saúde (SUS), a partir da 
publicação da Lei Orgânica 8.080 de 1990 (GIRARDI e CARVALHO, 2002; MACHADO; OLIVEIRA; MOYSES, 2011).

[Entre 1995 e 2000] os maiores índices de participação do setor público no emprego são observados entre os cirurgiões-dentistas $(72,86 \%)$, médicos $(66,63 \%)$, e assistentes sociais $(61,60 \%)$. Em contrapartida, os menores índices de participação do setor público se dão entre os farmacêuticos e ortoptistas, profissões cujos mercados de trabalho estão baseados principalmente em estabelecimentos privados lucrativos do comércio (GIRARDI e CARVALHO, 2002, p. 13).

Ao contrário da maioria das profissões de saúde, os farmacêuticos estão predominante e historicamente no setor privado lucrativo em função da indústria farmacêutica e, especialmente, do comércio varejista de medicamentos. De acordo com a Classificação Nacional de Atividades Econômicas (CNAE), as farmácias comerciais privadas são classificadas na classe "comercio varejista de produtos farmacêuticos para uso humano e veterinário" e consistem em um dos ramos mais importantes do mercado farmacêutico brasileiro, sendo responsáveis por $76 \%$ dos medicamentos consumidos pela população (BRASIL, 2007).

A abertura de farmácias e drogarias no Brasil possui legislação específica, entre as quais se destaca a lei 5.991, de 1973, que regulamenta comércio de medicamentos no país e exige a presença do farmacêutico durante todo o período de funcionamento da farmácia. Apesar dessa exigência, esses estabelecimentos sempre foram tratados como simples comércio. Esse cenário começou a se modificar a partir de 1990, com a implantação do Sistema Único de Saúde (SUS), publicação da Política Nacional de Medicamentos (PNM) e da "Lei de Genéricos", e a criação da Agência Nacional de Vigilância Sanitária (ANVISA). A idéia central neste momento era ampliar e assegurar o acesso da população a medicamentos eficazes, seguros e de qualidade, ao menor preço possível (BRASIL, 1973; MIZIARA, 2013; OLIVEIRA FILHO, 2013; NISHIJIMA; BIASOTO JR; LAGROTERIA, 2014).

Entre 2006 e 2013, o número de estabelecimentos farmacêuticos cadastrados na base de dados RAIS, do MTE cresceu 24\% no período, passando de 59.378 para 73.895 estabelecimentos no país (BRASIL, 2015a). Esses valores não divergem muito dos dados do Conselho Federal de Farmácia (CFF), segundo o qual o número de farmácias e drogarias registradas até 31 de dezembro de 2013 era de 75.716 estabelecimentos (CFF, 2014). 
O número de farmacêuticos no setor privado passou de 44.470, em 2003, para 86.052, em 2013, enquanto que no publico de 10.520 para 21.733 farmacêuticos empregados no mesmo período. Apesar do predomínio e aumento do emprego privado, especialmente no comercio varejista de farmácia, o número de postos de trabalho ocupados por farmacêuticos no setor público cresceu mais que o privado no período (107\% e $85 \%$, respectivamente). Em 2013, o setor público já representava 20\% do total de postos de trabalho ocupados por farmacêuticos (figura 14).

Figura 14. Distribuição dos farmacêuticos com vínculo formal ativo, segundo a natureza jurídica do estabelecimento. Brasil (2003 - 2013).

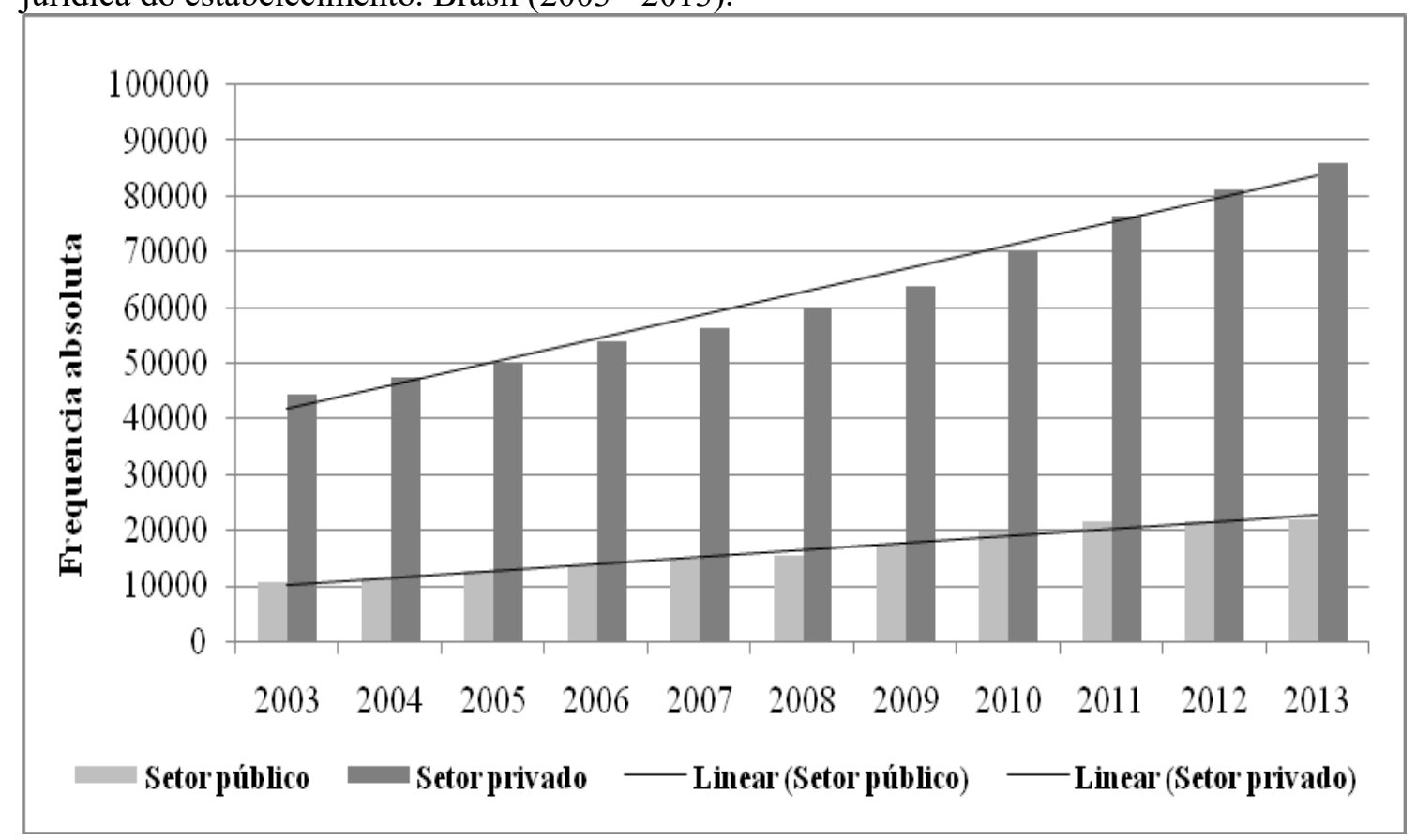

Fonte: RAIS - MTE (BRASIL, 2015a).

Embora, desde a década de 1990, o setor privado corresponda a mais de $80 \%$ dos empregos da profissão farmacêutica (GIRARDI e CARVALHO, 2002), o setor público merece destaque, especialmente a partir de 2008. Na primeira metade do período analisado (2003 a 2008) houve aumento de aproximadamente cinco mil empregos, enquanto que na segunda metade (2008 a 2013), o aumento foi superior a seis mil novos vínculos formais de trabalho (figura 14).

Entre 2007 e 2013, o número de postos de trabalho ocupados por farmacêuticos em estabelecimentos que atendem exclusivamente o SUS, aumentou de 12.122 para 20.264, o que significa um incremento de 67\% (BRASIL, 2015b).

O incremento da força de trabalho dos farmacêuticos deve ser resultado do crescimento do próprio setor saúde, que ampliou a oferta de postos de trabalho na 
última década. No setor publico, "o mercado de trabalho se expandiu largamente via Estratégia de Saúde da Família e atenção primária com prioridade às regiões menos assistidas (Nordeste, Centro-Oeste e Norte)" (FUNDAÇÃO OSWALDO CRUZ, 2012, p. 160).

O fenômeno observado no Brasil é semelhante ao restante do mundo: o farmacêutico trabalha predominantemente nas farmácias. Em 2012, 55\% dos farmacêuticos trabalhavam em farmácias comunitárias, $18 \%$ em hospitais, $10 \%$ na indústria, $5 \%$ na pesquisa e na educação superior e 5\% na regulação. A África é a região com menos de $5 \%$ da força de trabalho na indústria, em contraste com o Sudeste Asiático que mais de $30 \%$ está nesse ramo de atividade (FIP, 2012).

Entre 2008 e 2013, o número de farmacêuticos cadastrados nas UBS cresceu $75 \%$. O desempenho do setor público na ampliação dos postos de trabalho formal do farmacêutico provavelmente se deve à expansão da atenção primária, especialmente das equipes de Saúde da Família e do Núcleo de Apoio à Saúde da Família (NASF), e consequente aumento dos postos de trabalho nos estabelecimentos de saúde pode ter impacto direto no crescimento e distribuição regional das profissões de nível superior. De modo geral, as categorias profissionais que podem compor as equipes NASF, apresentaram crescimento muito superior aos enfermeiros e médicos, com taxas acima de 70\%, como é o caso dos farmacêuticos, fisioterapeutas, nutricionistas, profissionais de educação física e terapeutas ocupacionais (CARVALHO et al, 2016).

\section{A remuneração salarial caiu na última década}

Embora continue nas faixas intermediárias, a remuneração média do farmacêutico no mercado de trabalho formal, expressa em salários mínimos (SM), caiu na última década. Em 2003, quase metade $(n=24.857)$ dos farmacêuticos com emprego formal recebia entre 4,01 e $7 \mathrm{SM}$ e, em 2013, mais da metade $(\mathrm{n}=51.453)$ tinha remuneração média até $4 \mathrm{SM}$. Observa-se na figura 15 que os números de farmacêuticos com remuneração média até 4 SM aumentou, especialmente no período de 2006 a 2010, que cresceu $10 \%$, enquanto que a faixa com as maiores rendas médias caiu pouco mais da metade. 
Figura 15. Distribuição dos farmacêuticos com vínculo formal ativo, segundo a remuneração média em Salários Mínimos (SM). Brasil (2003 - 2013).

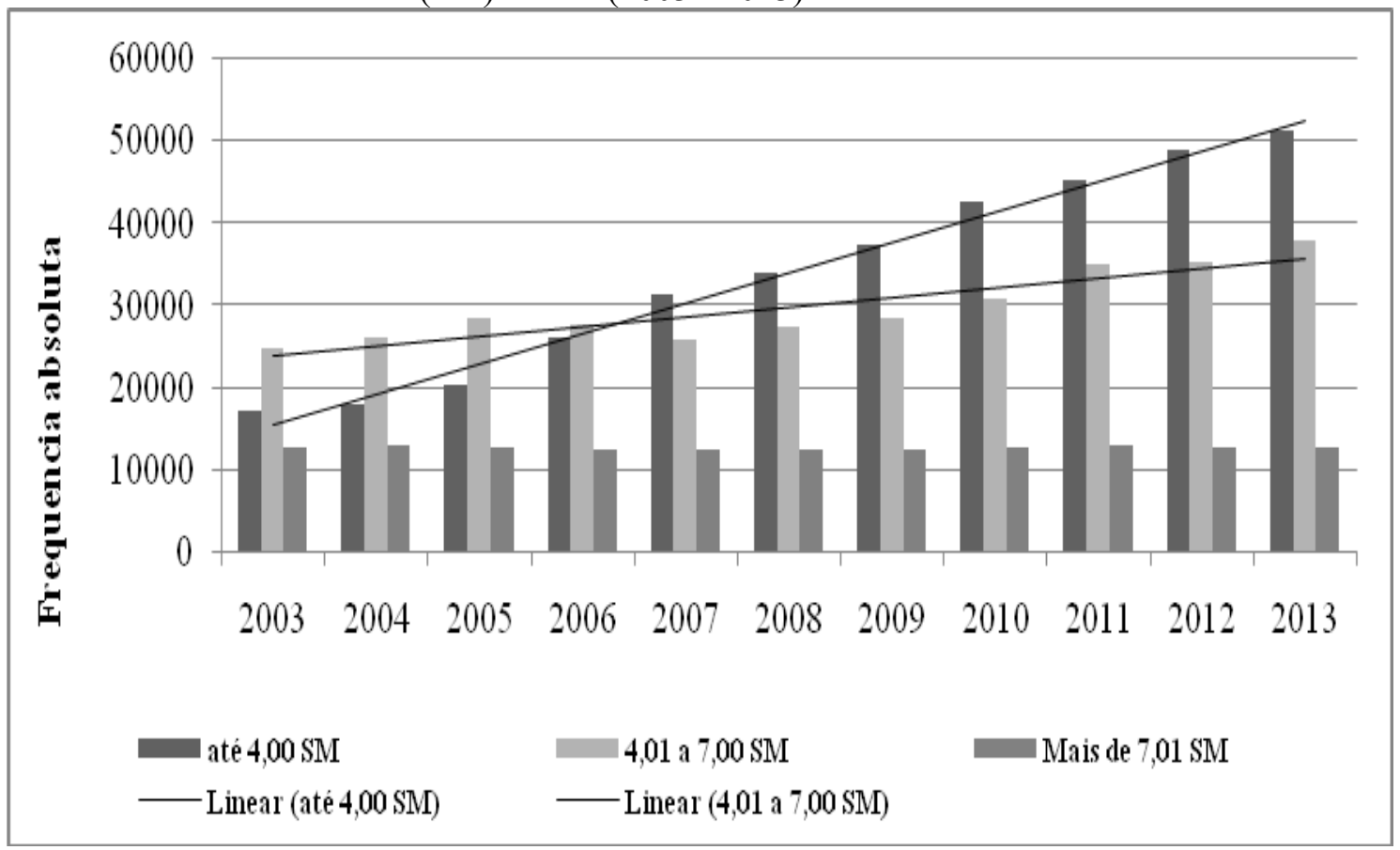

Fonte: RAIS - MTE (BRASIL, 2015a).

De fato, entre 2000 a 2010, a medicina foi a profissão que, proporcionalmente, apresentou o maior número de profissionais recebendo mais de $10 \mathrm{SM}$. A faixa salarial que aumentou a proporção de profissionais incluídos nela é a de 3 a 5 SM, com destaque para os farmacêuticos, que passaram de $15,2 \%$ para $32,1 \%$. Um importante deslocamento de rendimentos ficou a cargo dos nutricionistas, que possuíam $73,4 \%$ de seus profissionais recebendo acima de 5 SM, em 2000, e passaram para 56\% dos profissionais recebendo entre 2 e 5 SM, em 2010 (WAN DER MASS et al, 2014).

Embora a remuneração média em salários mínimos tenha decrescido na última década, especialmente na faixa de mais de $7 \mathrm{SM}$, a remuneração média em reais e a média salarial por hora contratada foi superior no setor público que no privado. Por exemplo, em 2008, a remuneração média no setor público era $\mathrm{R} \$ 2.614,00$ e no privado $\mathrm{R} \$ 1.835,00$, uma diferença de R\$ 779,00. Em 2013, a remuneração média no setor público havia subido para $\mathrm{R} \$ 4.136$ e no privado para $\mathrm{R} \$ 2.682,92$ (diferença de $\mathrm{R} \$$ $1.453,47)$, o que possivelmente se deve ao aumento do número de farmacêuticos com vínculo formal no setor público federal, nas faixas de remuneração entre 10 e $15 \mathrm{SM}$ e 15 e 20 SM, no período definido (BRASIL, 2015; EPSM, 2016). 
A capital brasileira com o menor número de farmacêuticos empregados é Macapá, com 175 profissionais registrados, e São Paulo possui o maior número de empregos formais ativos, com 24.212 vínculos ativos, o que representa $49 \%$ dos empregos da região Sudeste (BRASIL, 2015a).

Os empregos formais dos farmacêuticos estão regionalmente concentrados no Brasil. Em 2013, as regiões brasileiras participaram da seguinte maneira: o Norte com $6 \%$, o Nordeste $21 \%$, o Centro-Oeste $9 \%$, o Sudeste $45 \%$ e o Sul $19 \%$ do mercado de trabalho formal dos farmacêuticos do país (mapa 2).

Mapa 2. Distribuição dos farmacêuticos no mercado formal nas regiões brasileiras em dezembro de 2013.

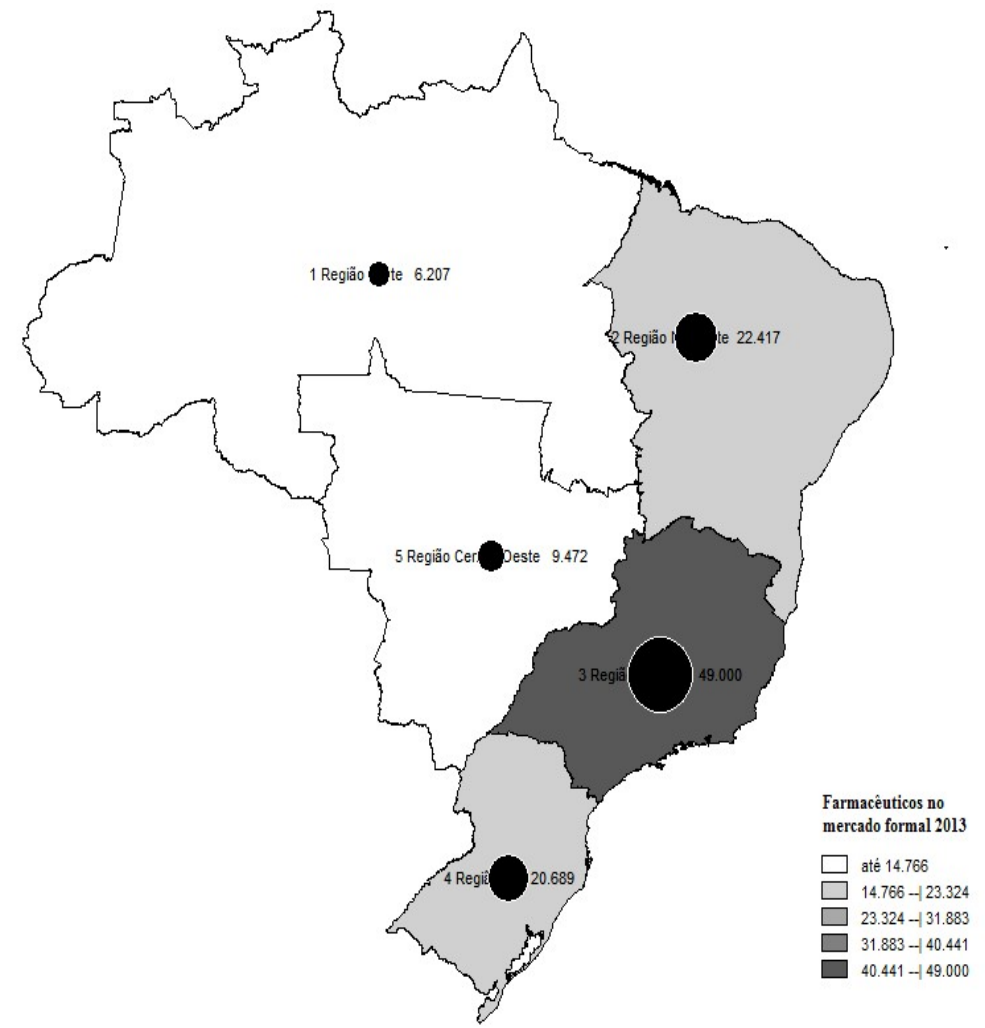

Fonte: RAIS - MTE (BRASIL, 2015a). Elaborado com auxílio do TABWIN®.

Em todas as regiões, a participação é predominantemente feminina, variando de $61 \%$ na região Nordeste a $76 \%$ no Sul do país, e o setor privado é o maior empregador, com variação de $60 \%$ no Norte e $83 \%$ na região Sudeste. Para termos a dimensão da participação dessa região nos empregos privados, somente a cidade de São Paulo 
emprega 18.932 farmacêuticos, o que representa $46 \%$ do total de vínculos formais ativos de trabalho de toda a região (BRASIL, 2015a).

No final da década de 1980, André Cezar Médici e Roberto Passos Nogueira escreveram sobre a distribuição regional dos profisssionais de saúde no país, com concentração na região Sudeste, e especialmente na cidade de São Paulo. Em 1982, a região Sudeste concentrava 55,4\% dos empregos de saúde, com 43,6\% da população, enquanto o Nordeste apenas $20 \%$ dos empregos e $29,1 \%$ da população brasileira. As demais regiões também apresentavam desníveis na proporção emprego/população. Além disso, nas regiões Sudeste e Sul prevaleciam os empregos privados e nas outras regiões, o emprego no setor saúde era predominantemente público (GIRARDI， 1986; NOGUEIRA, 1987).

Há, nitidamente, no Brasil uma concentração geográfica e institucional que conspira contra os princípios de universalidade e descentralização do sistema de saúde. Em 1980, a região sudeste, que apresentava $43 \%$ da população, acumulava nada menos que $55 \%$ dos médicos. Por sua vez, a região nordeste, com $29 \%$ da população, dispunha de $19 \%$ dos médicos. Quanto ao emprego total, em 1983, $45 \%$ dos profissionais trabalhando em estabelecimentos de saúde estavam situados nos estados de São Paulo e Rio de Janeiro, enquanto o Nordeste detinha apenas $20 \%$ do conjunto de 800 mil empregos existentes nesse ano (NOGUEIRA, 1987, p. 335).

De fato, a região Sudeste tem a maior oferta de emprego formal de trabalho e o maior número de escolas, com aproximadamente $45 \%$ os postos de trabalho farmacêutico e $50 \%$ dos cursos de graduação em Farmácia do país.

À semelhança dos EUA e do Reino Unido, o incremento do número de farmacêuticos no Brasil parece ter relação com a expansão das instituições de formação superior em farmácia em todo o país. Como o emprego no Brasil é também predominantemente privado, a abertura dessas instituições deve ser fortemente influenciada pela conformação da cadeia produtiva e do comercio de medicamentos e pelo sistema de saúde (HAWTHORNE e ANDERSON, 2009).

Há uma tendência de ter mais instituições de formação superior em locais com maior possibilidade de expansão do mercado de trabalho, o que, por sua vez, é afetado pela presença dessas instituições. Essa tendência possivelmente explica o fenômeno observado no Brasil, em que a região com o maior número de farmacêuticos tem o maior número de escola. Afinal, o Sudeste possui aproximadamente $50 \%$ dos cursos de Farmácia e concentra o maior número de trabalhadores farmacêuticos do país. 


\section{REFERÊNCIAS}

ANDERSON, C. et al. Education trends, innovations and transformations - Case Studies. In: 2013 FIPEd Global Education Report. 2013. Disponível em http://www.fip.org/files/fip/FIPEd_Global_Education_Report_2013.pdf. Acesso em: 05 out. 2015.

ASSUNCAO, A.A. et al . Recursos humanos e trabalho em saúde: os desafios de uma agenda de pesquisa. Cadernos de Saúde Pública, Rio de Janeiro, v. 23, supl. 2, 2007. Disponível em http://www.scielo.br/scielo.php?script=sci arttext\&pid=S0102311X2007001400009\&lng=pt\&nrm=iso. Acesso em: 14 nov. 2013. http://dx.doi.org/10.1590/S0102-311X2007001400009

BRASIL. Lei $\mathbf{n}^{0}$ 5.991, de 17 de dezembro de 1973. Dispõe sobre o controle sanitário do comércio de drogas, medicamentos, insumos farmacêuticos e correlatos, e dá outras providências. Diário Oficial da Republica Federativa do Brasil, Poder executivo, Brasília, DF, 19 dez 1973, seção I, p. 13.049. Disponível em http://www.paulinia.sp.gov.br/downloads/Lei\%205991_1973.pdf. Acesso em: 17 set. 2014.

BRASIL. Instituto Brasileiro de Geografia e Estatística. Classificação Nacional de Atividades Econômicas. Versão 2.0. Rio de Janeiro, 2007. Disponível em http://www.ibge.gov.br/home/estatistica/economia/classificacoes/cnae2.0/cnae2.0.pdf.

Acesso em: 05 out. 2015.

BRASIL. Ministério da Saúde. Secretaria de Atenção à Saúde. Departamento de Atenção Básica. Política Nacional de Atenção Básica. Brasília: Ministério da Saúde, 2012. Disponível em http://189.28.128.100/dab/docs/publicacoes/geral/pnab.pdf. Acesso em: 10 mar. 2014.

BRASIL. Ministério do Trabalho e Emprego (MTE). Bases Estatísticas RAIS e CAGED. 2015a. Disponível em: http://bi.mte.gov.br/bgcaged/inicial.php. Acesso em: 05 out. 2015.

BRASIL. Departamento de Informática do Ministério da Saúde (DATASUS). 2015b. Disponível em: http://datasus.saude.gov.br/. Acesso em: 05 out. 2015.

CARVALHO, M.N. et al. Necessidade e dinâmica da força de trabalho na atenção básica de saúde no Brasil. Ciência \& Saúde Coletiva, 2016 (no prelo). Disponível em: http://www.cienciaesaudecoletiva.com.br/artigos/artigo_int.php?id_artigo=15457.

Acesso em: 10 jul. 2016.

CONSELHO FEDERAL DE FARMÁCIA (CFF). Entrevista com Walter Jorge da Silva João. Farmácias: uma abordagem sanitária em 21/01/2014. Disponível em http://www.cff.org.br/noticia.php?id=1628. Acesso em: 05 out. 2015.

COSTA, S.M; DURÃES, S.J.A; ABREU, M.H.N.G. Feminização do curso de odontologia da Universidade Estadual de Montes Claros. Rio de Janeiro. Ciência \& Saúde Coletiva, v. 15, n. 1, p. 1865-1873, 2010. Disponível em: http://www.scielo.br/pdf/csc/v15s1/100.pdf. Acesso em: 05 out. 2015. 
COVVEY, J.R.; COHRON, P.P., MULLEN A.B. Examining Pharmacy Workforce Issues in the United States and the United Kingdom. American Journal of Pharmaceutical Education. v. 79, n. 2, p. 1-7, 2015. Disponível em: http://www.ncbi.nlm.nih.gov/pmc/articles/PMC4386738/. Acesso em: 29 fev. 2016.

DUSSAULT, G.; FRANCESCHINI, M.C. Not enough there, too many here: understanding geographical imbalances in the distribution of the health workforce. Human Resources for Health, v. 4, n. 12, p. 1 - 16, 2006. Disponível em http://www.human-resources-health.com/content/4/1/12. Acesso em: 05 out. 2015.

EPSM. Estação de Pesquisa Sinais de Mercado. Disponível em: http://epsm.nescon.medicina.ufmg.br/epsm/. Acesso em: 05 jun 2016.

FUNDAÇÃO OSWALDO CRUZ. A saúde no Brasil em 2030: diretrizes para a prospecção estratégica do sistema de saúde brasileiro. Rio de Janeiro: Fiocruz/IPEA/Ministério da Saúde /Secretaria de Assuntos Estratégicos da Presidência da República, 2012. Disponível em http://andromeda.ensp.fiocruz.br/teias/sites/default/files/biblioteca_home/Saude_Brasil_ 2030.pdf. Acesso em: 05 out. 2015.

FIP. INTERNATIONAL PHARMACEUTICAL FEDERATION. Global Pharmacy Workforce and Migration Report. 2006.

FIP. INTERNATIONAL PHARMACEUTICAL FEDERATION. FIP Global Pharmacy: Workforce Report, 2012. Disponível em: http://www.fip.org/files/members/library/FIP_workforce_Report_2012.pdf. Acesso em: 05 out. 2015.

GIRARDI, S.N. O perfil do "emprego" em saúde no Brasil. Cadernos de Saúde Pública, v. 2, n. 4, 1986. DOI: http://dx.doi.org/10.1590/S0102-311X1986000400003.

GIRARDI, S.N et al. Boletim Sinais de Mercado de Trabalho em Saúde. Ano 11, n. 1. Belo Horizonte: NESCON/UFMG, janeiro a março/2012.

GIRARDI, S.N.; CARVALHO, C.L. Configurações do mercado de trabalho dos assalariados em saúde no Brasil. In: BRASIL. Ministério da Saúde. Formação: Mercado de Trabalho em Saúde, v. 6, p. 15-36, 2002. Disponível em http://bvsms.saude.gov.br/bvs/publicacoes/profae/Revista2006.pdf. Acesso em: 10 set. 2015.

GIRARDI, S.N.; WAN DER MASS, L. Informações sobre Mercado de Trabalho em Saúde: Conceitos e bases de dados. Belo Horizonte: NESCON/UFMG, 2011.

HAWTHORNE, N; ANDERSON, C. The global pharmacy workforce: a systematic review of the literature. Human Resources for Health, v. 7, n. 48, 2009. Disponível em: http://www.human-resources-health.com/content/7/1/48. Acesso em: 05 out. 2015.

MACHADO, M.H; OLIVEIRA, E.S; MOYSES, N.M.N. Tendências do mercado de trabalho em saúde no Brasil. In: PIERANTONI, C.R; POZ, M.R.D; FRANÇA, T. (Orgs.). O Trabalho em Saúde: Abordagens quantitativas e qualitativas. $1^{\mathrm{a}}$ ed. Rio de Janeiro: CEPESC, UERJ, 2011, p. 103-116. Disponível em: 
http://docplayer.com.br/523814-O-trabalho-em-saude-abordagens-quantitativas-equalitativas.html. Acesso em: 05 out. 2015.

MÉDICI, A.C. A força de trabalho em Saúde no Brasil dos anos 70: percalços e tendências. Revista de Administração Pública, v. 20, n. 3, p. 54-69, 1986. Disponível em http://www.spell.org.br/documentos/ver/14757/a-forca-de-trabalho-em-saude-nobrasil-dos-anos-70--percalcos-e-tendencias/i/pt-br. Acesso em: 10 mar. 2014.

MIGUELOTE, V.R.S. et al. Distribuição da Força de Trabalho: eqüidade e negociação. Rio de Janeiro. Physis Revista de Saúde Coletiva. v. 18, n. 2, p. 317-338. 2008. Disponível em http://www.scielo.br/pdf/physis/v18n2/v18n2a07.pdf. Acesso em: 25 ago. 2015.

MIZIARA, N.M. Regulação do mercado de medicamentos: a CMED e a política de controle de preços. São Paulo: USP, 2013. (Dissertação de Mestrado). Disponível em: http://www.teses.usp.br/teses/disponiveis/2/2133/tde-12022014-103446/pt-br.php.

Acesso em: 05 out. 2015.

NISHIJIMA, M.; BIASOTO Jr, G.; LAGROTERIA, E. A competição no mercado farmacêutico brasileiro após uma década de medicamentos genéricos: uma análise de rivalidade em um mercado regulado. Economia e Sociedade, Campinas, v. 23, n. 1, p. 155-186, 2014. Disponível em: http://www.scielo.br/pdf/ecos/v23n1/a06v23n1.pdf. Acesso em: 05 out. 2015.

NOGUEIRA, R.P. A força de trabalho em saúde no contexto da reforma sanitária. Caderno de Saúde Pública, v. 3, n. 3, p. 332-342, 1987. Disponível em: http://www.scielosp.org/scielo.php?script $=$ sci_arttext\&pid=S0102311X1987000300011\&lng=pt. Acesso em: 05 out. 2015.

OLIVEIRA FILHO, J.B. O mercado farmacêutico de varejo no Distrito Federal do Brasil de 2000 a 2012. Brasília: UNB, 2013. (Dissertação de Mestrado). Disponível em:

http://repositorio.unb.br/bitstream/10482/14306/1/2013 JoseBatistaOliveiraFilho.pdf. Acesso em: 05 out. 2015.

ORGANIZAÇÃO MUNDIAL DA SAÚDE. Trabalhando juntos pela saúde. Brasília: Ministério da Saúde, 2007. 210 p. - (Série B. Textos Básicos de Saúde). Disponível em http://www.who.int/whr/2006/06_overview_pr.pdf. Acesso 15 de janeiro de 2014.

PEDUZZI, M. Trabalho e educação na saúde: ampliação da abordagem de recursos humanos. Ciência \& Saúde Coletiva, Rio de Janeiro, v. 18, n. 6, p. 15391541, junho, 2013.

http://www.scielo.br/scielo.php?script=sci arttext\&pid=S1413-

$\underline{81232013000600005 \& \operatorname{lng}=\mathrm{en} \& \mathrm{nrm}=\mathrm{iso}}$. Acesso em: 25 ago. 2015.

PIERANTONI, C.R. et al. Graduações em saúde no Brasil: 2000-2010. Rio de Janeiro: Cepesc: IMS/UERJ, 2012.

RENNIE, T; ANDERSON, C. Oversupply and Under-resourced: The Global Context of Pharmacy Education. American Journal of Pharmceutical Education. v. 77, n. 6, p. 
1-2, 2013. Disponível em: http://www.ncbi.nlm.nih.gov/pmc/articles/PMC3748292/. Acesso em: 29 fev. 2016.

SATURNINO, L.T.M et al. Farmacêutico: um profissional em busca de sua identidade. Rio de Janeiro. Revista Brasileira de Farmácia. 2012, 93(1): 10-16. Disponível em: http://www.rbfarma.org.br/files/rbf-2012-93-1-2.pdf. Acesso em: 05 out. 2015.

SIGRAS. Sistemas de Indicadores das Graduações em Saúde. http://www.obsnetims.org.br/sigras/

WAN DER MAAS, L. et al. Estudo de levantamento de aspectos demográficos, de formação e de mercado de trabalho das profissões de saúde nível superior no Brasil entre 1991 e 2010 (relatório final). Belo Horizonte: UFMG - NESCON, dezembro de 2014. Disponível em http://epsm.nescon.medicina.ufmg.br/epsm/Relate Pesquisa/Mercado $\% 20 \mathrm{de} \% 20$ trabalh o $\% 20$ das $\% 20$ profiss $\%$ C3 $\%$ B5es $\% 20 \mathrm{de} \% 20 \mathrm{sa}^{2} \% \mathrm{C} 3 \%$ BAde $\% 20 \mathrm{de} \% 20 \mathrm{n} \% \mathrm{C} 3 \%$ ADvel $\%$ 20superior\%20no\%20Brasil\%20(Rel.\%20Final).pdf. Acesso em: 05 out. 2015.

WERMELINGER, M. et al. A Força de Trabalho do Setor de Saúde no Brasil: focalizando a feminização. Rio de Janeiro. Revista Divulgação em Saúde para Debate, 2010, 45: 54-70. Disponível em: http://www.ensp.fiocruz.br/observarh/arquivos/A \%20Forca $\% 20 \mathrm{de} \% 20 \mathrm{Trabalho} \% 20 \mathrm{do}$ \%20Setor\%20de\%20Saude\%20no\%20Brasil\%20.pdf. Acesso em: 14 mar. 2014.

WORLD HEALTH ORGANIZATION. A universal truth: no health without a workforce. $\quad$ WHO, $2013 . \quad$ Disponível em http://www.who.int/workforcealliance/knowledge/resources/GHWA AUniversalTruth Report.pdf. Acesso em: 27 abr. 2014.

WORLD HEALTH ORGANIZATION. Human resources for health: foundation for universal health coverage and the post-2015 development agenda: report of the Third Global Forum on Human Resources for Health, p. 10-13 November 2013, Recife, Brazil. WHO, 2014. Disponível em http://www.who.int/workforcealliance/knowledge/resources/report3rd_GF_HRH.pdf?ua $=1$. Acesso em: 27 abr. 2014. 


\section{CAPÍtulo 4 - A FORÇA DE TRABALHO NA ATENÇÃo PRIMÁRIA DE SAÚDE}

"No coração de cada um dos sistemas de saúde, a força de trabalho é central para promover o avanço da saúde"

(Organização Mundial da Saúde).

Este capítulo trata da composição, expansão, diversificação e desigualdade na distribuição da força de trabalho em saúde no âmbito da atenção primária do SUS.

No Brasil, o relatório "A questão dos recursos humanos e a reforma sanitária", de 1987, realçou alguns dos obstáculos para a consolidação da universalização da cobertura e da garantia de equidade das ações de saúde no processo da construção do SUS: a distribuição geográfico-social e institucional dos recursos humanos, que concentrava $56 \%$ dos empregos na região Sudeste e apenas $20 \%$ na região Nordeste; a desigualdade das condições de inserção no mercado de trabalho (segmentação); a formação e a preparação dos recursos humanos; a composição das equipes em que 60 a $70 \%$ do pessoal ocupado nos estabelecimentos de saúde eram médicos e atendentes; e a valorização do profissional (CARVALHO; SANTOS; CAMPOS, 2013).

Desde o início dos anos 90, o SUS é o componente público do sistema de saúde brasileiro, oferece mais de quarenta mil unidades básica de saúde e quase seis mil hospitais, além de centros de atenção psicossocial, academias da saúde, e outros equipamentos distribuídos em todo País, e absorve em torno de $80 \%$ da força de trabalho do setor saúde, o que representa quase dois milhões de empregos. A rede de serviços é o principal empregador de enfermeiros (52\%), médicos (44\%) e cirurgiõesdentistas (27\%), especialmente da atenção primária de saúde e do setor privado complementar. Entre as profissões com menor participação no setor público estão os farmacêuticos (11\%), provavelmente por ser uma profissão com postos de trabalho hegemonicamente localizados em estabelecimentos privados do comércio varejista farmacêutico (PAIM et al, 2011; MENDES, 2013).

Como no Brasil não existem fontes de informação específicas, produzidas de forma periódica, os dados sobre a força de trabalho em saúde podem ser encontrados no basicamente em fontes estatísticas e de registros administrativos. Em 2000, o Ministério da Saúde (MS) implantou uma abrangente e detalhada base de dados acerca dos estabelecimentos de saúde, prestadores ou não do SUS, incluindo a força de trabalho que atua em cada estabelecimento: o CNES. O CNES tem como objetivo a coleta de 
dados sobre infraestrutura, recursos humanos, equipamentos e tipos de serviços. Quanto aos recursos humanos em saúde, é possível extrair diversos dados, entre os quais a ocupação, o tipo de vínculo e a carga horária (SALA; CARRO; SEIXAS, 2010; WAN DER MASS et al, 2014).

Para Ligia Giovanella e colaboradores, existe consenso entre os gestores sobre a oferta insuficiente quantitativa e qualitativamente em diversos países, especialmente na América do Sul, e uma estratégia para superação desse cenário tem sido a cooperação entre os países, sobretudo aqueles que possuem trabalhadores com formação em atenção primária, como é o caso de Cuba. Além da disponibilidade numérica, a disponibilidade para atuar na saúde da família é outro problema relevante para a atenção primária (apud CAVACANTI; NETO; SOUSA, 2015).

Na tentativa de modificar o cenário de escassez e distribuição desigual de trabalhadores nos serviços de saúde no Brasil, apontado por inúmeros relatórios e pesquisas, nacionais e internacionais, o governo federal tem implementado estratégias, programas e projetos dirigidos à reestruturação da atenção primária, como, por exemplo, a Estratégia de Saúde da Família (ESF), o Núcleo de Apoio à Saúde da Família (NASF), o Programa Nacional para Melhoria do Acesso e da Qualidade da Atenção Básica (PMAQ-AB), o Programa de Valorização do Profissional de Atenção Básica (PROVAB) e, mais recentemente, o "Mais Médicos" (LOPES, 2013; RIZZOTO et al, 2014).

\subsection{ATENÇÃO PRIMÁRIA DO SUS}

A década de 1990 foi marcada pela criação do SUS e expansão do mercado de trabalho no setor saúde no Brasil, sobretudo na esfera municipal. Em 1999, os municípios detinham 92\% dos estabelecimentos públicos do país, enquanto os níveis federal e estadual apenas $2 \%$ e $6 \%$, respectivamente. O emprego público no nível municipal cresceu 700\% entre 1992 e 2005 (VARELLA e PIARENTONI, 2008).

Logo após a criação do SUS, a atenção primária ganhou centralidade no modelo de atenção à saúde com a implantação do Programa Saúde da Família (PSF). De fato, o PSF foi iniciado em 1991 com o Programa de Agentes Comunitários de Saúde (PACS). Em janeiro de 1994 foram formadas as primeiras equipes de Saúde da Família, que posteriormente passaram a ter o Agente Comunitário de Saúde (ACS) como membro. Anos mais tarde, esse programa passou a ESF, prioritária para a reorganização do SUS, 
centralizada na saúde do individuo, da família e da comunidade, tendo a Unidade Básica de Saúde (UBS) como o estabelecimento de referência para as equipes de saúde (GIL, 2006; ABRAHÃO, 2007; SUMAR e FAUSTO, 2014).

Embora tenha se inspirado em outros modelos orientados pela família, alguns autores o consideram original, especialmente por considerar o trabalho em equipe multiprofissional como base de estruturação e organização, como refere Francisco Eduardo Campos e colaboradores no trecho a seguir:

(...) o PSF no Brasil, mesmo baseado nas idéias de atenção primária, prevenção de doenças e promoção da saúde aceitas internacionalmente, é original e inédito em sua concepção, não havendo registro de modelos semelhantes em outros países. Diferentemente da medicina familiar vigente em vários países da Europa, no Canadá e na Oceania, o PSF pressupõe o trabalho multiprofissional e em equipe como processo básico para a integralidade do cuidado na atenção primária à saúde (apud SOUSA e HAMANN, 2009, p. 1328).

A implantação da ESF exigiu dos municípios a contratação de um grande número de profissionais para a estruturação das equipes, que são responsáveis pelo acompanhamento de um número de famílias em um determinado território por meio de ações de promoção, prevenção, recuperação e reabilitação de doenças e agravos mais frequentes e na manutenção da saúde da comunidade (BRASIL, 1997; BRASIL, 2012a).

As UBS são estabelecimentos do SUS destinados ao atendimento da atenção básica e integral de uma população adstrita, de forma programada ou não, que podem oferecer assistência odontológica e de outros profissionais de nível superior. As UBS podem ou não ter equipe de Saúde da Família (eqSF) e são indispensáveis à realização das ações de atenção básica nos municípios e no Distrito Federal. Cada UBS sem eqSF deve abranger, no máximo, 18 mil habitantes, enquanto que as com eqSF devem atender, no máximo, 12 mil habitantes, o que significa que cada equipe deve se responsabilizar por, no máximo, 4 mil pessoas, podendo chegar a 3 mil ou menos de acordo com o grau de vulnerabilidade (BRASIL, 2011; BRASIL, 2012a).

Entre 1981 e 2008, o número de pessoas que buscou atendimento na atenção básica aumentou cerca de $450 \%$, fato que se deve a criação do SUS, ao crescimento do número de UBS e na ampliação da força de trabalho em saúde (PAIM et al, 2011). Em 2008, o MS implantou o Núcleo de Apoio à Saúde da Família (NASF) composto por 
profissionais de diferentes áreas de conhecimento, que devem atuar em parceria com as eqSF, com o objetivo de ampliar e diversificar as ações da atenção básica (BRASIL, 2008; BRASIL, 2012a).

A ESF significou a expansão da força de trabalho de nível superior na atenção básica. Além de ordenadora do modelo de sistema de saúde, essa estratégia incrementou o número de profissionais de saúde nos estabelecimentos de saúde e, consequentemente, ampliou a cobertura populacional do sistema de saúde no país. Em 1994 foram implantadas 328 equipes para a cobertura de um milhão de pessoas. Em 2012 havia quase 40 mil eqSF implantadas - e mais de 3 mil NASF - em todas as regiões do país, o que representa a cobertura de aproximadamente 120 milhões de pessoas (BRASIL, 2012a).

De fato, entre 2008 a 2013, enquanto a população brasileira passou de 189.614.814 para 201.062.789 habitantes e cresceu a uma taxa de $6 \%$ no período, as UBS passaram de 30.157 para 34.009 unidades, com taxa de crescimento de $13 \%$, e as eqSF cresceram $18 \%$, com um incremento aproximado de cinco mil equipes no sistema de saúde. Além disso, foram implantadas quase três mil equipes NASF (eqNASF) no país no período (tabela 10).

Tabela 9. Evolução da rede assistencial e equipes da atenção básica do SUS.

\begin{tabular}{lcccc}
\hline Rede Assistencial & Dez/2008 & Dez/2013 & Variação (n) & Tx. Cresc. (\%) \\
\hline UBS (unidades) & 30.157 & 34.009 & 3.852 & 13 \\
eqSF implantadas & 29.346 & 34.715 & 5.369 & 18 \\
eqNASF implantadas & - & 2.767 & 2.767 & - \\
\hline
\end{tabular}

Fonte: Adaptado de Carvalho et al (2016). eqSF $=$ Equipe de Saúde da Família; eqNASF $=$ Equipe do Núcleo de Apoio à Saúde da Família. Tx. Cresc. = Taxa de Crescimento Bruto

Segundo a PNAB, cada eqSF deve ser responsável por, no máximo, 4.000 pessoas, sendo a média recomendada de 3.000, respeitando critérios de equidade para essa definição. O cadastramento de cada profissional de saúde deve ser feito em apenas uma eqSF, exceção somente para o profissional médico, que poderá atuar em, no máximo, duas eqSF e com carga horária total de 40 horas semanais (BRASIL, 2012a).

As eqSF contemplam a inserção de médicos generalistas ou de família e comunidade, enfermeiros, auxiliares e técnicos em enfermagem e ACS. Em menor número, as equipes de Saúde Bucal tipo I e II, compostas pelos cirurgiões dentistas, auxiliares e técnicos em saúde bucal. Por fim, as equipes NASF tipo I, II e III, cuja 
composição varia de acordo com a carga horária e composição das equipes nas diferentes realidades locais. O MS recomenda que, nos grandes centros urbanos, as UBS sem ESF atendam no máximo 18 mil habitantes e com a ESF, até 12 mil habitantes (BRASIL, 2012a).

Em 2012, o MS criou a terceira modalidade, o NASF 3, permitindo que qualquer município implante eqNASF desde que tenha, pelo menos, uma eqSF e redefiniu os parâmetros de composição das modalidades de NASF - por exemplo, a carga horária de 20 horas foi estendida para todas as profissões (BRASIL, 2012a; BRASIL, 2012b; SANTOS e BENEDETTI, 2012).

A cobertura da ESF ultrapassou 60\% da população em 2015, com mais de 40 mil eqSF implantadas e atendimento de aproximadamente 130 milhões de brasileiros (CARVALHO et al, 2016).

\subsection{REDES DE ATENÇÃO À SAÚDE}

Os sistemas de atenção à saúde no mundo são dominados por sistemas fragmentados, que conceitualmente são aqueles que se organizam através de um conjunto de pontos de atenção isolados e sem ou quase nenhuma comunicação entre si, que dificilmente conseguem prestar atenção integral à população (MENDES, 2010).

Nesse sentido, um dos princípios doutrinários mais desafiadores do SUS é, sem dúvida, a integralidade, que significa grosso modo atender as necessidades de saúde das pessoas de forma integral, compreendendo que ela está inserida em um contexto social e, portanto, possivelmente precisam de um conjunto de ações e serviços com características variadas, diferentes níveis de densidade tecnológica, desde a promoção da saúde e prevenção de agravos até cura e reabilitação. Mas como garantir a integralidade num sistema de saúde em um país tão grande e regionalmente diverso?

Entre os princípios organizativos do SUS está a descentralização, orientada em direção aos municípios, em função da necessidade de garantir a implantação da atenção básica, especialmente volta aos cuidados primários de saúde de uma determinada comunidade.

Nesse contexto, o SUS foi inicialmente organizado em níveis de atenção (básica, secundária e terciária), nos quais foram estruturadas redes de estabelecimentos e serviços de saúde, que deveriam se comunicar entre si no mesmo nível de atenção e entre níveis diferentes. Em linhas gerais, por exemplo, os municípios deveriam 
organizar suas redes de serviços da atenção básica/primária, enquanto que os estados e o governo federal estruturariam redes de serviços especializados e de hospitais.

A partir da publicação da Norma Operacional Básica (NOB) em 1996, os gestores municipais passaram a receber recursos financeiros para assumir a rede de serviços básicos de saúde e até a rede hospitalar pública e privada conveniada, caso atendesse as exigências estabelecidas pela norma, e a municipalização do SUS começou a se efetivar no país (BODSTEIN, 2002).

Apesar do número expressivo de estabelecimentos e serviços de saúde, distribuídos em todas as regiões brasileiras - mais de 40 mil UBS, quase seis mil hospitais, 60 mil ambulatórios contratados e 2.500 Centros de Atenção Psicossocial (CAPS), a organização por níveis de atenção promoveu a configuração de um sistema de saúde fragmentado, composto por redes paralelas e pouco conectadas entre si, administradas por esferas diferentes de gestão que, apesar dos instrumentos e espaços de negociação, estabelecem arranjos e pactuação que nem sempre garantem a oferta da atenção integral aos usuários (BRASIL, 2014).

Quase quinze anos depois da NOB 96, o MS publicou a portaria 4.279 que estabelece a Rede de Atenção a Saúde (RAS) como uma estratégia de reestruturação do sistema de saúde e a define como:

\footnotetext{
Arranjos organizativos de ações e serviços de saúde, de diferentes densidades tecnológicas, que integradas por meio de sistemas de apoio técnico, logístico e de gestão, buscam garantir a integralidade do cuidado. Fundamenta-se na compreensão da APS como primeiro nível de atenção, enfatizando a função resolutiva dos cuidados primários sobre os problemas mais comuns de saúde e a partir do qual se realiza e coordena o cuidado em todos os pontos de atenção. Os pontos de atenção a saúde são entendidos como espaços onde se ofertam determinados serviços de saúde, por meio de uma produção singular (BRASIL, 2014, p. 18).
}

A nova PNAB, publicada 2012, reforçou que a atenção básica deve ser a principal porta de entrada do SUS e o centro de comunicação com toda a RAS, ordenando fluxos e contra fluxos de pessoas, de produtos e de informações entre os diferentes componentes das redes, sendo coordenadora do cuidado. Além disso, a estrutura operacional da RAS é composta por pontos de atenção, pontos de apoio terapêutico e diagnóstico, sistemas de apoio e sistemas logísticos. Os pontos de atenção são os locais em que se ofertam ações e serviços de saúde e são igualmente importantes para que se cumpram os objetivos da rede de atenção à saúde e se diferenciam, apenas, 
pela densidade tecnológica empregada no cuidado em saúde (por exemplo, domicílio e UBS), enquanto que os sistemas de apoio são os lugares institucionais da rede em que se prestam serviços comuns a todos os pontos de atenção à saúde, entre os quais estão o sistema de assistência farmacêutica que envolve a organização dessa assistência em todas as suas etapas (seleção, programação, aquisição, armazenamento, distribuição, prescrição, dispensação e promoção do uso racional de medicamentos) e os sistemas de informação em saúde (BRASIL, 2010; BRASIL, 2014).

Para Mendes (2010), as RAS devem basicamente ter missão e objetivos comuns, operar de forma cooperativa e interdependente, promover trocas constantes dos seus recursos e garantir atenção integral com intervenções promotoras da saúde, preventivas, curativas, cuidadoras, reabilitadoras e paliativas, gerando valor para a sua população, o que é depende do estabelecimento de relação entre os diferentes componentes da rede sem qualquer hierarquia, porque todos os pontos de atenção à saúde são igualmente importantes e se relacionam horizontalmente.

As RAS ainda estão em estruturação no país e as equipes de saúde da atenção básica (por exemplo, eqSF e eqNASF) devem desenvolver suas atividades com a perspectiva de integração horizontal e vertical do SUS, concebendo assim uma rede de cuidado integral a saúde das pessoas, das famílias e da comunidade.

\subsection{EXPANSÃO E DIVERSIFICAÇÃO DA FORÇA DE TRABALHO}

O período de 2005 a 2010 foi marcado pela expansão do SUS, o que resultou, de um lado, no incremento na participação dos municípios e relativa queda da União no total de empregos públicos em saúde, com destaque para o crescimento dos empregos na atenção primária e o aumento da escolaridade dos trabalhadores (MACHADO et al, 2011).

Nesse contexto, esta seção tem como objetivo descrever a força de trabalho de nível superior cadastrada nas UBS, nos últimos cinco anos, visando à contribuição para o debate sobre o planejamento e dimensionamento da força de trabalho em saúde no SUS.

\subsubsection{A força de trabalho global}


Além do processo de descentralização da gestão, o mercado de trabalho em saúde foi diretamente impactado pela reestruturação do modelo de atenção à saúde, com a criação dos programas PACS, em 1991, e PSF, em 1994, pelo MS (BRASIL, 2006a), o que possivelmente explica os resultados sobre a força global de trabalho nas UBS em 2008 e 2013 demonstrados na tabela a seguir.

Tabela 10. Número absoluto, percentual e taxa de crescimento bruto dos trabalhadores cadastrados nas UBS (Brasil, 2008/2013).

\begin{tabular}{llllll}
\multirow{2}{*}{ Ocupação } & \multicolumn{2}{c}{2008} & \multicolumn{2}{c}{2013} & \multirow{2}{*}{ Tx. Cresc. (\%) } \\
\cline { 2 - 5 } & & n & $\%$ & n & $\%$
\end{tabular}

\begin{tabular}{|c|c|c|c|c|c|}
\hline \multicolumn{6}{|l|}{ Nível superior } \\
\hline Assistente Social & 5.193 & 2,6 & 6.754 & 2,9 & 30,1 \\
\hline Cirurgião-Dentista & 39.392 & 19,6 & 42.634 & 18,4 & 8,2 \\
\hline Enfermeiro & 44.723 & 22,3 & 55.468 & 23,9 & 24,0 \\
\hline Farmacêutico \pm & 2.771 & 1,4 & 4.860 & 2,1 & 75,4 \\
\hline Fisioterapeuta & 5.188 & 2,6 & 9.248 & 4,0 & 78,3 \\
\hline Fonoaudiólogo & 2.179 & 1,1 & 3.377 & 1,5 & 55,0 \\
\hline Médico & 89.609 & 44,7 & 92.290 & 39,7 & 3,0 \\
\hline Nutricionista & 3.306 & 1,6 & 6.055 & 2,6 & 83,2 \\
\hline Psicólogo & 6.516 & 3,2 & 9.303 & 4,0 & 42,8 \\
\hline Outros & 5.324 & 0,8 & 2.486 & 0,9 & $-53,3$ \\
\hline Total & 204.201 & 100,0 & 232.475 & 100,0 & 13,8 \\
\hline
\end{tabular}

\begin{tabular}{lccccc}
\hline Nível médio & \multicolumn{5}{c}{ ( } \\
\hline Auxiliar de Enfermagem & 45.144 & 42,8 & 35.514 & 48,8 & $-21,3$ \\
Técnico em Enfermagem & 24.068 & 22,8 & 22.711 & 31,2 & $-5,6$ \\
Técnico em Farmácia & 586 & 0,6 & 1.618 & 2,2 & 176,1 \\
Técnico em Higiene Dental & 1.509 & 1,4 & 1.555 & 2,1 & 3,0 \\
Outros & 13.440 & 12,7 & 11.331 & 15,6 & $-15,7$ \\
Total & $\mathbf{1 0 5 . 4 6 1}$ & $\mathbf{1 0 0 , 0}$ & $\mathbf{7 2 . 7 2 9}$ & $\mathbf{1 0 0 , 0}$ & $\mathbf{- 3 1 , 0}$ \\
\hline Nível elementar & & & & & \\
\hline ACS & 218.265 & 93,5 & 250.157 & 93,6 & 14,6 \\
Parteira & 216 & 0,1 & 76 & - & $-64,8$ \\
Outros & 14.909 & 6,4 & 17.149 & 6,4 & 15,0 \\
Total & $\mathbf{2 3 3 . 3 9 0}$ & $\mathbf{1 0 0 , 0}$ & $\mathbf{2 6 7 . 3 8 2}$ & $\mathbf{1 0 0 , 0}$ & $\mathbf{1 4 , 6}$ \\
\hline
\end{tabular}

Fonte: DATASUS (2014). \pm Excluídos os farmacêuticos-bioquímicos. Tx. Cresc. $=$ Taxa de Crescimento Bruto. 
Em 2008, a força global de trabalho nos estabelecimentos de saúde da atenção primária do país estava composta majoritariamente por trabalhadores de nível elementar (43\%), seguidos por profissionais de nível superior (37\%) e de nível médio (19\%). Em 2013, se observa o crescimento da participação dos trabalhadores dos níveis elementar (47\%) e superior (40\%), e queda do percentual de técnicos e auxiliares (13\%), como demonstrado na tabela 10 .

Entre os trabalhadores de nível superior, enfermeiros, médicos e cirurgiõesdentistas são as três categorias profissionais hegemônicas na atenção primária do SUS. Contudo, nutricionistas e fisioterapeutas apresentaram as maiores taxas de crescimento entre 2008 e 2013 (148\% e 108\%, respectivamente), embora representem apenas 3\% e $5 \%$ do total da força de trabalho com formação superior. Os técnicos em farmácia estão entre os trabalhadores de nível médio que mais cresceram no período analisado $(176,1 \%)$, embora representem aproximadamente $2 \%$ da força de trabalho de nível médio, que, por sua vez, é predominantemente composta por auxiliares $(48,8 \%)$ e técnicos de enfermagem (31,2\%). Já no nível elementar, os ACS representam mais de $90 \%$ da força de trabalho desse nível de escolaridade, e cresceram a uma taxa de $14,6 \%$ no período analisado (tabela 10).

\subsubsection{A diversificação da força de trabalho de nível superior}

A composição interna da força de trabalho em saúde nas décadas de 90 e 2000 se diversificou e novas categorias de profissionais de nível superior foram incluídas, como, por exemplo, fonoaudiólogos e fisioterapeutas (GIRARDI e CARVALHO, 2002).

Entre 2008 e 2013, a população do país cresceu a uma taxa de 6\%, as UBS cadastradas no CNES de $12 \%$ e o número de profissionais de nível superior cadastrados nesses estabelecimentos de $24 \%$, o que significa expansão da capacidade instalada, aumento do número de postos de trabalho e possibilidade de ampliação da força de trabalho de todas as categorias de profissionais de nível superior nesse tipo de estabelecimento de saúde no âmbito do SUS.

Com a finalidade de ampliar das ações da atenção primária, o MS criou os NASF por meio da portaria $n^{0} 154$, de 24 de janeiro de 2008, que são equipes compostas por profissionais de diferentes áreas de conhecimento, com atuação em parceria com os profissionais eqSF, nas modalidades NASF 1 e NASF 2 (BRASIL, 2008). 
Quatro anos depois, com a publicação da portaria 3.124 de dezembro de 2012, o MS estabeleceu uma terceira modalidade de equipe - o NASF 3, permitindo que qualquer município do Brasil implante equipes NASF, desde que tenha ao menos uma eSF (BRASIL, 2012b).

A composição de cada um dos NASF é definida pelos gestores municipais, segundo critérios de prioridade identificados a partir dos dados epidemiológicos e das necessidades locais e das equipes de saúde que serão apoiadas. Podem compor equipes NASF, as seguintes ocupações: assistente social, profissional/professor de educação física, farmacêutico, fisioterapeuta, fonoaudiólogo, médico (acupunturista, ginecologista/obstetra, homeopata, pediatra, psiquiatra, geriatra, internista/clinica médica), nutricionista, psicólogo, terapeuta ocupacional, médico do trabalho, médico veterinário, profissional com formação em arte e educação (arte educador) e profissional de saúde sanitarista (BRASIL, 2008; BRASIL, 2012b; BRASIL, 2015), conforme resumido no quadro a seguir.

Quadro 2. Modalidades do Núcleo de Apoio à Saúde da Família (NASF).

\begin{tabular}{|c|c|c|}
\hline MODALIDADES & $\begin{array}{c}\text { No DE EQUIPES }^{\circ} \\
\text { VINCULADAS }\end{array}$ & $\begin{array}{l}\text { SOMATÓRIO DAS CARGAS } \\
\text { HORÁRIAS PROFISSIONAIS }\end{array}$ \\
\hline NASF 1 & $\begin{array}{l}5 \text { a } 9 \text { eqSF ou } \text { eAB para } \\
\text { populações } \\
\text { (eqCR, eqSFR e eqSFF) }\end{array}$ & $\begin{array}{l}\text { - Mínimo } 200 \text { horas semanais; } \\
\text { Cada ocupação deve ter no mínimo 20h } \\
\text { e no máximo } \mathbf{8 0 h} \text { de carga horária } \\
\text { semanal; }\end{array}$ \\
\hline NASF 2 & $\begin{array}{l}3 \text { a } 4 \text { eqSF e/ou eAB para } \\
\text { populações } \\
\text { (eqCR, eqSFr e eqSFíficas }\end{array}$ & $\begin{array}{l}\text { - Mínimo } 120 \text { horas semanais; } \\
\text { Cada ocupação deve ter no mínimo } 20 \mathrm{~h} \\
\text { e no máximo } 40 \mathrm{~h} \text { de carga horária } \\
\text { semanal; }\end{array}$ \\
\hline NASF 3 & $\begin{array}{l}1 \text { a } 2 \text { eqSF e/ou eqAB para } \\
\text { populações } \\
\text { (eqCR, eqSFr e eqSFF) }\end{array}$ & $\begin{array}{l}\text { - Mínimo } 80 \text { horas semanais; } \\
\text { Cada ocupação deve ter no mínimo } 20 \mathrm{~h} \\
\text { e no máximo } 40 \text { h de carga horária } \\
\text { semanal; }\end{array}$ \\
\hline
\end{tabular}

Fonte: Departamento de Atenção Básica do Ministério da Saúde. Extraído de http://dab.saude.gov.br/portaldab/ape nasf.php (BRASIL, 2016). eqSF = equipe de Saúde da Família; eqAB = equipe de Atenção primária; eqCR = equipes de Consultório de Rua; eqSFR = equipe de Saúde da Família Rural; eqSFF = equipe de Saúde da Família Fluvial. 
As ocupações de nível superior cadastradas nas UBS tiveram incremento de 31.524 trabalhadores e cresceram em torno de $16 \%$ no período estudado. Embora médicos, enfermeiros e cirurgiões-dentistas sejam as profissões hegemônicas nesses serviços de saúde, ocupando respectivamente 39,7\%, 23,9\% e 18,4\% dos postos de trabalho, tiveram as menos taxas de crescimento no período de 2008 a 2013 (tabela 11).

Tabela 11. Ocupações de nível superior cadastradas nas UBS. Brasil (2008/2013).

\begin{tabular}{|c|c|c|c|c|c|c|}
\hline \multirow{2}{*}{ Ocupação } & \multicolumn{2}{|c|}{ Dez/08 } & \multicolumn{2}{|c|}{ Dez/13 } & \multirow{2}{*}{ Variação } & \multirow{2}{*}{ Tx. Cresc. } \\
\hline & $\mathbf{n}$ & $\%$ & $\mathbf{n}$ & $\%$ & & \\
\hline \multicolumn{7}{|l|}{ eqSF } \\
\hline Cirurgião-Dentista & 39.392 & 19,6 & 42.634 & 18,4 & 3.242 & $8,2 \%$ \\
\hline Enfermeiro & 44.723 & 22,3 & 55.468 & 23,9 & 10.745 & $24,0 \%$ \\
\hline Médico & 89.609 & 44,7 & 92.290 & 39,7 & 2.681 & $3,0 \%$ \\
\hline \multicolumn{7}{|l|}{ eqNASF } \\
\hline Assistente Social & 5.193 & 2,6 & 6.754 & 2,9 & 1.561 & $30,1 \%$ \\
\hline Farmacêutico* & 2.771 & 1,4 & 4.860 & 2,1 & 2.089 & $75,4 \%$ \\
\hline Fisioterapeuta & 5.188 & 2,6 & 9.248 & 4,0 & 4.060 & $78,3 \%$ \\
\hline Fonoaudiólogo & 2.179 & 1,1 & 3.377 & 1,5 & 1.198 & $55,0 \%$ \\
\hline M. Veterinário & 565 & 0,3 & 273 & 0,1 & -292 & $-51,7 \%$ \\
\hline Nutricionista & 3.306 & 1,6 & 6.055 & 2,6 & 2.749 & $83,2 \%$ \\
\hline Prof. Ed. Física \pm & 98 & - & 240 & 0,1 & 142 & $144,9 \%$ \\
\hline Psicólogo & 6.516 & 3,2 & 9.303 & 4,0 & 2.787 & $42,8 \%$ \\
\hline T. Ocupacional & 695 & 0,3 & 1.244 & 0,5 & 549 & $79,0 \%$ \\
\hline \multicolumn{7}{|l|}{ Outros } \\
\hline Biólogo & 433 & 0,2 & 187 & 0,1 & -246 & $-56,8 \%$ \\
\hline Biomédico & - & - & 259 & 0,1 & 259 & - \\
\hline Brasil & 200.668 & 100,0 & 232.192 & 100,0 & 31.524 & $15,7 \%$ \\
\hline
\end{tabular}

Fonte: DATASUS (2014). M. Veterinário = Médico Veterinário; T. Ocupacional $=$ Terapeuta Ocupacional. Tx. Cresc. $=$ Taxa de Crescimento Bruto.

Já as categorias profissionais de menor participação na composição da força de trabalho nas UBS, com percentuais em torno de 0,1 a $3 \%$, tiveram taxas de crescimento de aproximadamente $50 \%$ a $150 \%$, como é o caso de fonoaudiólogos (55\%), farmacêuticos (75\%), fisioterapeutas (78\%), terapeutas ocupacionais (79\%), nutricionistas (83\%) e profissionais/professores de educação física (145\%). Algumas 
profissões experimentaram crescimento negativo, como, por exemplo, a medicina veterinária (tabela 11).

O estudo de Nunes et al (2015), realizado em municípios de pequeno porte no estado do Paraná, também identificou a presença marcante de equipes multiprofissionais nas UBS. Além dos profissionais das equipes mínimas da ESF, havia fisioterapeutas, médicos veterinários, psicólogos, nutricionistas, fonoaudiólogos, assistentes sociais, etc.

Esses profissionais têm potencial para exercer e apoiar ações de promoção, proteção e vigilância à saúde. Assim, a diversidade de categorias profissionais sugere, ainda que incipientemente, a perspectiva de ampliar a abrangência e o escopo das ações da $\mathrm{AB}$, bem como o aumento de sua resolutividade (NUNES et al, 2015, p. $38)$.

Entendendo a PNAB como referência e considerando a equipe mínima composta por médico, enfermeiro e cirurgiões-dentistas, entre 2008 e 2013 foi observado o seguinte fenômeno: no Brasil, enfermeiros e médicos cadastrados nas UBS cresceram a taxas de $42 \%$ e $17 \%$, enquanto que cirurgiões-dentistas apresentaram crescimento negativo. De modo geral, as categorias profissionais que podem compor equipes de NASF 1 ou 2, apresentaram crescimento superior aos enfermeiros e médicos. Algumas categorias cresceram taxas acima de $90 \%$, como é o caso de biomédicos, profissionais/professores de educação física, fisioterapeutas, nutricionistas e terapeutas ocupacionais. Fonoaudiólogos e psicólogos cresceram em torno de 50\%. Estes últimos provavelmente pela criação dos consultórios de rua, que desenvolvem ações na rua, em instalações específicas, na unidade móvel e também nas instalações das Unidades Básicas de Saúde do território onde está atuando, sempre articuladas e desenvolvendo ações em parceria com as demais equipes de atenção básica do território (UBS e NASF), e dos CAPS, da Rede de Atenção às Urgências e Emergências e dos serviços e instituições componentes do Sistema Único de Assistência Social (BRASIL, 2012a).

\subsubsection{Dinâmica regional da força de trabalho de nível superior}

A expansão da atenção primária e o aumento dos postos de trabalho nos estabelecimentos de saúde tiveram impacto direto no crescimento e distribuição regional das profissões de nível superior no sistema de saúde. De fato, um dos princípios da atenção primária é a descentralização e, assim, as eqSF devem estar o mais perto 
possível dos usuários dos serviços e as UBS consistem no tipo de estabelecimento de saúde predominante nesse nível de atenção. Nesse contexto, esta seção trata da análise da densidade regional das ocupações de nível superior, que podem compor equipes da ESF, cadastradas no CNES nas UBS, visando à identificação de possíveis iniquidades intra e inter-regionais.

Entre 2008 e 2013, a população brasileira passou de 189.612 .814 para 201.062.789 habitantes, o que resultou no incremento de 11.449.975 de habitantes e, portanto, uma taxa de crescimento de $6 \%$ no período. Por sua vez, as UBS cadastradas no CNES passaram de 30.157 para 34.009 unidades, o que significa um crescimento de $13 \%$ no mesmo período.

Enquanto as regiões Norte e Centro-Oeste tiveram incremento populacional de $12 \%$ e $9 \%$ respectivamente, e Nordeste, Sudeste e Sul cresceram apenas à taxa de 5\% cada. Em contraposição, as UBS cadastradas no CNES apresentaram dinâmica diferente. As maiores taxas foram observadas no Nordeste e Norte $(17 \%$ e $15 \%$ respectivamente), enquanto as regiões Centro-Oeste, Sudeste e Sul tiveram incremento de $7 \%, 10 \%$ e $11 \%$, respectivamente. Todavia, há coerência entre o crescimento das UBS e de profissionais de nível superior cadastrados nestes estabelecimentos nas regiões Nordeste (17\% e 15\%) e Norte (15\% e 13\%) (figura 16).

Figura 16. Taxa de crescimento da população brasileira, das unidades básicas de saúde e de ocupações de nível superior por região. Brasil (dez/2008 e dez/2013).

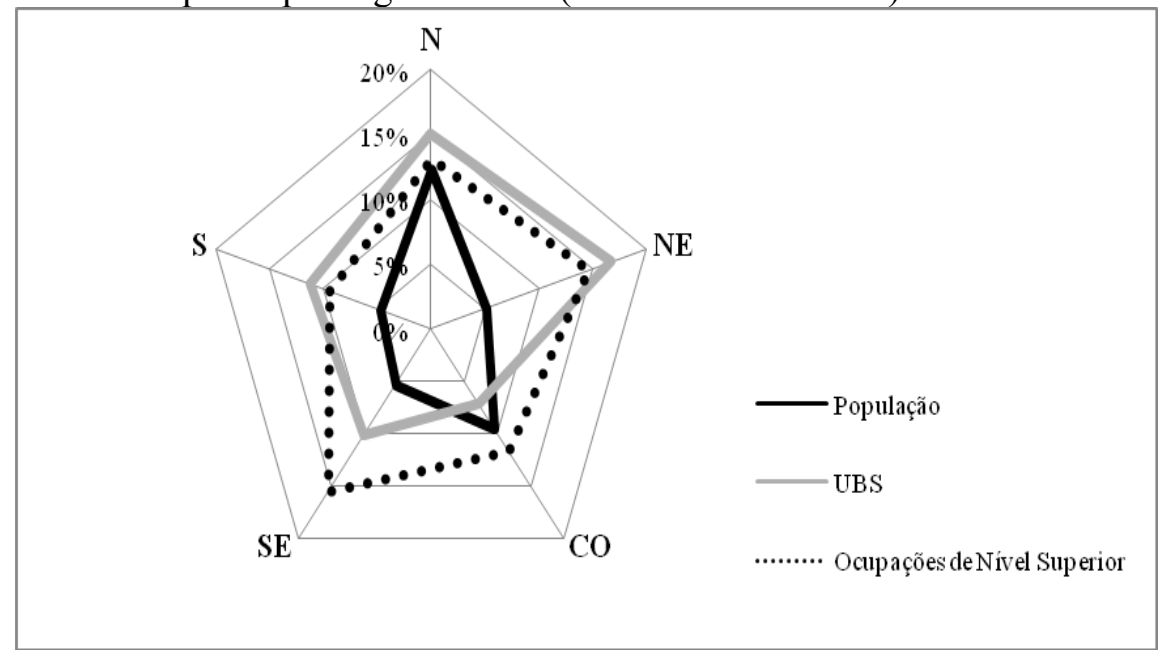

Fonte: DATASUS (2014). $\mathrm{N}=$ Norte; $\mathrm{NE}=$ Nordeste; $\mathrm{CO}=$ Centro-Oeste; $\mathrm{SE}=$ Sudeste; $\mathrm{S}=$ Sul.

O primeiro fenômeno observado na figura 16 é a distorção entre o crescimento populacional e o crescimento no número UBS cadastradas no CNES no período. 
Enquanto as regiões Norte e Centro-Oeste apresentaram o maior crescimento populacional, o Nordeste e Sudeste tiveram ampliação no cadastrado de UBS três pontos percentuais acima da taxa nacional. O mesmo fenômeno pode ser observado se comparados crescimento da população e de profissionais de nível superior cadastrados nas UBS.

O setor saúde no Brasil é dinâmico, com alta rotatividade de trabalhadores e absorve com rapidez as mudanças do mercado de trabalho. Segundo Machado (2007), a classificação de estabelecimentos tem-se mostrado uma tarefa difícil pela falta de consenso, nacional e internacional, sobre definições e pontos de clivagem das atividades exercidas pelas diferentes categorias profissionais e pela própria natureza das mudanças tecnológicas nos serviços de saúde. Esses fatores modificam rapidamente o perfil profissional, caracterizado pela polivalência e pela ampliação de competências específicas e, as novas modalidades de tratamento, como os cuidados domiciliares (os chamados home care) e o PSF, contribuem para a variedade de formas de empregabilidade, como contratos de trabalho temporários e outras modalidades de vínculos precários de trabalho.

Tabela 12. Equipes de Saúde da Família (eqSF) e do Núcleo de Apoio à Saúde da Família (eqNASF) implantadas, por região do Brasil (Dez/2013).

\begin{tabular}{lccc}
\hline Região & $\begin{array}{c}\text { eqSF } \\
\text { implantadas }\end{array}$ & $\begin{array}{c}\text { Cobertura* das } \\
\text { eqSF (\%) }\end{array}$ & $\begin{array}{c}\text { eqNASF } \\
\text { implantadas }\end{array}$ \\
\hline Norte & 2.647 & 50,7 & 230 \\
Nordeste & 13.588 & 73,2 & 1.357 \\
Centro-Oeste & 2.483 & 53,6 & 191 \\
Sudeste & 11.077 & 42,8 & 685 \\
Sul & 4.920 & 54,4 & 304 \\
\hline Brasil & $\mathbf{3 4 . 7 1 5}$ & $\mathbf{5 4 , 4}$ & $\mathbf{2 . 7 6 7}$
\end{tabular}

Fonte: DATASUS (2014). Cobertura calculada com base na estimativa de população - IBGE (2013).

Até dezembro de 2013, mais de 30 mil equipes de saúde da família - cobertura superior a $50 \%$ da população - e quase três mil equipes NASF foram implantadas em todo o país. A região Nordeste se destaca com a melhor oferta de eqSF e de eqNASF por 10 mil habitantes e cobertura acima de $70 \%$ da população, enquanto que o Sudeste 
apresentou o pior desempenho, com menos da metade da população coberta pela ESF (tabela 12).

Entre as categorias profissionais cadastrados nas UBS, que podem compor eqSF e ou eqNASF, a tabela 13 evidencia o crescimento dos postos de trabalho ocupados por todas as categorias profissionais, à exceção dos médicos veterinários, que tiveram redução do número de trabalhadores. As ocupações cirurgião-dentista, enfermeiro e médico representam os maiores contingentes de trabalhadores nas UBS, seguidos dos psicólogos, fisioterapeutas, assistentes sociais e nutricionistas.

Tabela 13. Número de trabalhadores de nível superior cadastrados nas UBS, segundo região do Brasil (dez/2008 e dez/2013).

\begin{tabular}{|c|c|c|c|c|c|c|c|c|c|c|c|c|}
\hline \multirow{2}{*}{ Ocupação } & \multicolumn{2}{|c|}{$\mathbf{N}$} & \multicolumn{2}{|c|}{$\mathbf{N E}$} & \multicolumn{2}{|c|}{$\mathrm{CO}$} & \multicolumn{2}{|c|}{ SE } & \multicolumn{2}{|c|}{$\mathbf{S}$} & \multicolumn{2}{|c|}{ Brasil } \\
\hline & 2008 & 2013 & 2008 & 2013 & 2008 & 2013 & 2008 & 2013 & 2008 & 2013 & 2008 & 2013 \\
\hline Assistente Social & 332 & 512 & 1.038 & 1.641 & 286 & 476 & 2.625 & 3.110 & 912 & 1.015 & 5.193 & 6.754 \\
\hline Cirurgião-Dentista & 2.240 & 2.633 & 11.345 & 12.475 & 2.955 & 3.168 & 16.039 & 17.309 & 6.813 & 7.049 & 39.392 & 42.634 \\
\hline Enfermeiro & 3.507 & 4.225 & 14.363 & 16.593 & 3.322 & 4.156 & 16.744 & 21.958 & 6.787 & 8.536 & 44.723 & 55.468 \\
\hline Farmacêutico* & 147 & 227 & 468 & 677 & 231 & 412 & 1.336 & 2.609 & 589 & 935 & 2.771 & 4.860 \\
\hline Fisioterapeuta $^{\S}$ & 185 & 455 & 945 & 2532 & 329 & 594 & 2.750 & 4.256 & 979 & 1.411 & 5.188 & 9.248 \\
\hline Fonoaudiólogo & 60 & 115 & 234 & 634 & 122 & 173 & 1.418 & 1.951 & 345 & 504 & 2.179 & 3.377 \\
\hline Médico & 4.804 & 4.878 & 19.294 & 19.745 & 5.887 & 5.819 & 43.996 & 46.019 & 15.628 & 15.829 & 89.609 & 92.290 \\
\hline Médico Veterinário & 25 & 11 & 157 & 93 & 157 & 11 & 181 & 102 & 180 & 56 & 565 & 273 \\
\hline Nutricionista & 183 & 313 & 813 & 1.529 & 213 & 397 & 1.351 & 2.608 & 746 & 1.208 & 3.306 & 6.055 \\
\hline Prof. Ed. Física ${ }^{ \pm}$ & 04 & 06 & 13 & 35 & 11 & 11 & 59 & 108 & 11 & 80 & 98 & 240 \\
\hline Psicólogo & 209 & 347 & 767 & 1.628 & 355 & 533 & 3.655 & 4.985 & 1.530 & 1.810 & 6.516 & 9.303 \\
\hline T. Ocupacional & 39 & 34 & 109 & 262 & 38 & 60 & 462 & 812 & 47 & 76 & 695 & 1.244 \\
\hline
\end{tabular}

Fonte: DATASUS (2014). $\mathrm{N}=$ Norte; $\mathrm{NE}=$ Nordeste; $\mathrm{CO}=$ Centro-Oeste; $\mathrm{SE}=$ Sudeste; $\mathrm{S}=$ Sul. Prof. Ed. Física $=$ Professor $/$ Profissional de Educação Física. T. Ocupacional $=$ Terapeuta Ocupacional. \pm Professor de Educação Física Ensino Fund, Professor de Educação Física Ensino Superior, Professor de Educação Física Ensino Médio. *Excluído o farmacêuticobioquímico.

Estudo realizado no período de 1991 a 2010 aponta que o maior aumento de postos de trabalho se deu na categoria Enfermeiro, com crescimento de 14,6\% ao ano, passando de 91.211 para 355.383 profissionais. Na seqüência, cresceram os Nutricionistas e Farmacêuticos com aumentos significativos, de 11,5\% e 9,5\%, respectivamente; os Veterinários $(8 \%)$, Fisioterapeutas $(7,6 \%)$, Assistentes Sociais $(6,7 \%)$, Psicólogos $(6,1 \%)$ e Biólogos (5,2\%). Entre os profissionais que menos 
cresceram no período estudado foram os Médicos e Dentistas, com 3\% cada (WAN DER MASS et al, 2014).

Entre as categorias profissionais cadastrados nas UBS que apresentaram as maiores taxas de crescimento nacional (acima de 70\%) estão os profissionais de educação física, nutricionistas, terapeutas ocupacionais, fisioterapeutas e farmacêuticos (tabela 14).

Tabela 14. Taxa de crescimento das ocupações de nível superior cadastradas em UBS no CNES, segundo região do Brasil (dez/2008 e dez/2013).

\begin{tabular}{lcccccc}
\hline \multicolumn{1}{c}{ Ocupação } & $\mathbf{N}$ & $\mathbf{N E}$ & $\mathbf{C O}$ & $\mathbf{S E}$ & $\mathbf{S}$ & Brasil \\
\hline Assistente Social & $103 \%$ & $58 \%$ & $66 \%$ & $18 \%$ & $11 \%$ & $30 \%$ \\
Cirurgião-Dentista & $18 \%$ & $10 \%$ & $7 \%$ & $8 \%$ & $3 \%$ & $8 \%$ \\
Enfermeiro & $20 \%$ & $16 \%$ & $25 \%$ & $31 \%$ & $26 \%$ & $24 \%$ \\
Farmacêutico* & $54 \%$ & $45 \%$ & $78 \%$ & $95 \%$ & $59 \%$ & $75 \%$ \\
Fisioterapeuta & $146 \%$ & $168 \%$ & $81 \%$ & $55 \%$ & $44 \%$ & $78 \%$ \\
Fonoaudiólogo & $92 \%$ & $171 \%$ & $42 \%$ & $38 \%$ & $46 \%$ & $55 \%$ \\
Médico & $2 \%$ & $2 \%$ & $-1 \%$ & $5 \%$ & $1 \%$ & $3 \%$ \\
Médico Veterinário & $-56 \%$ & $-41 \%$ & $-93 \%$ & $-44 \%$ & $-69 \%$ & $-52 \%$ \\
Nutricionista & $71 \%$ & $88 \%$ & $86 \%$ & $93 \%$ & $62 \%$ & $83 \%$ \\
Prof. Ed. Física & $50 \%$ & $169 \%$ & - & $83 \%$ & $627 \%$ & $145 \%$ \\
Psicólogo & $66 \%$ & $112 \%$ & $50 \%$ & $36 \%$ & $18 \%$ & $43 \%$ \\
T. Ocupacional & $-13 \%$ & $140 \%$ & $58 \%$ & $76 \%$ & $62 \%$ & $79 \%$ \\
\hline Fon & & & & & &
\end{tabular}

Fonte: DATASUS (2014). $\mathrm{N}=$ Norte; $\mathrm{NE}=$ Nordeste; $\mathrm{CO}=$ Centro-Oeste; $\mathrm{SE}=$ Sudeste; $\mathrm{S}=$ Sul. Prof. Ed. Física $=$ Professor/Profissional de Educação Física. T. Ocupacional $=$ Terapeuta Ocupacional. \pm Professor de Educação Física Ensino Fund, Professor de Educação Física Ensino Superior, Professor de Educação Física Ensino Médio. *Excluído o farmacêuticobioquímico.

Na região Norte, a fisioterapia, o serviço social e a fonoaudiologia se destacaram com as maiores taxa de crescimento (146\%, 103\% e 92\%, respectivamente); no Nordeste, a educação física, a fisioterapia e a terapia ocupacional cresceram a taxas maiores de 100\%. Na região Centro-Oeste, os destaques são a nutrição e a fisioterapia; no Sudeste nutrição e farmácia e, no Sul, a educação física apresentou crescimento bastante proeminente. Em relação ao crescimento negativo, as maiores perdas ocorreram nas profissões biólogo e médico veterinário, em todas as regiões, mas com destaque na região Centro-Oeste, com $-89 \%$ e $-93 \%$, respectivamente (tabela 14). 
A análise das taxas de crescimento de cada uma das catorze profissões, a partir dos valores que expressam o Brasil, sugere ter relação direta com a organização e a dinâmica da atenção primária do SUS, especialmente da ESF e do NASF.

Quando comparadas as regiões que polarizaram as taxas de crescimento dos estabelecimentos de saúde analisados e apresentaram as maiores taxas de crescimento das ocupações de nível superior, se observa que fisioterapeutas, fonoaudiólogos, profissionais de educação física, psicólogos e terapeutas ocupacionais cresceram acima de $100 \%$ na região Nordeste, enquanto que farmacêuticos se destacaram na região Sudeste (95\%). Os nutricionistas cresceram a taxas semelhantes em ambas as regiões, entre 88 e $93 \%$.

As taxas de crescimento das ocupações de nível superior nem sempre acompanham o crescimento populacional, o que se reflete na razão populacional de trabalhadores, como demonstra a tabela 15.

Tabela 15. Razão populacional das ocupações de nível superior cadastradas em UBS por 1.000 habitantes (Dez/2013).

\begin{tabular}{lcccccc}
\hline \multicolumn{1}{c}{ Ocupação } & N & NE & CO & SE & S & Brasil \\
\hline Assistente Social & 0,03 & 0,03 & 0,03 & 0,04 & 0,03 & 0,03 \\
Cirurgião-Dentista & 0,15 & 0,22 & 0,21 & 0,20 & 0,24 & 0,21 \\
Enfermeiro & 0,25 & 0,30 & 0,28 & 0,26 & 0,30 & 0,28 \\
Farmacêutico* & 0,01 & 0,01 & 0,03 & 0,03 & 0,03 & 0,02 \\
Fisioterapeuta & 0,03 & 0,04 & 0,04 & 0,05 & 0,05 & 0,05 \\
Fonoaudiólogo & 0,01 & 0,01 & 0,01 & 0,02 & 0,02 & 0,02 \\
Médico & 0,29 & 0,35 & 0,39 & 0,54 & 0,55 & 0,46 \\
Médico Veterinário & - & - & - & - & - & - \\
Nutricionista & 0,02 & 0,03 & 0,03 & 0,03 & 0,04 & 0,03 \\
Prof. Ed. Física & - & - & - & - & - & - \\
Psicólogo & 0,02 & 0,03 & 0,04 & 0,06 & 0,06 & 0,05 \\
T. Ocupacional & - & - & - & - & - & - \\
\hline Fonte: Dados popula & & & & & & \\
\hline
\end{tabular}

Fonte: Dados populacionais: IBGE - Estimativas de população (2013). Dados das ocupações: Ministério da Saúde - Cadastro Nacional dos Estabelecimentos de Saúde do Brasil - CNES (DATASUS). $\mathrm{N}=$ Norte; $\mathrm{NE}=$ Nordeste; $\mathrm{CO}=$ Centro-Oeste; $\mathrm{SE}=$ Sudeste; $\mathrm{S}=$ Sul. Prof. Ed. Física $=$ Profissional/Professor de Educação Física; M. Veterinário $=$ Médico Veterinário; $\mathrm{T}$. Ocupacional $=$ Terapeuta Ocupacional. *Incluídas todas as ocupações cadastradas nas UBS.

Entre as profissões que compõem a ESF, os médicos apresentaram a maior densidade populacional, com 0,46 profissionais para cada mil habitantes, o que se deve, 
pelo menos, a três fatores: podem compor duas eqSF, também podem compor eqNASF e o registro no CNES tem inúmeros problemas por causa da alta rotatividade dessa categoria profissional. Depois dos médicos, os profissionais de enfermagem e os cirurgiões-dentistas estão entre as ocupações com maior densidade populacional no país, com 0,28 e 0,21 profissionais para cada dez mil habitantes respectivamente (tabela $15)$.

Regionalmente, os médicos estão mais concentrados nas regiões Sudeste e Sul, enquanto que cirurgiões-dentistas e enfermeiros Nordeste e Sul. Assim, a região Sul se destaca na densidade populacional das três profissões nucleares das eqSF (tabela 15).

Quanto as categorias profissionais que podem compor equipes NASF, se observa que os assistentes sociais e fisioterapeutas possuem a maior densidade nacional e estão distribuidos proporcionalmene entre as regiões, os farmacêuticos e os nutricionistas concentrados no Sul, os fonoaudiólogos e psicólogos no Sudeste e Sul. Intrarregionalmente, os destaques são: serviço social, fisioterapia e psicologia na região Norte, fisioterapia no Nordeste e Centro-Oeste e psicologia no Sudeste e Sul (tabela 15).

Segundo dados do Global Health Observatory da OMS, a densidade de médicos por 1.000 habitantes no Brasil foi de 1,89, inferior a alguns países da América do Sul, como Argentina, Venezuela e Uruguai, em 2013. A densidade de cirurgiões-dentistas foi de 1,22 profissionais por 1.000 habitantes, superior a países como Colômbia e Cuba e inferior apenas ao Canadá e EUA em 2010. Já os dados da enfermagem são expressos por meio da equipe (enfermeiro e auxiliares), cuja densidade foi de 7,6 profissionais por 1.000 habitantes, sendo superior à Costa Rica e Panamá, em 2013 (WHO, 2015).

Embora médicos, enfermeiros e cirurgiões-dentistas sejam categorias numericamente expressivas, nacional e regionalmente, a densidade populacional varia de acordo com a categoria profissional e com as regiões do país. Enquanto cirurgiõesdentistas e médicos se concentraram nas regiões Sudeste e Sul, os profissionais de enfermagem apresentam maior densidade populacional no Nordeste.

No período de dezembro de 2010 a março de 2014, os estoques de médicos e enfermeiros aumentaram porque o mercado de cada profissão recebeu algo em torno de 50 mil trabalhadores no período (WAN DER MASS et al, 2014).

Por ser a categoria com maior densidade populacional entre as profissões que exercem atividades em UBS e, ao mesmo tempo, a profissão que atualmente é foco de políticas de provimento e formação no Brasil, como é o caso do recente Projeto "Mais Médicos", vamos discutir mais detalhadamente a situação dos médicos. 
De fato, conforme A Demografia Médica no Brasil, publicada pelo Conselho Federal de Medicina: "os médicos nunca foram tão numerosos, ao mesmo tempo em que persistem acentuadas desigualdades na distribuição dos profissionais entre as regiões, estados e municípios" (CFM, 2013, p. 12).

Regionalmente, as regiões Sudeste e Sul apresentaram razões populacionais de médicos cadastrados em UBS superiores a 0,46 (razão nacional), o que provavelmente se deve a influência dos fatores econômicos nas escolhas dessa categoria profissional. Póvoa e Andrade (2006) realizaram uma pesquisa sobre a distribuição geográfica dos médicos no Brasil e concluíram que o PIB per capita e a oferta de programas de residência são dois fatores que exercem influência na escolha locacional do profissional por uma cidade e ou região.

Segundo Chaves et al (2013), há grande concentração no número de vagas de residência médica na Região Sudeste e apenas 5,9\% se destinam a formar médicos para as equipes de Saúde da Família. Apesar dos esforços atuais para ampliar o número de médicos para a Estratégia de Saúde da Família, ainda são muito poucas as vagas de residência médica, destinadas a formar especialistas para essa área no Brasil.

A região Sudeste ainda é centro formador de especialistas no país, concentrando $63,5 \%$ das vagas de residências médicas, o que possivelmente se deve à existência de um grande número de hospitais, escolas médicas e centros de pesquisa na região, especialmente no estado de São Paulo (CFM, 2013).

Apesar do incremento de médicos na ESF nos últimos anos, especialmente em função dos programas federais de provimento, por exemplo, PROVAB e Mais Médicos, a baixa densidade populacional de médicos no país talvez ainda se deva a imagem desfavorável da atenção básica, a carga horária excessiva, a precariedade do vinculo de trabalho, a dificuldade de trabalho em equipe multiprofissional entre outros (SANTOS e BENEDETTI, 2012; WAN DER MASS et al, 2014).

Como vimos anteriormente, as equipes multiprofissionais da atenção básica podem contar com outras categorias profissionais de nível superior. Em 2008 foram criadas duas modalidades de NASF, que podiam ser implantadas pelos municípios. O NASF 1 deve realizar suas atividades vinculado a, no mínimo, 8 e a no máximo, a 20 eqSF, exceto nos municípios da região Norte com menos de 100.000 habitantes, em que o mínimo preconizado são 5 eqSF e o NASF 2 habilitado para municípios com densidade populacional inferior a 10 habitantes por $\mathrm{km}^{2}$, cujas equipes devem acompanhar, no mínimo, 3 eqSF. Os médicos também podem compor o NASF e ser 
registrados dois profissionais por equipe, contanto que não sejam do mesmo grupo do CBO. Já fisioterapeutas e terapeutas ocupacionais podem ser registrados dois profissionais que cumpram, no mínimo, 20 horas cada, enquanto que os demais profissionais devem cumprir, no mínimo, 40 horas semanais cada (BRASIL, 2008; SANTOS e BENEDETTI, 2012).

Quanto às ocupações que podem compor o NASF, os fisioterapeutas e os psicólogos se destacam com aproximandamente 0,46 profissionais por $10 \mathrm{mil}$ habitantes, sendo, portanto, as categorias profissionais com maior densidade populacional (tabela 15).

A fisioterapia foi a profissão mais recrutada para o NASF. A região Sudeste apresenta uma média de profissionais maior que as demais regiões, principalmente em relação ao Norte. Para as categorias profissionais de Nutrição, Educação Física, Psicologia e Serviço Social, esta diferença foi significante, sendo a media de profissionais na região Sudeste, respectivamente, mais de seis, oito, sete e cinco vezes superiores à região Norte (SANTOS e BENEDETTI, 2012)

Embora as políticas indutoras da expansão da atenção básica, como o Projeto de Expansão e Consolidação da Saúde da Família (PROESF), Programa de Melhoria do Acesso e da Qualidade na Atenção Básica (PMAQ), entre outros, tenham incrementado e diversificado a força de trabalho na atenção primária, a distribuição ainda é desigual entre as profissões e as regiões do país.

O aumento da oferta de cursos de graduação parece ter relação direta com a distribuição desigual da força de trabalho de nível superior nas UBS nas cinco regiões do país. Segundo os dados do Instituto Nacional de Estudos e Pesquisas Educacionais Anísio Teixeira (INEP), a distribuição dos cursos de graduação no Brasil ainda é desigual, sendo "as menores proporções nas regiões Norte $(n=2.004)$ e Centro-Oeste $(n=2.504)$ e as maiores nas regiões Sudeste $(n=13.278)$, Sul $(n=5.386)$ e Nordeste $(n=4.655)$ ", o que possivelmente explica o desempenho das regiões Sudeste e Sul na densidade populacional da maioria das profissões estudadas (SANTOS e BENDETTI, 2012, p. 192). 


\section{REFERÊNCIAS}

ABRAHÃO, A.L. Atenção Primária e o processo de trabalho em saúde. Informe-se em promoção da saúde, v.03, n.1. p.01-03. 2007. Disponível em: http://www.uff.br/promocaodasaude/ana.pdf. Acesso em: 03 Ago. 2016.

ASSUNCAO, A.A et al . Recursos humanos e trabalho em saúde: os desafios de uma agenda de pesquisa. Cadernos de Saúde Pública, Rio de Janeiro, v. 23, supl. 2, 2007. Disponível em http://www.scielo.br/scielo.php?script=sci arttext\&pid=S0102311X2007001400009\&lng=pt\&nrm=iso. Acesso em: 14 nov. 2013. DOI: http://dx.doi.org/10.1590/S0102-311X2007001400009

BODSTEIN, R. Atenção básica na agenda da saúde. Ciência \& Saúde Coletiva, Rio de Janeiro, v. 7, n. 3, p. 401-412, jan. 2002. Disponível em: http://www.scielosp.org/scielo.php?script=sci arttext\&pid=S1413-

81232002000300002\&lng=pt\&nrm=iso. Acesso em: 04 ago. 2016.

BRASIL. Ministério da Saúde. Secretaria de Assistência à Saúde. Coordenação de Saúde da Comunidade. Saúde da Família: uma estratégia para a reorientação do modelo assistencial. Brasília. Ministério da Saúde, 1997. Disponivel em http://bvsms.saude.gov.br/bvs/publicacoes/cd09 16.pdf. Acesso em: 15 jul. 2015.

BRASIL. Conselho Nacional de Saúde (CNS). Resolução no 287 de 08 de outubro de $1998 . \quad$ Disponível em http://bvsms.saude.gov.br/bvs/saudelegis/cns/1998/res0287_08_10_1998.htmlBRASIL. Acesso em: 10 mar. 2014.

BRASIL. Ministério da Saúde. Política Nacional de Medicamentos. Brasília. 1998. Disponível em http://bvsms.saude.gov.br/bvs/publicacoes/politica medicamentos.pdf. Acesso em: 20 nov. 2013.

BRASIL. Ministério da Saúde. Secretaria de Atenção à Saúde. Departamento de Atenção Básica. Saúde da família no Brasil: uma análise de indicadores selecionados: 1998-2004. Brasília: Ministério da Saúde, 2006a.

BRASIL. Ministério da Saúde. Trabalhadores de Saúde e sua trajetória na Reforma Sanitária. In: Cadernos RH Saúde. Brasília: Ministério da Saúde, 2006b.

BRASIL. Indicadores de gestão do trabalho em saúde: material de apoio para o Programa de Qualificação e Estruturação da Gestão do Trabalho e da Educação no SUS - ProgeSUS. Brasília: Ministério da Saúde, 2007. Disponível em http://bvsms.saude.gov.br/bvs/publicacoes/07 0158 M.pdf. Acesso em: 15 jul. 2015.

BRASIL. Ministério da Saúde. Portaria no 154, de 24 de janeiro de 2008. Cria os Núcleos de Apoio à Saúde da Família - NASF. Disponível em http://bvsms.saude.gov.br/bvs/saudelegis/gm/2008/prt0154_24_01_2008.html. Acesso em: 15 jul. 2015.

BRASIL. Ministério da Saúde. Portaria no 4.279, de 30 de dezembro de 2010. Estabelece diretrizes para a organização da Rede de Atenção à Saúde no âmbito do 
Sistema Único de Saúde (SUS). Disponível em http://conselho.saude.gov.br/ultimas_noticias/2011/img/07 jan_portaria4279 301210.p df. Acesso em: 03 ago. 2015.

BRASIL. Ministério da Saúde. Portaria no 2.488, de 21 de outubro de 2011. Aprova a Política Nacional de Atenção Básica, estabelecendo a revisão de diretrizes e normas para a organização da Atenção Básica, para a Estratégia Saúde da Família (ESF) e o Programa de Agentes Comunitários de Saúde (PACS). Disponível em: http://bvsms.saude.gov.br/bvs/saudelegis/gm/2011/prt2488 21_10 2011.html. Acesso em: 15 jun. 2016.

BRASIL. Ministério da Saúde. Secretaria de Atenção à Saúde. Departamento de Atenção Básica. Política Nacional de Atenção Básica. Brasília: Ministério da Saúde, 2012a. Disponível em http://189.28.128.100/dab/docs/publicacoes/geral/pnab.pdf. Acesso em: 15 jul. 2015.

BRASIL. Ministério da Saúde. Portaria no 3.124, de 28 de dezembro de 2012. Redefine os parâmetros de vinculação dos Núcleos de Apoio à Saúde da Família (NASF) Modalidades 1 e 2 às Equipes Saúde da Família e/ou Equipes de Atenção Básica para populações específicas, cria a Modalidade NASF 3, e dá outras providências. 2012b. Disponível em http://bvsms.saude.gov.br/bvs/saudelegis/gm/2012/prt3124_28_12_2012.html. Acesso em: 15 jul.2015.

BRASIL. Ministério da Saúde. Secretaria de Ciência, Tecnologia e Insumos Estratégicos. Departamento de Assistência Farmacêutica e Insumos Estratégicos. Serviços farmacêuticos na atenção básica à saúde. Brasília: Ministério da Saúde, 2014. (Cuidado farmacêutico na atenção básica; Caderno 1). Disponível em http://bvsms.saude.gov.br/bvs/publicacoes/servicos_farmaceuticos_atencao basica_sau de.pdf. Acesso em: 05 out. 2015.

BRASIL. Ministério da Saúde. Núcleo de Apoio à Saúde da Família. 2015. Disponível em http://dab.saude.gov.br/portaldab/ape_nasf.php. Acesso em: $10 \mathrm{dez}$. 2014.

CARVALHO, B.G. et al. Gerência de unidade básica de saúde em municípios de diferentes portes: perfil e instrumentos gerenciais utilizados. Revista da Escola de Enfermagem da USP, v. 48, n. 5, 2014. DOI: http://dx.doi.org/10.1590/S0080$\underline{6234201400005000018}$.

CARVALHO, M; SANTOS, NR.; CAMPOS, GWS. A construção do SUS e o planejamento da força de trabalho em saúde no Brasil: breve trajetória histórica. Saúde em Debate, Rio de Janeiro, v. 37, n. 98, setembro de 2013. Disponível em http://www.scielo.br/scielo.php?script $=$ sci arttext\&pid=S0103-

11042013000300002\&lng=en\&nrm=iso. Acesso em: 10 fev. 2014. DOI: http://dx.doi.org/10.1590/S0103-11042013000300002.

CARVALHO, M.N. et al . Expansão e diversificação da força de trabalho de nível superior nas Unidades Básicas de Saúde no Brasil, 2008 - 2013. Saúde em Debate, Rio de Janeiro, v. 40, n. 109, p. 154-162, Junho, 2016. Disponível em: 
http://www.scielo.br/scielo.php?script=sci arttext\&pid=S010311042016000200154\&lng=en\&nrm=iso. Acesso em: 03 Ago. 2016.

CAVALCANTI, P.C.S; NETO, A.V.O; SOUSA, M.F. Quais são os desafios para a qualificação da Atenção Básica na visão dos gestores municipais? Saúde em Debate. Rio de Janeiro, v. 39, n. 105, p. 323-336, Abr-Jun, 2015. DOI: 10.1590/0103110420151050002003 .

CFM. Demografia Médica no Brasil, v. 2. São Paulo: Conselho Regional de Medicina do Estado de São Paulo/Conselho Federal de Medicina, 2013.

CHAVES, H.L. et al. Vagas para Residência Médica no Brasil: Onde estão e o que é Avaliado. Revista Brasileira de Educação Médica, v. 37, n. 4, p. 557-565, 2013. http://www.scielo.br/pdf/rbem/v37n4/a11v37n4.pdf. Acesso em: 10 fev. 2014.

GIL, C.R.R. Atenção primária, atenção básica e saúde da família: sinergias e singularidades do contexto brasileiro. Cadernos de Saúde Pública, Rio de Janeiro, v. 22, n. 6, p. 1171-81, 2006.

GIOVANELLA, L. et al. Panorama de la Atención Primaria de Salud en Suramérica: concepciones, componentes y desafios. Saúde em Debate. Rio de Janeiro, v. 39, n. 105, p.300-322, Abr-Jun, 2015. DOI: 10.1590/0103-110420151050002002.

GIRARDI, S.N. O perfil do "emprego" em saúde no Brasil. Cadernos de Saúde Pública, Rio de Janeiro, v. 2, n. 4, dezembro de 1986. Disponível em http://www.scielo.br/scielo.php?script $=$ sci arttext\&pid=S0102-

311X1986000400003\&lng=en\&nrm=iso. Acesso em: 10 mar. 2014. DOI: http://dx.doi.org/10.1590/S0102-311X1986000400003.

GIRARDI, S.N; CARVALHO, C.L. Configurações do mercado de trabalho dos assalariados em saúde no Brasil. In: BRASIL. Ministério da Saúde. Formação: Mercado de Trabalho em Saúde, 2002, 6: 15-36. Disponível em http://bvsms.saude.gov.br/bvs/publicacoes/profae/Revista2006.pdf. Acesso em: 10 set. 2015.

LOPES, L.R.S. Demografia médica: provimento e fixação de médicos em áreas de maior vulnerabilidade. Rio de Janeiro: ESG, 2013 (Trabalho de Conclusão de Curso TCC). Disponível em http://www.esg.br/images/Monografias/2013/LOPES.pdf. Acesso em: 10 set. 2015.

MACHADO, M.H. Gestão municipal e contratação da força de trabalho, qual o foco do debate? Divulgação em Saúde para Debate, Rio de Janeiro, n. 40, p. 18-21, jun./2007.

MACHADO, M.H; OLIVEIRA, E.S; MOYSES, N.M.N. Tendências do Mercado de Trabalho em Saúde no Brasil. In: PIERANTONI, C; POZ, MRD; FRANÇA, T. (Orgs.). O Trabalho em Saúde: abordagens quantitativas e qualitativas. $1^{\mathrm{a}}$ ed. Rio de Janeiro: CEPESC, UERJ, 2011.

MACHADO, C.R; POZ, M.R.D. Sistematização do conhecimento sobre as metodologias empregadas para o dimensionamento da força de trabalho em saúde. Saúde em debate, v. 39, n. 104, p. 239-254, 2015. Disponível em: 
http://www.scielo.br/scielo.php?script=sci arttext\&pid=S010311042015000100239\&lng=en. Acesso em: 10 set. 2015.

MEDICI, A.C. A força de trabalho em Saúde no Brasil dos anos 70: percalços e tendências. Revista de Administração Pública, v. 20, n. 3, p. 54-69, 1986. Disponível em http://www.spell.org.br/documentos/ver/14757/a-forca-de-trabalho-em-saude-nobrasil-dos-anos-70--percalcos-e-tendencias/i/pt-br. Acesso em: 10 mar. 2014.

MENDES, E. V. As redes de atenção à saúde. Ciência \& Saúde Coletiva, v. 15, n. 5, p. 2297-2305, 2010.

MENDES, E. V. 25 anos do Sistema Único de Saúde: resultados e desafios. Estudos Avançados, v. 27, n. 78, p. 27-34, 2013.

MIGUELOTE, V.R.S et al. Distribuição da força de trabalho: eqüidade e negociação. Physis, Rio de Janeiro, v. 18, n. 2, 2008. Disponível em http://www.scielo.br/scielo.php?script $=$ sci arttext\&pid $=$ S010373312008000200007\&lng=en\&nrm=iso. Acesso em: 10 mar. 2014.

NOGUEIRA, R.P. A força de trabalho em saúde no contexto da reforma sanitária. Cadernos de Saúde Pública, v. 3, n. 3, p. 332-342, 1987. Disponível em http://www.scielo.br/scielo.php?script=sci arttext\&pid=S0102-

311X1987000300011\&lng=en\&nrm=iso. Acesso em: 10 mar. 2014.

NUNES, E.F.P.A et al. Força de trabalho em saúde na atenção básica em Municípios de Pequeno Porte do Paraná. Revista do Centro Brasileiro de Estudos de Saúde. v. 39, n. 104. Rio de janeiro, jan-mar 2015.

OLIVEIRA, E.S; MACHADO, M.H. Para medir o trabalho em saúde no Brasil: principais fontes de informação. Divulgação em saúde para debate, v. 45, 2010. Disponível $\mathrm{em}$ http://www.ensp.fiocruz.br/observarh/arquivos/artigo $\% 20 \mathrm{Fonte} \% 20 \mathrm{de} \% 20 \mathrm{Dados} \% 20 \mathrm{pa}$ ra\%20medir\%20o\%20Trabalho.pdf. Acesso em: 10 mar. 2014.

ORGANIZAÇÃO MUNDIAL DA SAÚDE. Estabelecendo e monitorando referenciais de desempenho em recursos humanos em saúde: abordagem sobre a densidade da força de trabalho. In: Spotlight: estatísticas da força de trabalho em saúde. Edição n.6, novembro de 2008. Disponível em http://www.who.int/hrh/statistics/Spotlight_6_PO.pdf. Acesso em: 15 jan. 2014.

ORGANIZAÇÃO MUNDIAL DA SAÚDE. Trabalhando juntos pela saúde. Brasília: Ministério da Saúde, 2007.

PAIM, J. et al. The Brazilian health system: history, advances and challenges. The Lancet, 2011. Disponível em http://www.thelancet.com/series/health-in-brazil. Acesso em: 15 jan. 2014.

POZ, M.R.D. A crise da força de trabalho em saúde. Cadernos de Saúde Pública, Rio de Janeiro, v. 29, n. 10, outubro de 2013. Disponível em http://www.scielo.br/scielo.php?script $=$ sci arttext\&pid $=$ S0102-

311X2013001000002\&lng=en\&nrm=iso. Acesso em: 12 jan. 2014. DOI: http://dx.doi.org/10.1590/0102-311XPE011013. 
RIZZOTO, M.L.F. et al. Força de trabalho e gestão do trabalho em saúde: revelações da Avaliação Externa do Programa Nacional de Melhoria do Acesso e da Qualidade da Atenção Básica no Paraná. Saúde em Debate. Rio de Janeiro. v. 38, número especial, p. 237-251. out 2014. http://www.scielo.br/pdf/sdeb/v38nspe/0103-1104-sdeb-38-spe0237.pdf. Acesso em: 15 mar. 2015.

SALA, A.; CARRO, ARL.; SEIXAS, PHA. Comparação entre as bases de dados relativas à força de trabalho em saúde no Estado de São Paulo. Boletim eletrônico do grupo técnico de avaliação e informações de saúde, Janeiro, 2010. p. 1-7. Disponível em http://portal.saude.sp.gov.br/resources/ses/perfil/gestor/homepage//gaisinforma/gais jornal_4.pdf. Acesso em: 15 dez. 2013.

SANTOS, S.F.S.; BENEDETTI, T.R.B. Cenário de implantação do Núcleo de Apoio a Saúde da Família e a inserção do profissional de Educação Física. Revista Brasileira de Atividade Física e Saúde, Pelotas, v. 17, n. 3, p. 188-194, 2012. Disponível em http://periodicos.ufpel.edu.br/ojs2/index.php/RBAFS/article/viewFile/1857/1697.

Acesso em: 13 jul. 2015.

SOUZA, A.I.S; OLIVEIRA, L.M.L.; CASTRO, M.M.C. O trabalho coletivo e as profissões de saúde. Revista Tempus Actas de Saúde Coletiva, v. 5, n. 1, 2011. Disponível em http://www.tempusactas.unb.br/index.php/tempus/article/view/921/931. Acesso em: 15 dez. 2013.

SUMAR, N.; FAUSTO, M. C. R. Atenção Primária à Saúde: a construção de um conceito ampliado. Journal of Management Primary Health Care, v. 5, n. 2, p. 202212, 2014. Disponível em http://www.jmphc.com/ojs/index.php/01/article/viewArticle/182. Acesso em: 19 fev. 2015.

VARELLA, T.C; PIERANTONI, C.R. Mercado de trabalho: revendo conceitos e aproximando o campo da saúde. A década de 90 em destaque. Physis: Revista de Saúde Coletiva, Rio de Janeiro, v. 18, n. 3, p. 521-544, setembro. 2008. Disponível em: $\quad$ http://www.scielo.br/scielo.php?script=sci arttext\&pid=S010373312008000300009\&lng=en\&nrm=iso. Acesso em: 10 dez. 2013.

WAN DER MAAS, L. et al. Estudo de levantamento de aspectos demográficos, de formação e de mercado de trabalho das profissões de saúde nível superior no Brasil entre 1991 e 2010 (relatório final). Belo Horizonte: UFMG - NESCON, dezembro de 2014a.

WAN DER MAAS, L. et al. Dimensionamento da estrutura e dinâmica do mercado de trabalho em Atenção Básica em Saúde - relatório final. Belo Horizonte: EPSM/NESCON/UFMG, 2014b.

WORLD HEALTH ORGANIZATION. Global Health Observatory (GHO) data. Disponível em http://www.who.int/gho/health_workforce/en. Acesso em: 02 set 2015.

WORLD HEALTH ORGANIZATION. A universal truth: no health without a workforce. $\quad$ WHO, $2013 . \quad$ Disponível em http://www.who.int/workforcealliance/knowledge/resources/GHWA AUniversalTruth Report.pdf. Acesso em: 27 abr. 2014. 
WORLD HEALTH ORGANIZATION. Human resources for health: foundation for universal health coverage and the post-2015 development agenda: report of the Third Global Forum on Human Resources for Health, 10-13 November 2013, Recife, Brazil. WHO, 2014. Disponível em http://www.who.int/workforcealliance/knowledge/resources/report3rd GF HRH.pdf?ua $\underline{=1}$. Acesso em: 27 abr. 2014. 


\section{CAPÍTULO 5 - A FORÇA DE TRABALHO NA ASSISTÊNCIA FARMACÊUTICA BÁSICA DO SUS}

"Mas na profissão, além de amar, tem de saber. E o saber leva tempo pra crescer" (Rubem Alves)

Este capítulo tem como objetivo discutir a participação do farmacêutico na composição da força de trabalho na atenção primária do SUS, especialmente no

subsistema que compete ao abastecimento, acesso e utilização de medicamentos: a assistência farmacêutica.

Historicamente, a assistência farmacêutica foi compreendida de diversas maneiras. Entre os profissionais não farmacêuticos, especialmente médicos e enfermeiros, o termo significava cuidado direto ao paciente, à semelhança de "assistência médica" e de "assistência de enfermagem". Para os farmacêuticos, que cunharam o termo, este inicialmente se referia a uma série de etapas meramente administrativas e gerenciais voltadas a garantia do abastecimento e qualidade do produto (o medicamento). Atualmente, é entendida como um conjunto de ações articuladas e interdependentes, cujo foco central é o usuário e não o medicamento.

O acesso aos medicamentos depende do acesso aos serviços de saúde, que é entendido como a relação entre a disponibilidade, a acessibilidade, a capacidade de pagamento e a aceitabilidade. A disponibilidade (availability) é definida como uma relação entre o tipo e a quantidade do produto ou serviço ofertado e o efetivamente utilizado. A acessibilidade (accessibility) refere-se à localização geográfica dos produtos e serviços e a do usuário. A capacidade de pagamento (affordability) é a relação entre o preço dos produtos ou serviços e a capacidade do usuário de pagar. A aceitabilidade (acceptability) considera as atitudes e, especialmente, as expectativas dos usuários sobre os produtos e serviços (MSH, 2012; LEITE et al, 2015).

Nesse sentido, a garantia do acesso e o uso correto e seguro dos medicamentos, a otimização dos recursos financeiros, a ampliação da participação e a integração do farmacêutico na rede de serviços de saúde e a articulação da assistência farmacêutica às demais políticas de saúde são alguns desafios atuais e futuros para a categoria farmacêutica e para o Estado brasileiro.

Como a assistência farmacêutica é complexa e multidisciplinar, outro grande desafio é a formação dos profissionais para atuação na área. $\mathrm{O}$ trabalho desenvolvido na 
assistência farmacêutica requer conhecimentos e habilidades das ciências exatas e naturais, ciências biológicas e das ciências farmacêuticas, mas também das ciências sociais e humanas e das ciências da saúde, especialmente da área de saúde coletiva, como veremos adiante.

Ao longo do tempo, a gestão da assistência farmacêutica foi entendida como um conjunto de ações técnico-operacionais delimitadas ao produto, quando muito ao fornecimento e abastecimento das unidades de saúde, com forte viés burocrático e centrado na logística dos medicamentos (MARIN et al., 2003; LEITE et al, 2015).

\subsection{ASSISTÊNCIA FARMACÊUTICA NO SISTEMA DE SAÚDE}

No Brasil, a distinção entre gerência e gestão está presente no cotidiano dos serviços de saúde. A gerência é conceituada como a administração de uma unidade ou órgão de saúde, tais como unidade básica de saúde e hospital, enquanto que a gestão é usualmente entendida como atividade exercida pelo gestor de um sistema de saúde, dentro de uma esfera de governo (municipal, estadual ou federal), por meio da execução das funções de coordenação, articulação, negociação, planejamento, acompanhamento, controle, avaliação e auditoria. Por exemplo, segundo a Norma Operacional Básica do SUS (NOB/SUS) de 1996, os Secretários Municipais e Estaduais de Saúde e o Ministro da Saúde, que representam, respectivamente, os governos municipais, estaduais, distrito federal e União são os gestores do SUS (SANTOS; NASCIMENTO, 2015; LEITE et al, 2015).

Apesar do SUS reconhecer dois grupos de funções gerenciais, um exercido nas instâncias de comando e coordenação e outro nos serviços de saúde, na prática a gestão e a gerência se confundem porque, além das funções técnicas e administrativas, a dimensão política está fortemente presente nas atividades de um gerente de estabelecimento de saúde, que toma decisões e negocia o tempo todo durante o processo trabalho e produção do cuidado em saúde (MACHADO; LIMA; BATISTA, 2011; LEITE et al 2015).

No bojo da implantação e organização do SUS também ocorreram mudanças no financiamento e acesso aos medicamentos essenciais, entre as quais se destacam a Política Nacional de Medicamentos (PNM), em 1999, a Política Nacional de Assistência Farmacêutica (PNAF), em 2004, publicada por meio da resolução $n^{\circ} 338$ do Conselho Nacional de Saúde (CNS), a criação do bloco de financiamento específico voltado à 
garantia da execução da política no país e o reconhecimento do necessário desenvolvimento de recursos humanos para a assistência farmacêutica (BRASIL, 2001; BRASIL, 2004; ARAUJO et al, 2008).

De caráter sistêmico e multiprofissional, a assistência farmacêutica é definida na PNM como:

\begin{abstract}
Grupo de atividades relacionadas com o medicamento, destinadas a apoiar as ações de saúde demandadas por uma comunidade. Envolve o abastecimento de medicamentos em todas e em cada uma de suas etapas constitutivas, a conservação e o controle de qualidade, a segurança e a eficácia terapêutica dos medicamentos, o acompanhamento e a avaliação da utilização, a obtenção e a difusão de informação sobre medicamentos e a educação permanente dos profissionais de saúde, do paciente e da comunidade para assegurar o uso racional de medicamentos (BRASIL, 2001, p. 34),
\end{abstract}

Em conformidade com a PNM, é possível dizer que a reorientação da assistência farmacêutica está fundamentada na descentralização da gestão, na otimização e eficácia do sistema de aquisição e distribuição, na promoção do uso racional de medicamentos e no desenvolvimento de sistemas que garantam a qualidade e possibilitem a redução dos preços dos produtos (BRASIL, 2001; OPAS, 2005).

A PNAF define assistência farmacêutica como:

Um conjunto de ações voltadas à promoção, proteção e recuperação da saúde, tanto individual como coletiva, tendo o medicamento como insumo essencial e visando ao acesso e ao uso racional, conjunto este, que envolve a pesquisa, o desenvolvimento e a produção de medicamentos e insumos, bem como sua seleção, programação, aquisição, distribuição, dispensação, garantia de qualidade dos produtos e serviços, acompanhamento e avaliação da sua utilização, na perspectiva da obtenção de resultados concretos e da melhoria da qualidade de vida da população (OPAS, 2005, p. 57).

Apesar de tardiamente, a descentralização da gestão da assistência farmacêutica teve início em 1999 com a criação do incentivo à Assistência Farmacêutica na Atenção Básica e vem sendo conduzida de modo articulado com municípios, estados e União e pactuada nas instancias de gestão do SUS: a Comissões Intergestores Bipartite (CIB) e Tripartite (CIT) (CARVALHO; CASTRO; COUTO, 2007; VIEIRA, 2010; LEITE et al, 2015).

Com o IAFAB, os municípios se tornaram responsáveis pela execução da assistência farmacêutica na atenção primária, desde a seleção de medicamentos à 
qualificação da dispensação nas unidades de saúde. Ao Ministério da Saúde coube o gerenciamento, a aquisição e distribuição de medicamentos considerados estratégicos (para o tratamento de tuberculose, hanseníase, diabetes, hipertensão entre outros) e o financiamento do custeio para medicamentos chamados à época de excepcionais (de alto custo), cabendo aos estados uma contrapartida, regulamentada por uma série de portarias (CARVALHO; CASTRO; COUTO, 2007).

Em 2007, o governo federal regulamentou o financiamento e a transferência dos recursos para as ações e os serviços de saúde, na forma de três componentes do bloco de financiamento: básico, estratégico e especializado (VIEIRA, 2010; LIMADELLAMORA et al, 2012).

O Componente Básico da Assistência Farmacêutica (CBAF) é financiado pela União, estados, Distrito Federal e municípios, com aplicação de valores mínimos per capita pactuados na CIT. Cada estado tem autonomia para pactuar com os seus municípios a melhor estratégia de execução dos recursos destinados à aquisição de medicamentos básicos (MACHADO-DOS-SANTOS e NASCIMENTO, 2015).

Desde a publicação da portaria $\mathrm{n}^{\circ} 2.982$, em 2009, parte dos recursos pactuados no componente básico pode ser utilizada para atividades destinadas à adequação de espaço físico das Farmácias do SUS, à aquisição de equipamentos e mobiliário para o suporte às ações na rede de serviços de saúde, assim como à realização de atividades de qualificação da força de trabalho da assistência farmacêutica na atenção primária. Todavia, cabe ao gestor definir como e onde utilizar o recurso financeiro: se aquisição dos medicamentos ou organização e qualificação da assistência farmacêutica (BRASIL, 2009).

Diante da necessidade de apoiar a ampliar e consolidar a assistência farmacêutica, o Ministério da Saúde instituiu, em 2012, o Programa Nacional de Qualificação da Assistência Farmacêutica no âmbito do SUS (QUALIFAR- SUS). A estruturação dos serviços farmacêuticos no SUS, como estratégia de qualificação do acesso aos medicamentos e da gestão do cuidado, é uma diretriz do programa, organizado nos eixos estrutura, educação, informação e cuidado (BRASIL, 2012).

Embora seja uma iniciativa importante, o QUALIFAR- SUS é um programa e, portanto, não tem sustentabilidade em longo prazo. Assim, o componente básico foi reavaliado e, em 2013, o Departamento de Assistência Farmacêutica (DAF) do MS publicou nova portaria com as normas de financiamento do CBAF, permitindo que as Secretarias Municipais de Saúde (SMS) utilizem anualmente até 15\% da soma dos 
valores dos recursos financeiros estaduais, municipais e do Distrito Federal para atividades destinadas à adequação de espaço físico das farmácias do SUS nos municípios, aquisição de equipamentos e mobiliário destinados ao suporte das ações de assistência farmacêutica e realização de atividades vinculadas à educação continuada voltada à qualificação da força de trabalho da assistência farmacêutica na atenção básica (BRASIL, 2013a).

De modo geral, a gestão da assistência farmacêutica no SUS tem inúmeros desafios, entre os quais se destacam a relação direta com a organização e funcionamento dos serviços de saúde, à complexidade das demandas e necessidades em saúde, às limitações burocráticas, legais e econômicas da administração pública e, especialmente, à fragmentação na coordenação e operacionalização das atividades do ciclo da assistência farmacêutica nas três esferas de governo. Além disso, é preciso romper com a visão simplificada da maioria dos farmacêuticos sobre assistência farmacêutica, frequentemente sinônimo da mera gestão logística dos medicamentos, tendo como única meta o abastecimento regular dos serviços de saúde.

Apesar dos desafios, a estruturação da assistência farmacêutica no SUS vem sendo considerada uma estratégia fundamental para a ampliação e a qualificação do acesso da população aos medicamentos e para a consolidação do próprio sistema de saúde. Hoje se pode notar a existência de um lugar institucional destinado à gestão da assistência farmacêutica nas esferas de governo, geralmente presente no organograma das secretarias de saúde como uma coordenação. Todavia, ainda tem muito por fazer se considerar a participação ainda incipiente do farmacêutico no cotidiano do cuidado nos serviços de saúde, na dispensação ou na oferta de outros serviços farmacêuticos (MACHADO-DOS-SANTOS e NASCIMENTO, 2015; LEITE et al, 2015).

Nesse processo, as concepções sobre a gestão da assistência farmacêutica se modificaram, passando do gerenciamento de um ciclo logístico e operativo centrado no medicamento para um conjunto articulado de ações e racionalidades orientadas pelo cuidado ao usuário.

\subsection{GERENCIAMENTO DO MEDICAMENTO NO SUS}

O gerenciamento do medicamento se confunde com os ciclos operativos propostos para a racionalização da assistência farmacêutica. Um dos primeiros ciclos foi publicado pelo Management Science for Health (MSH) e era basicamente composto de 
quatro etapas fundamentais para a garantia do acesso aos medicamentos essenciais. Esse ciclo foi denominado Ciclo Gerencial da Assistência Farmacêutica (figura 17) e estava centrado no abastecimento de medicamentos nos sistemas de saúde (CONSELHO FEDERAL DE FARMÁCIA, 2002).

Figura 17. Ciclo Gerencial da Assistência Farmacêutica.

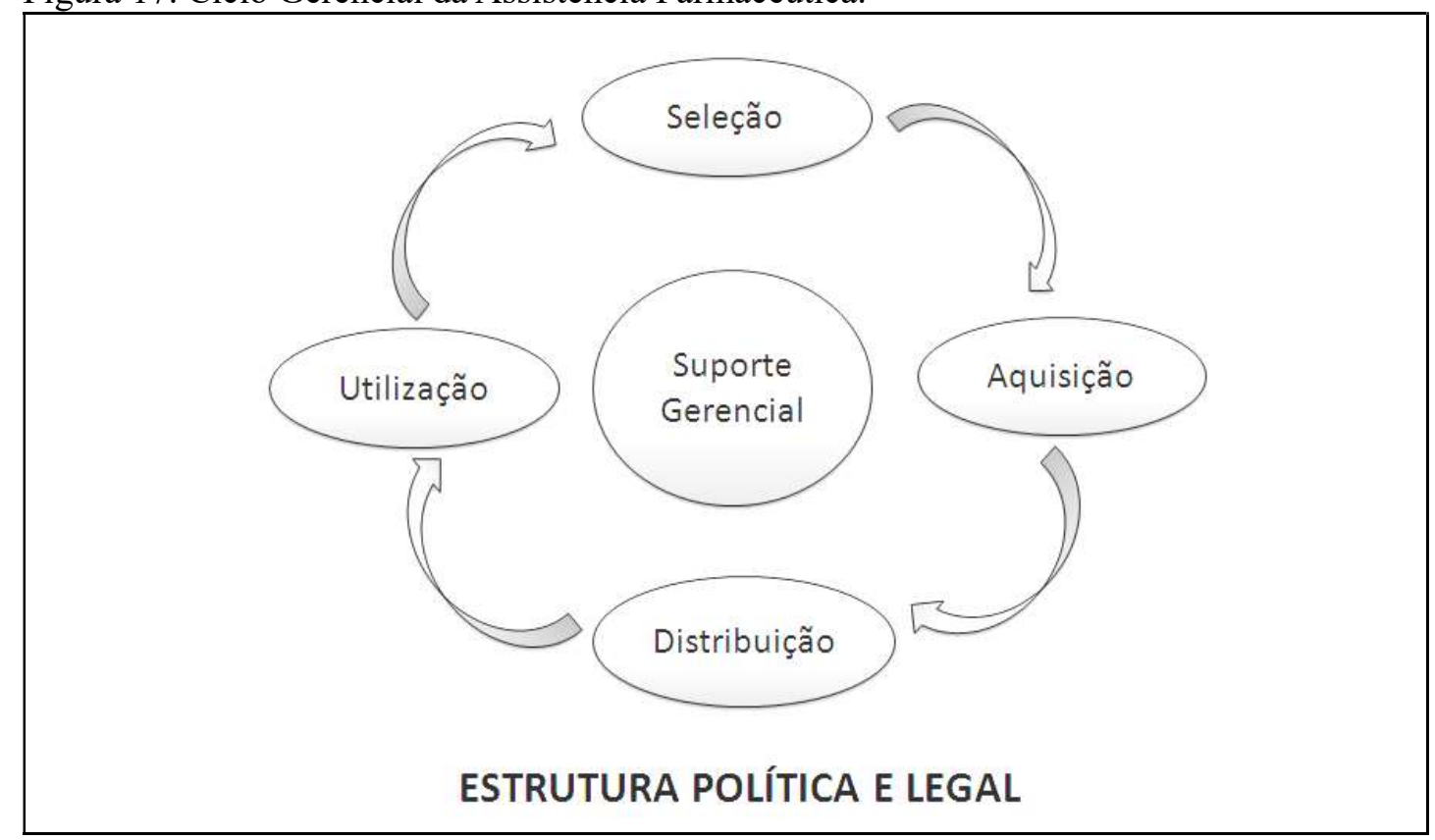

Fonte: CONSELHO FEDERAL DE FARMÁCIA (2002).

Com a implantação do SUS, as atividades de programação e armazenamento foram incluídas no Ciclo Gerencial da Assistência Farmacêutica. Assim, as atividades de seleção, programação, aquisição, armazenamento, distribuição e utilização contemplando a prescrição, dispensação e uso, passaram a compor o que ficou conhecido como ciclo da assistência farmacêutica (MARIN et al, 2003).

É importante destacar que o ciclo está apoiado em um arcabouço legal e político, que contempla aspectos relativos ao gerenciamento, financiamento, recursos humanos, sistema de informação, de controle e avaliação.

Com o objetivo de aproximar o ciclo do SUS, compreendendo a dimensão política da assistência farmacêutica, Oliveira, Bermudez e Osório-de-Castro (2007) propuseram um modelo que incorpora o processo de pesquisa e desenvolvimento, produção e registro de medicamentos e os aspectos políticos e normativos representados pela Vigilância Sanitária (figura 18). 
Figura 18. Ciclo da Assistência Farmacêutica no SUS.

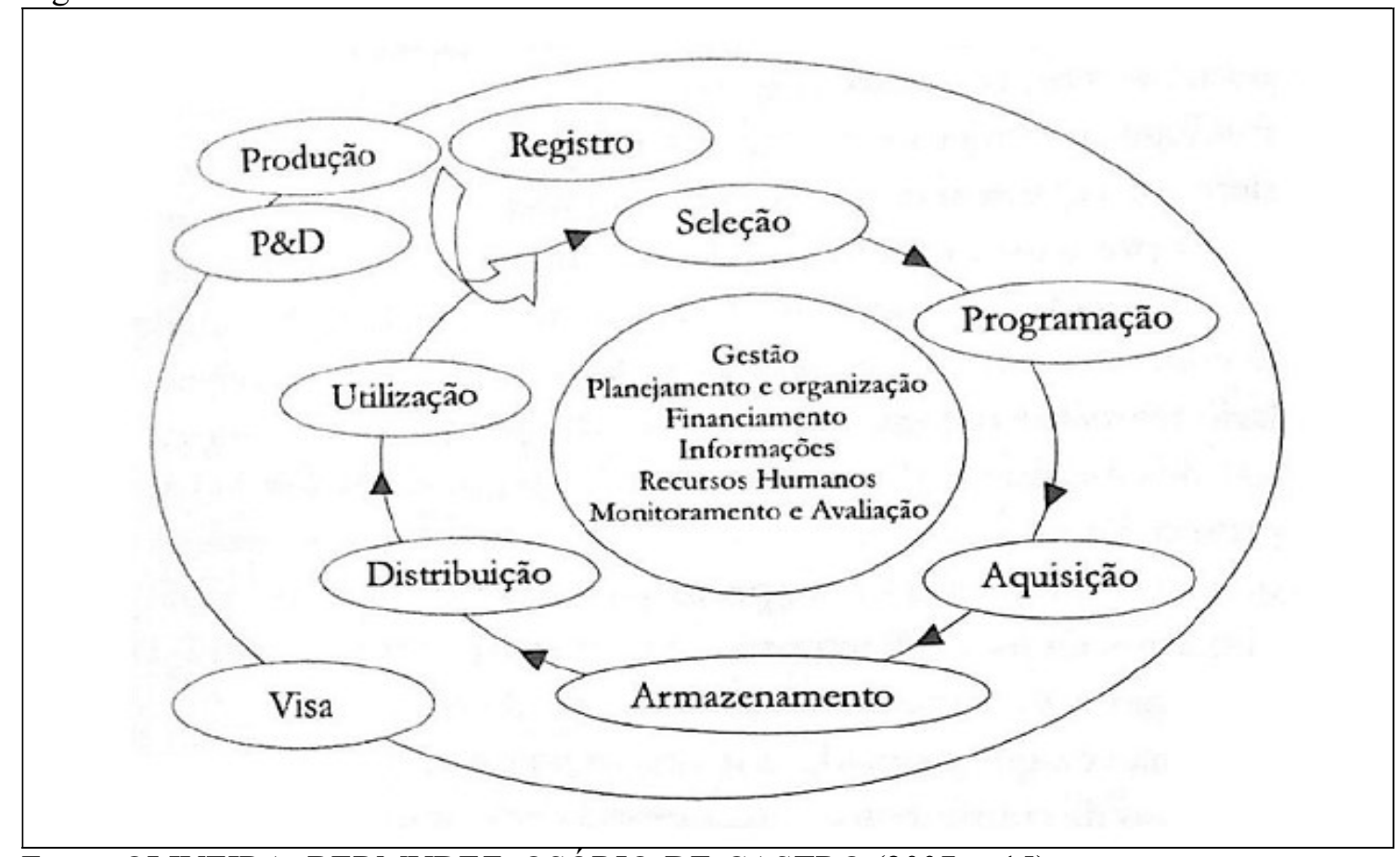

Fonte: OLIVEIRA; BERMUDEZ; OSÓRIO-DE-CASTRO (2007, p.15).

O ciclo se inicia pela seleção, que é o processo de escolha de medicamentos eficazes e seguros, para o atendimento das necessidades prioritárias da população, com a finalidade de garantir uma terapêutica medicamentosa de qualidade nos diversos níveis de atenção à saúde, realizada por Comissões de Farmácia e Terapêutica (CFT) ou congêneres, e tem como referência a Relação Nacional de Medicamentos Essenciais (RENAME). Depois de elaborada a relação de medicamentos essenciais do município, estado, distrito ou União, as coordenações de assistência farmacêutica procedem a programação, que consiste em estimar as quantidades a serem adquiridas pelo sistema ou serviço de saúde para atender as necessidades da população, definidas na seleção de medicamentos. Para que a programação seja o mais próxima da quantidade necessária para o período e para que não haja perdas, é importante o adequado registro do consumo de medicamentos nas unidades de saúde (MARIN et al, 2003; OLIVEIRA; BERMUDEZ; OSÓRIO-DE-CASTRO, 2007; OSÓRIO-DE-CASTRO et al, 2014).

Com base na legislação vigente, e especialmente nos princípios estabelecidos na Lei 8.666/93, os gestores realizam um conjunto de procedimentos para a compra dos medicamentos estabelecidos na programação, com o objetivo de abastecer a rede de serviços de saúde em quantidade, qualidade e melhor relação custo/efetividade possíveis. Para o efetivo abastecimento da rede de serviços, os medicamentos devem ser armazenados em locais apropriados, atendendo os requisitos técnicos e legais 
específicos referentes às Centrais de Abastecimento Farmacêutico (CAF), nas quais são realizadas atividades que envolvem a recepção/recebimento, estocagem, conservação, e controle de estoque de medicamentos, e distribuídos em tempo oportuno e com rapidez, por sistema de transporte adequado que garanta a qualidade e segurança dos medicamentos. Os serviços de saúde devidamente abastecidos devem ter condições estruturais, técnicas e operacionais para a efetivação da utilização de medicamentos, que é o uso propriamente dito de medicamentos pelo usuário, bem como é um momento importante no ciclo, diretamente relacionado aos resultados terapêuticos que se deseja (MARIN et al 2003; OLIVEIRA; BERMUDEZ; OSÓRIO-DE-CASTRO, 2007; OSÓRIO-DE-CASTRO et al, 2014).

Semelhantemente aos anteriores, nesse ciclo cada etapa depende da anterior e contribui diretamente para a viabilidade da seguinte. Portanto, a não execução ou execução inadequada de uma atividade prejudica todas as outras, comprometendo os objetivos e os resultados de todo o processo (OLIVEIRA; BERMUDEZ; OSÓRIO-DECASTRO, 2007).

Embora compreendam os aspectos que envolvem a utilização dos medicamentos, os ciclos logísticos e operativos da assistência farmacêutica apresentados até o momento foram concebidos no contexto do gerenciamento orientado pelo produto, especialmente à garantia do abastecimento e do acesso a medicamentos seguros e de qualidade nos serviços de saúde.

\subsection{SERVIÇOS FARMACÊUTICOS NA ATENÇÃO PRIMÁRIA}

Retomando conceitos apresentados no capítulo 4, a atenção primária se caracteriza por ações de promoção e proteção da saúde, prevenção de agravos, diagnóstico, tratamento, reabilitação, redução de danos e manutenção da saúde, que garantam o cuidado integral das pessoas, da família e da comunidade. É estratégica e central no modelo brasileiro de atenção à saúde e está organizada pela Estratégia de Saúde da Família (ESF), cujas ações são realizadas por equipes multiprofissionais. Além da ESF, a atenção primária conta o Núcleo de Apoio à Saúde da Família (NASF), que ampliou e diversificou a força de trabalho ao incluir outras categorias profissionais (farmacêuticos, fonoaudiólogos, profissionais de educação física, fisioterapeutas etc) no cuidado prestado aos usuários do sistema de saúde (GIL, 2006; BRASIL, 2014; SUMAR e FAUSTO, 2014; CARVALHO et al, 2016a). 
Os serviços de saúde existem para atender às necessidades de saúde das pessoas, que são social e historicamente construídas e só podem ser captadas na dimensão individual. O cuidado é resultado da combinação do atendimento de todas as necessidades de saúde, que podem ser agrupadas em quatro conjuntos: boas condições de vida, acesso às tecnologias (leves, leve-duras e duras), criação de vínculos e autonomia das pessoas. Contudo, se deve considerar que os usuários são produtores sentidos para o cuidado que recebem, ou seja, a mais dura tecnologia pode ser sentida como cuidadora. Por exemplo, depois de vencer todas as barreiras de acesso, ao ser submetido a uma tomografia ou ressonância magnética, ambas tecnologias duras, o usuário pode experimentar e traduzir o momento como altamente cuidador. Embora o cuidado seja multidimensional, vale chamar atenção para a dimensão profissional do cuidado que se dá no encontro entre profissionais de saúde e os usuários (NOGUEIRA e GOMES, 2012; LACAZ e CECÍLIO, 2012).

Nesse contexto, a assistência farmacêutica tem passado por inúmeras transformações, entre as quais se destaca o deslocamento da centralidade no gerenciamento do produto para a gestão orientada pelo cuidado da saúde das pessoas, da família e da comunidade. Portanto, a disponibilidade de medicamentos na atenção primária deve atender às necessidades em saúde, por meio do abastecimento suficiente, regular e oportuno, de forma integrada ao cuidado (care) orientado ao uso correto e seguro de medicamentos, realizado nos serviços de saúde do território (MARIN et al, 2003; BRASIL, 2014).

A concepção de "profissional do medicamento", tem origem histórica e ainda está fortemente enraizada nos farmacêuticos, é um dos desafios para a efetiva mudança do escopo do trabalho farmacêutico nos sistemas de saúde. Possivelmente em função dessa concepção do farmacêutico sobre o seu trabalho, as outras categorias profissionais e a própria sociedade acabem também associando o trabalho farmacêutico ao produto e tudo que se refere ao seu provimento. Médicos e enfermeiros geralmente associam o trabalho farmacêutico às atividades relacionadas estritamente ao produto, tais como conhecimento sobre a composição, mecanismo de ação e interações, controle de estoque e fornecimento ou dispensação dos medicamentos, relato de reações adversas etc (LOCH-NECKEL e CREPALDI, 2009; UPOTEY VARELA et al, 2011; MANZINI et al, 2015).

Em função do constante desabastecimento de medicamentos nos serviços de saúde, que enchiam os jornais na época da Central de Medicamentos (CEME), extinta 
em 1997, as funções logísticas da assistência farmacêutica, especialmente aquisição, armazenamento e distribuição, ganharam cada vez mais centralidade no trabalho farmacêutico, enquanto que as atividades referentes ao cuidado foram deslocadas à periferia, tais como dispensação, acompanhamento/seguimento farmacoterapêutico e atenção farmacêutica.

O termo pharmaceutical care foi empregado pela primeira vez em 1984, mas teve ampla notoriedade na década de 1990, quando definido pela farmacêutica norteamericana Linda Strand como a prática em que o farmacêutico se responsabiliza pelas necessidades do paciente relacionadas a medicamentos e responde por esse compromisso (PEREIRA e NASCIMENTO, 2011).

Com base na proposição de Strand, a OMS preconizou a atenção farmacêutica como modelo de prática farmacêutica nos serviços de saúde para o atendimento das necessidades da população (MARIN et al, 2003). Na publicação "How to Investigate Drug use in Health Care Facilities: selectec drug use indicators", de 1993, a OMS definiu pharmaceutical care como "um conjunto de atitudes, comportamentos, compromissos, inquietações, valores éticos, funções, conhecimentos, responsabilidades e destrezas do farmacêutico na prestação da farmacoterapia", com o objetivo de alcançar resultados terapêuticos (WHO, 1993, p. 4). Nesse momento, o farmacêutico assumiu que as suas atividades também envolvem o cuidado direto ao usuário de medicamentos e que não basta entregar e orientar, mas é preciso se comprometer efetivamente com os resultados terapêuticos.

Esse termo se espalhou pelo mundo e nos países de origem latina, especialmente na Espanha, foi traduzido como atención farmacéutica. No Brasil, em 2002, foi publicado o Consenso Brasileiro sobre Atenção Farmacêutica, que diz que atenção farmacêutica é modelo de prática farmacêutica que:

Compreende atitudes, valores éticos comportamentos, habilidades, compromissos e corresponsabilidades na prevenção de doenças, promoção e recuperação da saúde, de forma integrada à equipe de saúde. É a interação direta do farmacêutico com o usuário, visando uma farmacoterapia racional e a obtenção de resultados definidos mensuráveis voltados para a melhoria da qualidade de vida. Esta interação também deve envolver as concepções dos seus sujeitos, respeitadas as suas especificidades biopsicossociais sob a ótica da integralidade das ações de saúde (OPAS, 2002, p. 16-17). 
Segundo Hernandez et al (2011), cuidar é antes de tudo um ato que representa uma variedade de atividades dirigidas a manter e conservar a vida, permitindo que esta continue e se reproduza. É um ato de reciprocidade que se tende a dar, de modo temporal ou definitivo, a qualquer pessoa que precise de ajuda no atendimento às suas necessidades essenciais.

No processo de recomposição do cuidado no trabalho farmacêutico, outros termos também foram cunhados na década de 1990, como é o caso de serviços farmacêuticos (servicios farmacéuticos).

Para Marin (1999), os serviços farmacêuticos são ofertados no processo de atenção à saúde e, além do fornecimento de medicamentos de qualidade, tem como objetivos a contribuição para a promoção de hábitos de vida saudáveis para a população, a garantia do uso racional de medicamentos, e, por fim, a dispensação e os cuidados farmacêuticos de qualidade nos serviços de saúde.

No documento "Diretrizes para estruturação de farmácias no âmbito do Sistema Único de Saúde”, publicado em 2009, o Ministério da Saúde refere que os serviços farmacêuticos têm a "finalidade de propiciar o acesso qualificado aos medicamentos essenciais disponibilizados pela rede pública a seus usuários", "são integrados aos serviços de saúde e compreendem atividades administrativas" e envolvem atividades técnico-gerenciais, que exigem "conhecimentos e informações epidemiológicas, administrativas e gerenciais para o planejamento e execução das ações", e técnicoassistenciais, que, por sua vez, demandam "conhecimentos sobre os medicamentos, a terapêutica, as habilidades e as competências para estabelecer a relação com os usuários dos serviços e a equipe de profissionais de saúde" (BRASIL, 2009, p. 16 e 22).

Essa concepção de serviços farmacêuticos está fortemente fundamentada na logística do medicamento, especialmente no gerenciamento e na técnica, ao dar ênfase ao acesso como finalidade. Contudo, traz avanços importantes ao tratar a relação entre o farmacêutico e o usuário e a comunicação como elementos estruturantes das atividades técnico-assistenciais, ou seja, aquelas realizadas entre o acesso e o uso do medicamento.

A participação do farmacêutico no SUS, portanto, não envolve apenas a logística de abastecimento de medicamentos, que se refere à execução de atividades técnicogerenciais em forma de etapas dentro de um ciclo operativo, como vimos na seção anterior. Atualmente se pode dizer que o papel do farmacêutico no sistema de saúde envolve a gestão, a tecnologia e o cuidado das pessoas, da família e da comunidade por 
meio da oferta de serviços farmacêuticos orientados para o acesso e o uso correto e seguro de medicamentos essenciais e de outras tecnologias utilizadas no processo de cuidado, tais como diagnóstico laboratorial, alimentos funcionais, cosméticos etc (BRASIL, 2009; BRASIL, 2014; MANZINI et al, 2015).

Segundo a Organização Pan-Americana de Saúde (OPAS), um dos objetivos da prestação de serviços farmacêuticos é alcançar os melhores resultados possíveis de saúde e melhorar a qualidade de vida dos indivíduos, famílias e comunidades. Por definição, os serviços farmacêuticos consistem em um:

\begin{abstract}
Conjunto de ações no sistema de saúde destinadas a garantir o atendimento integral, integrada e continua com as necessidades e problemas da saúde tanto individual e populacional e coletivamente, de tomar o medicamento como um dos elementos essenciais, e contribuindo para o seu acesso equitativo e seu uso racional. Essas ações, realizadas pelo farmacêutico, ou sob a sua coordenação incorporado a uma equipe de saúde e com a participação comunitária, tem como objetivos a obtenção de resultados concretos na área da saúde, com vista a melhora da qualidade de vida da população (OPAS, 2013, p. 3).
\end{abstract}

Os serviços farmacêuticos devem contribuir para o cuidado da saúde individual e coletiva da população por meio da participação ativa do farmacêutico na equipe de saúde e na comunidade, e implicam atividades de promoção da saúde, dispensação, acompanhamento/seguimento farmacoterapêutico, farmacovigilância, apoio à automedicação responsável, entre outros (OPAS, 2013).

Além disso, esses serviços fazem parte do ciclo da assistência farmacêutica. Enquanto a assistência farmacêutica é multiprofissional, preferencialmente coordenada pelo farmacêutico, e visa garantir o acesso aos medicamentos pela população, os serviços farmacêuticos consistem em atividades realizadas exclusivamente pelo farmacêutico, envolvendo o usuário direta ou indiretamente.

Nessa perspectiva, recentemente, o MS publicou uma série de cadernos intitulados "Cuidado farmacêutico na atenção básica", nos quais os serviços farmacêuticos na atenção primária podem ser vistos sob dois pontos de vista, um da logística, que inclui o planejamento e o abastecimento, e o outro do cuidado farmacêutico, que envolve as dimensões clínico-assistencial e técnico-pedagógica descritas no trecho a seguir. 
A primeira refere-se ao cuidado farmacêutico e às ações clínicas diretas aos usuários, de forma individual ou compartilhada. Já a segunda se refere às ações que atendam, mais diretamente, às necessidades das equipes envolvidas no cuidado, por meio de educação permanente e de outras ações compartilhadas. A aposta, então, é que o farmacêutico possa qualificar a atenção integral aos usuários a partir da sua prática clínica, e também potencializar ações realizadas pelos demais profissionais no que se refere ao uso racional de medicamentos, seja no âmbito da promoção, da prevenção ou da reabilitação em saúde (BRASIL, 2014, p. 58).

Tomando como base a teoria do trabalho em saúde e as tecnologias de produção do cuidado de Emerson Elias Merhy, discutida no capítulo 2, o serviço farmacêutico ofertado nos sistemas de saúde se transforma em cuidado farmacêutico no encontro entre o farmacêutico e o usuário, e pode se materializar em inúmeras atividades, que vão desde a dispensação de medicamentos às ações nas equipes de saúde, o que inclui as visitas domiciliares, até os serviços clínico-farmacêuticos estruturados.

Nesse sentido, a assistência farmacêutica, um dos elementos constitutivos das Redes de Atenção à Saúde (RAS) como sistema de apoio à estrutura operacional, deve ser compreendida para além das suas funções logísticas de abastecimento do sistema de saúde. De fato, os serviços farmacêuticos realizados no seu âmbito devem ser compreendidos como sistema de apoio, ao compreenderem um conjunto de ações orientadas ao suprimento de medicamentos e disponibilização de produtos de modo oportuno, regular, suficiente e com qualidade, e pontos de atenção da RAS, ao se configurarem como serviços clínico-assistenciais ofertados nas diversas unidades da rede, cuja finalidade é promover o uso correto e seguro de medicamentos para o individuo, a família e a comunidade (BRASIL, 2011; BRASIL, 2014).

Ao considerar a assistência farmacêutica na RAS como ponto de atenção, para além dos aspectos legais, o momento da dispensação deve ser valorizado, pois envolve o conhecimento técnico, habilidades de comunicação e atitudes éticas, de respeito ao usuário e de valorização de seu direito à informação. Para Pepe e Castro (2000), é uma das últimas oportunidades de, ainda no serviço de saúde, avaliar os medicamentos prescritos, identificar, corrigir ou reduzir eventuais riscos associados à terapêutica.

Segundo Sartor e Freitas (2014), a dispensação é um serviço que possui cinco dimensões: acolhimento ao paciente; avaliação da prescrição, separação e preparação dos medicamentos, orientação durante o fornecimento/entrega de medicamentos e registro de dados e informações geradas (figura 19). 
Figura 19. Serviço de dispensação de medicamentos.

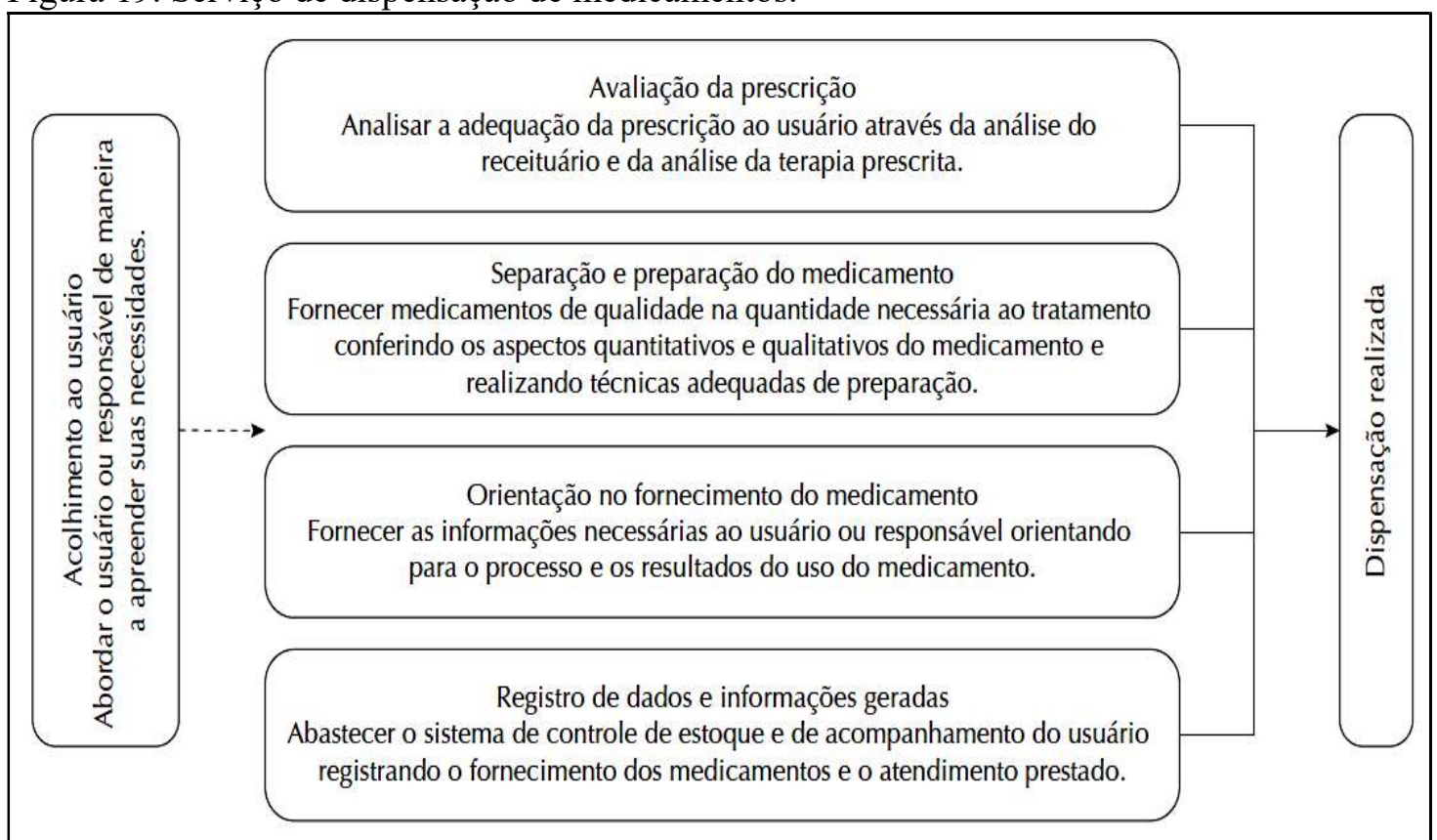

Fonte: Sartor e Freitas (2014, p. 830).

Durante a dispensação e o acompanhamento/seguimento farmacoterapêutico, a comunicação com o usuário sobre o uso correto de medicamentos é importante porque facilita a identificação de problemas de saúde e relacionados ao uso de medicamentos (POSSAMAI e DACOREGGIO, 2008).

Ao contrário do gerenciamento orientado pelo produto, na gestão orientada pelo usuário, a produção de cuidado deve nortear todas as atividades da assistência farmacêutica, que interagem de forma sistêmica e concomitante, ao contrário do gerenciamento do medicamento, em que as ações ocorrem em etapas fragmentadas e seqüenciais com o objetivo de garantir o abastecimento $\mathrm{e}$ fornecimento de medicamentos nos serviços de saúde.

Em suma, todas as atividades devem conduzir ao uso correto e seguro de medicamentos. O usuário deve receber o medicamento apropriado para as suas necessidades, em doses adequadas, por um período de tempo adequado, ao menor custo para si e sua comunidade, a partir do trabalho realizado pelo farmacêutico no contexto dos serviços de saúde, individualmente e ou numa equipe multiprofissional, seja em uma UBS ou em hospital. Portanto, a comunicação entre farmacêutico e usuário e farmacêutico e equipe de saúde é extremamente importante porque facilita a identificação de PRM, tanto individual como coletivamente (WHO, 1987; POSSAMAI e DACOREGGIO, 2008). 


\subsection{TRABALHADORES E TRABALHO NA ASSISTÊNCIA FARMACÊUTICA BÁSICA}

No mundo, e também no Brasil, o debate sobre o trabalho em saúde em todos os setores, inclusive na farmácia, ganhou destaque com a publicação do Relatório Mundial da Saúde 2006, que aponta a escassez de trabalhadores e a distribuição desigual da força de trabalho no setor saúde (ORGANIZAÇÃO MUNDIAL DA SAÚDE, 2007; FIP, 2012).

A maioria dos estudos brasileiros desenvolvidos sobre força de trabalho em saúde se refere à enfermagem em seus diversos cenários de trabalho. Em relação às outras categorias de trabalhadores de nível superior ainda há poucos estudos, especialmente na AB. Esses estudos, em geral, consistem em análises sobre o dimensionamento da força de trabalho (MACHADO e POZ, 2015).

Em 1988, um grupo consultivo da OMS se reuniu em nova Delhi para discutir o papel do farmacêutico no sistema de saúde. O relatório dessa reunião é considerado um marco para a reorientação da atuação do farmacêutico nos sistemas de saúde, deslocando a centralidade das ações no medicamento e voltando-as ao usuário. Houve, então, o reconhecimento de que o farmacêutico é o profissional com melhor capacitação para conduzir as ações destinadas à melhoria do acesso e promoção do uso racional dos medicamentos, sendo ele indispensável para organizar os serviços necessários para o desenvolvimento pleno da assistência farmacêutica (OPAS, 1993; ARAUJO et al, 2008).

A discussão sobre força de trabalho na assistência farmacêutica no SUS é peculiar e merece destaque. Entre 2008 e 2013, o número de farmacêuticos cadastrados nas UBS cresceu 75\% no país. À exceção do Nordeste (45\%), as taxas de crescimento foram superiores a 50\% nas demais regiões: Norte (54\%), Centro-Oeste (78\%), Sudeste (95\%) e Sul (59\%), o que possivelmente foi possível por dois fatores: implantação do NASF e crescimento da assistência farmacêutica no país. Além disso, o Brasil é um dos poucos países que tem um modelo público de assistência farmacêutica em que o farmacêutico coordena todas as atividades relacionadas à cadeia do medicamento nas esferas governamentais, desde a seleção até o uso (ARAUJO et al, 2008; CARVALHO et al, 2016a).

Estudos mostram que, apesar do crescimento da categoria farmacêutica como força de trabalho, profissionais de nível técnico e outras categorias profissionais atuam 
nos serviços de dispensação de medicamentos públicos e privados (VEBER et al, 2011; ARRAIS et al, 2007). Nesse contexto, conhecer a força de trabalho da assistência farmacêutica na atenção primária é imprescindível para a avaliação das conquistas e desafios relativos à gestão da disponibilidade, acesso e utilização de medicamentos no país, permitindo a elaboração e acompanhamento de políticas públicas correspondentes com as reais necessidades relativas à formação e qualificação de trabalhadores para o desenvolvimento da assistência farmacêutica e obtenção dos melhores resultados de saúde com os serviços de assistência farmacêutica.

Esta seção apresenta resultados da Pesquisa Nacional sobre Acesso, Utilização e Uso Racional de Medicamentos (PNAUM), cujo objetivo foi caracterizar a organização dos serviços de assistência farmacêutica na atenção primária do SUS, visando o acesso e a promoção do uso racional de medicamentos, bem como identificar e discutir os fatores que interferem na consolidação da assistência farmacêutica no âmbito municipal.

A PNAUM é um estudo transversal, exploratório, de natureza avaliativa, composto por um levantamento de informações numa amostra representativa de serviços de atenção primária, em municípios das regiões do Brasil. Ao final da pesquisa foram realizadas entrevistas com 507 coordenadores da assistência farmacêutica e com 1.139 responsáveis pela entrega de medicamentos nas unidades de dispensação (ÁLVARES et al, 2016).

Os dados da PNAUM mostram que a força de trabalho da assistência farmacêutica na atenção primária é predominantemente composta por mulheres, de 18 a 39 anos, com vínculo empregatício efetivo, há mais de um ano no cargo ou atividade e jornada de trabalho semanal superior a 30 horas. A escolaridade, por sua vez, varia de acordo com a atividade: nível superior na coordenação e nível técnico e ou auxiliar nas unidades de saúde, como veremos detalhadamente adiante.

\subsubsection{Perfil dos trabalhadores}

As mulheres são a maioria dos trabalhadores na função de coordenação da assistência farmacêutica em quase todas as regiões, porque no Nordeste os homens ocupam 50,1\% (IC95\% 39,2\% - 61,0\%; $p=0,008$ ) dos cargos de coordenação nos municípios, e também maioria dos trabalhadores das unidades de dispensação de medicamentos dos serviços de saúde da atenção primária em todas as regiões, com 
destaque para o Nordeste e o Sul, com participação em mais $80 \%$ dos municípios (figura 20).

Figura 20. Distribuição dos trabalhadores da coordenação e das unidades de dispensação, por sexo (Brasil e regiões, 2015).

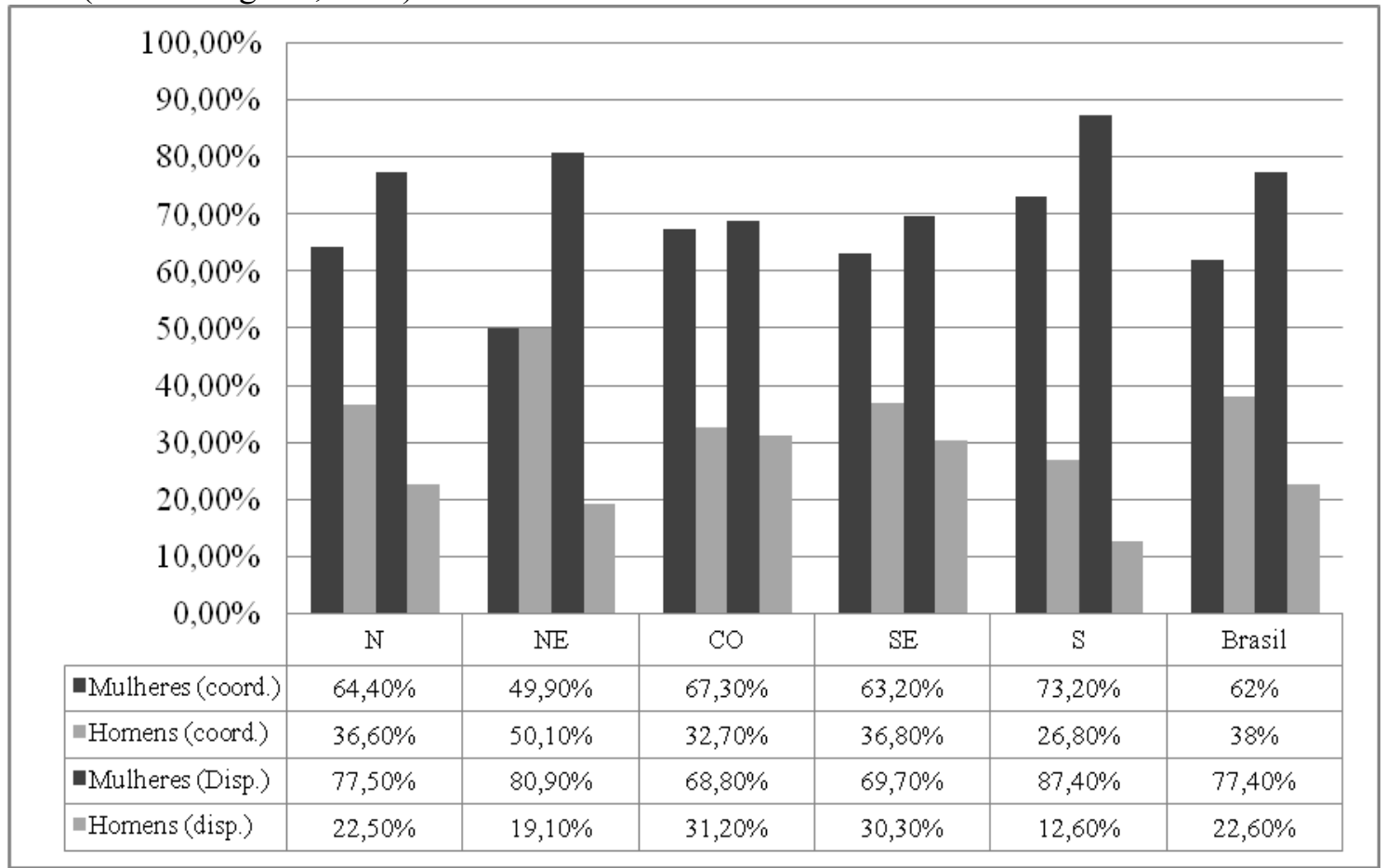

Fonte: PNAUM / MS (2015). $p$ valor (coordenação) $=0,008 ; p$ valor $($ dispensação $)=0,087$.

A participação das mulheres nessas funções é possivelmente motivada por razões diferentes. Enquanto a coordenação é hegemonicamente constituída por mulheres com formação superior, especialmente por graduação em Farmácia, a entrega de medicamentos ao usuário é realizada por mulheres com nível médio de escolaridade, fundamentalmente técnicas ou auxiliares de enfermagem. A literatura aponta que a inserção da mulher no mercado de trabalho da saúde é um fenômeno crescente no setor saúde, que conta mais de $70 \%$ de mulheres na força de trabalho. Em vários cursos de graduação da área da saúde, inclusive no curso de Farmácia, as mulheres já ocupam mais da metade das vagas oferecidas. Entre os profissionais de nível médio, a tendência a feminização é mais forte, representando $86,9 \%$ dos técnicos e auxiliares de enfermagem (MATOS; TOASSI; OLIVEIRA, 2013).

Contudo, alguns autores são cautelosos e não interpretam a hegemonia feminina em várias profissões como indicador de modernização, desenvolvimento ou evolução. Pelo contrário, percebem o lado perverso da intensificação da participação das mulheres no mercado de trabalho: as mulheres são mão de obra mais barata e aceitam trabalhar 
em condições mais precárias que os homens (GUEDES, 2010; WERMELINGER et al, 2010; BARBOSA et al, 2012).

Figura 21. Distribuição dos trabalhadores da coordenação e das unidades de dispensação, por faixa etária (Brasil e Regiões, 2015).

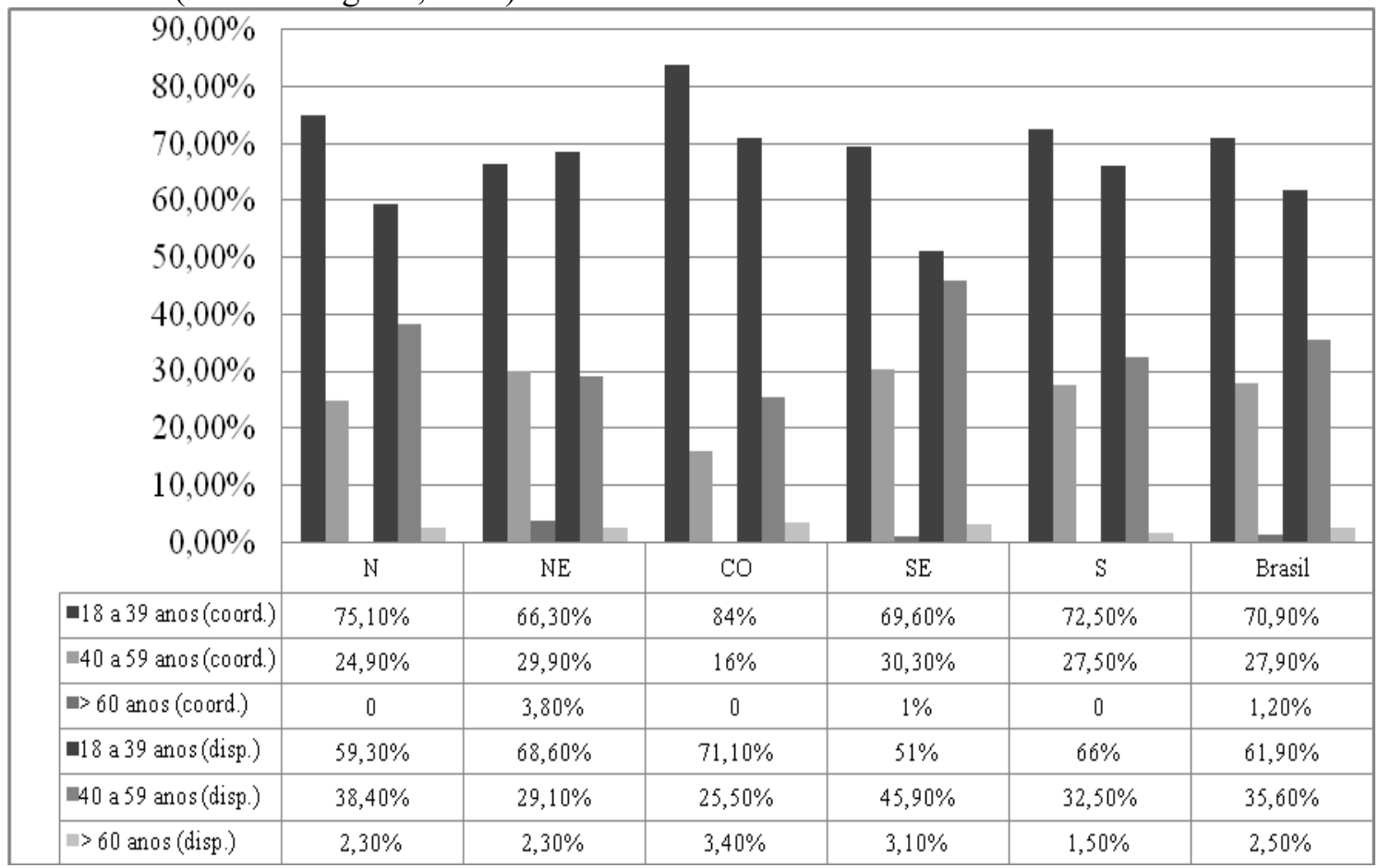

Fonte: PNAUM / MS (2015). $p$ valor (coordenação) $=0,022 ; p$ valor $($ dispensação $)=0,139$.

A figura 21 demonstra que a maioria da força de trabalho da assistência farmacêutica, tanto na coordenação quanto nas unidades de dispensação, é jovem, situada na faixa etária de 18 a 39 anos.

Nota-se que região Sudeste se destaca porque as faixas de 18 a 39 anos e 40 e 59 anos praticamente se equivalem, ou seja, a força de trabalho está quase que equitativamente distribuída nessas idades.

A coordenação da assistência farmacêutica municipal é composta predominantemente por trabalhadores com formação superior $(75,5 \%$; IC 95\% 70,8\% 79,6\%), seguidos de profissionais com pós-graduação lato sensu (21,1\%; IC 95\% 12,7\% - 25,7\%) ou stricto sensu (2,2\%; IC 95\% 1,1\% - 4,5\%) e ensino médio (1,2\%; IC 95\% $0,6 \%-2,1 \%)$. Regionalmente, o Nordeste se destaca por três aspectos importantes: 22,2\% (IC95\% 14,4\% - 32,8\%) dos municípios têm coordenadores com especialização e 3,8\% (IC95\% 1,2\% - 11,4\%) com mestrado ou doutorado em alguma área do conhecimento. 
Entre os trabalhadores de nível superior, os farmacêuticos são a maioria $(90,7 \%)$, seguidos de outros profissionais de nível superior, que representam apenas 6,9\%. Regionalmente, os farmacêuticos são hegemônicos em todas as regiões, com variação entre $84,5 \%$ no Norte e $95 \%$ no Sul (figura 22 ).

Figura 22. Distribuição do trabalhador da coordenação da assistência farmacêutica municipal, por escolaridade e formação (Brasil e regiões, 2015).

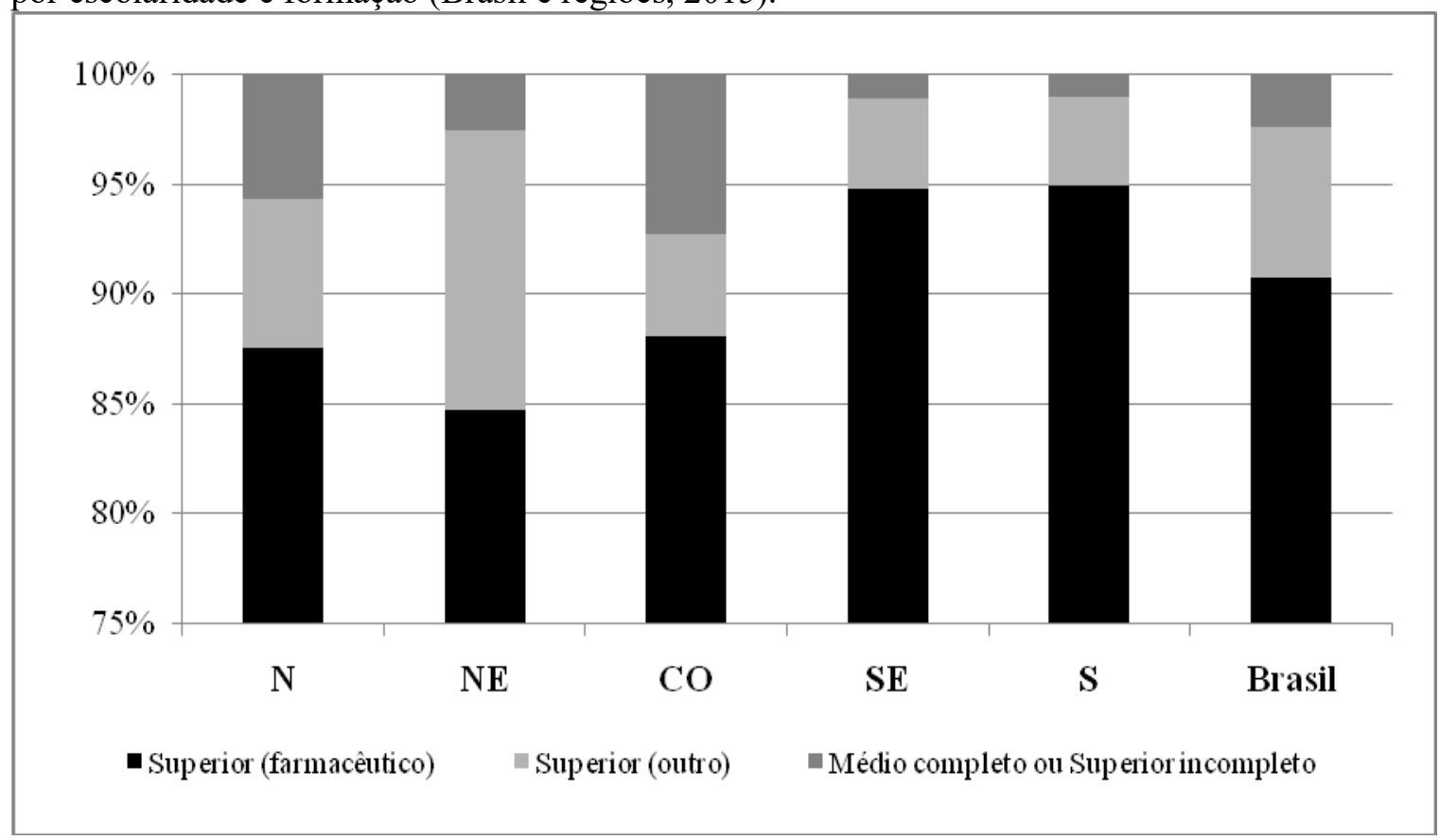

Fonte: PNAUM / MS (2015). $p$ valor 0,023.

A participação massiva dos farmacêuticos na função de coordenação provavelmente se deve a inúmeros fatores, que vão desde a existência de políticas norteadoras do setor, tais como a Política Nacional de Assistência Farmacêutica (PNAF), às iniciativas da reorientação da assistência farmacêutica no SUS e a estruturação da assistência farmacêutica no nível municipal (LEITE et al, 2015).

Ao contrário do observado na coordenação, nas unidades de dispensação de medicamentos dos serviços de saúde da atenção primária do SUS, a força de trabalho é majoritariamente composta por técnicos ou auxiliares de enfermagem (43,0\%; IC95\% 36,0 - 50,4), seguidos dos trabalhadores com formação superior, especialmente o farmacêutico (33,3\%; IC 95\% 26,4\% - 40,9\%) e o enfermeiro (10,8\%; IC 95\% 7,2\% $15,7 \%$ ).

A escolaridade e a formação do trabalhador da unidade de dispensação de medicamentos variam de acordo com a região. Nas regiões Norte, Sul e Nordeste, o trabalhador de nível médio (em geral, técnico ou auxiliar de enfermagem) é 
predominante. No Centro-Oeste e Sudeste os farmacêuticos estão em maior número (57,1\%, IC95\% 41,0\% - 71,9\%; 64,1\%, IC95\% 45,9\% - 78,9\%; $p$ valor 0,000 respectivamente) e no Nordeste, $21,5 \%$ (IC95\% 12,6\% - 34,0\%) dos municípios conta com enfermeiro como profissional que realiza a entrega de medicamentos nas unidades de saúde da atenção primária (figura 23).

Figura 23. Distribuição dos trabalhadores das unidades de dispensação, por escolaridade e formação (Brasil e regiões, 2015).

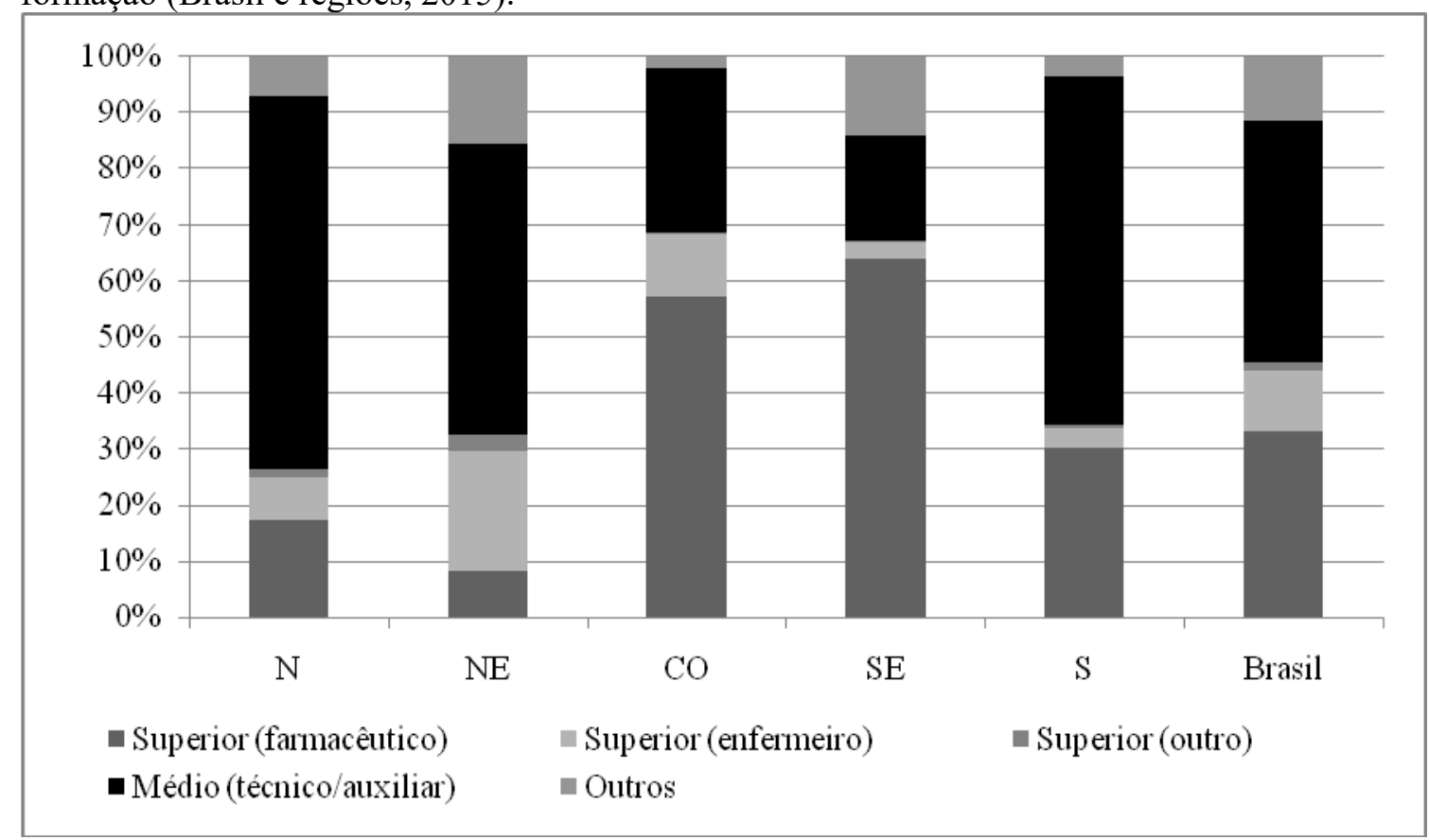

Fonte: PNAUM / MS (2015). $p$ valor 0,000.

Apesar da baixa ocorrência do farmacêutico na atenção primária, em um estudo realizado por Loch-Neckel e Crepaldi (2009), médicos, enfermeiros e cirurgiõesdentistas (odontólogos) de equipes da Estratégia em Saúde da Família (ESF) reconhecem a importância do farmacêutico para a ESF e relatam como principais atribuições desse profissional nas unidades de saúde: a) o conhecimento sobre medicamentos, especialmente composição e interações farmacológicas, b) o controle de estoque e organização da farmácia e c) a dispensação de medicamentos.

Semelhantemente aos achados do estudo brasileiro, um estudo realizado em Cuba identificou que as funções farmacêuticas mais reconhecidas pelos médicos e enfermeiros da atenção primária e dos hospitais se referem ao fornecimento de medicamentos e ao relato de reações adversas. Além disso, consideram a integração do farmacêutico com a equipe de saúde foi considerada regular (UPOTEY VARELA et al, 2011). 


\subsubsection{Caracterização do trabalho}

A maioria dos trabalhadores na gestão e na assistência ingressou no trabalho por concurso público (56\% e 57\%, respectivamente). Diferentemente do resultado nacional, as regiões Norte e Nordeste apresentaram distribuição proporcional entre concursados e comissionados na coordenação municipal da assistência farmacêutica e predomínio de servidores contratados nas unidades de dispensação (53,4\% e 48,5\%, respectivamente), conforme a figura a seguir.

Figura 24. Distribuição dos trabalhadores da coordenação e das unidades de dispensação, por tipo de vínculo de trabalho (Brasil e Regiões, 2015).

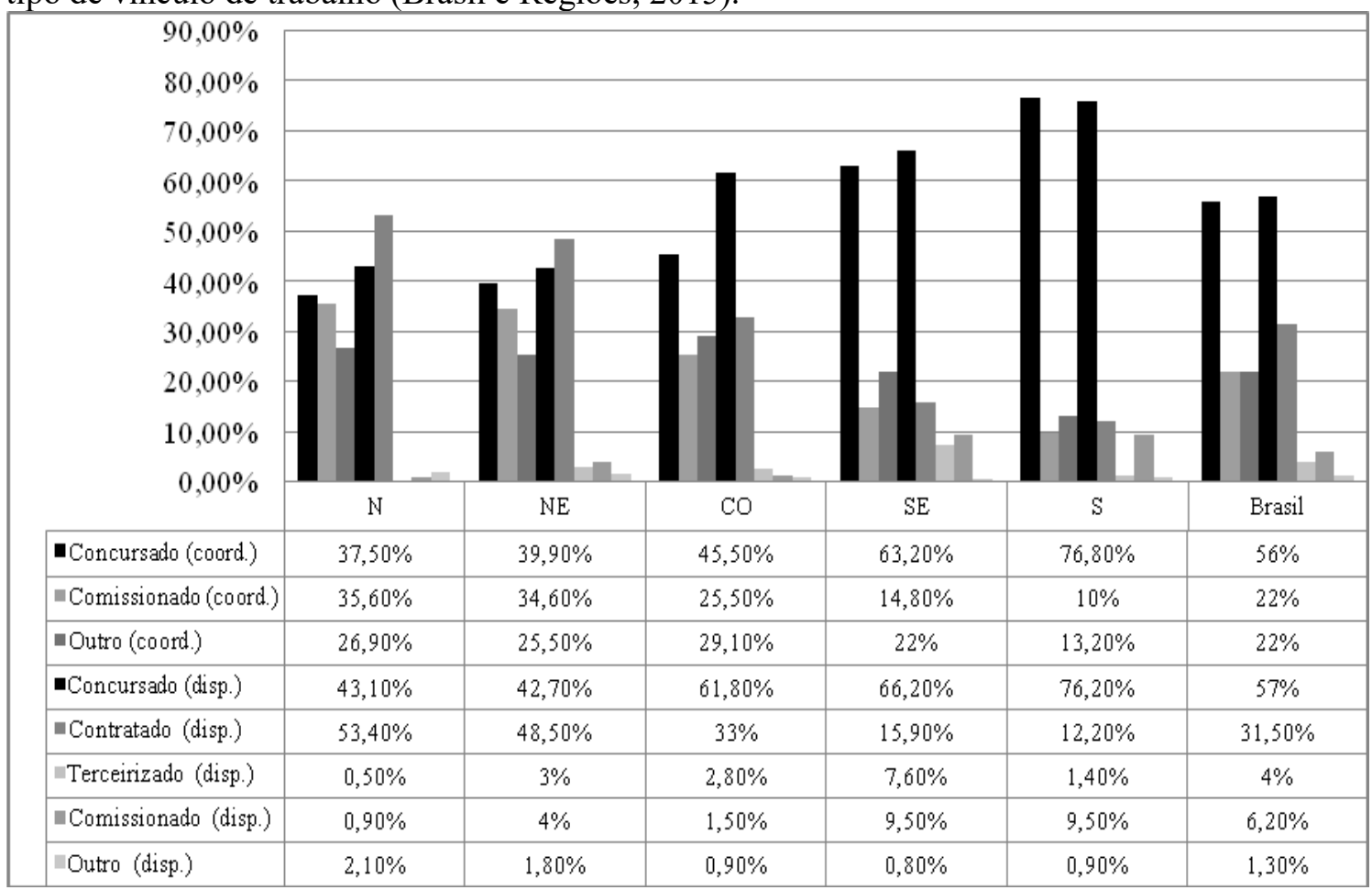

Fonte: PNAUM / MS (2015). Concursado $=$ Servidor concursado/cedido. $p$ valor (coordenação) $=0,000$; $p$ valor (unidade de dispensação) $=0,001$.

No Centro-Oeste, Sudeste e Sul mais de 60\% dos municípios possuem trabalhadores concursados, enquanto que nas regiões Norte e Nordeste o percentual de concursados e contratados é proporcional. Vale destacar a presença de trabalhadores terceirizados nas unidades de dispensação de medicamentos, variando de 0,5\% (IC95\% 0,1\% - 3,5\%) no Norte a 7,6\% (IC95\% 3,5\% - 15,6\%) no Sudeste, ou seja, aproximadamente $35 \%$ dos trabalhadores das unidades de dispensação são contratados ou terceirizados, o que pode indicar uma tendência de flexibilização e até precarização das relações de trabalho. 
Enquanto os servidores concursados são a maioria nas regiões Centro-Oeste, Sudeste e Sul, as regiões Norte e Nordeste se destacam pelo predomínio de servidores contratados. A terceirização representa 7,6\% do vínculo de trabalho na região Sudeste, o que provavelmente se deve a muitos fatores, entre os quais estão as limitações impostas pela Lei de Responsabilidade Fiscal.

A terceirização, uma das principais expressões de flexibilização, é uma forma especial de privatização que a administração pública utiliza para transferir parcialmente a responsabilidade da produção de alguns serviços, por meio da contratação de terceiros. Embora seja uma forma eficaz de garantir o cumprimento da Lei de Responsabilidade Fiscal, a flexibilização apresenta duas tendências: a desregulamentação da proteção do emprego e a precariedade das relações de trabalho (ALVES et al, 2010; MARQUES, 2013).

Figura 25. Distribuição dos trabalhadores da coordenação e das unidades de dispensação, por carga horária semanal (Brasil e Regiões, 2015).

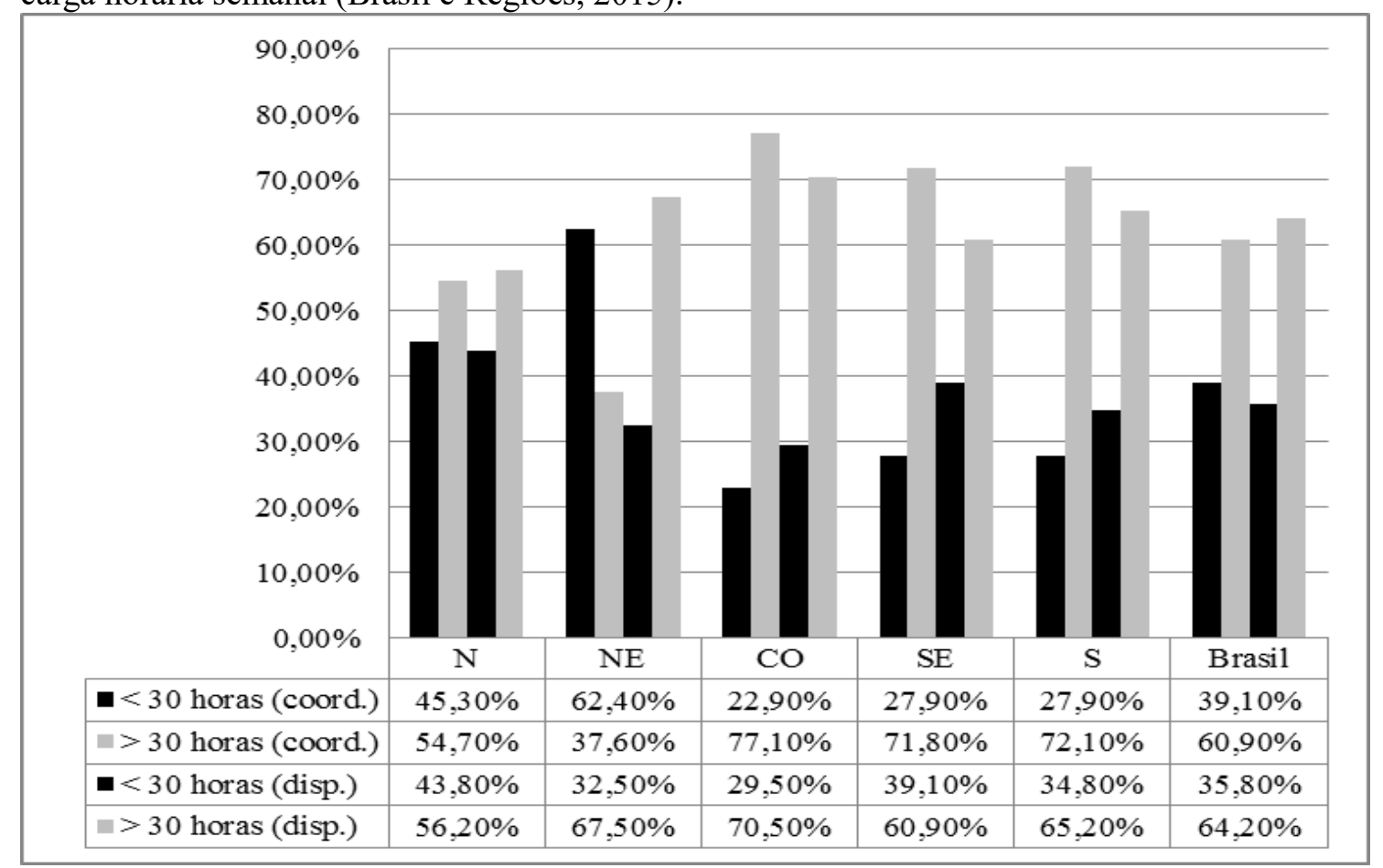

Fonte: PNAUM (2015). P valor (coordenação) $=0,000 ; P$ valor $($ dispensação $)=0,803$

Diferentemente das demais regiões, a maioria dos gestores da assistência farmacêutica do Nordeste possui jornada semanal inferior a 30 horas (figura 25), o que provavelmente se deve ao acúmulo de funções e atividades na assistência farmacêutica local ou outros vínculos de trabalho dentro ou fora do setor público de saúde. 
Figura 26. Distribuição dos trabalhadores da coordenação e das unidades de dispensação, por tempo como gestor (Brasil e Regiões, 2015).

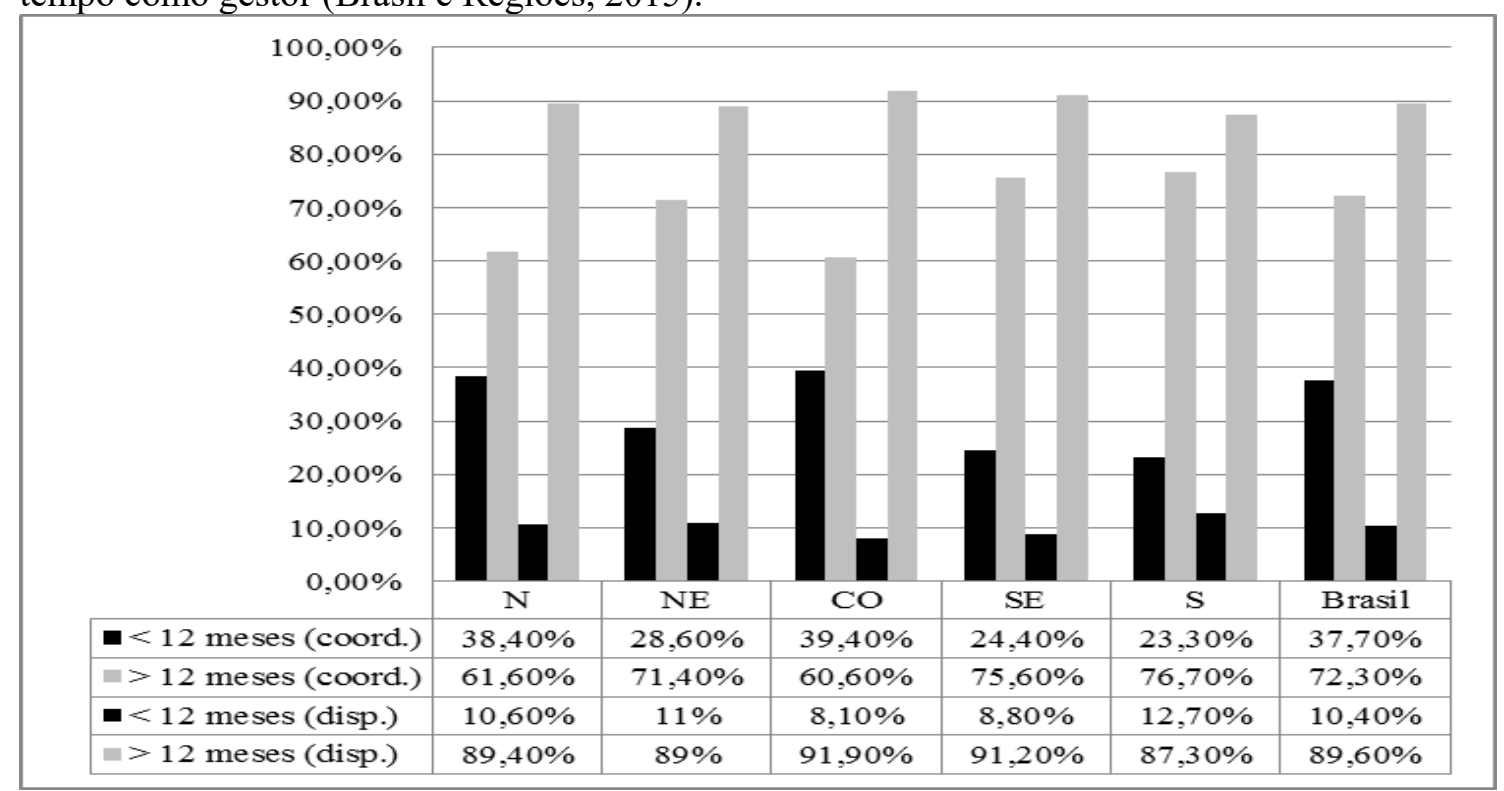

Fonte: PNAUM (2015). $P$ valor $($ coordenação $)=0,167 .=0,803 ; P$ valor $($ dispensação $)=0,886$.

Embora a maioria esteja há mais de 12 meses no cargo ou função, o percentual de trabalhadores no exercício do cargo de coordenador da assistência farmacêutica municipal é inferior ao de trabalhadores que exercem funções nas unidades de dispensação, o que provavelmente se deve a natureza do trabalho, pois geralmente a indicação dos trabalhadores para as funções de gestão depende mais de fatores políticos (e até político-partidários) que técnicos (figura 26).

\subsubsection{O farmacêutico na atenção primária}

No Brasil, o cenário é aparentemente favorável quanto ao número de farmacêuticos. Em 2013, segundo o Ministério do Trabalho e Emprego (MTE), havia 107.785 farmacêuticos no mercado formal de trabalho, o que representa 5,4 farmacêuticos por 10.000 habitantes, que é superior a países como México, Índia, Tailândia e todos os países Africanos, mas inferior a muitos países europeus, tais como Espanha e Portugal, e aos EUA (FIP, 2012; BRASIL, 2015).

Em todas as regiões brasileiras, a maioria dos municípios (acima de 80\%) possui farmacêuticos na coordenação da assistência farmacêutica, com destaque para o Sudeste e o Sul, com aproximadamente $95 \%$ de municípios (mapa 3). 
Mapa 3. Municípios com farmacêuticos na coordenação da assistência farmacêutica municipal nas diferentes regiões do país.

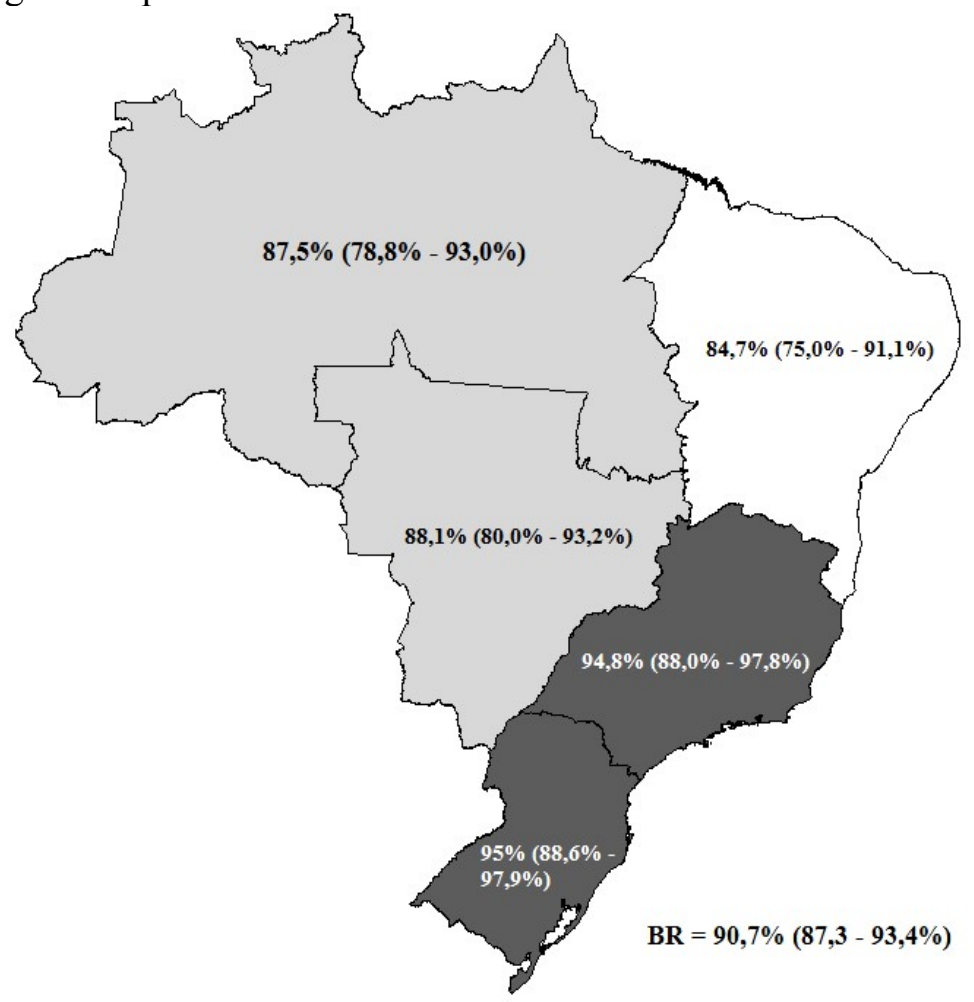

Fonte: PNAUM / MS (2015). Elaborado com o auxílio do Tabwin®.

Apesar das altas taxas de crescimento, entre $50 \%$ a $150 \%$, como é o caso de fonoaudiólogos (55\%), farmacêuticos (75\%), fisioterapeutas (78\%), terapeutas ocupacionais $(79 \%)$, nutricionistas $(83 \%)$ e professores de educação física $(145 \%)$, essas categorias profissionais ainda possuem baixa participação percentual na composição da força de trabalho nas UBS, variando entre 0,1 a 3\%. Em 2008, os farmacêuticos, por exemplo, $2,9 \%$ de todos os trabalhadores cadastrados em unidades básicas de saúde (CARVALHO et al, 2016b).

Segundo o relatório global sobre força de trabalho em Farmácia (FIP, 2012), nos países de baixa renda per capita (p. ex. República do Congo e Haiti), a escassez de farmacêuticos acabou resultando na dependência de trabalhadores de nível médio. Já nos países de alta renda per capita (p. ex. Austrália, Reino Unido e Japão), os farmacêuticos são a maioria na composição da força de trabalho. A participação de trabalhadores de nível técnico, em geral profissionais regulamentados e qualificados para apoiar o farmacêutico, varia de 43,2\% na Europa a 28,4\% nas Américas, enquanto que no Sudeste Asiático representa $67,5 \%$ do total da força de trabalho na área farmacêutica. Cabe ressaltar que esses resultados se referem ao mercado de trabalho de 
modo geral, sem qualquer abordagem específica em relação aos serviços da atenção primária de saúde nos países analisados (FIP, 2012).

Nas unidades de dispensação, o cenário difere bastante daquele apresentado para a coordenação da assistência farmacêutica, em que o farmacêutico é hegemônico, conforme o mapa abaixo.

Mapa 4. Municípios com farmacêuticos nas unidades de dispensação de medicamentos nas diferentes regiões do país.

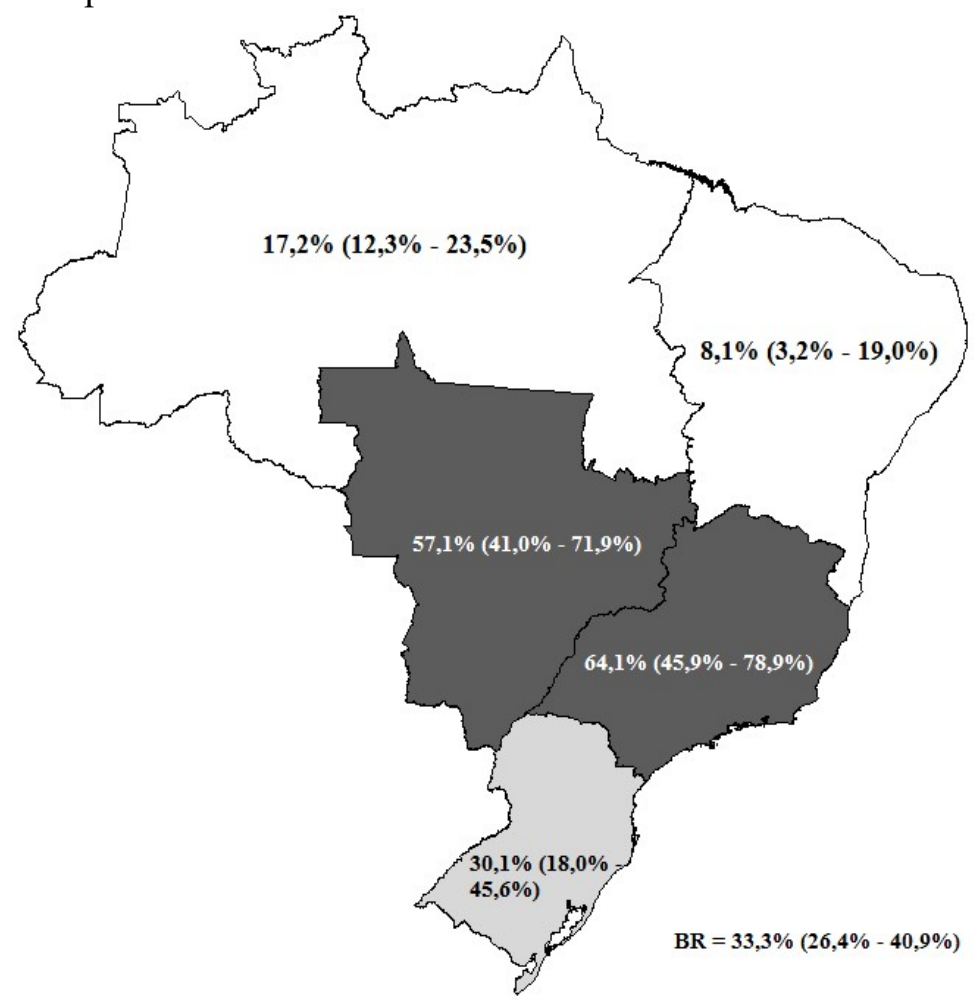

Fonte: PNAUM / MS (2015). Elaborado com o auxílio do Tabwin®.

Apenas aproximadamente 33\% (IC 95\% 26,34 - 40,9) dos municípios do país contam com o farmacêutico. Nas regiões Nordeste e Norte, a situação é bastante grave: $8,1 \%$ (IC 95\% 3,2 - 19,0) e 17,2\% (IC 95\% 12,3 - 23,5) possui farmacêutico. Já as regiões Centro-Oeste e Sudeste possuem pelo menos um farmacêutico em mais de 50\% dos municípios (mapa 4).

Semelhantemente ao comportamento dos países de baixa e alta renda, a alternância da hegemonia entre farmacêuticos e trabalhadores de nível médio nas unidades de dispensação também se verifica entre as regiões brasileiras. A participação dos farmacêuticos varia entre $8,1 \%$ no Nordeste a $64,1 \%$ no Sudeste, enquanto que os técnicos e auxiliares predominam no Norte, ocupando $66,6 \%$ dos postos de trabalho, e representam $19,0 \%$ da força de trabalho no Sudeste, o que provavelmente se deve aos 
mesmos fatores identificados nas regiões do mundo, entre os quais se destacam a oferta de cursos (formação superior e técnico), Índice de Desenvolvimento Humano (IDH) dentre outros fatores (HAWTHORNE e ANDERSON, 2009; FIP, 2012).

De fato, a região Sudeste concentra a formação farmacêutica do país: em 2013, havia 216 cursos de Farmácia (50\% do total), com 33.985 vagas, 14.475 ingressos e 7.626 egressos, enquanto que a região Norte tinha 27 cursos, com oferta de 3.155 vagas, 1.802 ingressos e apenas 862 egressos. Além disso, as regiões Sudeste e Sul possuem os melhores IDH, que é um indicador usado pela Organização das Nações Unidas (ONU) para avaliar a qualidade de vida de uma população. Nesse sentido, parece que o predomínio de profissionais de nível superior (especialmente farmacêuticos) ou de trabalhadores de nível técnico ou auxiliar depende da oferta de cursos de formação superior e das condições de fixação dos profissionais de saúde, que geralmente dependem do nível de riqueza e desenvolvimento regional (SIGRAS, 2015; IPEA, 2013; CAMPOS; MACHADO; GIRARDI, 2009).

Entre as funções desempenhas pelos farmacêuticos nas unidades de dispensação da atenção primária de saúde do SUS, a maioria dos entrevistados (90,4\%; IC95\% $66,9 \%$ - 97,7\%) realiza dispensação de medicamentos, seguida de supervisão $(86,8 \%$; IC95\% 77,2\% - 92,7\%) e atividades com a equipe de saúde da unidade $(52,7,4 \%$; IC95\% 41,1\% - 64,15), e menos de 30\% dos entrevistados realiza outras funções (tabela 16).

Tabela 16. Funções do farmacêutico nas unidades de dispensação (Brasil e Regiões, 2015).

\begin{tabular}{lcccccc}
\hline \multirow{2}{*}{ Funções } & $\mathbf{N}$ & $\mathbf{N E}$ & $\mathbf{C O}$ & $\mathbf{S E}$ & $\mathbf{S}$ & Brasil \\
\cline { 2 - 7 } & $\mathbf{( I C 9 5 \% )}$ & $\mathbf{( I C 9 5 \% )}$ & $\mathbf{( I C 9 5 \% )}$ & $\mathbf{( I C 9 5 \% )}$ & $\mathbf{( I C 9 5 \% )}$ & $\mathbf{( I C 9 5 \% )}$ \\
\hline Dispensação & $98,9 \%$ & $99,1 \%$ & $86,1 \%$ & $87,4 \%$ & $96,7 \%$ & $90,3 \%$ \\
& $(92,9-99,8)$ & $(93,4-99,9)$ & $(45,1-97,9)$ & $(50,9-97,9)$ & $(87,9-99,2)$ & $(66,9-97,7)$ \\
Supervisão & $76,6 \%$ & $55,5 \%$ & $87,8 \%$ & $92,9 \%$ & $82,8 \%$ & $86,8 \%$ \\
Atividades com a & $(63,9-85,8)$ & $(11,5-92,3)$ & $(68,6-96,0)$ & $(86,1-96,5)$ & $(68,3-91,5)$ & $(77,2-92,7)$ \\
equipe da unidade & $(50,4-81,0)$ & $(4,0-49,6)$ & $(21,7-69,5)$ & $(38,9-71,7)$ & $(38,0-81,1)$ & $(41,1-64,1)$ \\
Atividades com & $42,9 \%$ & $3,9 \%$ & $12,1 \%$ & $29,4 \%$ & $19,2 \%$ & $24,4 \%$ \\
NASF & $(30,0-56,9)$ & $(1,7-8,9)$ & $(4,3-29,4)$ & $(18,7-43,0)$ & $(8,4-38,2)$ & $(17,4-33,2)$ \\
Visita domiciliar & $34,4 \%$ & $3,9 \%$ & $3,8 \%$ & $14,2 \%$ & $17,5 \%$ & $13,7 \%$ \\
Coordenação de & $(21,9-49,4)$ & $(1,7-8,9)$ & $(1,2-11,4)$ & $(8,4-23,0)$ & $(7,3-36,5)$ & $(9,3-19,6)$ \\
grupos operativos & $(22,6-50,6)$ & $(3,8-59,4)$ & $(4,4-52,7)$ & $(11,9-33,1)$ & $(9,0-37,8)$ & $(14,0-29,6)$ \\
\hline
\end{tabular}

Fonte: PNAUM / MS (2015). 
Regionalmente, o Norte se destaca por apresentar o maior percentual de farmacêuticos envolvidos em atividades que não usuais do cotidiano do trabalho farmacêutico (NASF, visitas domiciliares e grupos operativos), enquanto que, diferente do esperado, o Nordeste apresentou os menor percentuais de farmacêuticos nessas mesmas funções (tabela 16).

Quanto às atividades exercidas pelos farmacêuticos, ou pelo menos reconhecidas como atividades, a orientação farmacêutica (37,8\%; IC 95\% 22,0\% - 56,8\%) e atenção farmacêutica $(36,3 \%$; IC $95 \% 21,5 \%$ - 54,3\%) foram as mais destacadas entre os entrevistados. Na região Nordeste, mais de $90 \%$ dos farmacêuticos referiu realizar orientação farmacêutica nas unidades de saúde, enquanto que no Centro-Oeste apenas $4,6 \%$ dos entrevistados relatou exercer essa atividade. À exceção do Nordeste, entre 29,4\% (Centro-Oeste) e 62,3\% (Norte) dos entrevistados referiram exercer a atenção farmacêutica nas unidades de dispensação da atenção primária do SUS (tabela 17).

Tabela 17. Atividades dos farmacêuticos nas unidades de dispensação (Brasil e Regiões, 2015).

\begin{tabular}{|c|c|c|c|c|c|c|}
\hline \multirow{2}{*}{ Atividades } & $\mathbf{N}$ & $\mathbf{N E}$ & $\mathrm{CO}$ & SE & $\mathbf{S}$ & Brasil \\
\hline & (IC95\%) & (IC95\%) & (IC95\%) & (IC95\%) & (IC95\%) & (IC95\%) \\
\hline Orientação & $23,8 \%$ & $91,3 \%$ & $4,6 \%$ & $25,6 \%$ & $64,6 \%$ & $37,8 \%$ \\
\hline farmacêutica & $(12,0-41,8)$ & $(85,2-95,0)$ & $(0,4-36,0)$ & $(7,9-57,7)$ & $(64,6-64,6)$ & $(22,0-56,8)$ \\
\hline Segmento & $3,3 \%$ & & & $4,7 \%$ & & 3,1 \\
\hline farmacoterapeutico & $(2,7-4,0)$ & & & $(1,2-16,9)$ & & $(0,7-11,7)$ \\
\hline Atenção & $62,3 \%$ & $2,0 \%$ & $29,4 \%$ & $45,8 \%$ & $35,4 \%$ & $36,3 \%$ \\
\hline farmacêutica & $(34,6-83,7)$ & $(0,3-13,6)$ & $(3,6-82,5)$ & $(22,2-71,5)$ & $(35,4-35,4)$ & $(21,5-54,3)$ \\
\hline Farmácia clínica & - & $\begin{array}{c}4,8 \% \\
(4,6-5,0)\end{array}$ & - & $\begin{array}{c}1,4 \% \\
(0,3-5,7)\end{array}$ & - & $\begin{array}{c}1,75 \% \\
(0,9-3,6)\end{array}$ \\
\hline $\begin{array}{l}\text { Consulta } \\
\text { farmacêutica }\end{array}$ & $\begin{array}{c}10,6 \% \\
(1,2-53,1)\end{array}$ & $\begin{array}{c}2,0 \% \\
(0,3-13,6)\end{array}$ & $\begin{array}{c}66,0 \% \\
(14,6- \\
95,7)\end{array}$ & $\begin{array}{c}16,0 \% \\
(4,7-42,5)\end{array}$ & - & $\begin{array}{c}17,1 \% \\
(6,5-37,9)\end{array}$ \\
\hline $\begin{array}{l}\text { Cuidado } \\
\text { farmacêutico }\end{array}$ & - & - & - & $\begin{array}{c}6,5 \% \\
(2,0-19,1)\end{array}$ & - & $\begin{array}{c}4,0 \% \\
(1,3-11,5)\end{array}$ \\
\hline
\end{tabular}

Fonte: PNAUM / MS (2015).

Entre outros fatores, como a PNAF, o QualifarSUS e a implantação do sistema de informações HORUS ${ }^{15}$, os resultados possivelmente apontam que o NASF tem se ${ }^{15}$ O Sistema Nacional de Gestão da Assistência Farmacêutica, denominado HORUS, foi desenvolvido
pelo Departamento de Assistência Farmacêutica (DAF) do Ministério da Saúde (MS) e tem como 
mostrado em uma estratégia interessante para o provimento do farmacêutico no setor público e possivelmente é responsável pelo número expressivo de farmacêuticos na dispensação de medicamentos, mas não promoveu a diversificação dos serviços ofertados por esse profissional na rede assistencial, especialmente a realização de visitas domiciliares.

A dispensação e o acompanhamento/seguimento farmacoterapêutico estão entre as atribuições do farmacêutico na atenção primária do SUS, especialmente nas eqNASF. Outras atividades de assistência à saúde também são consideradas atribuições do farmacêutico do NASF, tais como as visitas domiciliares, o uso de protocolos e linhas de cuidado, discussões de caso e construção do projeto terapêutico singular (BRASIL, 2010).

Mesmo após a implementação do NASF, os farmacêuticos nas unidades de saúde acabam realizando, na maioria das vezes, atividades técnico-gerenciais diretamente relacionadas ao abastecimento de medicamentos, ao invés trabalhar em equipe na lógica do matriciamento, como afirma o trecho extraído da dissertação de mestrado de Carina Nakamura sobre o farmacêutico no NASF:

As atividades gerenciais apresentam indicadores mais facilmente mensuráveis, quando comparados aos das atividades assistenciais. A falta de medicamentos ou o excesso em estoque são facilmente observados (...). Assim, as atividades gerenciais acabam se tornando um trabalho mais concreto e visível pela equipe de SF e pelos usuários, gerando então mais demanda e expectativa do farmacêutico para estas funções e não para outras. Durante uma oficina do NASF foi citado pela equipe de SF diversas vezes o interesse em ter o farmacêutico no CS [centro de saúde], mais precisamente na farmácia, todos os dias, demonstrando que esta é atividade esperada para este profissional, mais que a função de matriciamento (NAKAMURA, 2013, p. 102).

A assistência farmacêutica está em franco processo de mudança paradigmática, com a perspectiva de deslocar a centralidade das ações do farmacêutico do medicamento para o usuário. Contudo, os resultados podem ter alguma relação com confusões conceituais encontradas na literatura nacional e nos documentos oficiais, que misturam assistência e atenção farmacêutica, assim como serviços farmacêuticos, cuidados farmacêuticos, clínica farmacêutica e assistência farmacêutica clínica. É 
possível que os farmacêuticos tenham referido realizar funções e atividades mais conhecidas e ou consolidadas como trabalho farmacêutico, tais como a dispensação e a atenção farmacêutica.

De modo geral, os farmacêuticos têm expandido suas funções e responsabilidades na atenção primária em saúde em todo o mundo, com foco claro nos cuidados diretos aos pacientes. Estudos sobre a força de trabalho farmacêutico realizados nos EUA em 2009 e 2014 identificaram que a prestação de serviços e assistência aos pacientes por farmacêuticos aumentou. $\mathrm{O}$ segmento de farmacêuticos fornecedores de medicamentos que também cuidam dos pacientes passou de 17\% (2009) para 48\% (2014). Contudo, a manutenção em níveis estáveis dos fornecedores de medicamentos sugere a necessidade de manter os farmacêuticos também envolvidos no fornecimento de medicamentos, ou seja, na dispensação, como atividade fundamental para o bom desempenho dos serviços de saúde (SCHOMMER et al, 2015).

\section{REFERÊNCIAS}

ÁlVAreS, J. et al. Pesquisa Nacional sobre Acesso, Utilização e Promoção do Uso Racional de Medicamentos (PNAUM) - componente serviços: percurso metodológico. (Encaminhado para publicação na Revista de Saúde Pública da USP).

ALVES, S.M.P. et al. A flexibilização das relações de trabalho na saúde: a realidade de um Hospital Universitário Federal. Ciências e Saúde Coletiva, Rio de Janeiro, v. 20, n. 10, p. 3043-3050, Outubro 2015. Disponível em: http://www.scielo.br/scielo.php?script $=$ sci arttext\&pid=S1413-

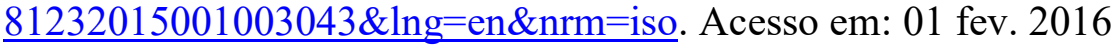

ARAUJO, A.L.A. et al. Perfil da assistência farmacêutica na atenção primária do Sistema Único de Saúde. Ciência \& Saúde Coletiva, Rio de Janeiro, v. 13, supl. abr. 2008 . Disponível em http://www.scielo.br/scielo.php?script=sci arttext\&pid=S141381232008000700010\&lng=pt\&nrm=iso. Acesso em: 10 nov. 2015.

ARRAIS, P.S.D. et al. Aspectos dos processos de prescrição e dispensação de medicamentos na percepção do paciente: estudo de base populacional em Fortaleza, Ceará, Brasil. Cadernos de Saúde Pública, v. 23. n. 4, p.927-939, 2007.

BARBOSA, R.H.S. et al. Gênero e trabalho em Saúde: um olhar crítico sobre o trabalho de agentes comunitárias/os de Saúde. Interface. Comunicação, Saúde, Educação, v.16, n.42, p.751-65, jul./set. 2012.

BRASIL. Ministério da Saúde. Secretaria de Políticas de Saúde. Departamento de Atenção Básica. Política Nacional de Medicamentos. Brasília: Ministério da Saúde, 2001. nov. 2015. 
BRASIL. Conselho Nacional de Saúde (CNS). Resolução n. 338, de 6 de maio de 2004. Aprova a Política Nacional de Assistência Farmacêutica. Diário Oficial da União. Brasília, p.52, 20 de maio de 2004. Seção 1.

BRASIL. Ministério da Saúde. Secretaria de Ciência, Tecnologia e Insumos Estratégicos. Departamento de Assistência Farmacêutica e Insumos Estratégicos. Diretrizes para estruturação de farmácias no âmbito do Sistema Único de Saúde. Brasília: Ministério da Saúde, 2009.

BRASIL. Ministério da Saúde (Brasil), Secretaria de Atenção à Saúde, Departamento de Atenção Básica. Diretrizes do NASF: Núcleo de Apoio à Saúde da Família. Brasília: Ministério da Saúde; 2010.

BRASIL. Ministério da Saúde. Secretaria de Ciência, Tecnologia e Insumos Estratégicos. Departamento de Assistência Farmacêutica e Insumos Estratégicos. Serviços farmacêuticos na atenção básica à saúde. Brasília: Ministério da Saúde, 2014. (Cuidado farmacêutico na atenção básica; Caderno 1). Disponível em http://bvsms.saude.gov.br/bvs/publicacoes/servicos_farmaceuticos_atencao_basica_sau de.pdf. Acesso em: 05 out. 2015.

BRASIL. Ministério do Trabalho e Emprego (MTE). Bases Estatísticas RAIS e CAGED. 2015. Disponível em: http://bi.mte.gov.br/bgcaged/inicial.php. Acesso em: 05 out. 2015.

CAMPOS, F.E; MACHADO, M.H; GIRARDI, S.N. A fixação de profissionais de saúde em regiões de necessidades. Divulgação Saúde para Debate, v. 44, p. 13-24, maio 2009. Disponível em http://www.cnts.org.br/public/arquivos/Artigo Campos.pdf. Acesso em: 05 out. 2015.

CARVALHO, M; SANTOS, NR.; CAMPOS, GWS. A construção do SUS e o planejamento da força de trabalho em saúde no Brasil: breve trajetória histórica. Saúde em Debate, Rio de Janeiro, v. 37, n. 98, setembro de 2013. Disponível em http://www.scielo.br/scielo.php?script $=$ sci arttext\&pid $=$ S0103-

$11042013000300002 \& \operatorname{lng}=$ en\&nrm=iso. Acesso em: 10 fev. 2014. DOI: http://dx.doi.org/10.1590/S0103-11042013000300002.

CARVALHO, M.N. et al. Expansão e diversificação da força de trabalho de nível superior nas unidades básicas de saúde no Brasil, 2008 - 2013. Saúde em Debate, 2016a (no prelo). Disponível em http://www.saudeemdebate.org.br/artigos/artigo_int.php?id_artigo=3777

CARVALHO, M.N. et al. Necessidade e dinâmica da força de trabalho na atenção básica de saúde no Brasil. Ciência \& Saúde Coletiva, 2016b (no prelo). Disponível em http://www.cienciaesaudecoletiva.com.br/artigos/artigo_int.php?id_artigo=15457.

Acesso em: 24 fev. 2016.

CONSELHO FEDERAL DE FARMÁCIA. Rename 2002 e o Ciclo Gerencial da Assistência Farmacêutica: Sugestões para a Conferência Nacional de Política de Medicamentos e Assistência Farmacêutica. Pharmacia Brasileira. Farmacoterapêutica. n. 04, 2002. Disponível em http://www.cff.org.br/userfiles/file/pdf/2002 4.pdf. Acesso em: 18 jul. 2015. 
CORADI, A.E.P. A importância do farmacêutico no ciclo da Assistência Farmacêutica. Arquivos Brasileiros de Ciências da Saúde, v.37, n. 2, p. 62-64, Maio/Ago 2012.

FIP. INTERNATIONAL PHARMACEUTICAL FEDERATION. FIP Global Pharmacy: Workforce Report, 2012. Disponível em: http://www.fip.org/files/members/library/FIP workforce Report 2012.pdf. Acesso em: 05 out. 2015.

GIL, C.R.R. Atenção primária, atenção básica e saúde da família: sinergias e singularidades do contexto brasileiro. Cadernos de Saúde Pública, Rio de Janeiro, v. 22, n. 6, p. 1171-81, 2006.

GUEDES, M.C. A inserção dos trabalhadores mais escolarizados no mercado de trabalho brasileiro: uma análise de gênero. Trabalho e Educação em Saúde, Rio de Janeiro, v. 8, n. 1, p. 55-75, junho 2010. Disponível em http://www.scielo.br/scielo.php?script=sci arttext\&pid=S198177462010000100004\&lng=en\&nrm=iso. Acesso em: 08 dez. 2015.

HAWTHORNE, N; ANDERSON, C. The global pharmacy workforce: a systematic review of the literature. Human Resources for Health, v. 7, n. 48, 2009. Disponível em: http://www.human-resources-health.com/content/7/1/48. Acesso em: 05 out. 2015.

HERNÁNDEZ, M.L.G et al. Construcción emergente del concepto: cuidado profesional de enfermería. Texto Contexto da Enfermagem, Florianópolis, 2011; 20 (Esp): 74-80.

IPEA. Índice de Desenvolvimento Humano Municipal Brasileiro. Brasília: PNUD, IPEA, FJP, 2013. http://www.pnud.org.br/arquivos/idhm-brasileiro-atlas-2013.pdf. Acesso em: 05 out. 2015.

LEITE et al (Orgs.). Gestão da Assistência Farmacêutica: proposta para avaliação no contexto municipal: a experiência em Santa Catarina. Florianópolis: Editora da UFSC, 2015.

LIMA-DELLAMORA, E.C et al. Dispensação de medicamentos do componente especializado em polos no Estado do Rio de Janeiro. Ciência \& Saúde Coletiva, v. 17, n. $9, \quad$ p. 2387-2396, 2012. Disponível em: http://www.scielo.br/pdf/csc/v17n9/a19v17n9.pdf. Acesso em: 05 out. 2015.

LOCH-NECKEL, G, CREPALDI, M.A. Pharmacist contributions for basic care from the perspective of professionals of familial health care teams. Brazilian Journal of Pharmaceutical Sciences v. 45, n. 2, abr./jun., 2009. Disponível em: http://www.scielo.br/pdf/bjps/v45n2/v45n2a11. Acesso em: 09 mar. 2016.

MACHADO, C.R.; POZ, M.R.D. Sistematização do conhecimento sobre as metodologias empregadas para o dimensionamento da força de trabalho em saúde. Saúde em Debate. v. 39, n. 104, p. 239-254, 2015. Disponível em: http://www.scielo.br/scielo.php?script $=$ sci arttext\&pid $=\mathrm{S} 0103-$ 11042015000100239\&lng=en. Acesso em: 09 mar. 2016. 
MACHADO, C.V; LIMA, L.D; BAPTISTA, T.W.F. Princípios organizativos e instâncias de gestão do SUS. In: GONDIM, R.; GABROIS, V.; MENDES, W. (Orgs.). Qualificação de gestores no SUS. Rio de Janeiro: EAD/ Ensp, 2011.

MANZINI, F. et al (Orgs.). O farmacêutico na assistência farmacêutica do SUS: diretrizes para ação. Brasília: Conselho Federal de Farmácia, 2015.

MARIN, N. Los servicios farmacéuticos en la atención de salud. In: BERMUDEZ, J.A.Z.; Medicamentos e a reforma do setor de saúde. São Paulo: Hucitec-Sobravime, 1999.

MARIN, N. et al. Assistência farmacêutica para gerentes municipais de saúde. Rio de Janeiro: OPAS/OMS, 2003. Disponível em http://www.paho.org/bra/index.php?option=com_docman\&task $=$ doc_view\&gid $=742 \& \mathrm{I}$ temid=423. Acesso em: 09 mar. 2016.

MARQUES, A.P.P. Reestruturação produtiva e recomposições do trabalho e emprego: um périplo pelas "novas" formas de desigualdade social. Ciência \& Saúde Coletiva, Rio de Janeiro, v. 18, n. 6, p. 1545-1554, Junho 2013. Disponível em: http://www.scielo.br/scielo.php?script $=$ sci arttext\&pid=S141381232013000600007\&lng=en\&nrm=iso. Acesso em: 09 mar. 2016.

MATOS, IB; TOASSI, RFC; OLIVEIRA, MC. Profissões e ocupações de saúde e o processo de feminização: tendências e implicações. Athenea Digital, n. 13, v. 2, p. 239244, julho de 2013. Disponível em https://www.lume.ufrgs.br/bitstream/handle/10183/118035/000894801.pdf?sequence=1. Acesso em: 08 dez. 2015.

NAKAMURA, C.A. O que faz o farmacêutico no NASF? Construção do processo de trabalho e promoção da saúde em um município do Sul do Brasil. Florianópolis: UFSC, 2013. [dissertação]

OLIVEIRA A.B. et al. Obstáculos da atenção farmacêutica no Brasil. Brazilian Journal of Pharmaceutical Sciences v. 41, n. 4, out./dez., 2005.

OLIVEIRA, M. A.; BERMUDEZ, J. A. Z.; OSÓRIO-DE-CASTRO, C. G. Assistência Farmacêutica e Acesso a Medicamentos. Rio de Janeiro: Editora Fiocruz, 2007.

OPAS. Organização Panamericana del Salud. El papel del farmacéutico en el sistema de atención de salud. Informe de La Reunión de la OMS Tokio, Japón, 31 de agosto al 3 de septiembre de $1993 . \quad$ Disponível em http://www.ops.org.bo/textocompleto/ime9848.pdf. Acesso em: 15 jan. 2014.

OPAS. Organização Pan-Americana da Saúde. Avaliação da Assistência Farmacêutica no Brasil. Brasília: Organização Pan-Americana da Saúde; BRASIL, Ministério da Saúde, $2005 . \quad$ Disponível em http://bvsms.saude.gov.br/bvs/publicacoes/avaliacao_assistencia_farmaceutica_estrutura _resultados.pdf. Acesso em: 15 dez. 2013.

OPAS. Organização Panamericana de Saúde. Consenso brasileiro de atenção farmacêutica. Brasília: OPAS, 2002. Disponível em: 
http://bvsms.saude.gov.br/bvs/publicacoes/PropostaConsensoAtenfar.pdf. Acesso em: 15 dez. 2013.

OPAS. Organización Panamericana de la Salud. Servicios farmacéuticos basados en la atención primaria de salud. Documento de posición de la OPS/OMS. Washington, DC: $\quad$ OPS, 2013.2 Disponível em http://www.paho.org/hq/index.php?option=com_docman\&task=doc_view\&gid=21582

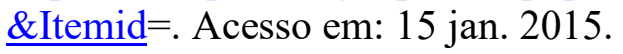

OSÓRIO-DE-CASTRO, C.G. et al (Orgs.). Assistência Farmacêutica: Gestão e prática para profissionais de saúde. Rio de Janeiro: Editora Fiocruz, 2014.

PAIM, J. et al. The Brazilian health system: history, advances and challenges. The Lancet, 2011. Disponível em http://www.thelancet.com/series/health-in-brazil. Acesso em: 15 jan. 2014.

PEREIRA, M.L.; NASCIMENTO, M.M.G. Das boticas aos cuidados farmacêuticos: perspectivas do profissional farmacêutico. Revista Brasileira de Farmácia. v. 92, n. 4, p. 245-252, 2011.

PEPE, V.L.E.; CASTRO, C.G.O. A interação entre prescritores, dispensadores e pacientes: informação compartilhada como possível benefício terapêutico. Cadernos de Saúde Pública 2000; 16:815-22.

POSSAMAI, F.P.; DACOREGGIO, M.S. A habilidade de comunicação com o paciente no processo de atenção farmacêutica. Trabalho, Educação e Saúde, v. 5 n. 3, p. 473490, 2008. Disponível em $h$ htp://www.scielo.br/pdf/tes/v5n3/08.pdf. Acesso em: 15 mar. 2015.

RIZZOTO, M.L.F. et al. Força de trabalho e gestão do trabalho em saúde: revelações da Avaliação Externa do Programa Nacional de Melhoria do Acesso e da Qualidade da Atenção Básica no Paraná. Saúde em Debate. Rio de Janeiro. v. 38, número especial, p. 237-251. out 2014. http://www.scielo.br/pdf/sdeb/v38nspe/0103-1104-sdeb-38-spe0237.pdf. Acesso em: 15 mar. 2015.

SANTOS, S.F.S.; BENEDETTI, T.R.B. Cenário de implantação do Núcleo de Apoio a Saúde da Família e a inserção do profissional de Educação Física. Revista Brasileira de Atividade Física e Saúde, Pelotas, v. 17, n. 3, p. 188-194, 2012. Disponível em http://periodicos.ufpel.edu.br/ojs2/index.php/RBAFS/article/viewFile/1857/1697.

Acesso em: 13 jul. 2015.

SARTOR, V.B.; FREITAS, S.F.T. Modelo para avaliação do serviço de dispensação de medicamentos na atenção básica à saúde. Revista de Saúde Pública, v. 48, n. 5, p. 827836, 2014. Disponível em: http://www.scielo.br/pdf/rsp/v48n5/pt 0034-8910-rsp-48-50827.pdf. Acesso em: 13 jul. 2015.

SERAFIN, C.; JÚNIOR, D.C.; VARGAS, M. Perfil do farmacêutico no Brasil: relatório. Brasília: Conselho Federal de Farmácia, 2015. Disponível em: http://www.cff.org.br/userfiles/file/Perfil $\% 20$ do\%20farmac $\%$ C3\%AAutico $\% 20$ no $\% 20 \mathrm{~B}$ rasil\%20_web.pdf. Acesso em: 30 mar. 2016. 
SIGRAS. Sistemas de Indicadores das Graduações em Saúde. http://www.obsnetims.org.br/sigras/. Acesso em: 30 mar. 2016.

SCHOMMER, J.C. et al. Pharmacist Contributions to the U.S. Health Care System Reported in the 2009 and 2014 National Pharmacist Workforce Surveys. INOVATIONS in pharmacy. v. 6, n. 2, Article 200, 2015. Disponível em http://pubs.lib.umn.edu/cgi/viewcontent.cgi?article $=1195 \&$ context=innovations. Acesso em: 21 mar. 2016.

VEBER, A.P. et al. Pharmaceutical assistance in local public health services in Santa Catarina (Brazil): characteristics of its organization. Brazilian Journal of Pharmaceutical Sciences. v. 47, n. 1, p. 75-80, 2011. Disponível em: http://www.scielo.br/scielo.php?script=sci arttext\&pid=S1984-

82502011000100009\&lng=pt. Acesso em: 21 mar. 2016.

VIEIRA, F.S. Qualificação dos serviços farmacêuticos no Brasil: aspectos inconclusos da agenda do Sistema Único de Saúde. Revista Panamericana de Salud Publica, v. 24, n. $2, \quad$ p. $91-100, \quad 2008 . \quad$ Disponível em http://www.scielosp.org/pdf/rpsp/v24n2/a03v24n2.pdf. Acesso em: 14 mar. 2014.

WERMELINGER, M. et al. A Força de Trabalho do Setor de Saúde no Brasil: focalizando a feminização. Rio de Janeiro. Revista Divulgação em Saúde para Debate, v. 45, p. 54-70, 2010. Disponível em: http://www.ensp.fiocruz.br/observarh/arquivos/A $\% 20 \mathrm{Forca} \% 20 \mathrm{de} \% 20$ Trabalho $\% 20 \mathrm{do}$ \%20Setor\%20de\%20Saude\%20no\%20Brasil\%20.pdf. Acesso em: 14 mar. 2014.

WORLD HEALTH ORGANIZATION (WHO). How to Investigate Drug use in Health Care Facilities: selectec drug use indicators. Geneva: WHO/DAP, 1993.

UPOTEY VARELA, N.M. et al. What is the role of the pharmacist?: physicians' and nurses' perspectives in community and hospital settings of Santiago de Cuba. Brazilian Journal of Pharmaceutical Science. São Paulo, v. 47, n. 4, p. 709-718, 2011. Disponível em: $\quad$ http://www.scielo.br/scielo.php?script=sci arttext\&pid=S1984-

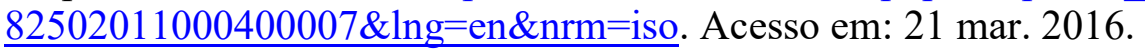




\section{CONSIDERAÇÕES FINAIS}

O aumento da participação do farmacêutico no setor público é um apontamento importante desta tese, que provavelmente é resultado do crescimento da assistência farmacêutica no SUS nas últimas décadas, cujos marcos temporais são a extinção da CEME, em 1997, e as publicações da PNM, em 1998, e da PNAF, em 2004.

$\mathrm{O}$ crescimento do número de farmacêuticos no setor público também deve ter relação com a participação do farmacêutico na atenção primária do SUS, que cresceu 75\% no período de 2008 a 2013, que, por sua vez, se deve a uma série de políticas e ações implementadas, entre as quais se destacam a PNAF em 2004, o HORUS em 2009 e, especialmente, o NASF em 2008 que são equipes compostas por profissionais de diferentes áreas de conhecimento, com atuação em parceria com os profissionais eqSF.

No cotidiano dos serviços, os trabalhadores de saúde realizam seu processo de trabalho em um núcleo tecnológico composto por trabalho morto e trabalho vivo. $\mathrm{O}$ trabalho morto é assim chamado porque tem trabalho vivo pregresso utilizado na transformação de matéria-prima em produto (equipamentos, instrumentos, medicamento etc) e o trabalho vivo, por sua vez, é ato, relação, execução do trabalho em si.

Partindo dos pressupostos que o farmacêutico é um trabalhador de saúde e que o trabalho em saúde é vivo em ato, o trabalho do farmacêutico deve ser compreendido como trabalho vivo em ato e o medicamento como produto, ou seja, trabalho morto que durante o seu processo produtivo capturou o trabalho vivo de outro trabalhador.

Diferentemente dos outros trabalhadores de saúde, que geralmente não participam diretamente da produção das tecnologias duras que utilizam durante o cuidado, o farmacêutico sempre esteve envolvido no processo produtivo de medicamentos, desde as boticas à indústria farmacêutica e às drogarias, com alternância entre períodos de aproximação e distanciamento do usuário. Portanto, o trabalho farmacêutico sempre teve um núcleo tecnológico centrado mais nas tecnologias duras (medicamento e equipamentos) e leve-duras (procedimento-padrão e protocolos) que tecnologias leves (vínculo e acolhimento).

Ao longo do tempo, o processo de trabalho farmacêutico se tornou quase que exclusivamente fabril, em que o trabalho vivo é capturado na obtenção de um produto (trabalho morto), com algumas exceções como é o caso das atividades de vigilância sanitária, e o núcleo tecnológico do trabalho foi dominado pelas tecnologias duras. Para 
acompanhar as transformações tecnológicas do mundo do trabalho, em meados da década de 1960, os cursos de Farmácia do país tiveram que mudar seus currículos para atender os dois campos de atividade profissional de maior interesse no momento: a indústria farmacêutica e os laboratórios de análises clínicas.

No SUS, o trabalho farmacêutico geralmente ocorre no âmbito da assistência farmacêutica, que historicamente esteve centrada na realização de um ciclo logístico de gerenciamento do medicamento, com a finalidade de garantir o abastecimento e o acesso aos medicamentos essenciais pela população.

Nesse contexto, o farmacêutico se identificou (e possivelmente ainda se identifica) como o profissional do medicamento e a sua formação foi (e ainda é) quase que exclusivamente voltada à realização de atividades técnico-gerenciais do produto, que é trabalho morto, transformando a dispensação de medicamentos na mera entrega de medicamentos ou, para alguns, como atividade de segunda categoria

Outro aspecto importante para o debate sobre o trabalho farmacêutico e a participação do farmacêutico na força de trabalho em saúde é seguinte: enquanto a assistência farmacêutica é multiprofissional, preferencialmente coordenada pelo farmacêutico, e visa garantir o acesso aos medicamentos pela população, os serviços farmacêuticos consistem em atividades realizadas exclusivamente pelo farmacêutico, envolvendo direta ou indiretamente o usuário. O cuidado farmacêutico, por sua vez, ocorre na esfera dos serviços farmacêuticos ofertados diretamente o usuário.

Entendendo que o ato de cuidar está no cerne dos serviços de saúde, estamos falando de que tipo de cuidar? Nesta tese, entendo o cuidar como ato contido no cuidado. Cuidar é reciprocidade e todo cuidado é dialógico e relacional, é trabalho vivo. Para que o trabalho-cuidado ganhe espaço nos serviços de saúde, é preciso lutar contra a transformação do cuidado em mercadoria. Afinal, o capitalismo transforma tudo em mercadoria.

O cuidado acontece na micropolítica do trabalho, ou seja, no encontro entre o trabalhador de saúde e o usuário. Contudo, os serviços de saúde estão organizados em uma rede de atenção à saúde e o cuidado ocorre nos serviços por meio de ações articuladas ou não entre os trabalhadores em saúde. O conjunto de trabalhadores, com formações e escolaridade diferentes, consiste na força de trabalho do sistema de saúde.

O trabalho como cuidado é afetado pela transição tecnológica, que altera de modo significativo à lógica de produção do cuidado, e muda o seu núcleo tecnológico de acordo com as necessidades do usuário dos serviços de saúde, ou seja, em vez de 
procedimento-centrado, tende a ser relacional-centrado, olhando sempre e se subordinando ao mundo das necessidades de saúde, individuais e coletivas.

Na atenção primária do SUS, além da coordenação da assistência farmacêutica municipal, o farmacêutico deve desenvolver atividades técnico-assistenciais nos serviços de saúde, entre as quais se destacam a dispensação, o acompanhamento/seguimento farmacoterapêutico, a atenção farmacêutica e a consulta farmacêutica.

Os resultados da PNAUM demonstram que o farmacêutico é encontrado majoritariamente na coordenação da assistência farmacêutica nos municípios, uma função de gestão do sistema de saúde, mas não são a maioria nas unidades de dispensação de medicamentos, sendo superados pelos trabalhadores de nível médio (por exemplo, técnicos e auxiliares de enfermagem), o que se deve muito provavelmente à centralidade do trabalho no gerenciamento do produto.

Apesar da implantação de eqNASF, que tem o trabalho em equipe como centro das práticas de cuidado, o farmacêutico da unidade básica de saúde acaba realizando mais (e ou reconhecendo o seu trabalho) funções que não envolvem diretamente outras categorias profissionais, como, por exemplo, a dispensação, do que as atividades previstas no processo de trabalho do NASF, por exemplo, as visitas domiciliares e os grupos operativos.

A presença marcante das mulheres nas atividades de coordenação da assistência farmacêutica municipal pode ser resultado da ampliação do acesso à formação superior em Farmácia e aumento do número de mulheres no mercado de trabalho farmacêutico. As mulheres também são maioria entre os trabalhadores das unidades de dispensação, cuja escolaridade predominante é o nível médio (técnico ou auxiliar).

Como existe a tese do estereótipo socialmente construído que associa o feminino ao trabalho do cuidado e da assistência, como é o caso da enfermagem, era esperado que as mulheres aparecessem mais nas unidades de dispensação de medicamentos e os homens nas funções de gestão. Todavia, a profissão farmacêutica se feminizou e possivelmente as mulheres sejam a maioria no cargo de coordenação municipal por dois aspectos: as instituições de ensino superior têm formado mais mulheres que homens e as mulheres freqüentemente aceitam funções com múltiplas tarefas.

Além disso, como a enfermagem historicamente é composta por mulheres e tem a imagem associada ao cuidado, não é difícil entender porque as unidades de 
dispensação são majoritariamente compostas por mulheres com nível médio de escolaridade, geralmente técnicas ou auxiliares de enfermagem.

O cuidado em saúde centrado no usuário ainda está tão distante do cotidiano do seu trabalho nas unidades básicas de saúde, que o farmacêutico não reconhece o cuidado farmacêutico como uma atividade, embora reconheça a atenção farmacêutica. $O$ farmacêutico está tão envolvido com a tecnologia dura (medicamento) e as tecnologias leve-duras (protocolos e procedimentos) que talvez ainda consiga perceber que o seu processo de trabalho deve envolver também as tecnologias leves (relacionais) de cuidado.

Ao contrário do gerenciamento orientado pelo produto, na gestão orientada pelo usuário, a produção de cuidado deve nortear todas as atividades da assistência farmacêutica, que interagem de forma sistêmica e concomitante, ao contrário do gerenciamento do medicamento, em que as ações ocorrem em etapas fragmentadas e seqüenciais com o objetivo de garantir o abastecimento e fornecimento de medicamentos nos serviços de saúde.

A mudança paradigmática no centro do trabalho farmacêutico não deve sair de um extremo, trabalho centrado no produto, para outro, o trabalho farmacêuticocentrado. Geralmente, os processos de produção da saúde ocorrem em um espaço de tensões, em que os trabalhadores podem produzir atos de saúde como procedimentos, e a oferta de serviços e a produção de procedimentos como cuidado, ou como resultado das ações de diferentes trabalhadores por meio de intervenções profissional-centradas, por exemplo, enfermeiro-centradas ou médico-centradas.

Assim, o centro do trabalho farmacêutico deve passar por um processo de reestruturação, deixando de ser o produto e passando para o usuário. Nesse contexto, o trabalho farmacêutico deve ser reconhecido como trabalho vivo em ato e incluir abordagens mais relacionais no processo de trabalho, que operam efetivamente no encontro entre o farmacêutico e o usuário.

$\mathrm{Na}$ assistência farmacêutica do SUS, entendendo que esta tem se tornado cada vez mais complexa, as atividades devem deslocar gradativamente a sua centralidade do gerenciamento logístico do medicamento para a gestão do medicamento orientada pelo usuário. Conseqüentemente, o farmacêutico coordenador da assistência farmacêutica, nas três esferas de governo (União, estados e municípios), deve deixar o gerenciamento da cadeia centrada no produto e assumir a gestão do medicamento centrada no usuário, 
enquanto que o trabalho farmacêutico nas unidades de saúde deve se reorganizar no sentido de garantir a oferta de serviços farmacêuticos diretamente aos usuários.

Apesar da diversificação e expansão da força de trabalho, o farmacêutico representa em torno de $3 \%$ da força de trabalho em saúde nas unidades básicas de saúde do SUS. Essa participação ocorre, geralmente, no âmbito da assistência farmacêutica, um subsistema historicamente resumido ao abastecimento e fornecimento de medicamentos. $\mathrm{Na}$ assistência farmacêutica básica, realizada nos municípios, a maioria dos farmacêuticos exerce cargo de gestão. Nas unidades de saúde, a atividade de entrega de medicamentos é majoritariamente realizada por outros trabalhadores, como, por exemplo, técnicos e auxiliares de enfermagem.

A participação efetiva do farmacêutico na composição da força de trabalho em saúde da atenção primária, especialmente nas unidades de dispensação de medicamentos, parece ter relação com a oferta diretamente de serviços ao usuário. Para mim, assistência farmacêutica é política ordenadora e executada por meio de serviços, e o cuidado é abrangente e vai desde a dispensação até as consultas farmacêuticas. O cuidado, por sua vez, está contido na assistência farmacêutica e deve ser norteador de todos os serviços, embora se concretize efetivamente no encontro entre o farmacêutico e o usuário.

O desafio pode ser superado, de um lado, por uma profunda reformulação da formação do farmacêutico, ou seja, da oferta da força de trabalho farmacêutico para o mercado, e, de outro, pela execução de políticas públicas orientadas ao provimento e incorporação efetiva do farmacêutico nas equipes de saúde dos setores público e privado, o que significa modificar a demanda no mercado de trabalho.

Essa mudança paradigmática tende a aumentar o reconhecimento do farmacêutico como profissional de saúde pelo próprio farmacêutico, pela equipe de saúde e pela população e, conseqüentemente, promover o incremento da participação do farmacêutico na composição da força de trabalho da atenção primária do SUS.

A participação do farmacêutico na composição da força de trabalho em saúde da atenção primária do SUS ainda está fortemente atrelada às funções técnico-gerenciais do medicamento, ou seja, ao abastecimento do sistema de saúde. Apesar do crescimento do número de profissionais cadastrados nos estabelecimentos de saúde da atenção primária, o farmacêutico representa apenas $3 \%$ da força de trabalho de nível superior cadastrada nas UBS. Nos municípios, os farmacêuticos são majoritariamente encontrados na gestão da assistência farmacêutica que nas unidades de dispensação de 
medicamentos das UBS, o que provavelmente se deve ao predomínio das funções técnico-gerenciais centradas no medicamento sobre as técnico-assistenciais de cuidado ao usuário. 
ANEXO

Mapa conceitual da tese.

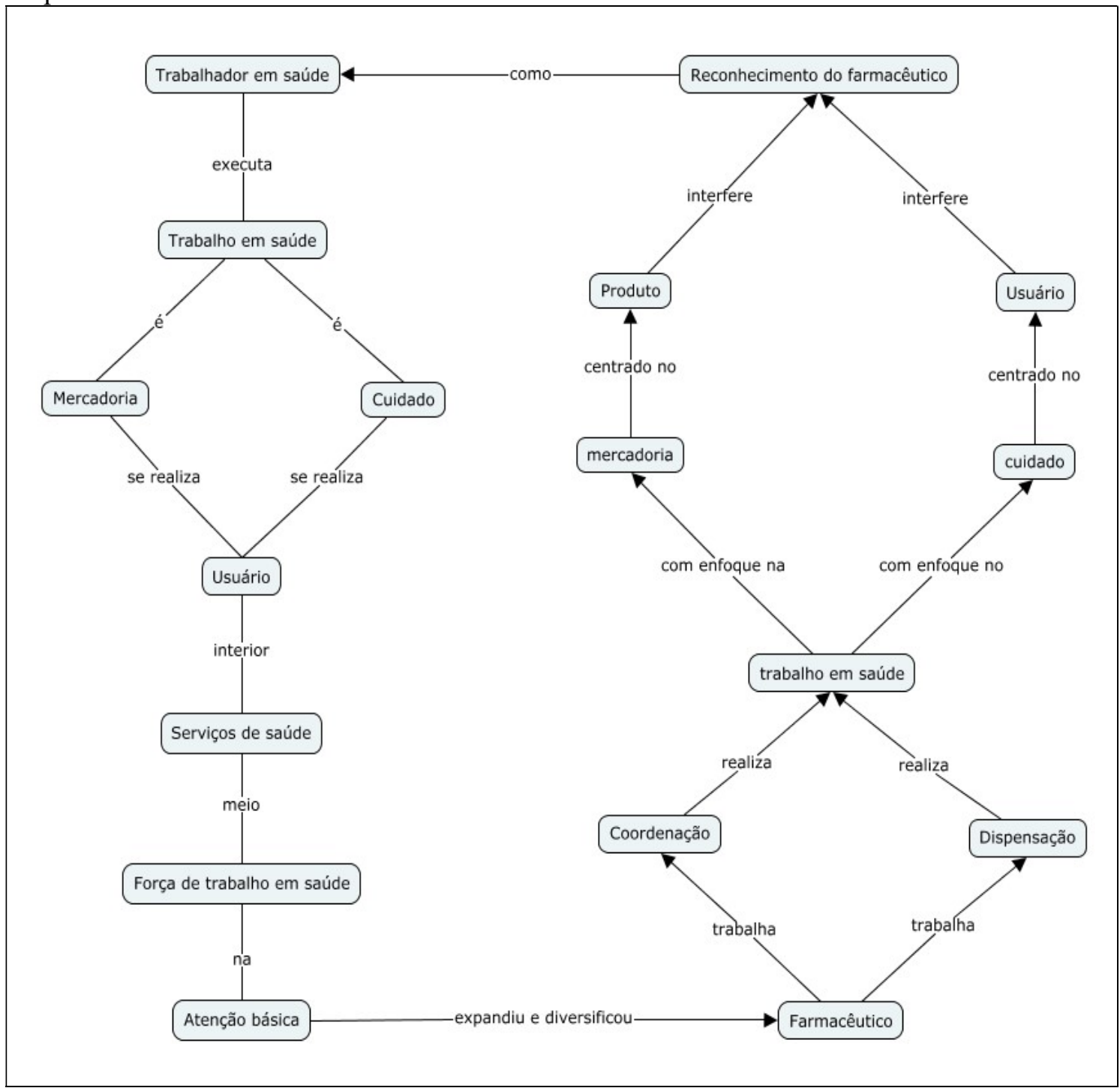

Fonte: Carvalho (2016). 